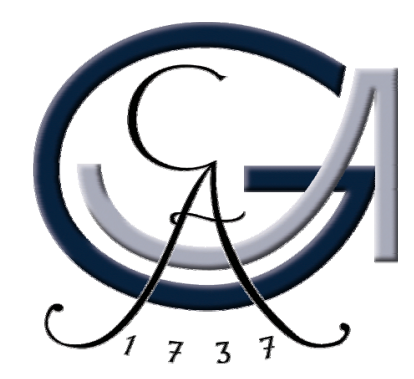

\title{
In vivo- und in vitro-Funktionsanalysen von Bax Inhibitor-1 bei humanen Karzinomzellen
}

\author{
Dissertation \\ zur Erlangung des Doktorgrades \\ der Mathematisch-Naturwissenschaftlichen Fakultäten \\ der Georg-August-Universität zu Göttingen
}

vorgelegt von

Tae-Won Kang

aus Jin-Hae, Süd-Korea

Göttingen, 2007 
D7

Referent: $\quad$ Prof. Dr. W. Engel

Korreferentin: PD Dr. S. Hoyer-Fender

Tag der mündlichen Prüfung: 03.05.2007 


\section{Inhaltsverzeichnis}

\section{Abkürzungsverzeichnis}

Fachwortverzeichnis

1. Einleitung

1.1 Isolierung und Charakterisierung von Bax Inhibitor-1 (BI-1) 16

1.2 Zur Funktion von BI-1 in der Apoptose 19

1.3 Zur zytoprotektiven Funktion von BI-1 21

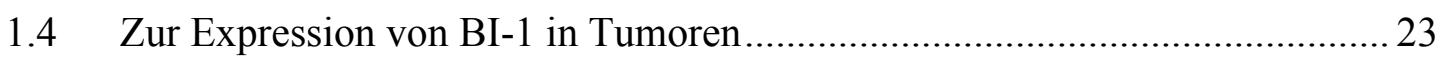

1.5 Ziele der vorliegenden Arbeit .................................................................... 24

2. Material und Methoden

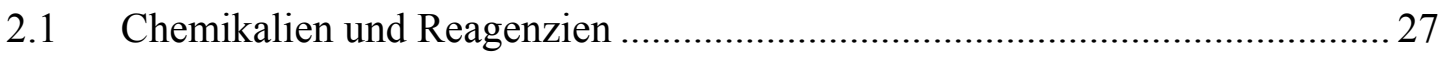

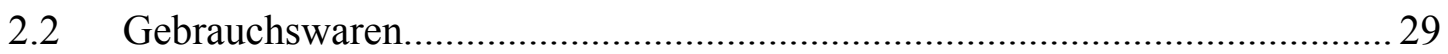

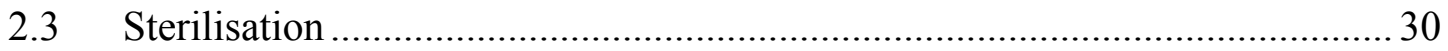

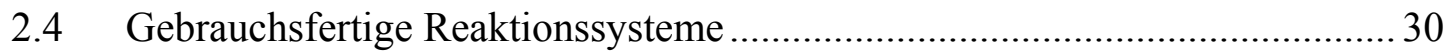

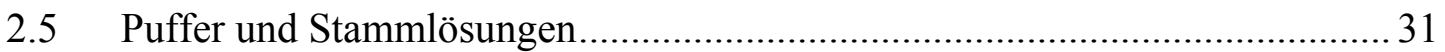

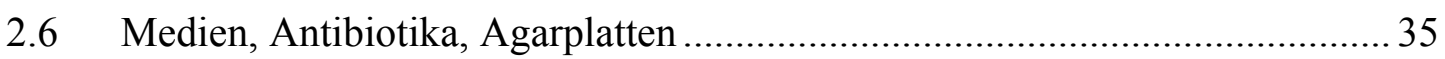

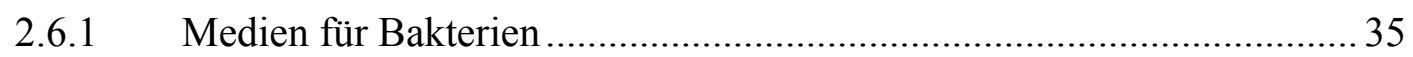

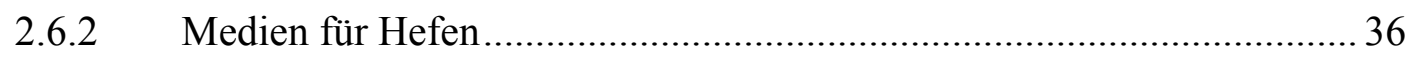

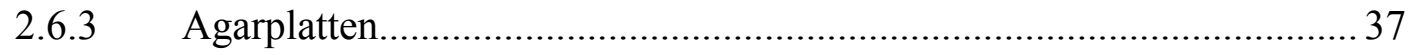

2.6.4 Medien für eukaryotische Zellkulturen.............................................. 37

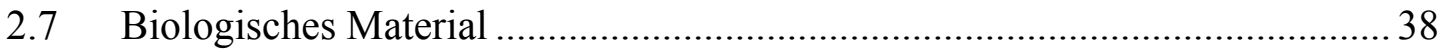

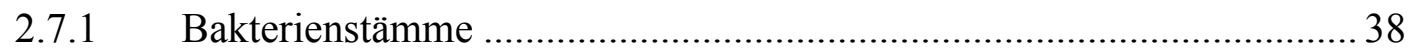

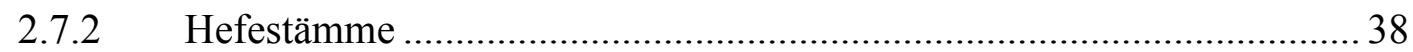

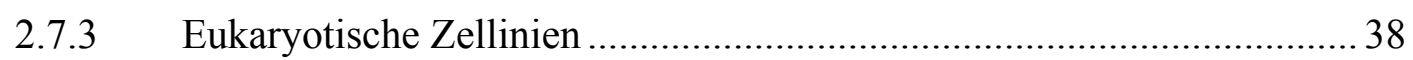

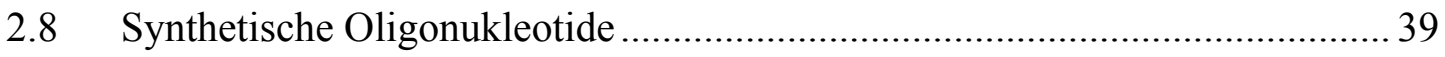

2.8.1 Synthetisch DNA-Oligonukleotide...................................................... 39

2.8.2 Synthetische RNA-Oligonukleotide ....................................................... 41 


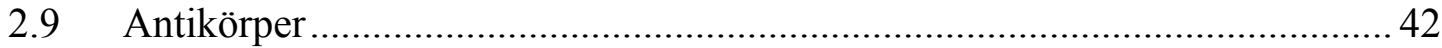

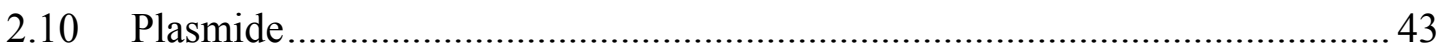

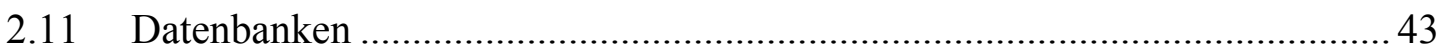

2.12 Isolierung und Aufreinigung von Nukleinsäuren ............................................. 44

2.12.1 Minipräparation von Plasmid-DNA....................................................... 44

2.12.2 Herstellung von Bakterien-Glycerin-Stocks ........................................... 44

2.12.3 Midipräparation von Plasmid-DNA........................................................ 44

2.12.4 Ethanolfällung von DNA aus wässrigen Lösungen .................................. 45

2.12.5 Phenol/Chloroform- Aufreinigung von Nukleinsäuren ............................ 45

2.12.6 Konzentrationsbestimmung von Nukleinsäuren ...................................... 45

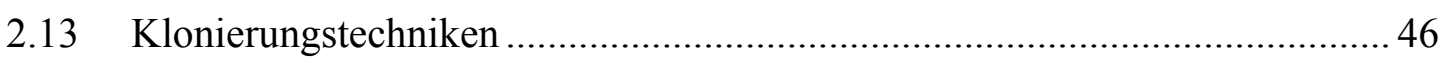

2.13.1 Spaltung von DNA mit Restriktionsendonukleasen ................................ 46

2.13.2 Isolierung von DNA-Fragmenten aus Agarosegelen ................................. 47

2.13.3 Dephosphorylierung von Plasmid-DNA................................................ 47

2.13.4 Ligation von DNA-Fragmenten.......................................................... 47

2.13.5 Subklonierung von PCR- und RT-PCR-Produkten ................................... 48

2.13.6 Transformation kompetenter Zellen mit Plasmid-DNA ........................... 48

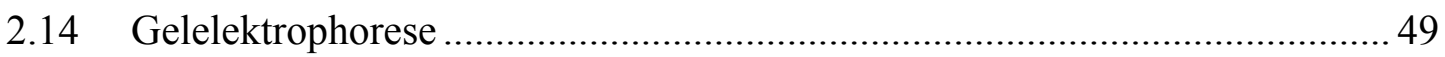

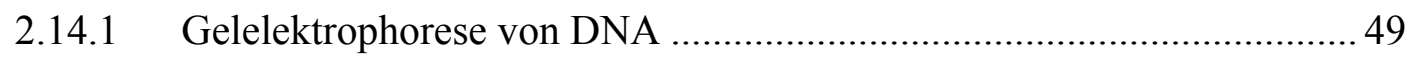

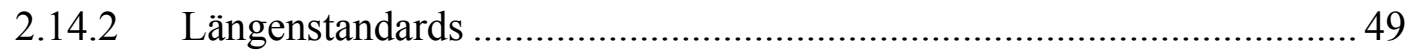

2.15 Transfertechniken ............................................................................... 49

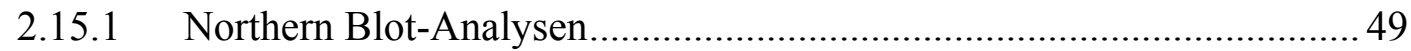

2.16 Radioaktive Markierung von DNA und Hybridisierung membrangebundener

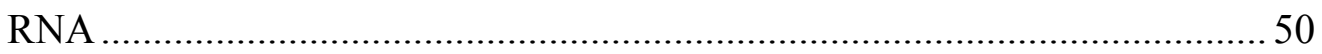

2.16.1 Random Prime-Markierung ................................................................ 50

2.16.2 Hybridisierung membrangebundener RNA mit radioaktiv markierten

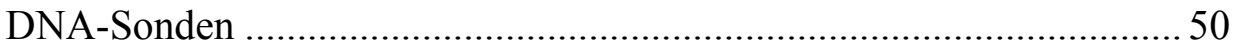

2.17 Polymerase-Kettenreaktion (PCR) ………………………………………. 51

2.17.1 PCR an Plasmid-DNA …………………………………………...... 51

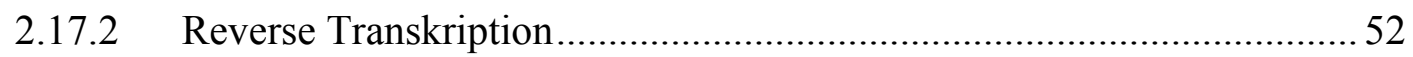

2.17.3 One-step RT-PCR ......................................................................... 53

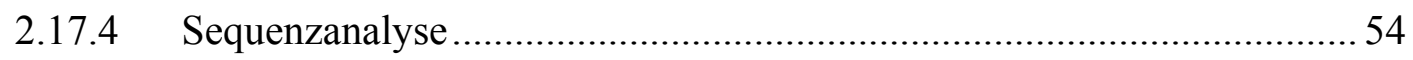




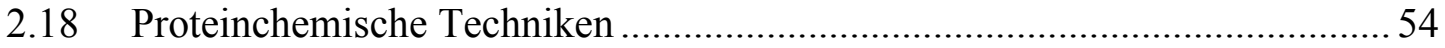

2.18.1 Isolierung von Gesamtprotein aus Zellkulturen.................................... 54

2.18.2 Bestimmung der Proteinkonzentration ................................................... 55

2.18.3 SDS-Polyacrylamidgelelektrophorese (SDS-PAGE) ............................ 55

2.18.4 Western Blot-Analysen von Proteinen auf PVDF-Membranen .............. 56

2.18.5 Färbung von Polyacrylamidgelen .....................................................56

2.18.6 Inkubation von membrangebundenen Proteinen mit Antikörpern ..........56

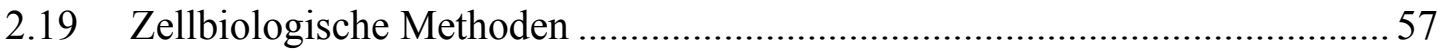

2.19.1 Zellkultur eukaryotischer Zellen.................................................... 57

2.19.2 Kryokonservierung und Revitalisierung von eukaryotischen Zellen ..... 58

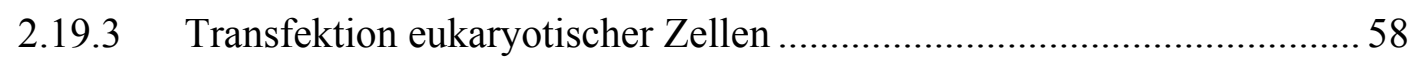

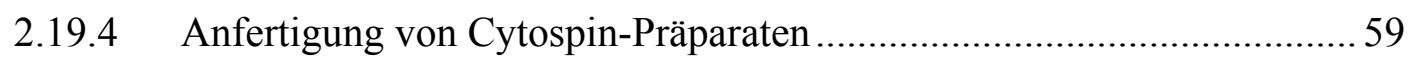

2.20 Herunterregulierung der Genexpression mittels RNA-Interferenz................59

2.20.1 Überblick über den Mechanismus von RNAi........................................6 60

2.20.2 Transfektion eukaryotischer Zellen mit siRNAs .................................62 62

2.21 Genexpressionsanalyse in verschiedenen Tumoren (Cancer Profiling Array)...

2.22 Methoden zur subzellulären Lokalisierung eines Proteins ............................ 64

2.22.1 Immunhistochemische Färbung eukaryotischer Zellen .......................... 64

2.22.2 Zelluläre Lokalisation von Fusionsproteinen ........................................ 65

2.23 Analysen von Zelltod und Apoptose …....................................................... 66

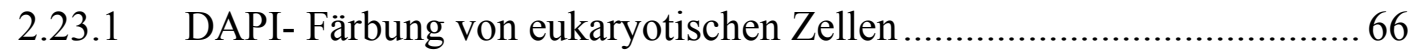

2.23.2 Immuncytochemische Färbung von eukaryotischen Zellen (Caspase-3) .. 66

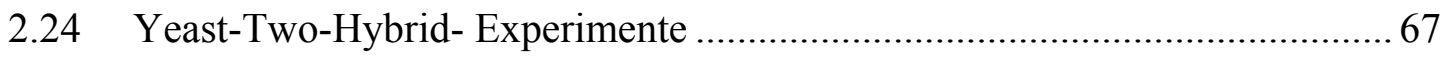

2.24.1 Transformation von pGBKT7-BI-1 im kleinen Ansatz ........................... 69

2.24.2 Transformation von pACT2 / cDNA-Bibliothek im großen Ansatz ...... 69

2.24.3 Selektion relevanter Transformanten .................................................. 70

2.24.4 Verifikation positiver Klone durch Erzeugung von Segreganten ............ 70

2.24.5 Isolierung des AD-Plasmids aus Hefezellen und Klon-Analyse ............ 71

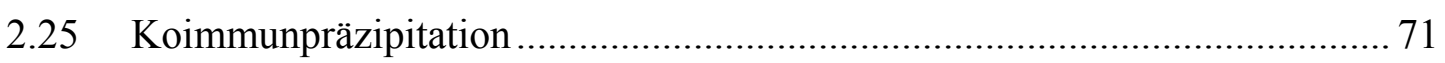

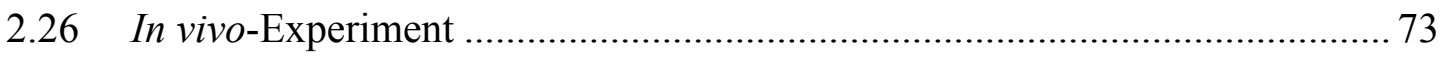




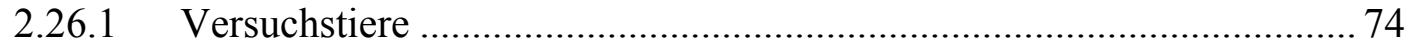

2.26.2 Operationsbesteck und Verbrauchsmaterialien ...................................... 74

2.26.3 Orthotope Implantation von MDA-MB-231-Zellen ................................. 75

2.26.4 Kontrolle des Wachstumsverlaufes des Tumors..................................... 75

2.26.5 Herstellung des D-BI-1/Atelocollagen-Komplexes................................. 76

2.26.6 Bildgebende Verfahren ...................................................................... 76

2.26.7 Histologische Untersuchungen an Tumorgewebe-Präparaten................. 84

2.26.8 Mikroskopische Analysen von Tumorgewebepräparaten im InfrarotBereich

3.1 Nachweis der BI-1-Expression in verschiedenen Tumoren 86

3.1.1 Nachweis der BI-1-Expression in humanen Mammakarzinomzellen .... 89

3.2 Herunterregulierung der BI-1-Expression in den humanen Mammakarzinomzelllinien MCF-7, T-47D und MDA-MB-231 mittels RNA-Interferenz......... 91

3.2.1 Herunterregulierung der BI-1-Expression in Mammakarzinomzellen mit Hilfe BI-1-spezifischer siRNA 91

3.2.2 Apoptoseinduktion in Mammkarzinomzellen nach Transfektion mit

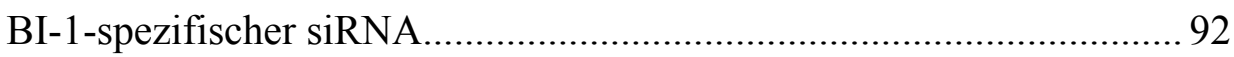

3.3 Identifikation von BI-1-Interaktionspartnern............................................. 95

3.3.1 Verwendung des Yeast-Two-Hybrid-Systems zur Identifikation von BI-1

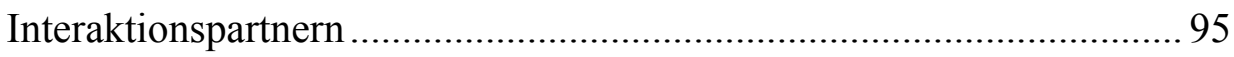

3.3.2 Beschreibung der identifizierten BI-1-Interaktionspartner aus dem YeastTwo-Hybrid-Experiment im Hinblick auf ihre Funktion bei der Apoptose

3.4 Überprüfung und Charakterisierung der Interaktion zwischen BI-1 und Death

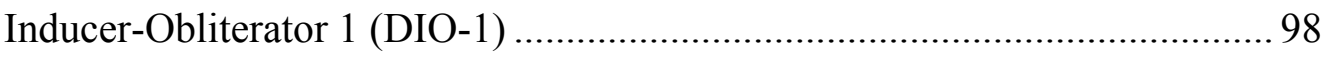

3.4.1 Nachweis der Interaktion von BI-1 und DIO-1 mittels Koimmunopräzipitation 100

3.4.2 Expressionsanalysen von DIO-1 in humanen Mamma- und Prostatakarzinom-Zelllinien 100

3.4.3 Analyse zur subzellulären Kolokalisation von DIO-1-DsRed- und BI-1- 
GFP-Fusionsproteinen in Säugerzellen

3.4.4 Analyse zur subzellulären Kolokalisation von BI-1-GFP-Fusionsproteinen und des endogenen DIO-1-Proteins mittels Immunzytochemie in Säugerzellen. 108

3.4.5 Untersuchung zur subzellulären Lokalisation des endogenen DIO-1-

Proteins mittels Immunzytochemie in Säugerzellen. 109

3.5 Analyse des möglichen Zusammenhangs von BI-1 und DIO-1 in Prostata- und Mammakarzinomzelllinien bei der BI-1-involvierten Apoptose

3.5.1 Subzelluläre Lokalisation von DIO-1 nach Herunterregulierung der Expression von BI-1 mittels RNA-Interferenz in Prostatakarzinomzelllinien.

3.5.2 Untersuchung der Translokation von DIO-1 in den Zellkern nach gemeinsamer Herunterregulierung der BI-1- und DIO-1-Expression mittels RNA-Interferenz

3.5.3 Untersuchung des Apoptose-Verhaltens von MDA-MB-231-Zellen bei gleichzeitiger Herunterregulierung der BI-1 und DIO-1 Expression mittels RNA-Interferenz

3.6 Experimenteller in vivo Ansatz zur Funktionsuntersuchung von BI-1 im Maus-

Tumormodell

3.6.1 Duplex-siRNA-Oligonukleotid-Transfektion von MDA-MB-231-Zellen mittels Atelocollagen 120

3.6.2 Untersuchung der Stabilität und der Wirkungsdauer des siRNA/AcKomplexes über einen längeren Zeitraum in vitro

3.6.3 Implantation der MDA-MB-231 Zellen in die Mammae der Maus ..... 122

3.6.4 Behandlung der Tumoren mit Duplex-siRNA/Ac-Komplexen

3.6.5 Messung der Tumorvolumina und die Gewichtsbestimmung der Mäuse während des Zeitraumes des in vivo-Experiments

3.6.6 Pilotexperiment zur Überprüfung der Durchführbarkeit der in vivoExperimente.

3.6.7 In vivo-Hauptexperiment

3.6.8 Molekulare Bildgebung der mit Cy5.5 gekoppelten siRNAs mittels eXplore Optix Imager. 
3.6.9 Sektion und Isolierung der Tumoren aus den Mammae der Versuchstiere

3.6.10 Histologische Untersuchungen an Tumorgewebeschnitten mittels Hämatoxylin-Eosin-Färbung sowie Cy5.5-Infrarotmikroskopie

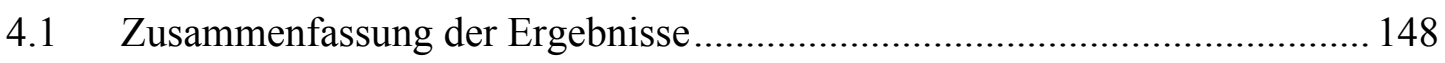

4.2 Analyse der BI-1-Expression in humanen Karzinomen ............................... 150

4.3 Die Rolle von BI-1 bei der Apoptose in humanen Karzinomzellen ............... 152

4.3.1 Apoptose-Induktion bei Prostatakarzinomzellen durch Herunterregulierung der BI-1-Expression

4.3.2 Apoptose-Induktion bei Mammakarzinomzellen durch Herunterregulierung der BI-1-Expression

4.4 Isolierung von weiteren putativen Interaktionspartnern von BI-1 …............. 156

4.5 Der BI-1-Interaktionspartner DIO-1 …................................................... 158

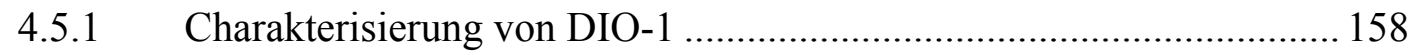

4.5.2 Zur Proteinstruktur von DIO-1 ..................................................... 159

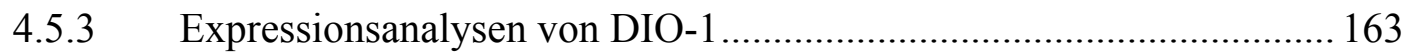

4.5.4 Zur subzellulären Lokalisation von DIO-1 und seiner Funktion in der Apoptose

4.5.5 Die Herunterregulierung der BI-1-Expression führt zur Akkumulation von DIO-1 im Nukleus

4.5.6 Die Funktion von BI-1 und dessen Interaktionspartnern in der Apoptose 167

4.6 Untersuchungen zur Funktion von BI-1 mittels Herunterregulierung der BI-1-

Expression in induzierten Mammakarzinomen bei Nacktmäusen................ 170

4.6.1 Untersuchungen mittels molekularer Bildgebungsverfahren ............... 170

4.6.2 Experimenteller in vivo -Ansatz zur Untersuchung der Funktion von BI-1

4.6.3 Kontrolle der Stabilität des siRNA/Ac-Komplexes mittels molekularen optischen Bildgebungsverfahren (eXplore Optix) und Detektion über die Infrarot-Mikroskopie 
4.6.4 Auswertung der Tumorprogression mit Hilfe von FD-VCT ................ 174

4.6.5 BI-1-Herunterregulierung im MDA-MB-231-Tumormodell führt zur Reduktion des Tumorwachstums in vivo ............................................ 180

4.7 Ausblick auf weiterführende Arbeiten.................................................... 182

5. Zusammenfassung 186

$\begin{array}{lr}\text { 6. Literaturverzeichnis } & 189\end{array}$ 


\section{Abkürzungsverzeichnis}

$\mathrm{Abb}$

Amp

As

ATP

$\mathrm{bp}$

bzw.

${ }^{\circ} \mathrm{C}$

ca.

cDNA

$\mathrm{Ci}$

$\mathrm{cm}$

d

DAPI

dATP

dCTP

dGTP

DEPC

DMSO

DNA

dNTPs

ds

DTT

dTTP

EDTA

et al.

FITC
Abbildung

Ampicillin

Aminosäure

Adenosintriphosphat

Basenpaar

beziehungsweise

Grad Celsius

circa (ungefähr)

komplementäre DNA

Curie

Zentimeter

Tag

4',6'-Diamidino-2-Phenylindol

Desoxyadenosintriphosphat

Desoxycytosintriphosphat

Desoxyguanosintriphosphat

Diethylpyrocarbonat

Dimethylsulfoxid

Desoxyribonukleinsäure

Desoxynukleotidtriphosphate

doppelsträngig

1,4-Dithiothreitol

Desoxythymidintriphosphat

Ethylendiamintetraessigsäure

et alteri (und andere)

Fluoreszeinisothiocyanat 


\begin{tabular}{|c|c|}
\hline FD-VCT & Flächendetektor-Computertomographen \\
\hline $\mathrm{g}$ & Gramm, Erdbeschleunigungskonstante \\
\hline GFP & green fluorescent protein \\
\hline GST & Glutathion-S-Transferase \\
\hline h & Stunde \\
\hline His & Histidin \\
\hline IPTG & Isopropyl- $\beta$-thiogalactopyranosid \\
\hline Kan & Kanamycin \\
\hline $\mathrm{kb}$ & Kilobasenpaare \\
\hline $\mathrm{kD}$ & Kilodalton \\
\hline Luc & Luciferase \\
\hline$\mu$ & micro $=10^{-6}$ \\
\hline$\mu g$ & Microgramm \\
\hline$\mu 1$ & Microliter \\
\hline$\mu \mathrm{m}$ & Micrometer \\
\hline$\mu \mathrm{M}$ & Micromolar \\
\hline $\mathrm{m}$ & milli $=10^{-3}$ \\
\hline M & Molar \\
\hline $\mathrm{mA}$ & Milliampere \\
\hline $\mathrm{MCS}$ & multiple cloning site (Polylinker) \\
\hline $\mathrm{mg}$ & Milligramm \\
\hline $\min$ & Minute \\
\hline $\mathrm{ml}$ & Milliliter \\
\hline $\mathrm{mM}$ & Millimolar \\
\hline $\mathrm{mm}$ & Millimeter \\
\hline $\mathrm{mm}^{3}$ & Kubikmillimeter \\
\hline MOPS & Morpholinopropansulfonsäure \\
\hline mRNA & messenger $\mathrm{RNA}=$ Boten-RNA \\
\hline $\mathrm{n}$ & nano $=10^{-9}$ \\
\hline $\mathrm{nm}$ & Nanometer \\
\hline OD & Optische Dichte \\
\hline $\mathrm{p}$ & pico $=10^{-12}$ \\
\hline
\end{tabular}




$\begin{array}{ll}\text { PCa (-Zellinie) } & \text { prostate carcinoma }=\text { Prostatakarzinom } \\ \text { PAGE } & \text { Polyacrylamidgelelektrophorese } \\ \text { PBS } & \text { Phosphat-gepufferte Kochsalzlösung } \\ \text { PCR } & \text { Polymerase-Kettenreaktion } \\ \text { pg } & \text { Picogramm } \\ \text { pH } & \text { Negativer dekadischer Logarithmus der Protonenkonzentration } \\ \text { RNA } & \text { Ribonukleinsäure } \\ \text { RNase } & \text { Ribonuklease } \\ \text { RT } & \text { Raumtemperatur; reverse Transkription } \\ \text { SDS } & \text { Natriumdodecylsulfat } \\ \text { sec } & \text { Sekunde } \\ \text { siRNA } & \text { small interfering RNA } \\ \text { sog. } & \text { sogenannt } \\ \text { ss } & \text { einzelsträngig } \\ \text { Tab. } & \text { Tabelle } \\ \text { Taq } & \text { Thermus aquaticus } \\ \text { U } & \text { Unit = definierte Enzymeinheit } \\ \text { UV } & \text { ultraviolettes Licht } \\ \text { u.a. } & \text { unter anderem } \\ \text { V } & \text { Volt } \\ \text { Vol } & \text { Volumen } \\ \text { X-GAL } & \\ \text { z.T. } & \text { zum Teil } \\ \text { z.B. } & \end{array}$




\section{Fachwortverzeichnis}

Englische Fachbegriffe der Molekularbiologie werden, soweit sinnvoll, auch als solche verwendet und nicht ins Deutsche übersetzt, da deutsche Ersatzwörter oftmals unwissenschaftlich klingen und nur eine Umschreibung dessen sind, was im Englischen mit einem Wort ausgedrückt werden kann. Die Bedeutung dieser Fachbegriffe wird hier nochmals aufgeführt, sofern dies nicht im Text geschieht.

Alignment

Annealing

antisense

Assay

downstream

Elongation

full length

housekeeping
Wörtlich übersetzt: anordnen, abgleichen

Zwei oder mehrere Sequenzen werden so angeordnet, dass sie bestmöglich übereinstimmen. Auf diese Weise können gleiche oder komplementäre Sequenzen oder Sequenz-bereiche ermittelt werden.

Wörtlich übersetzt: ausglühen, härten

Primer-Anlagerung während der PCR

Komplementär zum kodierenden Nukleinsäurestrang

Wörtlich übersetzt: untersuchen, Untersuchung

Test, Versuchsreihe

Wörtlich übersetzt: stromabwärts

In einer Kaskade: unterhalb, als nachgeschalteter Faktor

Bei einem Gen: weiter 3' gelegen

Wörtlich übersetzt: Verlängerung

Hier: DNA-Strang-Verlängerung während der PCR

Wörtlich übersetzt: Volle Länge

Hier: das gesamte Protein oder kompletten kodierenden

Bereich einer cDNA betreffend

Wörtlich übersetzt: Haushalt 
Ein housekeeping-Gen ist ein konstitutiv exprimiertes Gen, das in allen Zellen essentiell ist.

in frame

knockdown

Primer

Proofreading

real time

sandwich

screening

second messenger
Wörtlich übersetzt: im Rahmen

Bei der Herstellung eines Fusionsproteins muss darauf geachtet werden, dass bei der Klonierung der nachgeschalteten cDNA der Leserahmen der vorgeschalteten cDNA eingehalten wird.

Wörtlich übersetzt: herabsetzen, niederschlagen

Hier: Herunterregulierung der Expression eines Gens

Oligonukleotid von 20-35 Basenpaaren, welches von Polymerasen als Starthilfe zum Ansynthetisieren weiterer Nukleotide genutzt wird.

Wörtlich übersetzt: Korrekturlesen

Polymerasen mit einer Proofreading-Aktivität sind in der Lage, falsch eingebaute Nukleotide über ihre 3 ' $-5^{\prime}$ Exonuklease-Aktivität zu entfernen.

Wörtlich übersetzt: Echtzeit

Während der PCR kann die Zunahme der Amplifikate auf einem Monitor in Echtzeit verfolgt werden

Wörtlich übersetzt: belegtes Brot

Hier: Art des Aufbaus beim Western und Northern BlotTransfer. Die Membran wird zwischen Whatman-Papier + Gel und Whatman-Papier gelegt.

Wörtlich übersetzt: (durch)sieben, untersuchen Hier: Durchsuchen einer Bibliothek nach bestimmten Proteinen und Genen

Botenstoff, der in Reaktion auf extrazelluläre Signale in der Zelle gebildet wird und die Signalkaskade verstärkt 
fortsetzt

sense

Entspricht dem kodierenden Nukleinsäurestrang

silencing

Wörtlich übersetzt: zum Schweigen bringen

Bei der Transkription: Umstände, die die Transkription eines Gens unterdrücken

template

Wörtlich übersetzt: Schablone, Vorlage, Matrize

Hier: RNA oder DNA, die während einer PCR amplifiziert werden soll

upstream

Wörtlich übersetzt: stromaufwärts

In einer Kaskade: oberhalb, als vorgeschalteter Faktor

Bei einem Gen: weiter 5'-gelegen

yeast-two-hybrid-screening Hefesystem, um Proteine nachzuweisen, die an ein bestimmtes Protein, das untersucht werden soll, binden. 


\section{Einleitung}

Der programmierte Zelltod ist ein Mechanismus, der für die Homöostase von eukaryotischen Zellen unabdingbar ist. Störungen in der Zellproliferation oder in der Apoptose können zur Bildung von malignen Läsionen führen (Berges et al., 1995; Tu et al., 1996). Die Apoptose stellt eine Form des programmierten Zelltods dar, der von zahlreichen Genprodukten gesteuert wird. Viele dieser Gene sind in humanen Karzinomen mutiert oder fehlerhaft reguliert, wie z.B. das Tumorsupressorgen p53 und Gene aus der Bcl-2-Genfamilie (Fischer, 2001). Eine selektive Induktion der Apoptose in Karzinomzellen, z.B. durch die Expression des proapoptotischen Proteins Bax, könnte daher eine effektive Behandlung von Tumoren darstellen (Li et al., 2001). Bei der Progression von Tumoren konnte allerdings eine erhöhte Expression von Genen aus der antiapoptotischen Bcl-2-Genfamilie nachgewiesen werden, welche die Wirkung von Bax aufheben können. (Krajewska et al., 1996).

Das Bax Inhibitor-1 (BI-1)-Gen kodiert ebenfalls für ein solches antiapoptotisches Protein, das erstmals von Walter et al. (1994) als Testicular Enhanced Gene Transcript (TEGT) bei der Ratte beschrieben worden ist.

\subsection{Isolierung und Charakterisierung von Bax Inhibitor-1 (BI-1)}

Das BI-1-Gen kodiert für ein evolutionär hoch konserviertes integrales Membranprotein (Abb. 1.1) und wurde zunächst bei der Ratte und anschließend beim Menschen isoliert und charakterisiert (Walter et al., 1994; 1995). Ebenfalls konnten in den Genomen der Hefe, (Saccharomyces cerevisiae), von Pflanzen (Oryza sativa, Arabidopsis thaliana, Lycospersicon esculentum) und der Fruchtfliege (Drosophila melanogaster) homologe BI-1-Gene identifiziert werden (Kawai et al., 1999; Sanchez et al., 2000; Chae et al., 2003). Die abgeleitete Aminosäuresequenz des humanen BI-1-Gens weist ebenfalls Homologien zu Proteinen aus Bakterien auf. Es zeigt sich eine 25\%ige bzw. 27\%ige Homologie mit einem $24 \mathrm{kDa}$ großen Protein aus Pseudomonas aeruginosa bzw. mit einem 23,5 kDa großen Protein aus Escherichia coli (Walter et al., 1995). Southern- 
Blot-Analysen zeigten, dass das humane BI-1-Gen auf Chromosom 12 im Bereich q12q13 lokalisiert ist und als ein single-copy-Gen im menschlichen Genom vorliegt (Walter et al., 1995).

Das humane BI-1-Gen kodiert für ein stark hydrophobes integrales Membranprotein mit einer Größe von 237 Aminosäuren und einem Molekulargewicht von ca. 26,5 kDa. Die Suche nach Transmembran-Domänen im BI-1 Protein mittels des Kyte-DoolittlePlots zeigte, dass BI-1 über sechs bis sieben putative Transmembran-Domänen im Säuger-BI-1 Protein verfügt (Cowling und Birnboim, 1998; Xu und Reed, 1998). Die subzelluläre Lokalisation des BI-1 Proteins konnte in intrazellulären Membranen nachgewiesen werden, vorwiegend im Endoplasmatischen Retikulum (ER) und teilweise auch im Golgiapparat und in den Mitochondrien (Cowling und Birnboim, 1998; Xu und Reed, 1998).

Das BI-1 Gen stellt ein ubiquitär exprimiertes Gen dar und wird u. a. in Geweben wie Prostata, Testis, Herz, Gehirn, Lunge, Placenta, Leber, Niere und Pankreas exprimiert (Xu und Reed, 1998). Das BI-1-Gen zeigt in der Northern Blot Analyse zwei Transkripte mit einer Größe von 2,8 und 1,0kb, welche durch die Verwendung von zwei verschiedenen Polyadenylierungsstellen erzeugt werden (Walter et al., 1995).

\begin{tabular}{|c|c|c|}
\hline$h B I-1$ & (1) & --------MNIFDRKINFDALLKFSHITPSTQQHLKKVYASFALCMF \\
\hline RnBI-1 & (1) & ---MNIFDRKINFDALLKFSHITPSTQQHLKKVYASFALCMF \\
\hline $\mathrm{mBI}-1$ & (1) & --------MNIFDRKINFDALLKFSHITPSTQQHLKKVYASFALCMF \\
\hline AtBI-1 & (1) & MDAFSSFFDSQPGS--RSWSYDSLKNFRQISPAVQNHLKRVYLTLCCALV \\
\hline BnBI-1 & (1) & MDSFSSFFDSQPGS--RSWSYDSLKNLRQISPSVQNHLKRVYLTLCCALV \\
\hline NtBI -1 & (1) & MESCTSFFNSQSASSRNRWSYDSLKNFRQISPFVQTHLKKVYLSLCCALV \\
\hline \multirow[t]{2}{*}{ OsBI-1 } & (1) & MDAFYSTSSAYGAAA-SGWGYDSLKNFRQISPAVQSHLKLVYLTLCVALA \\
\hline & & II \\
\hline hBI-1 & $(40)$ & VAAAGAYVHMVTHF IQAGLLSALGSLI LMIWLMATPHSHETEQKRLGLLA \\
\hline RnBI-1 & $(40)$ & VAAAGAYVHVVTRF IQAGLLSALGALALMICLMATPHSHETEQKRLGLLA \\
\hline $\mathrm{mBI}-1$ & $(40)$ & VAAAGAYVHVVTHF IQAGLLSALGSLALMIWLMATPHSHETEQKRLGLLA \\
\hline AtBI-1 & $(49)$ & ASAFGAYLHVLWNIG--GILTTIGCIGTMIWLLSCPPYEHQ--KRLSLLF \\
\hline $\mathrm{BnBI}-1$ & $(49)$ & ASAFGAYLHVLWNIG--GILTTIGCFGSMIWLLSCPPYEQQ--KRLSLLF \\
\hline NtBI -1 & (51) & ASAAGAYLHILWNIG--GLLTTLGCVGS IVWLMATPLYEEQ--KRIALLM \\
\hline OsBI-1 & $(50)$ & AVGAYLHVALNIG--GMLTMLGCVGS IAWLFSVPVFEER--KRFGILI \\
\hline
\end{tabular}




\begin{tabular}{|c|c|c|}
\hline & & III \\
\hline$h B I-1$ & $(90)$ & GFAFLTGVGLGPALEFCIAVNPS ILPTAFMGTAMIFTCFTLSALYARRRS \\
\hline$n B I-1$ & $(90)$ & GFAFLTGVGLGPALELCIAINPS I LPTAFMGTAMIFTCFSLSALYARRRS \\
\hline$m B I-1$ & $(90)$ & GFAFLTGVGLGPALELCIAVNPS ILPTAFMGTAMIFTCFSLSALYARRRS \\
\hline tBI -1 & $(95)$ & VSAVLEGASVGPLIKVAIDVDPSILITAFVGTAIAFVCFSAAAMLARRRE \\
\hline $\mathrm{BnBI}-1$ & $(95)$ & LSAVLEGASVGPLIKVAVDFDPSILITAFVGTAIAFICFSGAAMLARRRE \\
\hline tBI -1 & $(97)$ & AAALFKGASIGPLIELAIDFDPS IVIGAFVGCAVAFGCFSAAAMVARRRE \\
\hline SBI-1 & $(96)$ & AAALLEGASVGPLIKLAVDFDSSILVTAFVGTAIAFGCFTCAAIVAKRRE \\
\hline & & VI \\
\hline$h B I-1$ & $(140)$ & YLFLGGILMSALSLLLLSSLGNVFFG-S IWPFQANLYVGLVVMC \\
\hline$n B I-1$ & $(140)$ & YLFLGGILMSAMSLMFVSSLGNLFFG-S IWLFQANLYMGLLVMCGFVLFD \\
\hline$m B I-1$ & $(140)$ & YLFLGGILMSAMS LMLLSSLGNLFFG-S IWLFQANLYLGLLVMCGFVLFD \\
\hline tBI-1 & $(145)$ & YLYLGGLLSSGLSMLMWLQFASS IFGGSASIFKFELYFGLLIFVGYMVV \\
\hline$n B I-1$ & $(145)$ & YLYLGGLLSSGLSMLMWLQFASS IFGGSAS I FKFELYFGLLIFVGYMV \\
\hline$B I-1$ & $(147)$ & YLYLGGLLSSGLS ILFWLHFASS IFGGSMALFKFEVYFGLLVFVGYI I \\
\hline$I-1$ & $(146)$ & AASIFGHSTGSFMFEVYFGLLIFLGYM \\
\hline
\end{tabular}

\begin{tabular}{|c|c|c|}
\hline & & VII? \\
\hline $\mathrm{hBI}-1$ & 89) & RKLMMI LAMNEKDK---KKE \\
\hline$n B I-1$ & $(189)$ & TQLI IEKAEHGDKDY IWHCIDLFLDFVTLFRKLMLI LAFNEKDK- \\
\hline $\mathrm{mBI}-1$ & $(189)$ & TQLI IEKAEHGDKDY IWHCVDLFLDFVTLFRKLML I LAFNEKDK---KKE \\
\hline$t B I-1$ & $(195)$ & LTLFTDFVAVFVRILI IMLKNSADK-EEKKK \\
\hline $\mathrm{BBI}-1$ & $(195)$ & TQDI IEKAHLGDMDYVKHSLTLFTDFVAVFVRVLI IMLKNSADK \\
\hline$B I-1$ & $(197)$ & TQDIIEKAHLGDLDYVKHALTLFTDFVAVFVRILI IMLKNASDI \\
\hline $\mathrm{BI}-1$ & (196) & HHGDMDYIKHALTLFTDFVAVLVRILVIMLKNASDK \\
\hline
\end{tabular}

$\begin{array}{rrl}\text { hBI-1 } & \text { (236) } & \text { KK-- } \\ \text { RnBI-1 } & \text { (236) } & \text { KK-- } \\ \text { mBI-1 } & \text { (236) } & \text { KK-- } \\ \text { AtBI-1 } & (244) & \text { KRRN } \\ \text { BnBI-1 } & (244) & \text { RRRN } \\ \text { NtBI-1 } & (246) & \text { KRRN } \\ \text { OsBI-1 } & \text { (246) } & \text { KKRS }\end{array}$

Abb. 1.1: Abgleich der BI-1 Proteinsequenzen von Pflanzen und Säugern. Der Abgleich der BI-1Proteinsequenzen erfolgte mit Hilfe des VectorNTI-Programms (Invitrogen). In den BI-1 Aminosäuresequenzen sind die invarianten Aminosäuren rot und die konservierten Sequenzen blau 
dargestellt. Die putativen Transmembrandomänen sind als Balken über den Sequenzen eingezeichnet (http://www.predictprotein.org). Die siebte Transmembrandomäne wird bei vielen Datenbanken als unwahrscheinlich eingestuft (mit Fragezeichen gekennzeichnet). Die dargestellten BI-1-Sequenzen sind von: At, Arabidopsis thaliana (Accession Nr.:BAA89541); Bn, Brassicca napus (Accession Nr.:AAK73101); Nt, Nicotiana tabacum (Accession Nr.:AAK73102); Os, Oryza sativa (Accession Nr.:BAA89540); h, Homo sapiens (Accession Nr.:NP003208); m, Mus musculus (Accession Nr.:NP080945); Rn, Rattus norvegicus (Accession Nr.:P55062).

\subsection{Zur Funktion von BI-1 in der Apoptose}

Die BI-1-Sequenz wurde von Xu und Reed (1998) über eine humane cDNA-Bibliothek bei der Suche nach einem humanen Protein identifiziert, welches die ApoptoseInduktion bei der Hefe durch die ektopische Expression von Bax inhibiert. Es konnte ebenfalls nachgewiesen werden, dass die Bax induzierte Apoptose in humanen embryonalen Nieren 293T-Zellen durch BI-1 verhindert wird. Zusätzlich war es durch die Überexpression von BI-1 möglich, die Apoptoseinduktion durch Entzug von Wachstumsfaktoren in GM701 Fibroblastenzellen zu unterdrücken (Xu und Reed, 1998).

Weiterhin gibt die Herunterregulierung der BI-1 Expression mittels AntisenseExperimenten einen Hinweis darauf, dass das endogene BI-1-Protein eine wichtige Rolle in der Apoptose-Suppression in bestimmten Tumorzellinien ausüben könnte (Xu und Reed, 1998). Experimente mit Hilfe der Kolokalisation und subzelluläre Fraktionsstudien haben gezeigt, dass BI-1 vorwiegend im Endoplasmatischen Retikulum (ER) lokalisiert ist (Jean et al., 1999). Westphalen et al. (2005) untersuchten die Kalziumkonzentration in ER und Mitochondrien von Chinesischen HamsterOvarzellen (CHO-Zellen) bei der BI-1 Überexpression. Dabei führte die BI-1Überexpression bei CHO-Zellen zur Reduktion des Kalziumsgehalts im ER und in den Mitochondrien. Zusätzlich zeigten Zellen aus Calreticulin knock-out Mäusen, bei denen der ER-Kalziumgehalt durch eine Mangel von Calreticulin reduziert wurde, eine stärkere Resistenz gegen Apoptose-Induktion als Wild-Typ Zellen (Nakamura et al., 2000). Auch embryonale Fibroblastenzellen der Maus, bei denen die Bax- und BakExpression herunterreguliert wurde, zeigten eine stärkere Resistenz gegenüber 
apoptotischen Stimuli bei einem reduzierten Kalziumgehalt im ER (Scorrano et al., 2003). Daher stellten Westphalen et al. (2005) die These auf, dass die Reduktion des Kalziumgehalts im ER durch die BI-1 Überexpression ursächlich für die ApoptoseResistenz der Zellen sein könnte. Wie BI-1 den Kalziumgehalt im ER reduziert, ist noch unbekannt. Ebenfalls unklar ist die genaue Funktion von BI-1 im ER.

BI-1 ist ein Regulator der Bcl-2- und Bax- kontrollierten intrinsischen ApoptoseSignalkaskade (Abb. 1.2). Weiterhin weist BI-1 Ähnlichkeit in der zytoprotektiven Funktion zu den antiapoptotischen, zur Bcl-Proteinfamilie gehörenden Proteinen Bcl-2 und $\mathrm{Bcl}-\mathrm{X}_{\mathrm{L}}$ auf, jedoch nicht mit den proapoptotischen Proteinen Bax und Bad (Xu und Reed, 1998). Wenn BI-1 in Säugerzellen überexprimiert wird, unterdrückt es den induzierten programmierte Zelltod, die von Etoposiden, Staurosporin und den Entzug von Wachstumsfaktoren, aber nicht die von Fas (CD95)-vermittelte Apoptose. Weiterhin kann BI-1 die Funktion des proapoptotischen Proteins Bax inhibieren, jedoch ist der genaue Mechanismus unklar (Xu und Reed, 1998). 


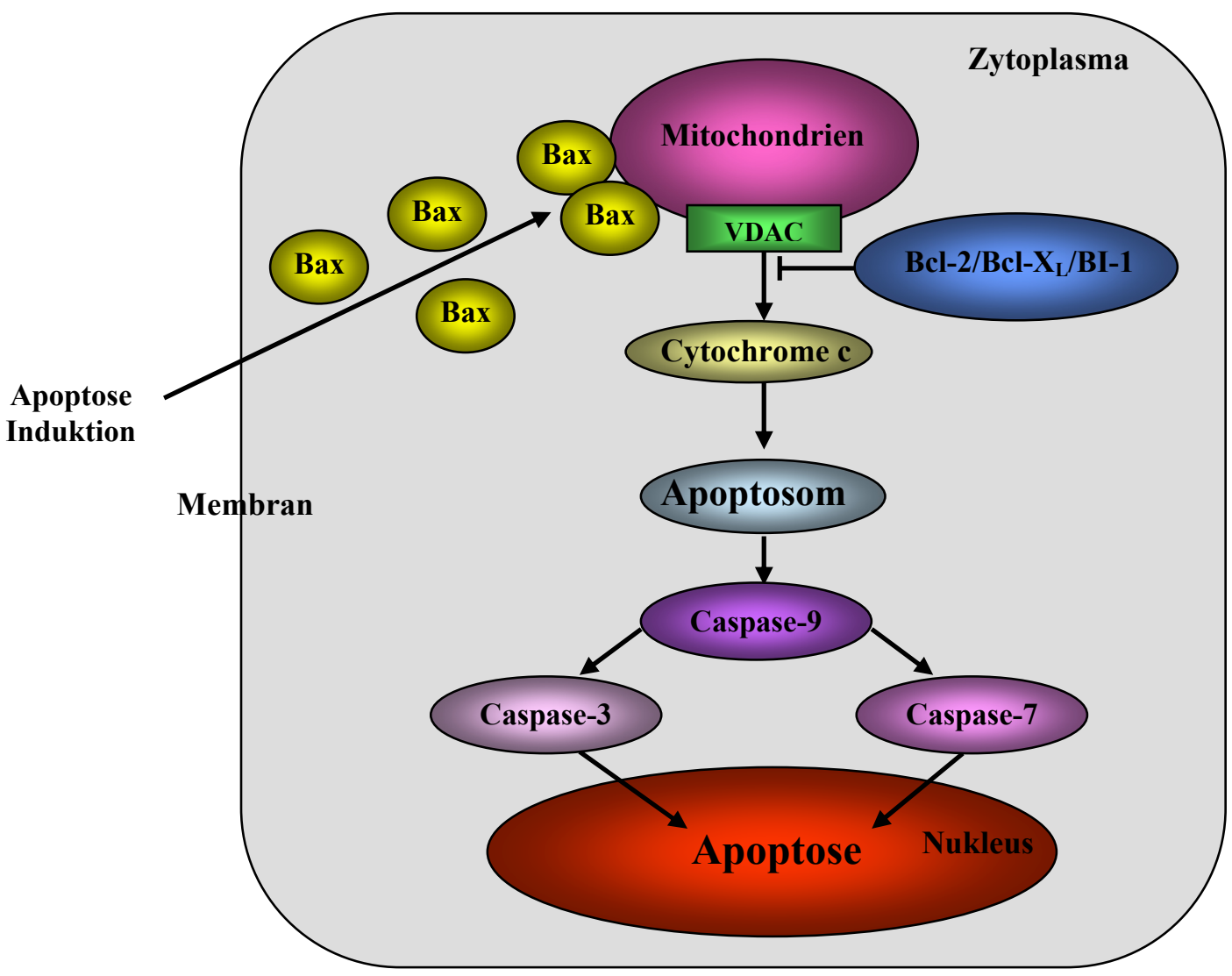

Abb. 1.2: Schematische Darstellung der Bax-induzierten Apoptose (modifiziert nach Yu et al., 2002 und Kim et al., 2002). Nach der Induktion der Apoptose führt die Aktivierung des Bax-Gens zu einer erhöhten Menge an Bax-Proteinen, die Homodimere bilden. Diese Homodimere translozieren anschließend vom Cytoplasma in die Mitochondrien. Sie beeinflussen dort spannungsabhängige AnionenKanäle (VDAC), die in der äußeren Mitochondrienmembran lokalisiert sind. Dies führt zur Freisetzung von Cytochrom c, welches die Caspase-Kaskade aktiviert. Die Freisetzung von Cytochrom c unterstützt die Oligomerisierung eines Cytochrom c/Apoptotic protease activating factor 1 (Apaf-1)/Procaspase-9Komplexes (Apoptosom). Die Aktivierung der Caspase-9 durch das Apoptosom führt zur Spaltung der downstream-Effektorproteine Caspase-3 und Caspase-7 und zur Apoptose. Ferner wird die Freisetzung von Cytochrom c durch die antiapoptotischen Proteine Bcl-2 und Bcl- $\mathrm{X}_{\mathrm{L}}$ inhibiert, die wie Bax eine Ionenkanalaktivität besitzen. BI-1 kann mit Bcl-2 und Bcl- $\mathrm{X}_{\mathrm{L}}$ interagieren und die Apoptose inhibieren.

\subsection{Zur zytoprotektiven Funktion von BI-1}

BI-1 übt eine Schutzfunktion bei bestimmten Zelltypen gegenüber Tumor necrosis (TNF)-related apoptosis-inducing ligand (TRAIL) aus, einem Protein aus der Tumor 
necrosis factor (TNF)-Familie der Zytokine (Burns und El-Deiry, 2001). Die isolierten Maus-Embryo-Fibroblastenzellen aus BI-1 knock out-Mäusen zeigen in vitro eine selektive Hypersensitivität gegen Apoptoseinduktion durch Chemikalien wie Thapsigargin, Tunicamycin und Brefeldin A und den dadurch verursachten ER-Stress (Chae et al., 2004). Mit Hilfe der BI-1 knock out-Mäuse konnte ausserdem gezeigt werden, dass für den intrinsischen Schutz gegen ER-Stress und IschämieReperfusionsverletzungen von Leber und Niere BI-1 notwendig ist. Dazu wurde bei den BI-1 knock out-Mäusen die Blutzufuhr der arteriellen und portalen Venen im medianen und linken Leberlappen für 90 min blockiert und wieder durchblutet. Anschliessend wurden Leber und Niere entnommen und auf Apoptose untersucht, wobei BI-1 knock out-Mäuse eine signifikant höhere Anzahl an apoptotischen Zellen in Leber und Niere aufwiesen als die Wild-Typ-Mäuse (Bailly-Maitre et al., 2006).

Dohm et al. (2006) untersuchten die Funktion von BI-1 in Ratten CSM14.1- und humanen SH-SY5Y Neuroblastomazellen, wobei bei stabilen BI-1-Transfektanten eine reduzierte Apoptose-Induktion durch Sauerstoff- und Glukose-Entzug und Thapsigargin, ein die $\mathrm{Ca}^{2+}$-ATPase des endoplasmatischen Retikulums blockierendes Agenz, festgestellt wurde. Bei Untersuchungen mit Staurosporin, einem die Mitochondrien abhängige Apoptose initiierenden Kinaseinhibitor, konnte bei den Neuroblastomzellen keine Inhibition der Apoptose durch BI-1 Überexpression festgestellt werden (Dohm et al., 2006).

Die anti-apoptotische Funktion der BI-1-Proteine ist von der Pflanze bis zum Säuger evolutionär konserviert. Dies wurde von $\mathrm{Yu}$ et al. (2002) durch die Inhibierung der Apoptose-Induktion durch Bax mit Hilfe transienter Kotransfektionen von BaxKonstrukten mit BI-1-Konstrukten von Arabidopsis thaliana (AtBI-1) in humanen Fibrosarkom-Zellen (HT1080) gezeigt. Weiterhin konnten Bolduc et al. (2003) durch die transiente Kotransfektion von Bax-Konstrukten mit den BI-1- Konstrukten von Brassica napus (BnBI-1) und Nicotiana tabacum (NtBI-1) in humane embryonale Nieren 293T-Zellen die Schutzwirkung von BI-1 nachweisen. Die zytoprotektive Funktion von BI-1 in Pflanzen wurde ebenfalls in transgenen Pflanzen aufgezeigt, wobei BI-1 aus Brassica nigra die Säugetier-Bax induzierte Apoptose inhibieren konnte (Kawai-Yamada et al., 2001). 
Deletionsexperimente der C-terminalen Domäne von BI-1-Homologen von Fruchtfliege, Tomate und Hefe haben gezeigt, dass die Schutzwirkung von BI-1 gegen Apoptoseinduktion verloren geht. Diese Ergebnisse weisen auf eine wichtige Rolle dieser Region von BI-1 hin (Chae et al., 2003). Zusätzlich konnten diese Beobachtungen ebenfalls von Kawai-Yamada et al. (2004) über die Herstellung von mutanten BI-1-Proteinen bestätigt werden. Dabei wurden die letzten sieben Aminosäuren am C-terminalen Ende des BI-1-Proteins von Arabidopsis thaliana durch andere Aminosäuren ohne die putative „coiled-coil“-Struktur ersetzt. Diese Substitutionsexperimente hatten zur Folge, dass das mutante BI-1 Protein die Baxinduzierte Apoptose in der Hefe nicht mehr inhibiert. Der genaue molekulare Mechanismus dieser Schutzfunktion von BI-1 konnte jedoch bisher nicht ermittelt werden.

\subsection{Zur Expression von BI-1 in Tumoren}

Eine cDNA-Microarry-Studie an primären Brusttumoren von 117 Patientinnen zeigte, dass BI-1 in Brustkrebszellen überexprimiert wird und mit der Expression des Östrogenrezeptors $\alpha$ assoziiert ist (Van't Veer et al., 2002). Schmitts et al. (2002) konnten eine fünf- bis zehnmal stärkere Expression von BI-1 in 16 Glioma-Proben im Vergleich $\mathrm{zu}$ normalen Gehirn- und anderen normalen Geweben feststellen. Eine Microarray Analyse von mehr als 8900 verschiedenen humanen Genen an einem Set von normalen und malignen Prostatageweben konnte eine erhöhte und spezifische BI-1Expression in den malignen Proben zeigen (Welsh et al., 2001).

Eine erhöhte BI-1-Expression wurde ebenfalls in ALK (Anaplastic Lymphoma Kinase)-positiven und anaplastischen, großzelligen Non-Hodgkin-Lymphomen über die subtraktive Hybridisierung zwischen ALK-positiven und ALK-negativen Lymphomen gefunden (Villalva et al., 2001).

Das BI-1-Gen ist weiterhin als differentiell exprimiertes Gen im Prostatakarzinom mit Hilfe der Atlas ${ }^{\mathrm{TM}}$ Array-Technologie identifiziert worden. Mittels quantitativer real time RT-PCR an Gesamt-RNA aus lasergestützten Mikrodissektaten von zusammengehörigen Normal- und Tumor-Prostatageweben epithelialen Ursprungs 
wurde gezeigt, dass BI-1 in 11 von 17 untersuchten Fällen (> Faktor 2) im Tumor überexprimiert wird (Grzmil et al., 2003).

In situ-Hybridisierungsexperimente an humanen Prostatapräparaten zeigten, dass die Expression von BI-1 auf die Epihelzellen beschränkt ist. Die quantitative RT-PCR an RNA aus fünf benignen Prostata-Hyperplasie-Präparaten zeigte keinen signifikanten Unterschied in der BI-1-Expression im Vergleich $\mathrm{zu}$ normalen epithelialen Prostatazellen (Grzmil et al., 2003).

Um die Funktion von BI-1 in humanen Prostatakarzinomzellen zu evaluieren, wurde eine spezifische Herunterregulierung der BI-1-Expression durch RNA-Interferenz an humanen PC-3-, LNCaP- und DU-145-Zellen durchgeführt. Dabei konnte nach 45 Stunden eine Apoptoserate von 45\% bei PC-3-, 18\% bei LNCaP- und 15\% bei DU-145Zellen beobachtet werden (Grzmil et al., 2003). Der Grund für die stärkere Apoptosewirkung nach BI-1-Herunterregulation in den PC-3-Zellen gegenüber den LNCaP- und DU-145-Zellen konnte bisher noch nicht geklärt werden.

\subsection{Ziele der vorliegenden Arbeit}

Im ersten Teil der hier vorliegenden Arbeit sollte die Expression von BI-1 in verschiedenen humanen Karzinomen untersucht werden. Weiterhin stand die Analyse der Expression von BI-1 in humanen Mammakarzinomen im Vordergrund. Mit Hilfe von gene silencing-Experimenten in etablierten Mammakarzinomzelllinien sollte die Funktion von BI-1 näher charakterisiert werden.

Im zweiten Teil der Arbeit sollten putative Interaktionspartner von BI-1 in humanen Karzinomzellen näher untersucht werden. Dabei sollte vor allem die mögliche Funktion von BI-1 und seiner Interaktionspartner evaluiert werden.

Im dritten Teil der Arbeit sollte der Effekt der Apoptose-Induktion durch die Einführung von BI-1-spezifischen Duplex-siRNA-Oligonukleotiden in induzierten Mammakarzinomen bei Nackt-Mäusen untersucht werden.

Die einzelnen Ziele waren: 
A. Analyse der BI-1-Expression in humanen Karzinomen und zur Funktion in humanen Mammakarzinomzellen

- Nachweis der BI-1-Expression in verschiedenen humanen Tumoren mit Hilfe des Cancer Profiling Arrays

- Nachweis der BI-1-Expression in humanen Mammakarzinomzellen

- Überprüfung der Herunterregulation der BI-1-Expression in den humanen Mammakarzinomzelllinien mittels RNA-Interferenz über Western blot-Analysen

- Untersuchung der Apoptoseinduktion in Mammkarzinomzellen nach Transfektion mit BI-1 spezifischer siRNA mit Hilfe der Immunzytochemie

B. Zur Funktion von BI-1 und dessen Interaktionspartner in humanen Karzinomzellen

- Identifikation von BI-1-Interaktionspartnern mittels Yeast-Two-HybridScreening

- Nachweis der Interaktion von BI-1 und DIO-1 mittels Koimmunopräzipitation

- Analyse zur subzellulären Kolokalisation von DIO-1 und BI-1 mit Hilfe von DIO-1-DsRed- und BI-1-GFP-Fusionsproteinen sowie mittels Immunzytochemie in Säugerzellen

- Expressionsanalysen von DIO-1 in humanen Mamma- und ProstatakarzinomZelllinien

- Untersuchung der subzellulären Lokalisation von DIO-1 nach Herunterregulierung der Expression von BI-1 mittels RNA-Interferenz in Prostatakarzinomzelllinien

- Untersuchung der Translokation von DIO-1 in den Zellkern nach gemeinsamer Herunterregulierung der BI-1- und DIO-1-Expression mittels RNA-Interferenz in Prostatakarzinomzelllinien

- Untersuchung des Apoptose-Verhaltens bei gleichzeitiger Herunterregulierung der BI-1 und DIO-1 Expression mittels RNA-Interferenz in Prostatakarzinomzelllinien

C. Herunterregulierung der BI-1-Expression in induzierten Mammakarzinomen bei Nackt-Mäusen

- In vitro-Untersuchungen zur Transfektionseffizienz und Stabilität der siRNA bei Transfektion mit Atelocollagen (Ac) in MDA-MB-231-Zellen 
- Implantation der MDA-MB-231-Zellen in die Mammae der Maus

- Behandlung der Mammakarzinome mit BI-1-siRNA/Ac-Komplexen in vivo

- Messung der Gewichts- und Tumorentwicklung während des Zeitraumes des in vivo-Experiments

- Vergleich der Tumorprogression von BI-1-siRNA behandelten und Kontrollbehandelten Mammakarzinomen mittels volumetrischer Computertomographie

- Molekulare Bildgebung der mit Cy5.5 gekoppelten D-BI-1-siRNA mittels eXplore Optix Imager in vivo

- Präparation der Tumore sowie histologische Untersuchungen an Tumorgewebeschnitten mittels Hämatoxylin-Eosin-Färbung und Cy5.5Infrarotmikroskopie 


\section{Material und Methoden}

\subsection{Chemikalien und Reagenzien}

Alle Substanzen, die nicht aufgeführt sind, wurden von den Firmen Carl Roth GmbH (Karlsruhe) und Sigma-Aldrich (Deisenhofen) bezogen.

\section{Chemikalien}

Acrylamid/Bisacrylamid 40\% (29:1)

Agar

Agarose

Albumin Fraktion V

Ampicillin

Ampuwa

Aprotinin

Bacto-Tryptone

Chloroform

Dextransulfat

Dimethyldicarbonat (DMPC)

Dimethylsulfoxid (DMSO)

Dithiothreitol (DTT)

dNTPs $(100 \mathrm{mM})$

Entwickler

Ethidiumbromid

Ethylendiamin-tetraacetat (EDTA)

Fixierer

Glycerol

Glycin

Glutathione Sepharose $^{\mathrm{TM}} 4 \mathrm{~B}$

Hefeextrakt

\section{Hersteller}

Carl Roth GmbH, Karlsruhe Carl Roth GmbH, Karlsruhe

Invitrogen, Karlsruhe

Biomol, Hamburg

Sigma-Aldrich, Deisenhofen

Fresenius AG, Bad Homburg

Sigma-Aldrich, Deisenhofen

Carl Roth GmbH, Karlsruhe

Baker, Deventer, NL

GE Healthcare, Freiburg

Sigma-Aldrich, Deisenhofen

Carl Roth GmbH, Karlsruhe

Biomol, Hamburg

Boehringer, Mannheim

Kodak, Darmstadt

Sigma-Aldrich, Deisenhofen

ICN, Aurora, USA

Kodak, Darmstadt

Carl Roth GmbH, Karlsruhe

Carl Roth GmbH, Karlsruhe

GE Healthcare, Freiburg

Carl Roth GmbH, Karlsruhe 
Isopropyl- $\beta$-D-thiogalactopyranosid (IPTG) Biomol, Hamburg

Kanamycin

Sigma-Aldrich, Deisenhofen

Lachsspermien-DNA

Sigma-Aldrich, Deisenhofen

Leupeptin

Sigma-Aldrich, Deisenhofen

(N-Morpholino)-Propansulfonsäure (MOPS)

Carl Roth GmbH, Karlsruhe

MangoTaq-DNA-Polymerase

Bioline, Luckenwalde

B-Mercaptoethanol

Serva, Heidelberg

NuPAGE TM MES Running buffer (20x)

Invitrogen, Karlsruhe

NuPAGE TM LDS Sample buffer (4x)

Invitrogen, Karlsruhe

Natriumdodecylsulfat (SDS)

Serva, Heidelberg

OligoFectamine

Invitrogen, Karlsruhe

Orange-G

Sigma-Aldrich, Deisenhofen

Penicillin/Streptomycin

PAN, Aidenbach

PfuTurbo-DNA Polymerase

Stratagene, La Jolla, USA

Phenol

Invitrogen, Karlsruhe

Platinum-Taq-DNA Polymerase

Invitrogen, Karlsruhe

PMSF

Sigma-Aldrich, Deisenhofen

Proteinase K

GE Healthcare, Freiburg

Radioaktiv markierte Reagenzien: $\left[\alpha{ }^{32} \mathrm{P}\right]-$ GE Healthcare, Freiburg dCTP, $\left[\alpha^{32} \mathrm{P}\right]-\mathrm{dATP}$

Rapid-Hyb Hybridisierungspuffer

GE Healthcare, Freiburg

Rediprime $^{\mathrm{TM}}$ II

GE Healthcare, Freiburg

Restriktionsenzyme

Invitrogen, Karlsruhe

Reverse Transkriptase SuperScript II

Invitrogen, Karlsruhe

RNase A

Invitrogen, Karlsruhe

RNase-Inhibitor

MBI, St. Leon-Rot

RNA-Längenstandard

Invitrogen, Karlsruhe

Roti®Fect

Carl Roth GmbH, Karlsruhe

Roti ${ }^{\circledR}-N a n o q u a n t$

Carl Roth GmbH, Karlsruhe

S.O.C. Medium

Invitrogen, Karlsruhe

Simply Blue Safe Stain

Invitrogen, Karlsruhe

$\mathrm{T}_{4}$-DNA-Ligase

Promega, Mannheim 
Taq-DNA-Polymerase

$\mathrm{N}, \mathrm{N}, \mathrm{N}, \mathrm{N}^{\prime}, \mathrm{N}^{\prime}-$ Tetramethylethylenediamine (TEMED)

Tris

Triton X-100

Tween 20

Vecta Shield mit DAPI

X-Gal

Zellkulturmedien
GE Healthcare, Freiburg

Carl Roth GmbH, Karlsruhe

Carl Roth GmbH, Karlsruhe

Fluka, Deisenhofen

Merck, Darmstadt

VectorLab, Burlingame, USA

Biomol, Hamburg

PAN, Nürnberg

\subsection{Gebrauchswaren}

Nicht aufgeführte Gebrauchswaren wurden von den Firmen Schütt und OmnilabKrannich (Göttingen), sowie Sarstedt (Nümbrecht) bezogen.

\section{Gebrauchswaren}

12well- und 24well-Zellkultur-Platten

96well-Mikrotiterplatten

Blottingpapier GB 002, 003, 004

CentriSart I

FALCON culture slides

PVDF-Membran

Einmalfilter Minisart

NML (Porengröße 0,20 und 0,45 $\mu \mathrm{m}$ ) Filterpapier 0858

Hybond C Membran

Membranfilter

Petrischalen

Pipettenspitzen

\section{Hersteller}

Corning Inc., New York, USA

Greiner, Nürtingen

Schleicher \& Schüll, Dassel

Sartorius, Göttingen

Becton Dickinson, Le Pont De Claix, Frankreich

Macherey \& Nagel, Düren

Sartorius, Göttingen

Schleicher \& Schüll, Dassel

GE Healthcare, Freiburg

Millipore, Morlsheim

Greiner Nunc., Nürtingen

Eppendorf, Hamburg 


$\begin{array}{ll}\text { Reaktionsgefäße } & \text { Eppendorf, Hamburg } \\ \text { Quarz-Küvetten } & \text { Hellma, Mühlheim } \\ \text { Röntgenfilme (Hyperfilm }{ }^{\mathrm{TM}} \text {-MP) } & \text { GE Healthcare, Freiburg } \\ \text { Sterilfilter } & \text { Sartorius, Göttingen } \\ \text { Objektträger Superfrost@Plus } & \text { Schütt, Göttingen } \\ \text { Zellkulturflaschen } & \text { Greiner Nunc., Nürtingen }\end{array}$

\subsection{Sterilisation}

Die Sterilisation von Gebrauchswaren, Lösungen und Kulturmedien erfolgte für $60 \mathrm{~min}$ bei $121^{\circ} \mathrm{C}$ und 1,5 Bar im Dampfdruckautoklaven (Webco, Bad Schwartau) oder wurde über Nacht bei $220^{\circ} \mathrm{C}$ hitzesterilisiert. Hitzeempfindliche Lösungen wurden steril filtriert (Porengröße: 0,2 $\mu \mathrm{m}$ ). Wässrige Lösungen für RNA-Präparationen und RNAAnalysen wurden mit $1 \%$ o (v/v) Dimethyldicarbonat versetzt, für 12 bis 24 h bei RT inkubiert und anschließend autoklaviert.

\subsection{Gebrauchsfertige Reaktionssysteme}

\section{Reaktionssysteme}

DYEnamic ET-Terminator-Mix

DirectPCR tail reagent

ECL Plus

Microspin ${ }^{\mathrm{TM}}$-S200 HR Säulen

MontageTMPCR Centrifugal Filter Devices

OneStep RT-PCR-Kit

Plasmid Midi Kit Nucleobond AX100

Plasmid Midi Kit

Protein G Immunoprecipitation Kit

\section{Hersteller}

GE Healthcare, Freiburg

Peqlab, Erlangen

GE Healthcare, Freiburg

GE Healthcare, Freiburg

Millipore, Schwalbach

Qiagen, Hilden

Macherey \& Nagel, Düren

Invitrogen, Karlsruhe

Sigma-Aldrich, Deisenhofen 
QIA Ex II Gel Extraction Kit

Rediprime $^{\mathrm{TM}}$ II Random Prime-

Labeling System

RNeasy Mini Kit

Tri-Reagent ${ }^{\mathrm{TM}}$
Qiagen, Hilden

GE Healthcare, Freiburg

Qiagen, Hilden

Sigma-Aldrich, Deisenhofen

\subsection{Puffer und Stammlösungen}

Lösungen für den routinemäßigen Gebrauch wurden nach Sambrook et al. (1989) angesetzt. Die benötigten Chemikalien wurden den Erfordernissen gemäß in bidestilliertem oder DEPC- behandeltem Wasser gelöst und nach Bedarf autoklaviert oder steril filtriert.

Puffer und Stammlösungen

Alkalische-Phosphatase-Färbelösung

AP-Puffer

Blockpuffer I

Blockpuffer II (Western Blot)

Blockpuffer III (Immunhistochemie)

\section{Zusammensetzung}

$45 \mu 1 \mathrm{NBT}(75 \mathrm{mg} / \mathrm{ml}$ in DMF)

$35 \mu 1 \mathrm{BCIP}(50 \mathrm{mg} / \mathrm{ml}$ in DMF)

In $10 \mathrm{ml}$ AP-Puffer

$100 \mathrm{mM} \mathrm{NaCl}$

$50 \mathrm{mM} \mathrm{MgCl}_{2}$

$100 \mathrm{mM}$ Tris/HCl pH 9.5

1x PBS

2-5\% Magermilchpulver

1x TBS/0,1\% Tween 20

5\% Magermilchpulver

1x PBS 
$3 \%$ BSA

Coomassie-Lösung

$30 \%(\mathrm{v} / \mathrm{v})$ Methanol

$10 \%(\mathrm{v} / \mathrm{v})$ Essigsäure

0,05\% (w/v) Coomassie-Brilliant

Blau R250

dNTP-Mix (25 mM)

$100 \mathrm{mM}$ dATP

$100 \mathrm{mM}$ dGTP

$100 \mathrm{mM}$ dCTP

$100 \mathrm{mM}$ dTTP

Glycinpuffer

$1,44 \%(w / v)$ Glycin

$0,3 \%(\mathrm{w} / \mathrm{v})$ Tris

$0,1 \%(\mathrm{w} / \mathrm{v}) \mathrm{SDS}$

10x IP-Puffer

500mM Tris $\mathrm{pH} 7,55$

$1,5 \mathrm{M} \mathrm{NaCl}$

5\% Natriumdeoxycholat

10\% NP-40 (oder IGPAL)

Lysispuffer für Proteine

$150 \mathrm{mM} \mathrm{NaCl}$

10 mM EDTA

50 mM Tris-HCl, $\mathrm{pH}$ 7,6

$1 \%$ Triton $\mathrm{X}-100$

$1 \%$ Proteinase-Inhibitoren:

Leupetin $(1 \mu \mathrm{g} / \mathrm{ml})$

Aprotinin $(1 \mu \mathrm{g} / \mathrm{ml})$

$\operatorname{PMSF}(1 \mu \mathrm{g} / \mathrm{ml})$ 
MOPS Puffer (10x)

P1 Puffer (Plasmid-Minipräparation)

P2 Puffer (Plasmid-Minipräparation)

P3 Puffer (Plasmid-Minipräparation)

10x PBS

Sammelgelpuffer

$\operatorname{SSC}(20 x)$

Stop-Mix I

Stop-Mix II
$50 \mathrm{mM} \mathrm{NaAc}$

$10 \mathrm{mM}$ EDTA

200 mM MOPS (pH 7,0)

$50 \mathrm{mM}$ Tris- $\mathrm{HCl}, \mathrm{pH} 8,0$

10 mM EDTA

$100 \mu \mathrm{g} / \mathrm{ml}$ RNase A

$200 \mathrm{mM} \mathrm{NaOH}, 1 \%$ SDS

3.0 M Natriumacetat ( $\mathrm{pH} 5,5)$

$1,37 \mathrm{M} \mathrm{NaCl}$

$81 \mathrm{mM} \mathrm{Na}_{2} \mathrm{HPO}_{4}$

$27 \mathrm{mM} \mathrm{KCl}$

$14,7 \mathrm{mM} \mathrm{KH}_{2} \mathrm{PO}_{4}$

0,5 M Tris/HCl pH 6,8

$0,4 \%$ SDS

$3 \mathrm{M} \mathrm{NaCl}$

$0.3 \mathrm{M}$ Natriumcitrat

pH 7.0 mit $\mathrm{NaOH}$

95\% Formamid

$20 \mathrm{mM}$ EDTA

0,05\% Bromphenolblau

0,05\% Xylencyanol

15\% Ficoll 400

200 mM EDTA

$0,1 \%$ Orange $\mathrm{G}$ 
50x TAE-Puffer

TBE-Puffer $(5 \mathrm{x})$

10x TBS

TE-Puffer

Transferpuffer (Western Blot)

Trenngelpuffer

Trypsin/EDTA-Lösung

20x Turbo-Puffer

Waschlösung I (Northern Blot)

Waschlösung II (Northern Blot)
2 M Tris-Acetat

0,05 M EDTA

pH 8,3

445 mM Tris/HCl, $\mathrm{pH} 8,0$

445 mM Borsäure

10 mM EDTA

$1,37 \mathrm{M} \mathrm{NaCl}$

100 mM Tris/HCl, pH 7,3

10 mM Tris- $\mathrm{HCl}, \mathrm{pH} 8,0$

$1 \mathrm{mM}$ EDTA

$25 \mathrm{mM}$ Tris

150 mM Glycin

20\% Methanol

pH 8.3

1,5 M Tris/HCl pH 8,8

$0,4 \%$ SDS

$0,05 \%$ Trypsin

$0,02 \%$ EDTA

in PBS

$0,2 \mathrm{M} \mathrm{NaOH}$

Mit festem $\mathrm{H}_{3} \mathrm{BO}_{3}$ auf $\mathrm{pH} 8,0$

$2 \times \mathrm{SSC}$

$0,2 \times \mathrm{SSC}$

$0,1 \%$ SDS 


$\begin{array}{ll}\text { Waschlösung III (Western Blot) } & 1 \mathrm{x} \text { PBS } \\ & 0,1 \% \text { Tween-20 } \\ & \\ \text { Waschlösung IV (AK-Aufreinigung) } & 1 \mathrm{x} \text { TBS/PBS } \\ & 2 \% \text { Magermilchpulver } \\ & 20 \mathrm{mg} \quad \mathrm{X}-\mathrm{Gal} / \mathrm{ml} \quad \text { N.N.-Dimethyl- } \\ \text { X-Gal-Stammlösung } & \text { formamid }\end{array}$

\subsection{Medien, Antibiotika, Agarplatten}

\subsubsection{Medien für Bakterien}

LB (Luria-Bertani)-Medium:

$$
\begin{aligned}
& 1 \% \text { Trypton } \\
& 0,5 \% \text { Hefeextrakt } \\
& 1 \% \mathrm{NaCl} \\
& \mathrm{pH} 7.0 \\
& 1,6 \% \text { Trypton } \\
& 1 \% \mathrm{Hefeextrakt} \\
& 0,5 \% \mathrm{NaCl} \\
& \mathrm{pH} 7.0
\end{aligned}
$$$$
\text { 2x YT - Medium: }
$$

Die Medien wurden mit bidestilliertem Wasser angesetzt, autoklaviert und bei $4^{\circ} \mathrm{C}$ aufbewahrt. Für die Selektion wurden der jeweiligen Resistenz entsprechend Ampicillin (Endkonzentration 50-200 $\mu \mathrm{g} / \mathrm{ml}$ ) bzw. Kanamycin (Endkonzentration 25 $\mu \mathrm{g} / \mathrm{ml})$ zugegeben. 


\subsubsection{Medien für Hefen}

YPDA-Medium (Vollmedium): $20 \mathrm{~g} / 1$ Trypton

$20 \mathrm{~g} / \mathrm{l} \mathrm{Hefeextrakt}$

2\% Glukose

$20 \mathrm{mg} / \mathrm{l}$ Adeninhemisulfat

pH 5,8 mit $\mathrm{HCl}$

2x YT-Medium:

$1,7 \mathrm{~g} / 1$ Hefe-Stickstoff-Basis ohne Amminosäuren

$5 \mathrm{~g} / 1$ Ammoniumsulfat

10\% sterile Mangel-Nährlösung

2\% Glukose

10x Mangel-Nährlösung:

In Abhängigkeit vom gewünschten Selektivmedium wurden von den folgenden Komponenten eine oder mehrere weggelassen.

$200 \mathrm{mg} / \mathrm{l}$ Adeninsulfat

200 mg/l Arginin

$200 \mathrm{mg} / 1$ Histidin

$300 \mathrm{mg} / 1$ Isoleucin

$1000 \mathrm{mg} / \mathrm{l}$ Leucin

$300 \mathrm{mg} / \mathrm{l} \mathrm{Lysin}$

$200 \mathrm{mg} / \mathrm{l}$ Methionin

$500 \mathrm{mg} / \mathrm{l}$ Phenylalanin

$2000 \mathrm{mg} / 1$ Threonin

$200 \mathrm{mg} / 1$ Tryptophan

300 mg/1 Tyrosin

$200 \mathrm{mg} / 1$ Uracil

$1500 \mathrm{mg} / \mathrm{l}$ Valin

Die Medien wurden mit bidestilliertem Wasser angesetzt, autoklaviert und bei $4^{\circ} \mathrm{C}$ aufbewahrt. 


\subsubsection{Agarplatten}

Zur Herstellung von Agarplatten wurde dem LB-Medium vor dem Autoklavieren 1,5\% (w/v) Agar zugefügt, nach dem Autoklavieren auf $55^{\circ} \mathrm{C}$ abgekühlt, ggf. mit den u. a. Reagenzien versetzt und in Petrischalen gegossen. Nach dem Aushärten wurden die Agarplatten bei $4^{\circ} \mathrm{C}$ aufbewahrt.

Ampicillin: Endkonzentration $50 \mu \mathrm{g} / \mathrm{ml}$

Kanamycin: Endkonzentration $25 \mu \mathrm{g} / \mathrm{ml}$

\subsubsection{Medien für eukaryotische Zellkulturen}

Die zur Kultur eukaryotischer Zellen verwendeten Medien wurden käuflich erworben (PAN, Nürnberg) und vor Gebrauch mit fetalem Kälberserum (FKS) und Antibiotika (Penicillin/Streptomycin) versetzt und sterilfiltriert. Für die Zellkultur wurden folgende Medien verwendet:

Medium für PC-3-, LNCaP-, DU 145-, MDA-MB-453, HCC-70 und T-47DZellen:

RPMI 1640 (PAN)

$100 \mu \mathrm{g} / \mathrm{ml}$ Streptomycin

$100 \mathrm{U} / \mathrm{ml}$ Penicillin

10\% Fetales Kälberserum

Medium für NIH 3T3-, MCF-7 und

MDA-MB-231-Zellen:

DMEM (PAN)

2 mM L-Glutamin

$100 \mu \mathrm{g} / \mathrm{ml}$ Streptomycin

$100 \mathrm{U} / \mathrm{ml}$ Penicillin

10\% Fetales Kälberserum

Medium für ZR-75-1

RPMI 1640 (PAN)

$100 \mu \mathrm{g} / \mathrm{ml}$ Streptomycin 


\author{
$100 \mathrm{U} / \mathrm{ml}$ Penicillin \\ $10 \%$ Fetales Kälberserum \\ $10 \mathrm{nM}$ Hepes
}

Zur Langzeitlagerung der Zellen in flüssigem Stickstoff wurde das entsprechende Medium mit 8\% DMSO versetzt.

\title{
2.7 Biologisches Material
}

\subsubsection{Bakterienstämme}

Für die Transformation von Plasmiden in kompetente Bakterienstämme wurde der Bakterienstamm Escherichia coli DH5 $\alpha$ (Hanahan, 1983) von Invitrogen (Karlsruhe) verwendet.

\subsubsection{Hefestämme}

Für das Yeast-Two-Hybrid- System wurde der Hefestamm Saccharomyces cerevisiae AH109 von Clontech (Heidelberg) verwendet.

\subsubsection{Eukaryotische Zellinien}

MDA-MB-231 Humane Mammakarzinomzellinie, ATCC, Rockville, USA Östrogenrezeptor-(ER-) negative Zellen (Cailleau et al., 1974)

MDA-MB-453 Humane Mammakarzinomzellinie, ATCC, Rockville, USA ER-negative Zellen (Cailleau et al., 1978) 
HCC70 Humane Mammakarzinomzelllinie, ATCC, Rockville, USA ER-positive Zellen (Gazdar et al., 1998)

ZR-75-1 Humane Mammakarzinomzelllinie, ATCC, Rockville, USA ER-positive Zellen (Engel et al., 1978)

MCF-7 Humane Mammakarzinomzellinie, ATCC, Rockville, USA ER-positive Zellen (Soule et al., 1973)

T-47D Humane Mammakarzinomzelllinie, ATCC, Rockville, USA ER-positive Zellen (Keydar et al., 1979)

PC-3 Humane Prostataadenokarzinom-Zelllinie, ATCC, Rockville, USA Androgenunabhängige Zellen (Kaighn et al., 1979; Ohnuki et al., 1980)

LNCaP Humane Prostataadenokarzinom-Zelllinie, ATCC, Rockville, USA Androgenabhängige Zellen (Horoszewicz et al., 1983)

NIH/3T3 Mausfibroblasten, ATCC, Rockville, USA

(Jainchill, et al., 1969)

\subsection{Synthetische Oligonukleotide}

\subsubsection{Synthetisch DNA-Oligonukleotide}

Für die Sequenzierung von Konstrukten bzw. die Generierung von cDNA-Produkten wurden synthetische Oligonukleotide von den Firmen Invitrogen (Karlsruhe), Biomers.net (Ulm) und Operon (Köln) verwendet. 
Vektor-spezifische Primer:

GAPDH-Fw

5'-CCA GCA AGA GCA CAA GAG GAA GAG-3'

(Homo sapiens)

GAPDH-Rev

5'-AGC ACA GGG ATA CTT TAT TAG ATG-3'

(Homo sapiens)

GFPC1-TOP+ 5'-GAT CAC ATG GTC CTG CTG GAG TTC GT-3'

GFPC1-R+ 5'-GTA AAA CCT CTA CAA ATG TGG TAT GG-3'

pGADT7F 5'-TCG ATG ATG AAG ATA CCC CAC CAA ACC-3'

pGADT7R 5'-AGA TGG TGC ACG ATG CAC AGT TGA AGT G-3'

pGBKT7F 5'-TCA TCG GAA GAG AGT AGT AAC AAA GG-3'

pGBKT7R 5'-CTA AGA GTC ACT TTA AAA TTT GTA TAC AC-3'

EGFP-V1-Rev 5'-GTC CTC GAT GTT GTG GCG GAT CTT G-3'

EGFP-V2-Fw 5'-CCA CAA CGT CTA TAT CAT GGC CGA CA-3'

SP6new 5'-TTA GGT GAC ACT ATA GAA TAC TCA AGC-3'

T3new 5'-TTA ACC CTC ACT AAA GGG AAC AAA AGC-3'

T7new 5'-AAT ACG ACT CAC TAT AGG GCA AAT TGG-3'

\section{BI-1-spezifische Primer:}

BI-1ORFEcoRIfwd 5'-GCA GAA TTC ATG AAC ATA TTT GAT CGA AAG-3'

BI-1ORFxhoIrev 5'-GAT CTC GAG TTT CTT CTC TTT CTT CTT-3'

BI-1EcoRIntfwd 5'-GCA GA TTC CAT GAA CAT ATT TGA TCG AAA G-3'

BI-1hindIIIrev 5'-CCC AAG CTT GTT TCT TCT CTT TCT TCT T-3'

BI-1_xho-FwS2 5'-GAT CTC GAG CCA TGA ACA TAT TTG ATC GAA AG-3'

FwBI-1Xhol 5'-GAT CTC GAG ATG AAC ATA TTT GAT CGA AAG-3'

RevBI-1EcoRIcr 5'-GCA GAA TTC GTT TCT TCT CTT TCT TCT T-3' 


\title{
DIO-1-spezifische Primer
}

\author{
DIO-1seq-821rev 5'-CTG AAG CTC TTT CAA GGT CAG GCC ATC-3' \\ DIO-1seq-859for 5'-AGA GGC CCC TGA AAG GGA TCC AGA GTC-3' \\ DIO1FwNcoI 5'-TAT ACC ATG GAC GAC AAA GGC GAC CCG AGC-3' \\ DIO1RvNotI 5'-TGT GCG GCC GCA CAC AAA GCT GCA ACT CCC AG-3' \\ DiolseqFw 5'-CAG TCT GCT TCC ACA GCT GTC AA-3' \\ DiolseqRv 5'-CAA TAC ATT TTG AGG CAC CAG GC-3' \\ Dio-1Fw 5'-AGG AAG CAG CTT GTG AGA GCA GCA-3' \\ Dio-1Rev 5'-CCG GGC AGT GTG GCT ATGCAA T-3'
}

\subsubsection{Synthetische RNA-Oligonukleotide}

Die synthetischen siRNA-Oligonukleotide wurden von der Firma Eurogentec (Seraing, Belgien) bezogen.

Humanes BI-1 „D-BI-1“

Zielsequenz: $\quad$ 5'-CCCCGUCAACGCAGCAGCA -3'

Erster Strang: $\quad 5^{\prime}-\mathrm{Cy} 5.5^{*}$ CCCCGUCAACGCAGCAGCAdTdT -3 '

Zweiter Strang: $\quad$ 5'-UGCUGCUGCGUUGACGGGGdTdT -3'

Luciferase (Photinus pyralis)

Zielsequenz: $\quad$ 5'-CGUACGCGGAAUACUUCGA -3'

Erster Strang: $\quad$ 5'-CGUACGCGGAAUACUUCGAdTdT -3'

Zweiter Strang: $\quad$ 5'-UCGAAGUAUUCCGCGUACGdTdT -3' 


\subsection{Antikörper}

\section{Primärantikörper}

Polyklonaler Antikörper gegen humanes

BI-1 aus Ziege (A-18)

Polyklonaler Antikörper gegen humanes

DIO-1 aus Kaninchen (M-300)

Monoklonaler Antikörper Bip/GRP78 aus Maus (610978)

Monoklonaler Antikörper EEEA1 aus Maus (610456)

Polyklonaler Antiköper Anti-GFP, Nterminal (G1544) aus Kaninchen

Monoklonaler Antikörper gegen $\alpha$-Tubulin (clone B-5-1-2)

\section{Sekundärantiköper}

Anti-Kaninchen IgG Alkalische Phosphatase konjugiert (A-3687) aus Ziege Anti-Kaninchen IgG HRP konjugiert aus Ziege

Anti-Kaninchen IgG, Cy3 konjugiert (C2306)

Anti-Kaninchen IgG, FITC konjugiert

Anti-Maus IgG Alkalische Phosphatase konjugiert (A-9316)

Anti-Maus IgG HRP (horse radish peroxidase) konjugiert aus Kaninchen

Anti-Maus IgG Cy3 konjugiert

Anti-Maus IgG FITC konjugiert

Anti-Ziege IgG Alkalische Phosphatase
Santa Cruz Biotechnologie, Heidelberg

Santa Cruz Biotechnologie, Heidelberg

Becton Dickinson, Le Pont De Claix, Frankreich

Becton Dickinson, Le Pont De Claix, Frankreich

Sigma-Aldrich, Deisenhofen

Sigma-Aldrich, Deisenhofen

Sigma-Aldrich, Deisenhofen

Sigma-Aldrich, Deisenhofen

Sigma-Aldrich, Deisenhofen

Sigma-Aldrich, Deisenhofen

Sigma-Aldrich, Deisenhofen

Sigma-Aldrich, Deisenhofen

Sigma-Aldrich, Deisenhofen Sigma-Aldrich, Deisenhofen Sigma-Aldrich, Deisenhofen 
konjugiert (A-4062)

\subsection{Plasmide}

\author{
pBluescript SK (+/-) \\ pBluescript $\mathrm{KS}(+/-)$ \\ pGEM-Teasy \\ pEGFP-C1 \\ pEGFP-N2 \\ pDsRed-N1 \\ pGEM-Teasy \\ pGADT7 \\ pGBKT7
}

\author{
Stratagene, La Jolla, USA \\ Stratagene, La Jolla, USA \\ Promega, Wisconsin, USA \\ Clontech, Palo Alto, CA, USA \\ Clontech, Palo Alto, CA, USA \\ Clontech, Palo Alto, CA, USA \\ Promega, Wisconsin, USA \\ Clontech, Palo Alto, CA, USA \\ Clontech, Palo Alto, CA, USA
}

\subsection{Datenbanken}

Nukleotid- und Proteinsequenzen wurden mit den Sequenzdatenbanken Genbank (http://www.ncbi.nlm.nih.gov) und EMBL (http://www.ebi.ac.uk) mit Hilfe des BLASTProgramms (Altschul et al., 1990) analysiert. Die Erstellung von RestriktionsSchnittstellen-Kartierungen und den Auswahl und Überprüfung der Spezifität von Oligonukleotiden erfolgte durch das Bioinformatik-Programm VectorNTI Advance Version 9 und 10 (Invitrogen). Die Analyse von Proteindomänen erfolgte mit Hilfe des PredictProtein-Programms (http://www.predictprotein.org) und des ExPASyProteomic-Tools (http://www.expasy.org). 


\subsection{Isolierung und Aufreinigung von Nukleinsäuren}

\subsubsection{Minipräparation von Plasmid-DNA}

Zur schnellen Isolierung rekombinanter Plasmide wurde zunächst eine geringe Menge an Plasmid-DNA präpariert. Hierzu wurden $5 \mathrm{ml}$ einer angeimpften Übernachtkultur bei $5000 \mathrm{x}$ g zentrifugiert und das Pellet in $250 \mu \mathrm{l}$ P1-Lösung resuspendiert. Nach Zugabe von $250 \mu 1$ P2 (modifizierte alkalische Lyse (Birnboim und Doly, 1979)) und $250 \mu 1$ P3 (Neutralisierung) wurde die Probe bei 16000 x g zentrifugiert. Der Überstand wurde in ein neues Gefäß überführt, mit 0,7 Vol Isopropanol versetzt, und bei $16000 \mathrm{x}$ g wurde die Plasmid-DNA gefällt. Anschließend wurde das DNA-Pellet mit 500 $\mu 1$ 70\% Ethanol gewaschen und nach dem Trocknen in 20-50 $\mu 1 \mathrm{H}_{2} \mathrm{O}$ aufgenommen.

\subsubsection{Herstellung von Bakterien-Glycerin-Stocks}

$3 \mathrm{ml}$ einer Bakteriensuspension wurden mit $100 \mu \mathrm{l}$ sterilem Glycerin versetzt, gut gemischt und bei $-80^{\circ} \mathrm{C}$ aufbewahrt.

\subsubsection{Midipräparation von Plasmid-DNA}

Zur Isolierung größerer Mengen hochreiner Plasmid-DNA wurde das Plasmid-Midi Kit der Firma Qiagen (Hilden) verwendet. Die DNA wird dabei über Säulen aus dem Kit affinitätschromatographisch aufgereinigt. Die Aufarbeitung erfolgte nach dem Protokoll des Herstellers. Die mit dieser Methode isolierte Plasmid-DNA kann u.a. für die Transfektion von Zelllinien, für Restriktionsanalysen, Hybridisierungsexperimente und zur Subklonierung oder Sequenzierung eingesetzt werden. 


\subsubsection{Ethanolfällung von DNA aus wässrigen Lösungen}

(Sambrook et al., 1989)

Die Ethanolfällung wurde eingesetzt, um DNA zu konzentrieren und sie von Salzverunreinigungen zu befreien. Zur Fällung von Plasmid-DNA oder PCR-Produkten wurde der Ansatz mit 1/10 Vol 3M Kaliumacetat-Essigsäure, pH 5.2, und 3 Vol 96\% Ethanol versetzt. Die Präzipitation erfolgte durch Inkubation für 10 min bei RT oder für mehrere Stunden bei $-20^{\circ} \mathrm{C}$. Der Ansatz wurde für $30 \mathrm{~min}$ bei $16000 \mathrm{x}$ g zentrifugiert und das Pellet mit 70\%igem Ethanol gewaschen. Anschließend wurde das Pellet getrocknet und in einem entsprechenden Volumen $\mathrm{H}_{2} \mathrm{O}$ aufgenommen.

\subsubsection{Phenol/Chloroform- Aufreinigung von Nukleinsäuren}

Die Phenol/Chloroform-Extraktion dient der Reinigung der DNA von Proteinen und Membranbestandteilen (Kirby, 1956; Marmur, 1960). Die zu extrahierenden DNAProben wurden mit gleichen Volumina Phenol versetzt und intensiv gemischt. Die Phasentrennung erfolgte durch Zentrifugation bei 16000 x g für 2-5 min. Die wässrige Phase wurde in ein neues Eppendorf-Gefäß überführt und die Extraktion nun mit 1 Vol Phenol/Chloroform/Isoamylalkohol (25:24:1) wiederholt. Die sich in der wässrigen Phase befindende DNA wurde anschließend einer Ethanolfällung (2.12.4) unterzogen.

\subsubsection{Konzentrationsbestimmung von Nukleinsäuren}

Die Konzentration von Nukleinsäuren wurde mit einem Spektralphotometer (Ultrospec 300pro, GE Healthcare, Freiburg) bestimmt. Nach Abgleichen der Nullwerte konnten das Absorptionsmaximum der gemessenen Nukleinsäuren (bei $260 \mathrm{~nm}$ ) bestimmt und gleichzeitig Verunreinigungen durch Proteine (bei $280 \mathrm{~nm}$ ) bzw. Salze (bei $320 \mathrm{~nm}$ ) festgelegt werden. Die Berechnung der Nukleinsäurekonzentration wurde nach folgender Formel durchgeführt: 


$$
\begin{aligned}
& \mathrm{C}[\mu \mathrm{g} / \mu \mathrm{l}]=\left(\mathrm{E}_{260}-\mathrm{E}_{320}\right) \times \mathrm{f} \times \mathrm{c} \\
& C=\text { Konzentration der gemessenen Probe } \\
& E=\text { Extinktion } \\
& F=\text { Verdünnungsfaktor } \\
& c=\text { nukleinsäurespezifischer Koeffizient in } \mu \mathrm{g} / \mu \mathrm{l} \\
& \text { für doppelsträngige DNA: } \quad c=0,05 \mu \mathrm{g} / \mu \mathrm{l} \\
& \text { für einzelsträngige DNA: } \quad c=0,025 \mu \mathrm{g} / \mu \mathrm{l} \\
& \text { für RNA: } \quad \mathrm{c}=0,04 \mu \mathrm{g} / \mu \mathrm{l}
\end{aligned}
$$

Der Quotient $E_{260} / E_{280}$ ist ein Maß für die Reinheit der DNA bzw. RNA und sollte etwa $2,0 \pm 0,2$ betragen.

Zur Bestimmung von niedrigen Konzentrationen wurde eine bestimmte Menge der DNA auf ein Agarosegel neben einem DNA-Standard (MassRuler, MBI) aufgetragen, bei dem für jede Bande die entsprechende Menge DNA bekannt ist. Nach dem Lauf wurde das Gel mit Ethidiumbromid gefärbt und die DNA unter UV-Licht sichtbar gemacht und fotografiert. Die $\mathrm{zu}$ bestimmenden Banden wurden mit Banden des Standards ähnlicher Größe verglichen und so die Konzentration der Probe bestimmt.

\subsection{Klonierungstechniken}

\subsubsection{Spaltung von DNA mit Restriktionsendonukleasen}

Zur enzymatischen Spaltung von DNA wurde der Restriktionsansatz in einem Volumen von mindestens $10 \mu \mathrm{l}$ bei der für das Enzym optimalen Temperatur für 1-2 h oder über Nacht inkubiert, wobei pro $\mu$ g DNA 2-3 U des jeweiligen Restriktionsenzyms eingesetzt wurden. Für den simultanen Verdau mit zwei Restriktionsendonukleasen wurde ein Puffer eingesetzt, der beiden Enzymen eine ausreichende Aktivität erlaubte. 


\subsubsection{Isolierung von DNA-Fragmenten aus Agarosegelen}

Die Isolierung von DNA-Fragmenten aus Agarosegelen erfolgte mit Hilfe des QIAEXII-Kits (Qiagen, Hilden). Nach dem Lösen der Agarose wird die DNA selektiv an Partikel aus Silicagel in Anwesenheit von chaotropen Salzen gebunden und anschließend mit Wasser eluiert. Die über ein Agarosegel aufgetrennten DNAFragmente wurden mit einem sterilen Skalpell aus dem Gel geschnitten und nach dem Protokoll der Firma Qiagen weiterbehandelt.

\subsubsection{Dephosphorylierung von Plasmid-DNA}

Um eine Religation linearisierter Plasmid-DNA $\mathrm{zu}$ verhindern, wurde eine Dephosphorylierung durchgeführt. Endständige 5'-Phosphatgruppen des Vektors werden mit Hilfe des Enzyms Alkalische Phosphatase entfernt. Dazu wurde die DNA mit $2 \mathrm{U}$ Alkalischer Phosphatase für $1 \mathrm{~h}$ bei $37^{\circ} \mathrm{C}$ inkubiert. Anschließend wurde die DNA mit Phenol/Chloroform aufgereinigt, mit 2,5 Vol Ethanol und 1/10 Vol $3 \mathrm{M}$ Natriumacetat ( $\mathrm{pH} 4.8$ ) gefällt und in $\mathrm{H}_{2} \mathrm{O}$ resuspendiert.

\subsubsection{Ligation von DNA-Fragmenten}

Die Ligation wurde zur Verknüpfung von linearer Plasmid-DNA mit DNA-Fragmenten genutzt. Das Enzym T4-DNA-Ligase katalysiert dabei die Bildung von Phosphodiesterbindungen zwischen 3'-Hydroxyl- und 5'-Phosphatenden der linearisierten DNA, so dass rekombinante DNA-Moleküle entstehen. Es wurde folgender Ligationsansatz verwendet:

$\begin{array}{ll}25-50 \mathrm{ng} & \text { Vektor-DNA } \\ 30-120 \mathrm{ng} & \text { Insert-DNA } \\ 1 \mu \mathrm{l} & \text { T4-DNA-Ligase }(5 \mathrm{U} / \mu \mathrm{l}) \\ 1 \mu \mathrm{l} & 10 \times \text { Ligationspuffer } \\ \text { ad } 10 \mu \mathrm{H}_{2} \mathrm{O} & \end{array}$


Der Ansatz wurde über Nacht bei $4^{\circ} \mathrm{C}$ inkubiert.

\title{
2.13.5 Subklonierung von PCR- und RT-PCR-Produkten
}

Taq- und andere Polymerasen besitzen eine terminale Transferase-Aktivität, die zu einer Addition von einem Nukleotid an das 3'-Ende von PCR-Produkten führt. In Anwesenheit aller 4 Nukleotide wird hauptsächlich dA angehängt. Diese terminale Transferase-Aktivität ist die Grundlage für die TA-Klonierungsstrategie. Für die Subklonierung von PCR- und RT-PCR-Produkten wurde das pGEM-Teasy Vektor System verwendet, welches 5' T-Überhänge besitzt. Folgende Komponenten wurden gemischt:

\author{
50 ng pGEM-T Easy Vektor \\ PCR-Produkt (3:1, Insert: Vektor-Verhältnis) \\ $1 \mu 1$ T4-DNA-Ligase 10x Puffer \\ $1 \mu 1$ T4-DNA-Ligase \\ in einem Gesamtvolumen von $10 \mu 1$
}

Die Bestandteile wurden gemischt und über Nacht bei $4^{\circ} \mathrm{C}$ inkubiert. Die Produkte einer Ligation wurden anschließend in kompetente E. coli Bakterien transformiert (siehe 2.13.6).

\subsubsection{Transformation kompetenter Zellen mit Plasmid-DNA}

(Hanahan, 1983)

Für die Transformation wurden zunächst die kompetenten Zellen auf Eis 5 min aufgetaut, 3-5 $\mu 1$ des Ligationsansatzes zu $50 \mu \mathrm{l}$ kompetente Zellen hinzugefügt und für 20 min auf Eis inkubiert. Dann wurden die Zellen einem Hitzeschock bei $42^{\circ} \mathrm{C}$ für 1 min ausgesetzt und sofort wieder für 2 min auf Eis gestellt. Nach Zufügen von $1 \mathrm{ml}$ SOC-Medium wurde der Transformationsansatz für $1 \mathrm{~h}$ bei $37^{\circ} \mathrm{C}$ unter Schütteln inkubiert. Danach wurden 50-500 $\mu \mathrm{l}$ der transformierten Zellen auf geeigneten Agarplatten ausgestrichen und über Nacht bei $37^{\circ} \mathrm{C}$ inkubiert. 


\subsection{Gelelektrophorese}

\subsubsection{Gelelektrophorese von DNA}

Zur Auftrennung von DNA-Fragmenten wurden Agarose-Gelelektrophoresen durchgeführt. Je nach Größe der Fragmente wurden Gele mit 0,5-2,0\% (w/v) Agaroseanteil verwendet. Die Agarose wurde in $100 \mathrm{ml}$ 0,5x TBE-Puffer durch Kochen gelöst, mit Ethidiumbromid (Endkonzentration $0,5 \mu \mathrm{l} / \mathrm{ml}$ ) versetzt und in den Gelträger überführt. Nach vollständiger Verfestigung des Gels wurde die Elektrophorese in einer mit 0,5x TBE-Puffer gefüllten Gelkammer bei konstanter Spannung von 50-150 V durchgeführt.

\subsubsection{Längenstandards}

Um die Größe von DNA- bzw. RNA-Fragmenten auf Agarosegelen zu bestimmen, wurden Längenstandards parallel mitgeführt.

1 kb DNA Ladder

100 bp DNA Ladder
Invitrogen, Karlsruhe

Invitrogen, Karlsruhe

\subsection{Transfertechniken}

\subsubsection{Northern Blot-Analysen}

Die im denaturierenden Agarosegel aufgetrennten RNA-Fragmente wurden mit Hilfe des Northern-Blot-Verfahrens auf Nitrocellulosefilter übertragen. Der Transfer der RNA auf die Membran erfolgte über Nacht mit einem Turbo-Blotter (Schleicher \& Schüll, Dassel) nach dem Protokoll des Herstellers. Am nächsten Morgen wurden die 
Positionen der Geltaschen auf der Membran markiert. Der Filter wurde zur Fixierung der RNA für $2 \mathrm{~h}$ bei $80^{\circ} \mathrm{C}$ inkubiert.

\subsection{Radioaktive Markierung von DNA und Hybridisierung membrangebundener RNA}

\subsubsection{Random Prime-Markierung}

(Feinberg und Vogelstein, 1983)

Der Ready Prime Kit II (GE Healthcare, Freiburg) wurde für die Markierung von DNAFragmenten mit $\left[\alpha-{ }^{32} \mathrm{P}\right]$ Isotopen verwendet. Die Methode basiert auf dem Prinzip des random priming, welches von Feinberg and Vogelstein (1989) entwickelt wurde. Der Reaktionsmix enthält dATP, dGTP, dTTP, Klenow Fragment (4-8 U) und zufällige Oligodeoxyribonukleotide, hauptsächlich 9-mere. 25-50 ng der DNA wurden in einem Gesamtvolumen von $46 \mu 1$ bei $95^{\circ} \mathrm{C}$ für 3-5 min denaturiert. Die Probe wurde dann in das Ready Prime Reaktionsgefäß überführt, gut gemischt, und zum Schluss wurden $4 \mu 1$ von $\left[\alpha-{ }^{32} \mathrm{P}\right] \mathrm{dCTP}(40 \mu \mathrm{Ci})$ zum Reaktionsmix zugegeben. Die Markierungsreaktion wurde bei $37^{\circ} \mathrm{C} 30-60$ min durchgeführt. Die markierte DNA wurde anschließend mit Hilfe von MicroSpin S-200HR Säulen (GE Healthcare) aufgereinigt. Die spezifische Aktivität der DNA-Probe wurde im Szintillationszähler (Tri-Carb 4530, Packard Instruments, Warrenville, USA) gemessen. Sie lag in der Regel zwischen 4 x $10^{8}$ und 5 x $10^{9} \mathrm{cpm} / \mu \mathrm{g}$ DNA.

\subsubsection{Hybridisierung membrangebundener RNA mit radioaktiv markierten DNA-Sonden}

Die fixierten Nitrocellulosefilter mit darauf gebundener RNA wurden für mindestens 1 h bei $65^{\circ} \mathrm{C}$ in Rapid Hyb Puffer (GE Healthcare) im Rollofen (Bachofer, Reutlingen) prähybridisiert. Anschließend wurden die denaturierte Sonde sowie $300 \mu l$ 
Lachsspermien-DNA (10 $\mathrm{mg} / \mathrm{ml})$ zur Hybridisierungslösung gegeben. Die Hybridisierung erfolgte über Nacht unter denselben Bedingungen wie die Prähybridisierung. Die Filter wurden danach 15-30 min in Waschlösung I bei RT und 25 min in Waschlösung II bei $65^{\circ} \mathrm{C}$ gewaschen. Die noch feuchten Membranen wurden zur Auswertung mit einem Röntgenfilm in einer Autoradiographie-Kassette bei $-70^{\circ} \mathrm{C}$ oder mit einer Phosphorimagermembran (Bio-Rad, Hercules, USA) bei RT exponiert. Die Phosphorimagermembran wurde anschließend in einem Phosphorimager (Personal Molecular Imager FX, Bio-Rad, Hercules, USA) mit Hilfe des Quantity One-SoftwareProgramms analysiert.

\subsection{Polymerase-Kettenreaktion (PCR)}

(Saiki et al., 1985)

\subsubsection{PCR an Plasmid-DNA}

Die Methode wurde mit folgendem Reaktionsansatz durchgeführt:

$\begin{aligned} \mathrm{x} \mu \mathrm{l} & \text { template-DNA }(10-50 \mathrm{ng}) \\ 1 \mu \mathrm{l} & \text { Primer } 1(10 \mathrm{pmol} / \mu \mathrm{l}, \text { sequenzspezifisch }) \\ 1 \mu \mathrm{l} & \text { Primer } 2(10 \mathrm{pmol} / \mu \mathrm{l} \text {, sequenzspezifisch }) \\ 5 \mu \mathrm{l} & \text { dNTPs }(2 \mathrm{mM}) \\ 5 \mu \mathrm{l} & \text { Taq-Polymerase Puffer }(10 \mathrm{x}) \\ 0,5 \mu \mathrm{l} & \text { Platinum Taq-Polymerase }(2,5 \mathrm{U} / \mu \mathrm{l}) \\ \text { ad } 50 \mu \mathrm{l} & \mathrm{dH}_{2} \mathrm{O}\end{aligned}$

Die DNA-Amplifikation erfolgte mittels 30-40 Zyklen in einem Primus 96 Thermocycler der Firma MWG Biotech (High Point, NC, USA). Die Anzahl der Zyklen, die einzelnen Temperaturschritte und die jeweilige Dauer der Zyklen mussten 
für jedes DNA-Fragment und die dafür eingesetzten Primer neu gewählt werden. Ein Zyklus bestand aus folgenden Einzelschritten:

$\begin{array}{lll}95^{\circ} \mathrm{C} & 30-60 \mathrm{sec} & \text { Denaturierung } \\ 50-65^{\circ} \mathrm{C} & 30-90 \mathrm{sec} & \text { Annealing } \\ 72^{\circ} \mathrm{C} & 30-90 \mathrm{sec} & \text { Elongation }\end{array}$

Vor Beginn des ersten Zyklus wurde 1-3 min bei $95^{\circ} \mathrm{C}$ denaturiert. Nach Beendigung der gewünschten Zyklen schloss sich ein letzter Elongationsschritt von 7 min bei $72^{\circ} \mathrm{C}$ an. 1/10 Vol des Ansatzes wurde mit Stop-Mix II gemischt und je nach Größe des PCRProdukts auf ein 1-1,5\%iges Agarosegel aufgetragen und elektrophoretisch aufgetrennt.

\subsubsection{Reverse Transkription}

Um eine repräsentative Population von cDNA aus Gesamt-RNA zu erhalten, wurde die Reverse Transkription mit SuperScript II (Invitrogen, Karlsruhe) und oligo(dT)Primern, die mit den poly $(\mathrm{A})^{+}-$Sequenzen der mRNA paaren, durchgeführt. Es entsteht ein sog. cDNA-Strang (für complementary DNA), der zur mRNA komplementär ist und später DNA-abhängigen DNA-Polymerasen zugänglich gemacht werden kann.

Für die Reverse Transkription wurden 2-5 $\mu$ g RNA mit $1 \mu$ l oligo(dT)-Primer $(0,5$ $\mu \mathrm{g} / \mu \mathrm{l})$ in $12 \mu \mathrm{l}$ Gesamtvolumen gemischt und $10 \mathrm{~min}$ bei $70^{\circ} \mathrm{C}$ inkubiert. Nach Zugabe von:

$4 \mu 15 x$ First Strand buffer

$2 \mu 1 \operatorname{DTT}(0,1 \mathrm{M})$

$5 \mu 1$ dNTP (2mM)

$1 \mu 1$ RNase-Inhibitor

wurde die Probe 2 min bei $42^{\circ} \mathrm{C}$ inkubiert und $1 \mu$ SuperScript II hinzugefügt. Die Reverse Transkription wurde $50 \mathrm{~min}$ bei $42^{\circ} \mathrm{C}$ durchgeführt. 


\subsubsection{One-step RT-PCR}

Um spezifische RT-PCR-Produkte zu erhalten, wurde das QIAGEN OneStep RT-PCR Kit verwendet. Es enthält optimierte Komponenten, die sowohl eine Reverse Transkription als auch eine PCR Amplifikation nebeneinander in einer sog. „One Step“ Reaktion erlauben.

Mastermix:

5 x Qiagen OneStep RT-PCR Puffer

dNTP-Mix (10 mM je dNTP)

Vorwärtsprimer $(10 \mathrm{pmol} / \mu \mathrm{l})$

Rückwärtsprimer (10 pmol/ $\mu \mathrm{l})$

Qiagen OneStep RT-PCR Enzymmix

RNase-Inhibitor $(20 \mathrm{U} / \mu \mathrm{l})$

RNase-freies Wasser

\begin{tabular}{c} 
Pro Reaktion \\
\hline $10 \mu \mathrm{l}$ \\
$2 \mu \mathrm{l}$ \\
$1 \mu \mathrm{l}$ \\
$1 \mu \mathrm{l}$ \\
$2 \mu \mathrm{l}$ \\
$1 \mu \mathrm{l}$ \\
ad $50 \mu \mathrm{l}$
\end{tabular}

$2 \mu \mathrm{g}$ Gesamt-RNA wurden zum Mastermix in einem PCR-Gefäß zugefügt, die Probe wurde in einen Thermocyler gestellt und das RT-PCR-Programm nach dem Protokoll des Herstellers durchgeführt. Nach der Amplifikation wurde die Probe auf einem Agarosegel kontrolliert.

Thermocycler - Bedingungen:

$\begin{array}{lll}\text { Reverse Transkription: } & 30 \mathrm{~min} & 50{ }^{\circ} \mathrm{C} \\ \text { Initialer PCR - Aktivierungsschritt: } & 15 \mathrm{~min} & 95^{\circ} \mathrm{C} \\ \text { 40 Zyklen: } & & \\ \text { Denaturierung: } & 30 \mathrm{sec} & 94{ }^{\circ} \mathrm{C} \\ \text { Annealing: } & 40 \mathrm{sec} & 56-60{ }^{\circ} \mathrm{C} \text { (Primer-abhängig) } \\ \text { Elongation: } & 1 \mathrm{~min} & 72{ }^{\circ} \mathrm{C}\end{array}$




\subsubsection{Sequenzanalyse}

Die nichtradioaktive Sequenzierung basiert auf dem Prinzip des Kettenabbruchverfahrens (Sanger et al., 1977), wobei vier Didesoxynukleotide zum Einsatz kommen, die jeweils mit verschiedenen Fluoreszenzfarbstoffen markiert sind, welche wiederum während der gelelektrophoretischen Analyse über Laserabtastung automatisch detektiert werden. Die Sequenzreaktion wurde mit $0,2 \mu \mathrm{g}$ Plasmid-DNA, $10 \mathrm{pmol}$ sequenzspezifischem Primer und 2,5 $\mu$ l ET-Mix (DYEnamic ET terminator Cycle sequencing Kit der Firma GE Healthcare, Freiburg) in einem Gesamtansatz von $10 \mu 1$ nach folgendem Programm durchgeführt:

$\left.\begin{array}{ll}95^{\circ} \mathrm{C} & 1 \mathrm{~min} \\ 95^{\circ} \mathrm{C} & 20 \mathrm{sec} \\ 50^{\circ} \mathrm{C} & 30 \mathrm{sec} \\ 60^{\circ} \mathrm{C} & 1 \mathrm{~min} \\ 60^{\circ} \mathrm{C} & 5 \mathrm{~min}\end{array}\right\} \begin{aligned} & \text { Denaturierung } \\ & \text { Denaturierung } \\ & 25 \text { Zyklen } \\ & \text { Annealing } \\ & \text { Elongation } \\ & \text { Elongation }\end{aligned}$

Nach der Reaktion wurde der Ansatz mit $10 \mu \mathrm{H}_{2} \mathrm{O}$ aufgefüllt und über SephadexG50Säulen aufgereingt. Die gelelektrophoretische Analyse erfolgte mit der automatischen Sequenzanlage MegaBACETM1000 der Firma Molecular Dynamics (GE Healthcare).

\subsection{Proteinchemische Techniken}

\subsubsection{Isolierung von Gesamtprotein aus Zellkulturen}

Einer dicht bewachsenen großen $\left(75 \mathrm{~cm}^{2}\right)$ Zellkulturflasche (Konfluenz $\left.>80 \%\right)$ wurden nach dem Waschen mit PBS $300 \mu$ Lysis-Puffer zugefügt. Die adhärenten Zellen wurden mit einem Zellschaber vom Boden der Zellkulturflasche gelöst und in ein Eppendorf-Gefäß überführt. Die Proben wurden durch Ultraschall (Sonifier 250, Branson Ultrasonic, Danbury, USA) homogenisiert und unlösliche Bestandteile durch 
Zentrifugation bei 16000 x g für $10 \mathrm{~min}$ entfernt. Der die Zellproteine enthaltende Überstand wurde in ein sauberes Eppendorf-Gefäß überführt, die Proteinkonzentration wurde bestimmt und das Lysat in geeigneten Aliquots bei $-80^{\circ} \mathrm{C}$ aufbewahrt.

\subsubsection{Bestimmung der Proteinkonzentration}

Die Bestimmung der Konzentration von Proteinen wurde mit einer UV-Methode nach Waddel (1956) in einem Spektralphotometer (Ultrospec 300pro, GE Healthcare, Freiburg) durchgeführt. Folgende Gleichung wurde zugrunde gelegt:

$$
\text { Protein }(\mu \mathrm{g} / \mathrm{ml})=144 \times \mathrm{A}_{215} / \mathrm{A}_{225}
$$

Die entsprechenden Verdünnungsfaktoren wurden nachträglich eingerechnet.

\subsubsection{SDS-Polyacrylamidgelelektrophorese (SDS-PAGE)}

Zur Auftrennung der Proteine wurden Gradientengele (NuPAGE ${ }^{\mathrm{TM}} 4-12 \%$ Bis-Tris Gel, Invitrogen, Karlsruhe) verwendet. Dieses Polyacrylamid-Gelsystem beruht auf dem SDS-PAGE-Prinzip (Laemmli, 1970). Durch die Verwendung von aufeinander abgestimmten Gelen und Puffern bei einem pH-Wert von 7.0 ist zum einen die Stabilität der Proteine, aber auch die der Gele erhöht, was zu einem besseren Ergebnis der Elektrophorese führt.

Die Proteinproben wurden mit 0,3 Vol Probenpuffer (LDS Sample Buffer (4x), $\mathrm{NuPAGE}^{\mathrm{TM}}$, Invitrogen, Karlsruhe) versetzt, $10 \mathrm{~min}$ bei $70^{\circ} \mathrm{C}$ erhitzt und nach Abkühlen auf Eis auf das Gel aufgetragen. Die Elektrophorese erfolgte mit 1x MESPuffer (Invitrogen) bei 150-180V für ca. $1 \mathrm{~h}$. Zur Bestimmung der Größe der aufgetrennten Proteine wurde parallel $\mathrm{zu}$ den Proteinproben ein vorgefärbter Proteinstandard (NuPAGETM See Blue Plus2, Invitrogen) mitaufgetragen. 


\subsubsection{Western Blot-Analysen von Proteinen auf PVDF-Membranen}

(Gershoni und Palade, 1982, 1983)

Eine auf die Größe des zu blottenden Polyacrylamidgels zugeschnittene PVDFMembran (Macherey \& Nagel) wurde kurz (5-10 sek) in 100\% Methanol getaucht und anschließend in Transferpuffer für 10 min äquilibriert. Auf 3 ebenfalls auf die Größe zurechtgeschnittene Whatman GB004 Filter (Schleicher \& Schüll, Dassel), die in Transferpuffer getränkt wurden, wurde die PVDF-Membran und sofort das nach der elektrophoretischen Auftrennung der Proteine mit Wasser abgespülte Polyacrylamidgel gelegt. Drei weitere mit Transferpuffer getränkte Filter wurden nach dem sandwichModel oben aufgesetzt. Der Transfer wurde in einem Elektroblotter (Biometra, Göttingen) bei $100 \mathrm{~mA}$ für $1 \mathrm{~h}$ durchgeführt.

\subsubsection{Färbung von Polyacrylamidgelen}

Die SDS-Polyacrylamidgele wurden zwecks Proteinfärbung oder Kontrolle des Western Blot-Transfers mit Simply Blue Safe-Stain (Invitrogen) nach dem MikrowellenProtokoll des Herstellers gefärbt, anschließend in $20 \% \mathrm{NaCl}$ aufbewahrt oder eingeschweißt.

\subsubsection{Inkubation von membrangebundenen Proteinen mit Antikörpern}

Um unspezifische Bindungsstellen abzublocken, wurde die Membran zunächst in $1 \mathrm{x}$ PBS mit 1\% BSA (Blocklösung I) für $1 \mathrm{~h}$ bei RT inkubiert. Nach extensivem Waschen in 1x PBS/0,1\% Tween 20 (Waschlösung III) erfolgte die Inkubation mit dem Primärantikörper bei einer für den jeweiligen Antikörper entsprechenden Verdünnung in Blocklösung I bei $4^{\circ} \mathrm{C}$ über Nacht. Anschließend wurde die Membran 2x 5 min in Waschlösung gewaschen und mit einem entsprechenden Sekundärantikörper in einer Verdünnung von 1:2000 bis 1:10000 in Blocklösung für $2 \mathrm{~h}$ bei RT inkubiert. 
Für die Detektion der Proteine mit Hilfe von Alkalische Phosphatase wurde die Membran 2x 5 min in Waschlösung III, 1x 5 min in 1x PBS und 1x 5 min in AP-Puffer bei RT gewaschen. Zum Schluss wurden die Proteine auf der Membran durch Inkubation im Dunkeln in $10 \mathrm{ml}$ Färbelösung (Alkalische Phosphatase-Färbelösung) sichtbar gemacht und die Reaktion mit Wasser gestoppt.

Für die Detektion der Proteine mit Hilfe von Enhanced Chemiluminescence Kit (ECL Plus-Kit der Fa. GE Healthcare) wurde die Membran 2x 5 min in Waschlösung III und 1x5 min in 1x PBS gewaschen, um Milchpulverrückstände zu entfernen. Anschließend wurde etwa $1 \mathrm{ml}$ der ECL Plus-Arbeitslösung hergestellt, indem Luminol/EnhancerLösung und die stabile Peroxid-Lösung der Fa. GE Healthcare 1:40 gemischt wurden. Die HRP setzt das Substrat der Arbeitslösung um. Die Produkte bilden ein sichtbares Präzipitat um den Antigen-Antikörperkomplex. Die Lösung wurde auf die Membran gegeben und 5 min inkubiert. Anschließend wurde die abgetropfte Membran in Plastik eingeschweißt und in eine Filmkammer gelegt. Der Film wurde in der Dunkelkammer aufgelegt und nach $60 \mathrm{sec}$ entwickelt. Je nach Intensität der Banden konnte die Entwicklungszeit verlängert oder verkürzt werden.

\subsection{Zellbiologische Methoden}

\subsubsection{Zellkultur eukaryotischer Zellen}

Die adhärent wachsenden PC-3-, LNCaP-, DU 145-, MDA-MB-453-, HCC-70- und T47D-Zellen wurden in käuflich erworbenem RPMI 1640-Medium (PAN, Nürnberg) mit Zusatz von 1,2\% Penicillin/Streptomycin und 10\% FKS in oberflächenbehandelten Gewebekulturflaschen kultiviert. Die adhärent wachsenden NIH 3T3-, MCF-7- und MDA-MB-231-Zellen wurden in käuflich erworbenem DMEM-Medium (PAN, Nürnberg) mit Zusatz von 1,2\% Penicillin/Streptomycin und $10 \%$ FKS in oberflächenbehandelten Gewebekulturflaschen kultiviert. Die Inkubation erfolgte im Brutschrank mit $5 \% \mathrm{CO}_{2}$ bei $37^{\circ} \mathrm{C}$. In Abhängigkeit von der Proliferationsrate wurden die Zellen ein- bis zweimal pro Woche geteilt. Die Zellen wurden dabei mit 1x DPBS 
(PAN) gewaschen und mit einer Trypsin/EDTA-Lösung (0,05\% Trypsin/ 0,02\% EDTA in $\mathrm{Ca} / \mathrm{Mg}$-freier PBS-Lösung; PAN, Nürnberg) so lange inkubiert, bis sich die Zellen vom Boden der Kulturflasche gelöst haben. Nach dem Ablösen der Zellen wurden 1:2 bis 1:5 Verdünnungen der Zellsuspension in frischem Medium hergestellt.

\subsubsection{Kryokonservierung und Revitalisierung von eukaryotischen Zellen}

Die bis $\mathrm{zu}$ einer Konfluenz von $>80 \%$ gewachsenen Zellen wurden mit DPBS gewaschen, trypsiniert und anschließend in einer entsprechenden Menge Kulturmedium mit $8 \%$ DMSO resuspendiert. Nach 7 Tagen Aufbewahrung bei $-70^{\circ} \mathrm{C}$ wurden sie in flüssigem Stickstoff konserviert. Zur Revitalisierung wurden die Zellen schnell aufgetaut, in vorgewärmtes Kulturmedium überführt und über Nacht inkubiert. Am nächsten Morgen wurde das Medium zur vollständigen Entfernung des DMSO gewechselt.

\subsubsection{Transfektion eukaryotischer Zellen}

Die Transfektion eukaryotischer Zellen erfolgte zum Nachweis der subzellulären Lokalisation von Fusionsproteinen und zum Nachweis der Kolokalisierung mit Hilfe von immunhistochemischen Experimenten. Das verwendete Transfektionsreagenz Roti ${ }^{\circledR}-$ Fect (Carl Roth GmbH, Karlsruhe) ist ein polykationisches Lipid. Es bildet mit der DNA einen stabilen Komplex aufgrund der entgegengesetzten Ladungen. Die DNA wird in diesem Fall nicht in den Liposomen verpackt, sondern lagert sich außen an. Beim Kontakt der Liposomen mit der Zellmembran wird die DNA in die Zelle aufgenommen, wobei der genaue Mechanismus noch nicht bekannt ist. Bei der Transfektion besitzt jede Kombination von Zellinie und Plasmid einen Satz von optimalen Parametern in Hinblick auf die Transfektionseffizienz. Für jede Zellinie muss daher das beste Verhältnis von Transfektionsreagenz und DNA ermittelt werden. Zu beachten ist aber, dass Transfektionsreagenzien unterschiedlich toxisch auf verschiedene Zellen wirken, was auch bei ansonsten sehr guter Transfektionseffizienz 
die Menge der DNA im Tranfektionsansatz limitiert. Es wurden für die Transfektionsexperimente nur Zellen verwendet, die sich in einer permanenten Wachstumsphase befanden. Einen Tag vor der Transfektion wurden die Zellen auf entsprechenden Objektträgern (FALCON culture slides, Le Pont De Claix, Frankreich) so ausplattiert, dass am folgenden Tag eine Konfluenz von 50-70\% erreicht wurde. RPMI 1640-Medium ohne Zusätze wurde mit DNA und Transfektionsreagenz nach Vorschrift des Anbieters gemischt, bei RT 45 min inkubiert und vorsichtig auf die Zellen, die vorher mit PBS gewaschen und mit Kulturmedium ohne Antibiotika bedeckt worden waren, aufgetropft. Nach 3-4 Stunden wurde zu dem Transfektionsmedium Kulturmedium mit Antibiotikazusatz gegeben. Am nächsten Tag wurde das Transfektionsmedium komplett gegen normales Kulturmedium ausgetauscht und die Zellen zwecks Proteinexpression 24-36 h unter Kulturbedingungen inkubiert.

\subsubsection{Anfertigung von Cytospin-Präparaten}

Um Zellen auf einem Objektträger zu fixieren, kann neben der Kultivierung auch die Methode der Cytospin-Präparation verwendet werden. Dazu wurden in einem speziellen Rotor (Sigma, Rotor 11234) 7x 105 Zellen auf einen Objektträger bei 90 x g für 7 min zentrifugiert. Nach dem Trocknen über Nacht wurden die Zellen anschließend für immunhistochemische Experimente verwendet oder die Cytospin-Präparate bei $-20^{\circ} \mathrm{C}$ in Aluminiumfolie gewickelt aufbewahrt.

\subsection{Herunterregulierung der Genexpression mittels RNA-Interferenz}

Der Terminus RNA-Interferenz (RNAi) beschreibt die Verwendung von doppelsträngiger RNA, um spezifische mRNAs für die Degradierung zu markieren, wodurch die Expression der entsprechenden Gene verringert wird. RNAi ist eines aus einer breiten Klasse von RNA-silencing-Phänomenen, die in Pflanzen, Tieren und Pilzen gefunden worden sind (Cogoni und Macino, 2000; Elbashir et al., 2001a, b; 
Tuschl, 2001). Die Entdeckung von RNAi hat das Verständnis verändert, wie die Zellen ihre Genome bewachen. Sie führte zur Entwicklung neuer Strategien, um Genfunktionen $\mathrm{zu}$ blockieren, und könnte in Zukunft $\mathrm{zu}$ RNA-basierenden Medikamenten führen, um eventuell menschliche Krankheiten zu behandeln.

\subsection{1 Überblick über den Mechanismus von RNAi}

Im ersten Schritt wird doppelsträngige RNA in 21-23 Nukleotide small interfering RNAs (siRNA) geteilt, welche auch als guide RNAs bezeichnet werden (Hammond et al., 2001b, Sharp, 2001). Untersuchungen haben gezeigt, dass siRNAs produziert werden, wenn das Enzym Dicer, ein Mitglied der RNase III-Familie der dsRNAspezifischen Ribonukleasen, prozessiv dsRNA (direkt oder über ein Transgen oder Virus eingeführt) in ATP-abhängiger Weise schneidet. Das sukzessive Schneiden degradiert die RNA in 19-21 bp-Duplexe (siRNAs), die jedes einen 2-NukleotidÜberhang am 3'-Ende besitzen (Bernstein et al., 2001; Hutvagner et al., 2002). Im Effektor-Schritt binden die siRNA-Duplexe an einen Nuklease-Komplex, um den sog. RISC ( $\underline{R} N A$-induced silencing $\underline{\text { complex}) ~ z u ~ b i l d e n . ~ D a s ~ A T P-a b h a ̈ n g i g e ~ E n t w i n d e n ~ d e r ~}$ siRNA-Duplexe ist für die Aktivierung von RISC notwendig. Der aktive RISC geht gezielt gegen homologe Transkripte durch Basenpaarung vor und schneidet die mRNA 12 Nukleotide vom 3'-Terminus der siRNA (Hammond et al., 2001a; Sharp, 2001). 
A

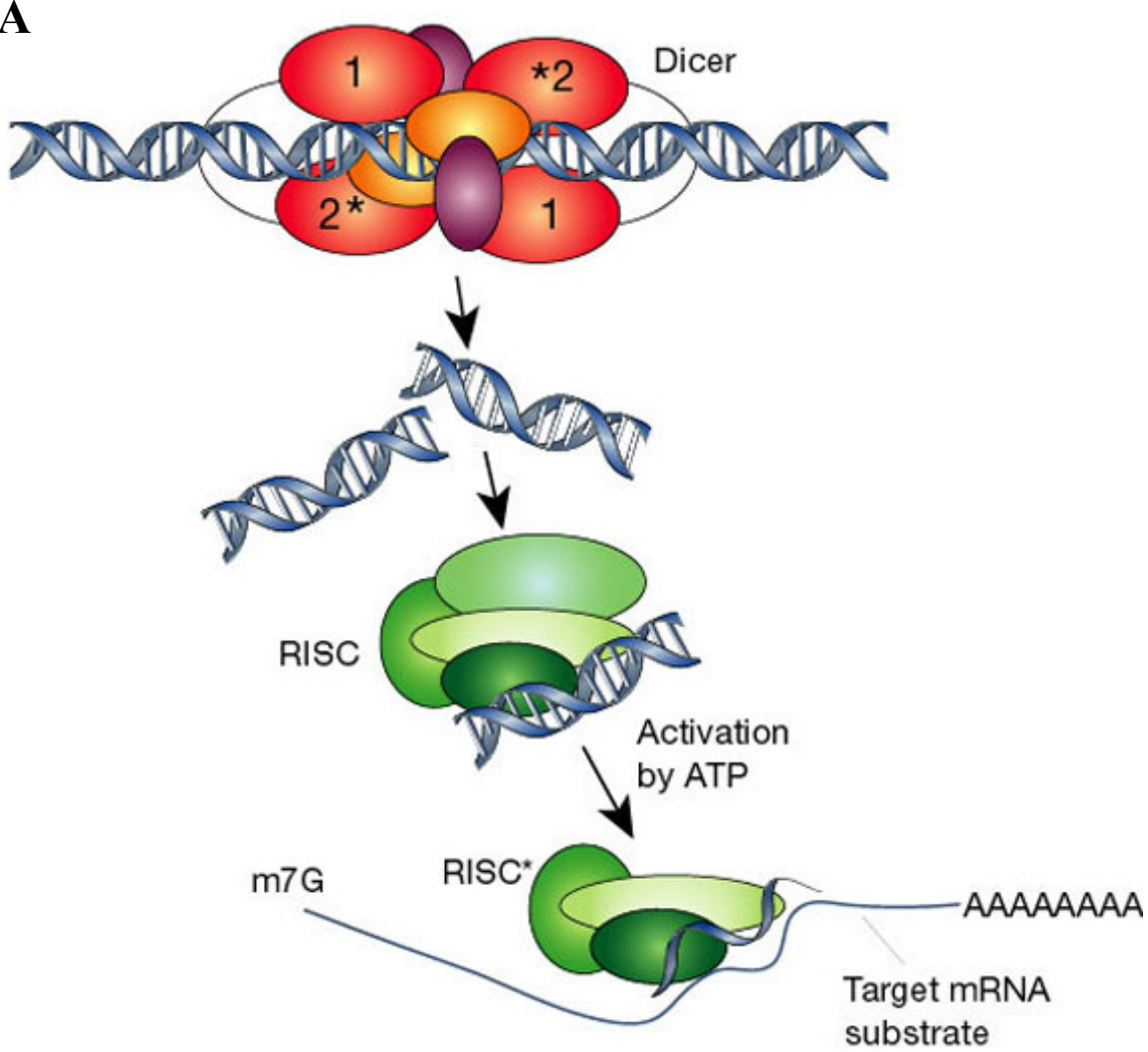

B

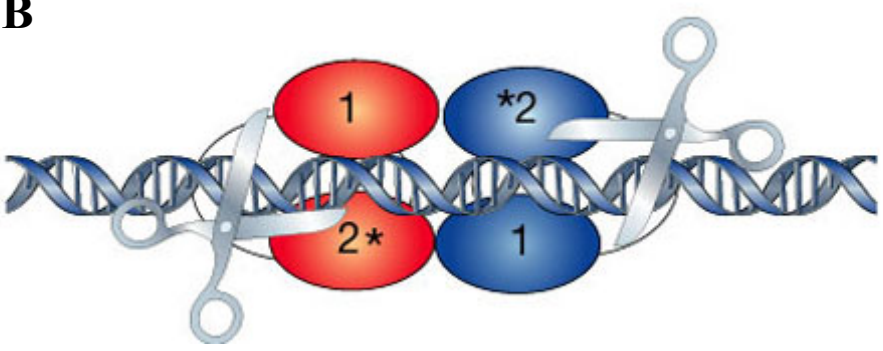

Abb. 2.1: Dicer und RISC (RNA-induced silencing complex) (Hannon, 2002). A) RNAi wird durch das Enzym Dicer initiiert (2 Dicer-Moleküle mit jeweils 5 Domänen sind gezeigt), welches doppelsträngige RNA in 22-Nukleotide kleine small interfering RNAs prozessiert. Basierend auf dem bekannten Mechanismus für die RNase III-Enzymfamilie wird angenommen, dass Dicer als Dimer arbeitet. Das Schneiden in genau gleich große Fragmente wird durch den Fakt bestimmt, dass jeweils eines der aktiven Zentren in jedem Dicer-Protein defekt ist (*), so dass das Schneiden im Abstand von 911 Nukleotiden durch bakterielle RNase III zu einem im Abstand von 22 Nukleotiden durch die DicerFamilie verändert ist. Die siRNAs werden in eine Multikomponenten-Nuklease (RISC, grün) inkorporiert. Kürzliche Arbeiten schlagen vor, dass RISC von einer latenten Form, die doppelsträngige siRNA enthält, in eine aktive Foorm (RISC*) durch Entwindung der siRNAs überführt werden muss. RISC* verwendet dann die entwundenen siRNAs als einen Führer für die Substratselektion. B) Schematische Darstellung von Dicer-Bindung und Schneiden von dsRNA (zur Übersicht sind nicht alle Domänen von Dicer gezeigt, und die beiden Dicer-Moleküle werden in verschiedenen Farben dargestellt). Abweichung von 
dem Konsensus-RNase III- aktiven Zentrum in der zweiten RNase III-Domäne inaktivieren das katalytische Zentrum, was zum Schneiden in 22-Nukleotid-Abständen führt.

\subsubsection{Transfektion eukaryotischer Zellen mit siRNAs}

Die auf RNAi basierende Methode kann verwendet werden, um eine spezifische mRNA zur Degradierung zu markieren, wodurch es zur Verminderung der entsprechenden Genexpression (gene silencing) kommt. Es wurde ebenfalls gezeigt, dass sequenzspezifische einzelsträngige RNA-Oligonukleotide sowohl in sense- als auch in antisense-Orientierung als Negativkontrolle für dieses spezifische gene silencing eingesetzt werden können, da sie keinen Effekt auf die spezifische mRNADegradierung haben (Tuschl et al., 1999).

Tranfektionen von Prostata- und Mammakarzinom-Zellen wurden mit dem Transfektionsreagenz OligoFectamine (Invitrogen, Karlsruhe) durchgeführt, welches stabile Komplexe zwischen Lipiden und Oligonukleotiden bildet. So können die RNAMoleküle effizient in die Säugetier-Zellen aufgenommen werden. Die Transfektion wurde nach dem Protokoll des Herstellers entweder mit genspezifischen siRNADuplex-Oligonukleotiden oder mit einzelsträngigen sense- und antisense- RNAOligonukleotiden (IBA, Göttingen; Eurogentec, Sareing, Belgien) in einer Konzentration von 60-150 nM im Transfektionsmedium durchgeführt. Als eine weitere Kontrolle wurden die PCa-Zellen mit siRNA-Duplex-Oligonukleotiden gegen das Luciferase-Gen des Leuchtkäfers (Photinus pyralis; nicht-verwandte Sequenz) transfiziert (Sequenzen der Oligonukleotide siehe 2.8.2).

Für die Tranfektion wurden die Prostata- und Mammkarzinom-Zellen entweder in kleinen Kulturflaschen $\left(22 \mathrm{~cm}^{2}\right)$, 12-Well-Platten oder auf Objektträger mit Kulturflasche (Falcon Culture slide, Becton Dickinson, Frankreich) bis zu einer Konfluenz von 20\% (DU 145, PC-3, MDA-MB-231) bzw. 40-50\% (LNCaP, MDAMB-453, T-47D) kultiviert. Alle Angaben der nachfolgend beschriebenen Transfektion beziehen sich auf 1 Well einer 12-Well-Platte oder Falcon Culture Slide, für kleine Kulturflaschen wurden die 3-fachen Mengen verwendet. $3 \mu$ Duplex-RNA (20 $\mu \mathrm{M})$ wurden mit $100 \mu$ l Optimem I (Invitrogen) in einem 1,5 ml-Gefäß vermischt. $3 \mu 1$ 
OligoFectamine wurde zu $20 \mu$ l Optimem I in einem weiteren 1,5 ml-Gefäß gegeben und für 10 min bei RT inkubiert. Anschließend wurde die OligoFectamine-Lösung zu der RNA-Probe hinzugefügt und für $25 \mathrm{~min}$ bei RT inkubiert. Während dieser Inkubationszeit wurden die Zellen mit PBS gewaschen und $1 \mathrm{ml}$ Optimem I wurde in jedes Well gegeben. Anschließend wurde das Transfektionsgemisch (RNA/OligoFectamine in Optimem I) vorsichtig auf die Zellen gegeben und die Zellen bei $37^{\circ} \mathrm{C}$ und $5 \% \mathrm{CO}_{2}$ in einem Inkubator $8-12 \mathrm{~h}$ kultiviert. Nach Entnahme des Transfektionsmediums wurde normales Kulturmedium zu den Zellen gegeben und die Zellen unter den gleichen Bedingungen weiterkultiviert. Nach verschiedenen Zeitpunkten nach der Transfektion wurden die Zellen zur Isolierung von Proteinen, RNA und für immunhistochemische Experimente zur Verifizierung des gene silencing und zur Untersuchung der Effekte des jeweiligen Gen-knockdowns gesammelt.

\subsection{Genexpressionsanalyse in verschiedenen Tumoren (Cancer Profiling Array)}

Der Cancer Profiling Array (Clontech) ist eine Nylonmembran, auf der mehr als 240 cDNA-Paare aufgespottet sind, wobei jedes Paar cDNAs die entsprechenden RNAs aus Tumor- und Normalgewebe eines Patienten repräsentiert. Dieser Array ermöglicht es, die differentielle Genexpression in verschiedenen Tumoren in einem schnellen Verfahren zu analysieren. Nach der Identifizierung von differentiell exprimierten Genen mit den Atlas ${ }^{\mathrm{TM}}$ Arrays kann der Cancer Profiling Array dafür verwendet werden, die Verteilung eines differentiell exprimierten Gens bei vielen Proben zu untersuchen. Einige Proben präsentieren verschiedene Stadien der Malignität eines Tumortyps, wodurch ein bestimmtes Tumorstadium mit einem distinkten Genexpressionsmuster korreliert werden kann. Zusätzlich zu den klinischen Proben enthält der Array Krebszelllinien, sowie Negativ- und Positivkontrollen. Amplifizierte full-length cDNA bewahrt die relative Abundanz von mRNA in einer Probe. Dadurch ergibt sich die Möglichkeit, die differentielle Expression eines Gens unter vielen verschiedenen Proben zu detektieren. Das quantitative Profil der Genexpression auf dem Array wird auf 3 verschiedene housekeeping-Gene normiert. 
Der Cancer Profiling Array wurde zur Bestimmung der Rolle eines bestimmten Gens (BI-1) in einem breiten Bereich von Krebszelltypen verwendet. Zur Markierung der Probe wurde das Strip-EZTM DNA -Kit (Ambion) verwendet. 50 ng linearisiertes cDNA-template wurden auf $9 \mu 1$ Gesamtvolumen mit Wasser aufgefüllt, bei $95-100^{\circ} \mathrm{C} 5$ min denaturiert und in Trockeneis schockgefroren. Nach dem Auftauen wurden folgende Komponenten hinzugefügt:

2,5 $\mu 1$ 10x Decamer solution

$5 \mu 15 x$ Puffer (-dATP, -dCTP)

2,5 $\mu 110 \mathrm{x}$ dCTP

$5 \mu \mathrm{l}\left[\alpha-{ }^{32} \mathrm{P}\right] \mathrm{dATP}(10 \mathrm{mCi} / \mathrm{ml})$

$1 \mu 1$ Exonuklease-freies Klenow

Das Reaktionsgemisch wurde 40 min bei $37^{\circ} \mathrm{C}$ inkubiert und die Reaktion durch Zugabe von $1 \mu 1$ 0,5 M EDTA-Lösung gestoppt. Die Aufreinigung der Probe und die Hybridisierung wurden wie in Abschnitt 2.12.1 beschrieben, durchgeführt. Nach Exposition auf einem PhosphorImager-Film (Personal Molecular Imager FX, Bio-Rad, Hercules, USA) erfolgte die Quantifizierung der Signale mit Hilfe des Quantity OneProgramms.

\subsection{Methoden zur subzellulären Lokalisierung eines Proteins}

\subsubsection{Immunhistochemische Färbung eukaryotischer Zellen}

Die Prostata- und Mammakarzinom-Zellen wurden bis zu einer 20-80\%igen Konfluenz auf spezielle Objektträger mit angehefteter Kulturflasche (FALCON culture slides, Le Pont De Claix, Frankreich) in entsprechendem Kulturmedium kultiviert. Die Zellen wurden einmal mit PBS gewaschen und in 3,7\% Formaldehyd in PBS für 20 min fixiert. Nach Permeabilisierung der Zellmembran für 15 min in $0,1 \%$ Triton X-100 in PBS wurden die Zellen kurz in PBS gewaschen und 30 min bei RT mit 1\% BSA in PBS zur 
Blockierung unspezifischer Bindungsstellen inkubiert. Anschließend erfolgte die Inkubation mit dem Primärantikörper in entsprechender Konzentration in Blockpuffer über Nacht bei $4^{\circ} \mathrm{C}$ in einer feuchten Kammer. Die Zellen wurden 5 min in PBS gewaschen und mit dem Sekundärantikörper in entsprechender Verdünnung $2 \mathrm{~h}$ bei RT inkubiert. Nach intensivem Waschen mit PBS (2x $5 \mathrm{~min}$ ) wurden die Proben, die mit einem Alkalische Phosphatase-konjugierten Sekundärantikörper behandelt worden waren, $5 \mathrm{~min}$ in AP-Puffer inkubiert und die Signale anschließend mit AlkalischePhosphatase-Färbelösung detektiert. Alle Proben wurden zum Schluss mit Wasser (3x 5 min) gewaschen und die Zellen entweder mit Glycerin-Gelatine (bei Verwendung eines mit Alkalischer Phosphatase gekoppelten Sekundärantikörper; Aquamount; BDH Chemicals Ltd., Poole, England) oder mit Vectashield Mounting Medium (bei Verwendung eines Fluoreszenz-markierten Sekundärantikörpers; VectorLab, Burlingame) eingedeckt. Unter dem Mikroskop (BX60, Olympus) wurden die immunhistochemischen Präparate analysiert, fotografiert und mit dem analySISProgramm (soft imaging $\mathrm{GmbH}$ ) bearbeitet.

\subsubsection{Zelluläre Lokalisation von Fusionsproteinen}

Für die zelluläre Lokalisation von BI-1 und DIO-1 wurde der jeweilige Bereich in den pEGFP-C1-, pEGFP-N2- und pDsRed1-N1-Vektor kloniert (Clontech, Heidelberg). Dabei wurde beachtet, dass sich der Leserahmen nicht verändert. Es entstand ein Fusionskonstrukt, bei dem BI-1 und DIO-1 an den C- bzw. N-Terminus der EGFP- und DsRed kodierenden Sequenz gekoppelt sind. Prostata- und Mammakarzinom-Zellen wurden auf speziellen Objektträgern mit aufgesetzter Kulturflasche (Le Pont De Claix, Frankreich) kultiviert und gemäß 2.19.3 mit den pECFP-C1/N2-BI-1- und pDsRed1N1-DIO-1-Konstrukten transfiziert. Nach einer 24-stündigen Inkubation wurden die Zellen einmal mit PBS gewaschen und für $10 \mathrm{~min}$ in 70\% Methanol in PBS fixiert. Nach kurzem Waschen in PBS wurden die Zellen nach 2.18.4 mit anti-ZiegeAntikörper/anti-Kaninchen-Antikörper angefärbt und mit VectaShield/DAPI eingedeckt. Unter einem Fluoreszenz-Mikroskop (BX60, Olympus) wurden die Zellen ausgewertet und fotografiert. 


\subsection{Analysen von Zelltod und Apoptose}

\subsubsection{DAPI- Färbung von eukaryotischen Zellen}

Apoptose führt zu charakteristischen Eigenschaften in der Zelle, wie Schrumpfen der Zelle, Blasen in der Membran, Chromatin-Kondensation und Kern-Fragmentierung. Dramatische Veränderungen geschehen während des apoptotischen Tods vor allem im Zellkern. Später zerfällt der Nukleolus, die Kernmembran bildet tiefe Invaginationen und der Kern bildet dichte granuläre Partikel (apoptotische Körper). ChromatinKondensation, Kern-Schrumpfung und Bildung der apoptotischen Körper können durch Fluoreszenz-Mikroskopie nach Färbung der Kerne mit DNA-spezifischen Fluorochromen (DAPI) beobachtet werden (Collins et al., 1997; Feldkamp et al., 1999). Für die DAPI-Färbung wurden die Zellen auf Objektträger zentrifugiert (2.18.4) und für $10 \mathrm{~min}$ in Aceton fixiert. Anschließend wurden die Zellen mit Vectashield Mounting Medium mit DAPI (VectorLab, Burlingame, USA) inkubiert. Die angefärbten Zellen wurden unter einem Fluoreszenz-Mikroskop BX60 (Olympus Optical Co., Japan) bei einer 200-fachen Vergrößerung analysiert und in 5 verschiedenen Sichtfeldern gezählt.

\subsubsection{Immuncytochemische Färbung von eukaryotischen Zellen (Caspase-3)}

Diese Analysen wurden in Kooperation mit PD Dr. Stefan Schweyer aus der Abteilung der Pathologie, Georg-August-Universtität Göttingen, durchgeführt.

In den apototischen Signalweg sind verschiedene Gruppen von Molekülen involviert. Ein Teil dieser Vermittler der Apoptose gehört zu den Asparat-spezifischen CysteinylProteasen oder Caspasen. Ein Mitglied dieser Familie, Caspase-3 (CPP32, Apopain, YAMA), wurde als Schlüsselprotein in der Apoptose von Säugerzellen identifiziert (Kothakota et al., 1997).

Zur Bestimmung der Caspase-3-Aktivität wurden die Zellen auf Objektträger zentrifugiert (2.19.4), getrocknet und in Aceton fixiert. Anschließend wurden sie mit 
dem polyklonalen Kaninchen-Antikörper gegen die humane aktive Caspase-3 (clone AF835, R\&D Systems GmbH, Wiesbaden) inkubiert. Nach Inkubation mit einem biotinylierten Sekundarantikörper und mit Alkalischer Phosphatase gekoppeltem Streptavidin (Dako) wurden die Signale mit Fast Red (Dako) sichtbar gemacht. Die Zellen wurden mit Hämalaun gegengefärbt. Positive Zellen zeigen eine rote cytoplasmatische Färbung um den klar abgegrenzten Zellkern. Die Kontrollen wurden wie oben beschrieben gefärbt, wobei Primär- oder Sekundärantikörper ausgelassen wurde. Als Positivkontrollen wurden Gewebeschnitte mit tophischer Gicht verwendet (Schweyer et al., 2000).

\subsection{Yeast-Two-Hybrid- Experimente}

(Fields und Song et al., 1989)

Das Yeast-Two-Hybrid-System wurde zur in vivo Identifizierung von Interaktionspartnern des BI-1-Proteins angewendet. Es basiert auf der Tatsache, dass viele eukaryotische Transkriptionsfaktoren aus zwei funktionell unabhängigen Domänen bestehen. So enthält der GAL4-Transkriptionsaktivator der Hefe eine DNABindungsdomäne (DNA-BD) und eine transkriptionsaktivierende Domäne (AD). Die DNA-BD erkennt und bindet an eine als UAS (,upstream activating sequence“) bezeichnete Sequenz stromaufwärts von GAL4-responsiven Domänen, während die AD mit anderen Komponenten der Transkriptionsmaschinerie interagiert, die an der Initiation der Transkription beteiligt sind. Beide Domänen, die im Normalfall Teile eines einzigen Proteins sind, werden gleichermaßen zur Aktivierung eines Gens benötigt. Werden beide jedoch in derselben Wirtszelle infolge einer Manipulation getrennt exprimiert, kommt es zu keiner direkten Interaktion von DNA-BD und AD und somit auch zu keiner Aktivierung GAL4-responsiver Gene. Im Yeast-Two-HybridSystem wurden zwei verschiedene Klonierungsvektoren benutzt, um getrennte Fusionen dieser beiden GAL4-Domänen mit (Teilen von) Proteinen zu konstruieren, die auf eine Interaktion hin untersucht werden sollten. Dabei wurde das Köder („Bait“)-Protein BI-1 durch Integration der entsprechenden Gensequenz in den Vektor pGBKT7 mit der 
GAL4-DNA-BD fusioniert. Die verwendete Prostata-cDNA-Bibliothek (Clontech, Heidelberg) war in den Vektor pACT2 eingebaut, um Fusionen von Proteinen, für die die cDNAs kodieren, mit der GAL4-AD zu erhalten. Beide Plasmide wurden in den Hefestamm AH109 transformiert, in dem die Fusionsproteine exprimiert und in den Zellkern transportiert werden. Im Fall einer Interaktion von BI-1 mit einem in der cDNA-Bibliothek kodierten Protein kommt es zu einer Verbindung zwischen GAL4DNA-BD und GAL4-AD und damit zu einer funktionellen Rekonstitution des GAL4Transkriptionsaktivators. Dieser ist daraufhin in der Lage, die Transkription von Reportergenen (lacZ und HIS3), die stromabwärts der GAL4-Bindungsstellen lokalisiert sind, zu aktivieren, was die Proteininteraktion phänotypisch detektierbar macht (Abb. 2.2).

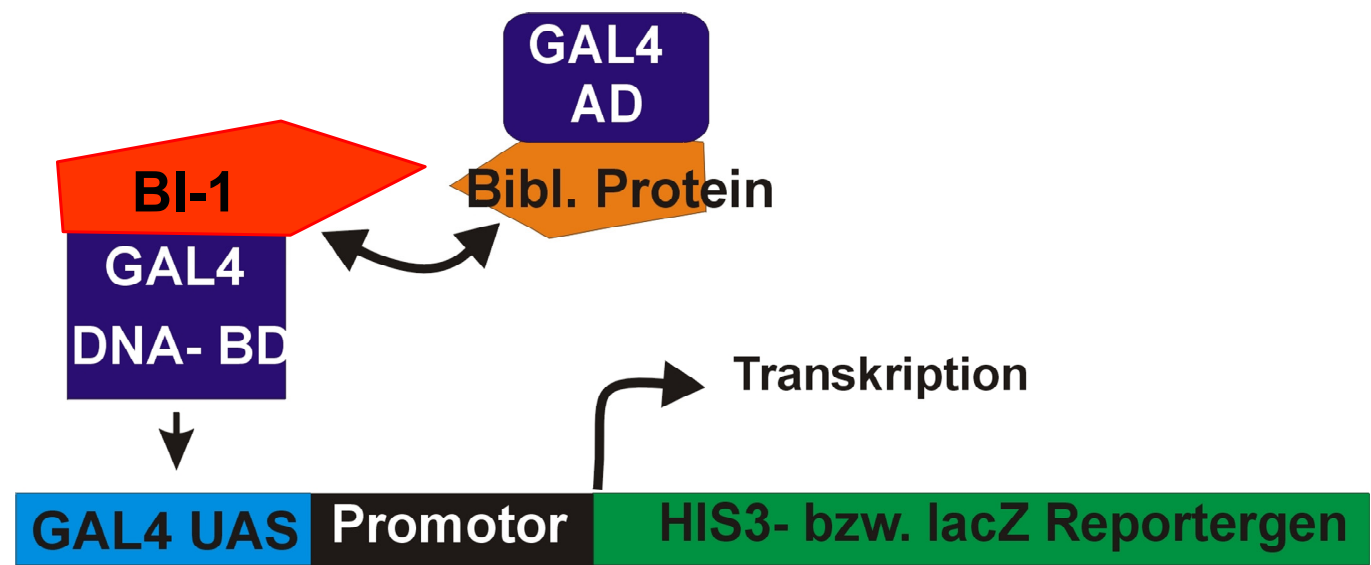

Abb. 2.2: Schematischer Ablauf des Yeast-Two-Hybrid-Systems. Die Interaktion zwischen BI-1 und einem Protein der Bibliothek rekonstituiert den GAL4-Transkriptionsaktivator, was zur Expression der Reportergene HIS3 und lacZ führt. 


\subsubsection{Transformation von pGBKT7-BI-1 im kleinen Ansatz}

Es wurden $300 \mathrm{ml}$ YPDA- Nährlösung mit $25 \mathrm{ml}$ einer Übernachtkultur von AH109 beimpft und $3 \mathrm{~h}$ bei $30^{\circ} \mathrm{C}$ inkubiert, wodurch eine $\mathrm{OD}_{600}$ von 1.8 erzielt wurde. Nach Zellernte und Waschen mit sterilem Wasser wurde das Pellet in $1.5 \mathrm{ml}$ TE/Lithiumacetat-Lösung suspendiert, um kompetente Zellen zu generieren. Das für die Transformation verfügbare Volumen belief sich auf $2.8 \mathrm{ml} .100 \mu \mathrm{l}$ dieser Suspension wurden mit $1 \mu \mathrm{g}$ Plasmid DNA des Konstruktes pGBKT7-BI-1 und $100 \mu \mathrm{g}$ Lachsspermien- DNA $(10 \mu \mathrm{g} / \mu \mathrm{l}) \quad$ vermischt. Nach Zusatz von $600 \mu \mathrm{l}$ PEG/Lithiumacetat-Lösung wurde der Ansatz $30 \mathrm{~min}$ bei $30^{\circ} \mathrm{C}$ geschüttelt. Anschließend wurden $70 \mu \mathrm{DMSO}$ zugefügt und die Zellen 15 min lang einem $42^{\circ} \mathrm{C}$ Hitzeschock ausgesetzt. Die so behandelten Zellen wurden auf Eis abgekühlt, pelletiert und in $0.5 \mathrm{ml}$ TE-Puffer suspendiert. Von dieser Suspension wurden $100 \mu \mathrm{l}$ auf einem $\mathrm{SD} /-$ Trp- Selektivnährboden ausgestrichen und bei $30^{\circ} \mathrm{C}$ für 3-4 Tage inkubiert.

\subsubsection{Transformation von pACT2 / cDNA-Bibliothek im großen Ansatz}

Die auf dem SD/-Trp-Nährboden herangewachsenen transfomierten Hefezellen (AH109-pGBKT7-BI-1) wurden in der gleichen Weise behandelt wie zuvor beschriebenen kleinen Ansatz, jedoch ist hier für die Transformation der cDNABibliothek das präparierte Volumen an Zellsupension $(2.8 \mathrm{ml})$ komplett verwendet worden. Es wurden $50 \mu \mathrm{g}$ Plasmid -DNA eingesetzt, da bei diesem Verhältnis von Zellen zu transformierter DNA-Menge die Transformationseffizienz in Vorversuchen einen Maximalwert von 1 x $10^{4}$ Transformanten/ $\mu$ g DNA erreicht hatte. Analog sind die Mengen den übrigen Komponenten des Transformationsansatzes erhöht worden. Nach der Transformation wurden die Zellen zunächst $1 \mathrm{~h}$ bei $30^{\circ} \mathrm{C}$ in $14 \mathrm{ml}$ YPDANährlösung inkubiert, bevor sie in Volumenanteilen von $300 \mu \mathrm{l}$ auf 28 SD/Trp-Leu-HisSelektivnährböden ausgestrichen und bei $30^{\circ} \mathrm{C}$ inkubiert worden. Zur Kontrolle wurden jeweils $3 \mu \mathrm{l}$ der Transformationsmischung auf SD/-Leu und auf SD/-Leu-TrpSelektivnährböden ausgestrichen. 


\subsubsection{Selektion relevanter Transformanten}

Durch die Selektion sollten Transformanten ausfindig gemacht werden, in denen das DNA-BD/BI-1-Fusionsprotein mit einem AD-Fusionsprotein der Bibliothek interagiert. Da der verwendete Hefestamm AH109 zwei Reportergene (HIS3 und lacZ) besitzt, die beide unter der Kontrolle des GAL4-Transkriptionsaktivators stehen, jedoch verschiedene Promotoren haben, ist eine Doppelselektion der erhaltenen Cotransformanten möglich. Die Selektion HIS3-exprimierender Zellen ist durch ihre Fähigkeit zum Wachstum auf SD/-Ade-Leu-Trp-His-Nährboden erfolgt. Die hier erhaltenen Kolonien wurden darüber hinaus auf die Expression des lacZ-Gens bzw. auf die Aktivität der $\beta$-Galactosidase getestet. Dazu wurden die Kolonien mit einem sterilen Filterpapier von der Nährbodenplatte abgehoben und durch Einfrieren in flüssigem Stickstoff und anschließendes Auftauen bei Raumtemperatur permeabilisiert. Die so behandelten Zellen wurden auf einen zweiten Filter gelegt, der mit Z-Puffer/X-GalLösung getränkt war. Sofern das (künstliche) Substrat X-Gal durch die B-Galactosidase umgesetzt wurde, zeigten die entsprechenden Kolonien nach einigen Stunden eine Blaufärbung.

\subsubsection{Verifikation positiver Klone durch Erzeugung von Segreganten}

$\mathrm{Da}$ in einigen bei der Doppelselektion erhaltenen putativ positiven Klonen die Aktivierung der Reportergene nicht auf einer Interaktion der beiden Fusionsproteine beruht, sondern allein durch das AD- Fusionsprotein hervorgerufen wird, wurden durch Elimination des DNA-BD-Plasmids (pGBKT7-BI-1) Klone erzeugt, die nur noch das AD-Plasmid (pACT2/cDNA-Klon) trugen. Dies wurde erreicht, indem die Klone zunächst einen Tag in SD-Leu-Nährlösung angezogen und anschließend (in einer $10^{-4}$ Verdünnung) auf SD/-Leu und zur Kontrolle auch auf SD/-Leu-Trp- Nährboden ausgestrichen wurden. Um Segreganten zu identifizieren, wurden daraufhin einzelne Kolonien vom SD/-Leu-Nährboden auf markierte Bereiche eines frischen SD/-Leu- und eines SD/-Leu-Trp-Nährbodens übertragen. Klone, die nur auf dem SD/-LeuNährboden heranwuchsen, enthielten lediglich das AD-Plasmid. Diese Klone wurden 
dann auf SD-Leu-His-Selektivnährböden ausgestrichen. Bei positiven Kandidaten durfte kein Wachstum auf diesen Platten erfolgen.

\subsubsection{Isolierung des AD-Plasmids aus Hefezellen und Klon-Analyse}

Nachdem die Interaktion eines AD-Fusionsproteins mit NIF3L1 durch die oben beschriebenen Verfahren bestätigt worden war, wurde das entsprechende AD-Plasmid (pACT2) aus den Hefezellen isoliert. Dafür wurden die hergestellten Segreganten (II. 8.7.5) herangezogen. Zwei $\mathrm{ml}$ SD-Leu-Selektivnährmedium wurden mit einer entsprechenden Kolonie angeimpft und über Nacht bei $30^{\circ} \mathrm{C}$ und intensivem Schütteln inkubiert. Am nächsten Tag wurde $1.5 \mathrm{ml}$ in ein Reaktionsgefäß (Eppendorf) überführt und für $5 \mathrm{sec}$ bei $12000 \mathrm{x}$ g bei RT zentrifugiert (Eppendorf-Zentrifuge). Der Überstand wurde dekantiert und das Pellet in $200 \mu$ Lyse-Puffer für Hefen resuspendiert. Anschließend wurden $200 \mu \mathrm{l}$ Phenol/Chloroform (1:1) sowie 0.3 g Glasperlen (Sigma) hinzugegeben und 2 min intensiv gevortext. Danach wurde der Ansatz zentrifugiert (5 min, $12000 \mathrm{x} \mathrm{g,} \mathrm{RT)} \mathrm{und} \mathrm{mit} \mathrm{2.5} \mathrm{Vol.} \mathrm{Ethanol} \mathrm{und} \mathrm{1/10} \mathrm{Vol.} 3 \mathrm{M} \mathrm{NaAc,} \mathrm{pH} \mathrm{5.2} \mathrm{gefällt,}$ in 70\%igen Ethanol gewaschen und in $50 \mu \mathrm{H}_{2} \mathrm{O}$ suspendiert. Anschließend wurde die isolierte Plasmid-DNA als Template in einer PCR Reaktion verwendet, unter Verwendung von zwei flankierenden vektorspezifischen Primern (MATCHMAKER $A D$ LD-Insert Screening Amplimer Primer, Clontech). Das Amplifikat wurde in den pGEMT-Vektor (Promega) einkloniert. Nach einer Mini-Präparation sind die darin enthaltenen cDNA-Klone in beide Richtungen mit den plasmidspezifischen Primern SP6 und T7 sequenziert und anschließend mit dem BLAST-Programm (Altschul et al., 1990) analysiert worden.

\subsection{Koimmunpräzipitation}

Mit Hilfe der Immunpräzipitation lassen sich Proteine gezielt aus einem Zelllysat isolieren. Hierzu benutzt man spezifische Antikörper, die an eine Matrix gebunden sind. Die Proteine binden somit über den Antikörper an die Matrix und können durch 
Zentrifugation von den übrigen Proteinen getrennt werden. Als Matrix wird normalerweise an Agarose gebundenes Protein A, G oder L benutzt.

Durch nachfolgende SDS-Page und Western blot-Analysen lassen sich unter anderem Protein-Proteininteraktionen nachweisen (Koimmunpräzipitation). Man verwendet hierfür zwei verschiedene Antikörper, die für die beiden Proteine, für die eine Interaktion nachgewiesen werden soll, spezifisch sind. Der eine Antikörper wird für die Immunpräzipitation verwendet und an die Matrix gebunden, der jeweils andere für die Western blot- Analyse eingesetzt. Interagieren die beiden Proteine, so werden beide zusammen als Komplex an die Matrix gebunden und können aufgereinigt werden. Nach Auftrennung über SDS-PAGE kann mit dem zweiten Antikörper, der gegen das jeweils andere Protein gerichtet ist, die Interaktion nachgewiesen werden.

Die Prostatakarzinomzelllinie LNCaP wurde in zwei großen Kulturflaschen so in RPMI 1640 ausplattiert, dass die Zellen am nächsten Morgen eine Konfluenz von 80- 90\% zeigten. Diese Zellen wurden mit den Vektoren pEGFP-C1-BI-1 (7 $\mu \mathrm{g}$ DNA pro großer Kulturflasche) transfiziert. Das Transfektionsmedium wurde nach 4-5 h gegen Komplettmedium (RPMI 1640) ausgetauscht. Am nächsten Morgen wurde das Medium erneut gewechselt. Die Zellen wurden für weitere 48 Stunden inkubiert. Anschließend wurden die Zellen unter Fluoreszenzmikroskop (mit GFP-Filter) auf die Transfektionseffizienz überprüft. Die folgende Koimmunpräzipitation wurde mit dem Protein G Immunoprecipitation Kit (Sigma) durchgeführt. Für die Zelllyse wurden 0,7 $\mathrm{ml}$ des im Kit enthaltenen 1x IP Puffer, dem $5 \mu \mathrm{g} / \mathrm{ml}$ Aprotin, Pepstatin und Leupeptin, $1 \mathrm{mM} \mathrm{Na}_{3} \mathrm{VO}_{4}, \mathrm{NaF}$ und PMSF beigefügt wurden, auf die Zellen gegeben. Das Lysat wurde $5 \mathrm{~min}$ auf Eis gestellt und anschließend bei $4^{\circ} \mathrm{C}$ für $10 \mathrm{~min}$ bei $12000 \mathrm{x} \mathrm{g}$ zentrifugiert. Der Überstand wurde in ein neues Eppendorf-Gefäß überführt und davon die Proteinkonzentration bestimmt. Pro Immunpräzipitation (IP) wurde mindestens 1 mg Proteine benötigt. Auf die dem Kit beigefügten Säulen wurden die entsprechenden Mengen Proteinlösung und Antikörper (DIO-1 Ak: $2 \mu \mathrm{g} / \mathrm{mg}$ Protein) gegeben und das Volumen der Lösung mit 1x IP Puffer auf $600 \mu 1$ aufgefüllt. Anschließend wurden die Säulen für $1 \mathrm{~h}$ bei $4^{\circ} \mathrm{C}$ auf einem Rotationsschüttler inkubiert. Währenddessen wurde die Protein-G- bzw. A-Agarose vorbereitet. Pro IP wurden je $30 \mu 1$ der Protein- Agarose (A und G) mit $1 \mathrm{ml} \mathrm{1x}$ IP- Puffer gewaschen, indem vorsichtig gevortext und anschließend bei 12000 x g zentrifugiert wurde. Der Überstand wurde vorsichtig 
abgenommen und der Waschschritt noch 2x wiederholt. Anschließend wurden die Agaroseperlen in $50 \mu 1$ 1x IP- Puffer aufgenommen und die Protein-G- und A-Agarose miteinander vermengt. Nach der Inkubation wurden von diesem Gemisch $60 \mu \mathrm{lu}$ dem Zelllysat auf die Säulen gegeben und diese für weitere $2 \mathrm{~h}$ bei $4^{\circ} \mathrm{C}$ auf dem Rotationsschüttler inkubiert. Anschließend wurde der untere Teil der Säulen abgebrochen und für die spätere Verwendung aufbewahrt. Die Säulen wurden in die dem Kit beigefügten $2 \mathrm{ml}$ - Gefäße gestellt und für $15-30 \mathrm{sec}$ bei $12000 \mathrm{x} \mathrm{g}$ bei $4^{\circ} \mathrm{C}$ zentrifugiert. Der Durchfluss wurde verworfen. Anschließend wurden die Agaroseperlen zum Waschen in $700 \mu 1$ 1x IP- Puffer resuspendiert und die Säulen bei 12000 x g für $15-30 \mathrm{sec}$ bei $4^{\circ} \mathrm{C}$ zentrifugiert. Der Durchfluss wurde wieder verworfen und dieser Schritt noch weitere 5x wiederholt. Der letzte Waschschritt wurde mit $0,1 \mathrm{x}$ IP- Puffer durchgeführt. Die Säulen wurden mit den aufbewahrten abgebrochenen Teilen verschlossen. Anschließend wurde der NuPAGETMLDS Samplebuffer (4x) 1:1 mit PBS gemischt und $50 \mu 1$ davon auf jede Säule gegeben. Diese wurden für $10 \mathrm{~min}$ bei $95^{\circ} \mathrm{C}$ unter leichtem Schütteln auf dem Thermomixer inkubiert. Der Verschluss der Säulen wurde wieder geöffnet und die Säulen in 1,5 ml Eppendorfgefäße gestellt. Diese wurden für $30 \mathrm{sec}$ bei 12000 x g zentrifugiert. Das erhaltene Eluat konnte über SDSPAGE aufgetrennt werden. Anschließend wurde eine Western blot-Analyse mit dem GFP- Antikörper (Klon G) durchgeführt.

\subsection{In vivo-Experiment}

Die folgenden histologischen Methoden wurden in Zusammenarbeit mit Frau PD Dr. F. Alves aus der Abteilung Onkologie/Hämatologie (Georg-August-Universität, Göttingen) durchgeführt. Die Haltung und Zucht der Versuchstiere, sowie die Implantation von Tumorzellen wurde in der Tierexperimentellen Abteilung der Universität Göttingen durchgeführt (Tierversuchsantrag Nr.: 33.42502/01-25.05; Bezirksregierung Braunschweig) 


\subsubsection{Versuchstiere}

Die verwendeten weiblichen Nacktmäuse des Stammes NU/NU-nuBR wurden von der Fa. Charles River Laboratories (Hannover) bezogen. Die Fütterung und Tränke erfolgte ad libitum mit einem hochkalorischen, pelletierten 1439 Extrudat (Altromin, Lage) und destilliertem Wasser. Das entmineralisierte Wasser wurde mit $\mathrm{HCl}$ auf $\mathrm{pH}$ 2,5 angesäuert und zur Infektionsprophylaxe mit Oxytetracyclin (3g/l) versetzt. Die Tiere wurden je nach Gruppengröße in Macrolonkäfigen Typ 2 und 3, die mit Filterhauben versehen waren, auf staubfreier Einstreu S 8/15 (Altromin, Lage) gehalten. Das Wasser und die Einstreu wurden zweimal wöchentlich gewechselt. Die Temperatur betrug konstant $25^{\circ} \mathrm{C}$ bei einer relativen Luftfeuchtigkeit von $70 \%$. Während der gesamten Versuchsdauer unterlagen die Mäuse einem natürlichen Tag-Nacht-Rhythmus.

Manipulationen an Tieren wurden in S2-Werkbänken durchgeführt. Die Tötung der Tiere erfolgte durch zervikale Dislokation.

\subsubsection{Operationsbesteck und Verbrauchsmaterialien}

Chirurgiebesteck

Einmalkanülen, 26G

Forene (Isofluran)

Ketanest ( Ketamin, $10 \mathrm{mg} / \mathrm{ml}$ ) PBS

PBS

Polyglycolsäure-Faden, 8-0, resorb., atraum. Braun, Spangenberg

Nadel

Rompun ( Xylazin, Sol. 2\%)

Vicryl-Faden, 3-0 resorb., traumat. Nadel
Aesculap, Tuttlingen

Braun, Spangenberg

Abbot, Wiesbaden

Parke-Davis, Berlin

GibcoBRL, Schottland

Bayer, Leverkusen

Ethicon, Norderstedt 


\subsubsection{Orthotope Implantation von MDA-MB-231-Zellen}

Die für die Implantation verwendeten MDA-MB-231-Zellen wurden in Zellkultur unter den in Abschnitt 2.6.4 beschriebenen Zellkulturbedingungen gezüchtet. Eine Million

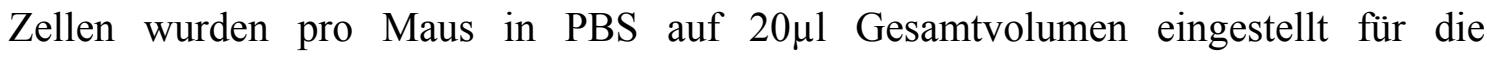
Implantation vorbereitet. Der Eingriff fand unter einer S2-Werkbank statt.

Nach Desinfekton der Haut mit Alkohol (Softasept-Spray) erfolgte unter Injektionsnarkose $(80 \mathrm{mg} / \mathrm{kg}$ Ketamin $+16 \mathrm{mg} / \mathrm{kg}$ Xylazin $)$ die Eröffnung der Bauchhöhle im inguinalen Drittel der linea alba. Die für die Implantation vorgesehene Mamma wurde freipräpariert und die Zellen wurden direkt in die Brustdrüse eingespritzt. Die Mamma wurde reponiert und die Bauchhöhle mit einschichtigen Knopfheften verschlossen. Hierzu wurde eine traumatische Nadel mit einem 3-0 resorbierbaren Vicrylfaden verwendet. Abschließend erfolgte eine Desinfektion der Operationsnaht mit Alkohol und die Kennzeichnung des Tieres mit einer Ohrmarke. Die Tiere wurden zum Aufwachen und zur Nachbeobachtung in einen mit sterilen Kompressen ausgelegten Makrolonkäfig überführt. Zum Zeitpunkt der Implantation der Tumorzellen waren die Mäuse 8 Wochen alt.

\subsubsection{Kontrolle des Wachstumsverlaufes des Tumors}

Die Kontrolle des Tumor-Wachstumsverlaufes wurde zunächst mit Hilfe einer Schieblehre gemessen bis die Tumoren ein Volumen von mindestens $50 \mathrm{~mm}^{3}$ besaßen. Zur Erfassung des Tumorwachstums wurden jeden Tag Länge, Breite und Höhe der Tumore mit einer Schieblehre gemessen. Das Tumorvolumen wurde nach folgender Formel berechnet:

Tumorvolumen $\mathrm{V}=$ Länge $\mathrm{x}$ Breite $\mathrm{x}$ Höhe $/ 2$

$\mathrm{Ab}$ dem Zeitpunkt der Behandlung des Tumors mit dem D-BI-1/AtelocollagenKomplex wurde der Wachstumsverlauf mit Hilfe eines Flächendetektor-VolumenComputertomographen (FD-VCT) gemessen. 


\subsubsection{Herstellung des D-BI-1/Atelocollagen-Komplexes}

Das Atelocollagen (2\%) wurde von der Fa. Vikomed (Berlin) bezogen. Atelocollagen ist ein TypI-Collagen, das Telopeptid-frei ist und dadurch keine Immunreaktion in der Maus hervorruft (Stenzel et al., 1974). Atelocollagen stabilisiert die siRNA sowohl in vitro als auch in vivo und dient gleichzeitig als Transfektionsmedium da es von Zellen sehr effizient aufgenommen wird (Minakuchi et al., 2004). Atelocollagen ist bei niedriger Temperatur löslich, verdichtet und vernetzt sich dennoch sehr gut im Körper. Atelocollagen wird im Körper graduell abgebaut und kann siRNA in vivo bis zu sieben Tage stabilisieren (Minakuchi et al., 2004). Die siRNA (D-BI-1 und Luciferase) wurde in $0,5 \%$ igem Atelocollagen mit einer Konzentration von $7 \mu \mathrm{M}$ vorbereitet.

\subsubsection{Bildgebende Verfahren}

\subsubsection{Untersuchungen mit dem Fächendetektor-Volumen- Computertomographen (FD-VCT)}

Der Universität Göttingen steht seit Februar 2004 ein Volumen-CT mit zwei Flächendetektoren aus amorphem Silizium zur Verfügung. Dieser Prototyp eines Flächendetektor-Volumen-CT (FD-VCT) ist eine Entwicklung des General Electric (GE) Global Research Centers (Niskayuna, NY, USA). Die RöntgenComputertomographie hat sich in den letzten Jahren von einem Schicht- zu einem Volumenbildgebungsverfahren weiter entwickelt. Neben den CT-Detektoren mit derzeit bis zu 64 Zeilen werden in Zukunft auch ausgedehnte Flächendetektoren zum klinischen Einsatz kommen. Einen Grund für diese Entwicklung stellt die 3D-Ortsauflösung dar, die mit derartigen Detektoren noch einmal erheblich gesteigert werden kann. Die hohe Detektorelementdichte der Flächendetektoren (1024 x 1024 Elemente) ermöglicht die Darstellung $\mathrm{zu}$ untersuchender Organe oder Körperbereiche mit einer isotropen Ortsauflösung von ca. 0,2 mm mit einer effektiven Scanzeit im Millisekundenbereich. Bei den allerersten experimentellen Versuchsaufbauten und einigen Mikro-CTSystemen, bei denen Röntgenstrahler und Detektor ortsfest sind, mussten die 
Untersuchungsobjekte auf einem Drehteller bewegt werden. Bei dem hier verwendeten FD-VCT-System führen die Röntgenröhre und die Flächendetektoren in einer geschlossenen Abtasteinheit (Gantry) eine miteinander gekoppelte Drehbewegung um ein gemeinsames Rotationszentrum aus. Zu dem System gehört ferner ein Netzwerk aus verschiedenen Rechnern, die das Gesamtsystem steuern sowie die Datenübertragung und die anschließenden Rekonstruktionsrechnungen bis hin zur Archivierung realisieren.

Als Röntgenstrahler wird eine luftgekühlte Röntgenröhre mit Wolframanode (Performix 630, GE Medical Systems) eingesetzt. Das Detektorsystem besteht aus zwei quadratischen Flächendetektoren, die in einem Winkel von etwa $120^{\circ}$ parallel zur Systemachse aneinander stoßen. Das FD-VCT-System wird als Axialsystem betrieben, d.h. die Datenerfassung erfolgt längs der Systemachse in voneinander unabhängigen Einzelschritten jeweils während einer $360^{\circ}$ umfassenden Rotation der Röntgenröhre und des Detektorsystems um das stationäre Untersuchungsobjekt (Abb. 2.3). Anschließend wird bis zur vollständigen Erfassung des zu untersuchenden Objektvolumens der Objektlagerungstisch schrittweise vorwärts bewegt. Während des Tischvorschubs erfolgt keine Exposition. 


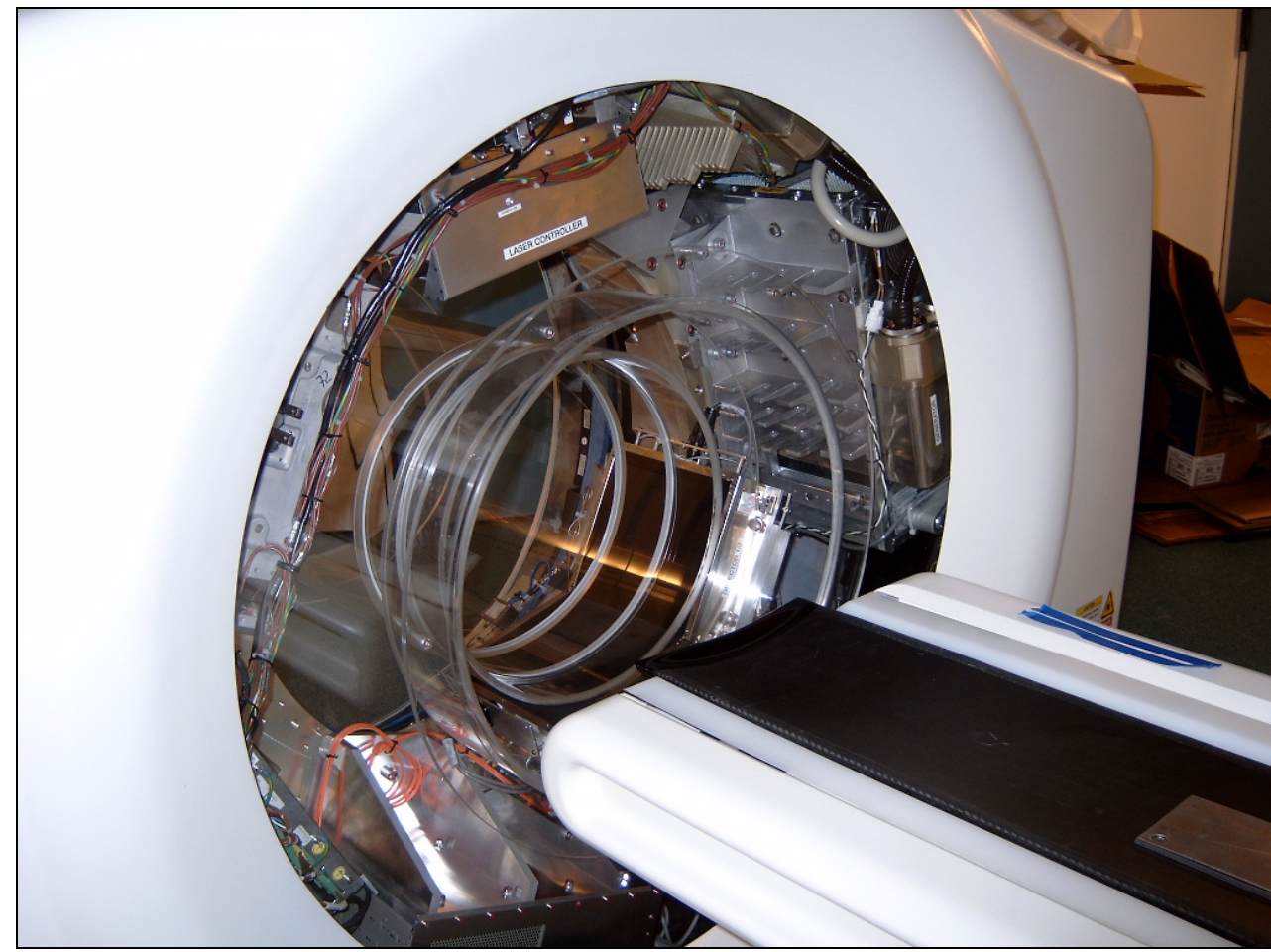

Abb. 2.3: Fächendetektor-Volumen-Computertomograph: Der FD-VCT besitzt zwei Flächendetektoren mit einer Matrix von 1024 x 1024 Elemente. Die Darstellung der zu untersuchenden Organe oder Körperbereiche von Mäusen ist mit einer isotropen Ortsauflösung von ca. 0,2 mm mit einer effektiven Scanzeit im Millisekundenbereich möglich. Auf dem Bild ist der Objektlagerungstisch und der Abtasteinheit (Gantry) zu sehen.

Zur Durchführung der Untersuchungen wurden die Mäuse zunächst mit Hilfe eines Ketamin/Xylazin-Gemisches narkotisiert, wie unter 2.26.3 beschrieben und auf dem Objektlagerungstisch fixiert. Bei Aufnahmen mit Kontrastmittel wurden exakt $20 \mathrm{sec}$ vor der beginnenden Rotation $150 \mu$ Isovist ${ }^{\circledR} 300$ (Schering, Berlin) intravenös in die Schwanzvene der Maus appliziert. Folgende Scan-Parameter wurden standardisiert verwendet: Bei einer Röhrenspannung von $80 \mathrm{kV}$ und einem Röhrenstrom von $100 \mathrm{~mA}$ wurde innerhalb der Rotationszeit von 7,9 sek eine Z-Achsenüberdeckung von 4,2 cm erreicht. Aus den gewonnen Daten erfolgte eine Bildrekonstruktion mit einem adaptierten Kegelstrahlalgorithmus. Dieser Aufnahmemodus erlaubt die Rekonstruktion von 1000 Projektionen. Mit Hilfe einer Advanced Workstation 4.2 wurden dann entweder dreidimensionale Darstellungen oder zweidimensionale Schichtdarstellungen generiert, die in allen Ebenen und Winkeln beurteilt werden konnten. Die Segmentierung des Tumors wurde mit Hilfe des Volume Viewer Voxtool 3.0.64u (GE Healthcare) durchgeführt. Das Tumorvolumen wurde aus den segmentierten 
Tumordaten gemessen. Weiterhin wurden die Hounsfield-Messungen aus den segmentierten Tumordaten in das FD-VCT-Histo-Programm von C. Dullin (Universitätsklinikum Göttingen, Abt. Radiologie) übertragen. Dieses Programm errechnet aus FD-VCT-Daten die Histogramme für die Tumoren. Die Hounsfield-Skala ist ein in der Computertomographie (CT) verwendete Einheit, die von Godfrey Hounsfield erhoben wurde (1967). Dabei wird die Schwächung der Röntgenstrahlung in bestimmten Geweben bestimmt und so können die pathologische Abweichungen von gesunden Geweben determiniert werden (Abb. 2.4). Die Hounsfield-Einheit wird nach folgender Formel berechnet:

[CT-Zahl in Houndsfield-Einheit] $(\mu$ Gewebe $):=\frac{\mu \text { Gewebe }-\mu \text { Wasser }}{\mu \text { Wasser }-\mu \text { Luft }} \cdot 1000$

Dabei beschreibt der Adsorptionskoeffizient $\mu$ die Abschwächung der monochromatischen Röntgenstrahlung beim Durchdringen von Materie entlang des durchstahlten Weges. 


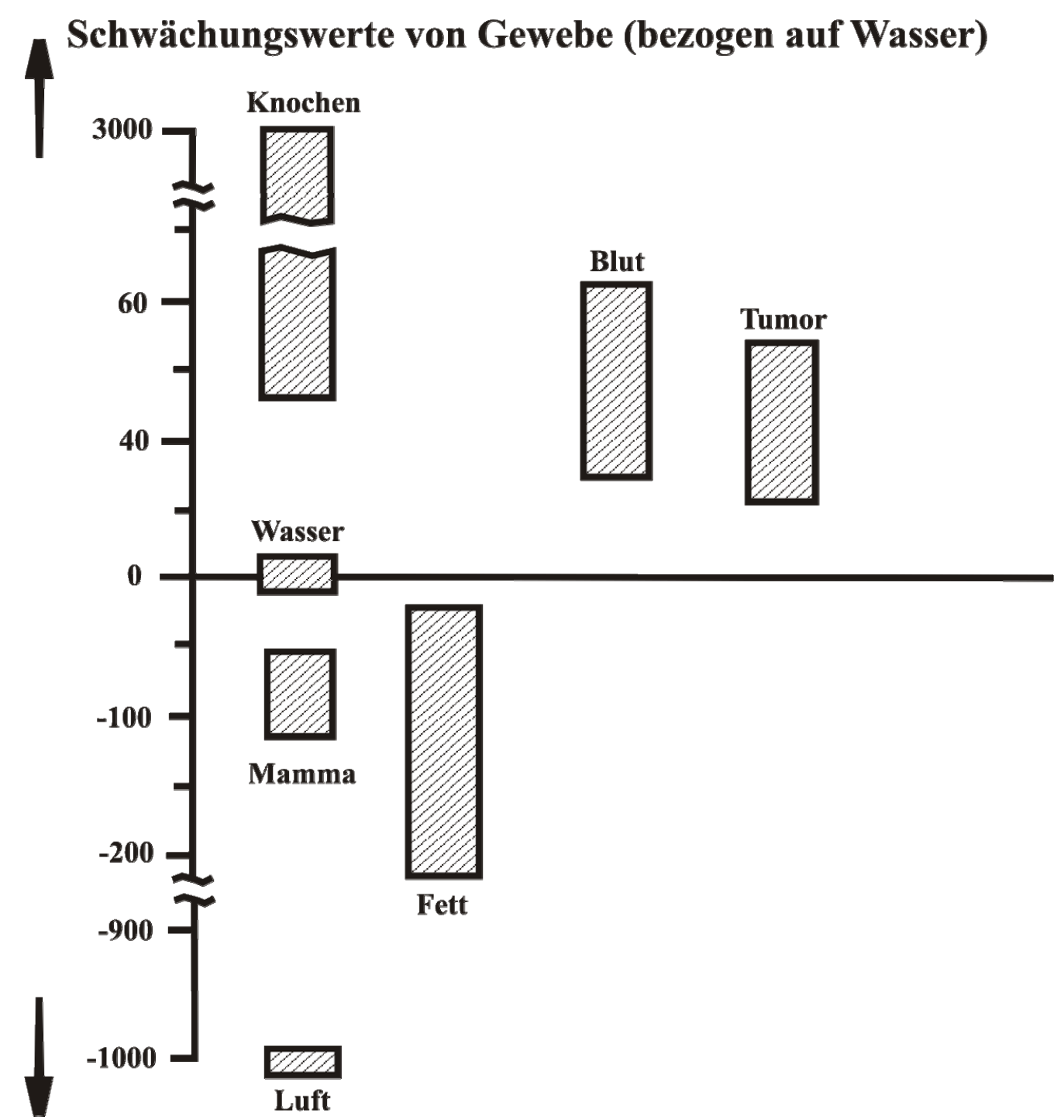

Abb. 2.4: Relative Schwächungskoeffizienten bezüglich Wasser (Hounsfield-Einheiten) für einige typische Gewebearten. Wasser hat dabei die Hounsfield-Einheit 0 während die vitalen Tumoren etwa 20-50 Hounsfield-Einheiten besitzen. Bei den FD-VCT Messungen wurden die Messbereiche auf -200 bis 200 Hounsfield-Einheiten beschränkt.

\subsubsection{Molekulare Bildgebung mit Hilfe des eXplore Optix-Systems}

Ergänzend zu den Untersuchungen mit dem FD VCT wurde zur optischen Bildgebung das eXplore Optix System (GE Medical Systems) verwendet, so dass neben anatomischen Strukturen auch biologische Vorgänge auf molekularer Ebene sichtbar gemacht werden können (Abb. 2.5). 


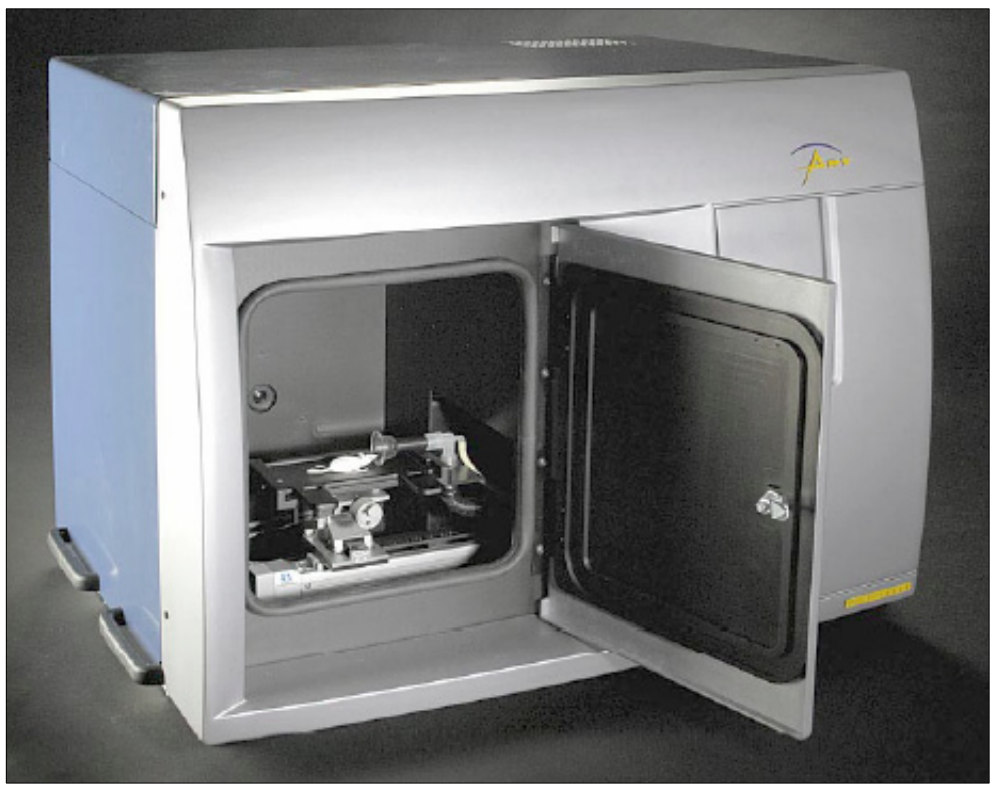

Abb. 2.5: Das eXplore Optix-System. Mit Hilfe des eXplore Optix-Systems (GE Medical Systems) ist es möglich, biologische Vorgänge auf molekularer Ebene sichtbar zu machen. Das System verwendet einen Pulslaser mit einer Wellenlänge von $670 \mathrm{~nm}$ und einen Detektionsfilter mit einem WellenlängenBereich von 700 nm. (Quelle: http://www.art.ca/en/products/eXploreOptixPaper040130.pdf)

Das eXplore Optix-System wurde zur Charakterisierung, Quantifizierung und bildlichen Darstellung zellulärer und molekularer Vorgänge in lebenden Tieren mit Hilfe spezifischer oder nicht spezifischer Fluoreszenzmarker konzipiert. Die molekulare in vivo-Bildgebung mittels eXplore Optix ermöglicht die Durchführung von Langzeitstudien in ein und demselben Tier, wodurch präzise Daten zu operativen Eingriffen, Tumor-Wachstumsverläufen und Behandlungsergebnissen erhoben werden können.

Zur Durchführung der Untersuchungen wurden die Mäuse zunächst wie unter 2.26.3 beschrieben, mittels eines Ketamin/Xylazin-Gemisches narkotisiert und auf dem Untersuchungstisch fixiert. Um die Körpertemperatur der Mäuse konstant zu halten, wurde der Untersuchungstisch auf ca. $39^{\circ} \mathrm{C}$ geheizt. Beim Messungsvorgang wird durch Umlenkspiegel der Laser über die Mess-Bereiche gelenkt und über eine Sammellinse und einen Sammelspiegel in den Photomultiplier geleitet (Abb. 2.6). Dabei wird durch das eXplore Optix-System die sog. time-correlated single photon counting (TCSPC)Technik mit zeitkorrelierter Zählung einzelner Photonen zur Messung von Fluoreszenz und Absorption verwendet. Mit Hilfe dieser Technik kann die Photonenmigration 
kurzer Lichtimpulse bei spezifischen Wellenlängen detektiert werden. Die Verteilung der Ankunftszeiten der Impulse können gemessen und anschließend zur Quantifizierung des Fluoreszenzemitters sowie zur Angabe der Fluoreszenzlebensdauer verwendet werden. Durch die Anwendung eines Pulse-Lasers ist es möglich die Fluoreszenz- und die Biolumineszenzintensitätsmessung und tomographische Bildgebung durchzuführen. Weiterhin ist es möglich auch Tiefen-, Konzentrations-, Absorptions- und Streuungsmessung sowie die Fluoreszenzlebensdauer zu bestimmen (Long and Vemon, 2004).

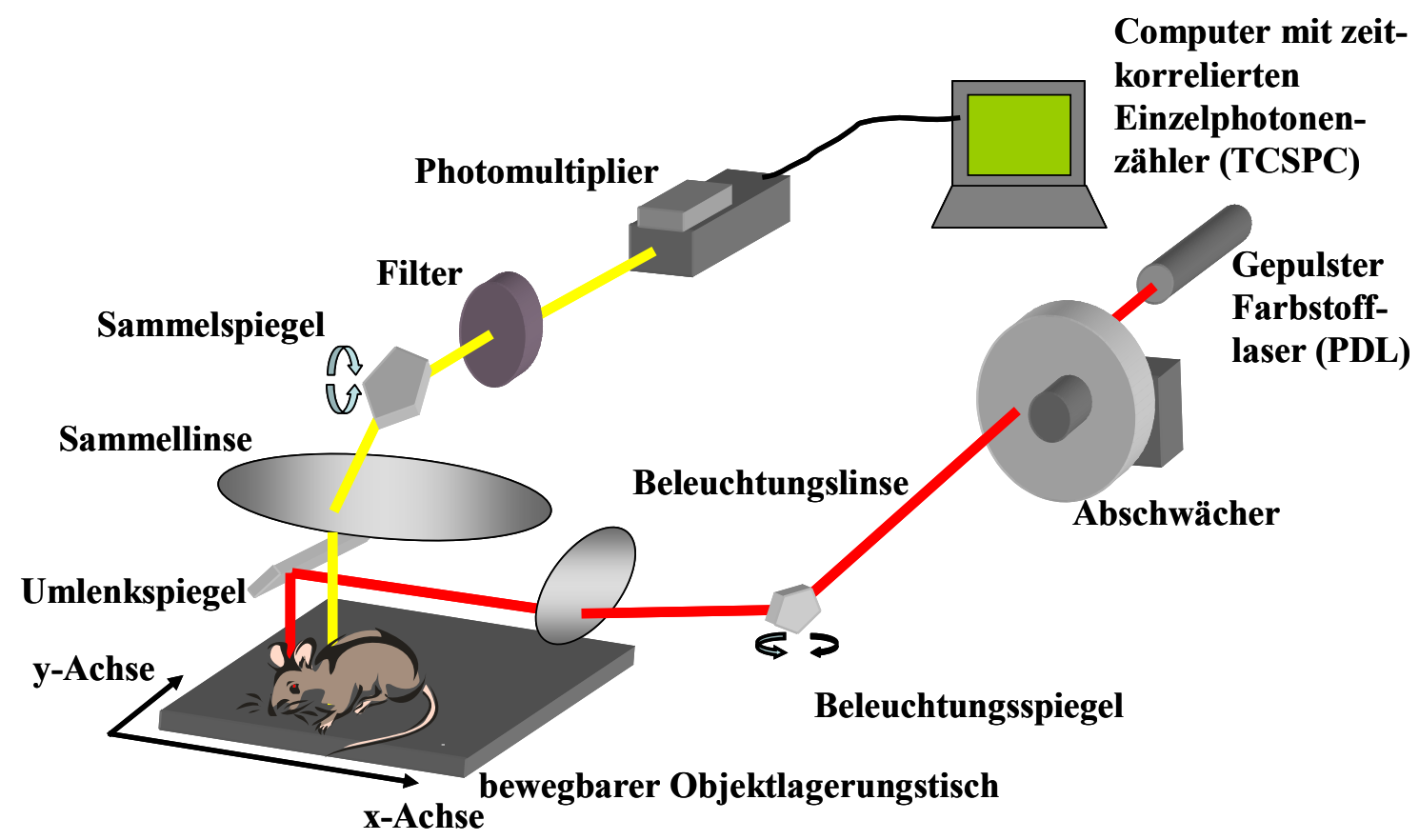

Abb. 2.6: Aufbau des eXplore Optix-Systems. Beim Messvorgang wird der gepulste Farbstofflaser über die Beleuchtungsspiegel in die Beleuchtungslinse gelenkt und durch die Umlenkspiegel über die MessBereiche gesteuert. Die emittierten Photonen vom Untersuchungsobjekt werden über die Sammellinse und den Sammelspiegel in den Photomultiplier geleitet. Die Signale werden anschließend von einem Computer mit zeitkorreliertem Einzelphotonenzähler (TCSPC) verarbeitet. (Quelle: http://ikrweb.unimuenster.de/aptdir/veranstaltungen/vortraege/Goettingen/Dullin-Das\%20eXplore\%20Optix-

Projekt\%20am\%20UKG.pdf)

Die für die Untersuchung verwendete Laserwellenlänge betrug $670 \mathrm{~nm}$, wobei die Detektionswellenlänge bei $700 \mathrm{~nm}$ lag. Der verwendete Fluoreszenzfarbstoff Cy5.5, der an die siRNA gekoppelt wurde, besitzt ein Absorptionsmaximum von $679 \mathrm{~nm}$ und ein 
Emissionsmaximum von $702 \mathrm{~nm}$ (Abb. 2.7). Über die Messungen mit Hilfe des eXplore Optix-Systems ist es daher möglich, die mit Cy5.5 gekoppelte siRNA in vivo zu lokalisieren und die Stabilität der siRNA/Ac-Komplexe über längere Zeit zu analysieren.

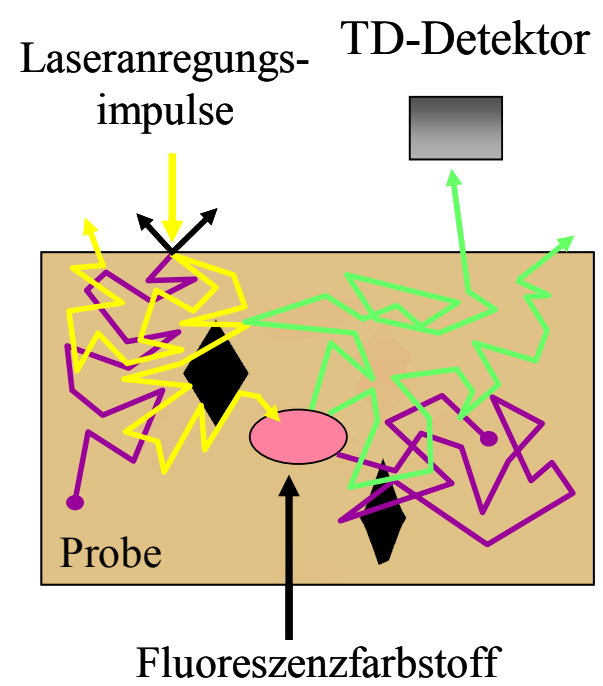

(Cy5.5)

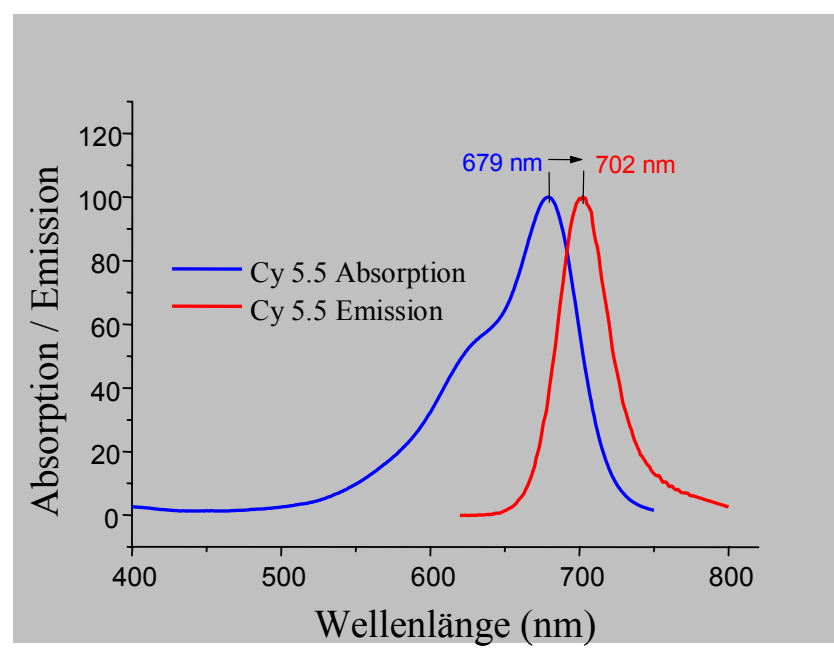

Laserwellenlänge : $670 \mathrm{~nm}$

Detektionswellenlänge : $700 \mathrm{~nm}$

Abb. 2.7: Fluoreszenzfarbstoffmessung mit Hilfe des eXplore Optix-Systems. Die Laserimpulse regen den Fluoreszenzfarbstoff an, der wiederum Photonen emittiert. Diese Photonen-Emission können anschließend durch den Time Domain-Detektor (TD-Detektor) gemessen werden. Der hier verwendete Fluoreszenzfarbstoff Fluorophor Cy5.5 besitzt ein Absorptionsmaximum bei $678 \mathrm{~nm}$ und ein Emissionsmaximum von $702 \mathrm{~nm}$. Die für die Untersuchung verwendete Laserwellenlänge betrug $670 \mathrm{~nm}$, wobei die Detektionswellenlänge bei $700 \mathrm{~nm}$ lag. (Bild-Quelle: http://ikrweb.uni-muenster.de/aptdir/ veranstaltungen/vortraege/Goettingen/Dullin-Das\%20eXplore\%20Optix-Projekt\%20am\%20UKG.pdf) 


\subsubsection{Histologische Untersuchungen an Tumorgewebe-Präparaten}

\subsubsection{Herstellung von Kryoschnitten aus Tumorgeweben}

Die aus der Sektion entnommenen Tumoren wurden halbiert und je eine Hälfte mit HOPE (HEPES-Glutamic Acid Buffer Mediated Organic Solvent Protection Effect)fixiert (Fa. DCS, Hamburg) und die andere Hälfte für die Kryoschnitte verwendet. Dabei wurde die Tumorhälfte mit Hilfe von flüssigem Stickstoff eingefroren und bei $80^{\circ} \mathrm{C}$ aufbewahrt. Anschließend wurde ein $7 \mu \mathrm{m}$-Tumorgewebeschnitt mit Hilfe des Mikrotoms (JUNG RM 2035, Leica) angefärbt und die Zellkerne wurden mit DAPI gefärbt.

\subsubsection{Herstellung von HOPE-fixierten Materialien}

Ein neues Verfahren der Gewebekonservierung zur Herstellung von Paraffinschnitten bei weitgehender Erhaltung der Makromoleküle in ihrer nativen Struktur stellt die HOPE-Fixierung dar. Bei diesem Verfahren werden bei der Gewebsprozessierung weder Alkohole noch organische Lösemittel oder Aldehyde ("Formalin", Glutaraldehyd) eingesetzt, welche die nativen Sturkturen verändern können. Mit der HOPE-Fixierung können in der Immunhistochemie auch solche Antikörper eingesetzt werden, die bisher nur als "kryogängig" angesehen wurden (ohne EpitopDemaskierung), d.h. ohne Hitzevorbehandlung oder proteolytischen Abbau (Umland et al., 2003). Durch die HOPE-Fixierung ist es ebenfalls möglich hoch-molekulare DNA und RNA $(>20 \mathrm{~kb})$ aus den HOPE-fixierten Paraffinschnitten $\mathrm{zu}$ extrahieren und für weiteren Anwendungen wie PCR und RT-PCR zu verwenden (Wiedorn et al., 2002). Bei der HOPE-Fixierung wurden die Tumoren zunächst in HOPE-Puffer für 36 Stunden fixiert. Anschließend wurden die Tumoren in Aceton bei $0-4^{\circ} \mathrm{C}$ für zwei Stunden inkubiert und dehydriert. Nach der Dehydratation mit Aceton wurden die Tumoren in Paraffin eingebettet und geschnitten. Die Schnitte wurden getrocknet und mit Isopropanol $\left(58^{\circ} \mathrm{C}\right)$ entparaffiniert. Anschließend wurden die Gewebeschnitte mit $70 \%$ igem Aceton für $20 \mathrm{~min}$. rehydriert und für $10 \mathrm{~min}$. in destilliertem Wasser bei $4^{\circ} \mathrm{C}$ 
inkubiert (Olert et al., 2001). Die mit HOPE-fixierten Tumorgewebeschnitten wurden zur Hämalaun-Eosin Färbung, wie in Abschnitt 2.26.7.3 beschrieben, weiterbehandelt.

\subsubsection{Hämalaun-Eosin Färbung von HOPE-fixierten Tumorgewebeschnitten}

Für die mikroskopische Untersuchung wurden die Tumorgewebeschnitte mit Hämalaun-Eosin gefärbt. Die Zellkerne färben sich hierbei blau. Alle anderen Zellstrukturen werden durch Eosin rötlich gefärbt. Die Gewebeschnitte wurden zunächst für 2x 10 min in Xylol-Ersatz entparaffiniert und anschließend durch eine absteigende Alkoholreihe für jeweils 2 min rehydriert. Die Färbung erfolgte zunächst für 5-10 min in Hämalaun. Anschließend wurde gründlich mit $\mathrm{H}_{2} \mathrm{O}$ gespült und 5-10 min mit Eosin-Färbelösung (Eosin-Stammlösung 1:10 in $\mathrm{H}_{2} \mathrm{O}$ verdünnt) gegengefärbt. Die Gewebeschnitte wurden in $\mathrm{H}_{2} \mathrm{O}$ gespült, dehydriert $(50 \%, 70 \%, 90 \%, 100 \%)$ und naß mit Eukit eingedeckt.

\subsubsection{Mikroskopische Analysen von Tumorgewebepräparate im Infrarot-Bereich}

Für die Untersuchungen der Kryoschnitte wurde ein Infrarot-Mikroskop verwendet. Das Infrarot-Mikroskop Axiovert 200M der Fa. Zeiss ist mit einer ORCA-ER Hamamatsu Digital-Kamera ausgestattet und ermöglicht Aufnahmen im Absorptions- und Emissionswellenlängen-Bereich von Cy5.5. Die Aufnahme und Bearbeitung der Bilder erfolgte mit der Software AxioVs40 (Version 4.4.1.0) der Fa. Zeiss. 


\section{Ergebnisse}

Das Bax Inhibitor-1 (BI-1)-Gen ist als differentiell exprimiertes Gen im Prostatakarzinom mit Hilfe der Atlas ${ }^{\mathrm{TM}}$ Array-Technologie identifiziert worden. Mittels quantitativer real time RT-PCR an Gesamt-RNA aus lasergestützten Mikrodissektaten von zusammengehörigen Normal- und Tumor-Prostatageweben epithelialen Ursprungs wurde gezeigt, dass BI-1 in 11 von 17 untersuchten Fällen (> Faktor 2) im Tumor überexprimiert wird. Die spezifische Herunterregulierung der BI-1-Expression durch RNA-Interferenz führte zur Apoptose in humanen Prostatakarzinomzellen (Grzmil et al., 2003). In der vorliegenden Arbeit sollten die Funktion von BI-1 und deren putative Interaktionspartner in humanen Karzinomzellen näher untersucht werden. Die Daten von Abschnitt 3.1 und 3.2 wurden unter Mitautorenschaft in Grzmil et al. (2006) veröffentlicht.

\subsection{Nachweis der BI-1-Expression in verschiedenen Tumoren}

Zunächst wurde die BI-1-Genexpression in verschiedenen Tumoren untersucht. Dazu wurde der Cancer Profiling Array von Clontech verwendet. Auf diesem Array befinden sich cDNAs von 241 Tumor- und korrespondierenden Normalgeweben von Patienten, sowie cDNAs von 9 Krebszelllinien. Für die Hybridisierung wurde ein humanes BI-1 cDNA-Fragment (Nukleotidposition 41 bis 754 der mRNA-Sequenz (NCBI: NM_003217)) verwendet. Das BI-1-cDNA-Fragment wurde mit dem Restriktionsenzym EcoRI aus dem pGEM-Teasy Vektor isoliert und radioaktiv markiert (siehe Material und Methoden). Nach der Hybridisierung wurden die Signale nach 24 Stunden Exposition im Phosphorimager quantifiziert (Abb. 3.1, A, B). Bei der Auswertung wurde die BI-1 Signalstärke der Tumoren und der korrespondierenden Normalgewebe von einzelnen Patienten ins Verhältnis gesetzt.

Eine Hochregulierung der BI-1-Expression wurde bei Mammakarzinomen (15 von 50 Patienten), Uteruskarzinomen (14 von 42 Patienten) und Ovarialkarzinomen (7 von 14 Patienten) gefunden. Eine Herunterregulierung der BI-1-Expression von 50\% oder mehr 
wurde im Magenkrebs (13 von 28 Patienten), Darmkrebs (13 von 34 Patienten), Nierenkrebs (11 von 20 Patienten), Lungenkrebs (9 von 21 Patienten) und Rektumkrebs (4 von 18 Patienten) detektiert.

Die stärkste Hochregulierung des BI-1-Gens wurde beim Mammakarzinom nachgewiesen. Das durchschnittliche Expressionsverhältnis von Tumor- zu Normalgewebe betrug dabei $3,2 \pm 2,4$ und zeigte damit eine bis $\mathrm{zu}$ 11,8-fache Hochregulierung der BI-1-Expression. Ovarial- und Uteruskrebsgewebe zeigten ein durchschnittliches BI-1-Expressionsverhältnis von Tumor- und Normalgewebe von 3,1 $\pm 1,2$ bzw. 2,5 $\pm 0,4$. Der Faktor der Hochregulierung des BI-1-Expression im Tumorgewebe betrug bis zu 4,8 bzw. 3,3 .

Die stärkste Herunterregulierung der BI-1-Expression wurde in Nieren-, Magen- und Lungenkrebs gefunden. Das durchschnittliche Verhältnis des BI-1-Signals von Tumorzu Normalgewebe beträgt hier das 2,38-, 2,33- und 2,27-fache. Dies entspricht einer Herunterregulierung um das 4,17-, 6,25- und 3,23-fache. In Darm- und Rektumkrebs betrugen die durchschnittlichen BI-1-Expressionsverhältnisse jeweils 2,13 wobei Herunterregulierungen der BI-1-Expression um das 3,4- und 2,63-fache in diesen Tumoren erreicht wurden. 
A

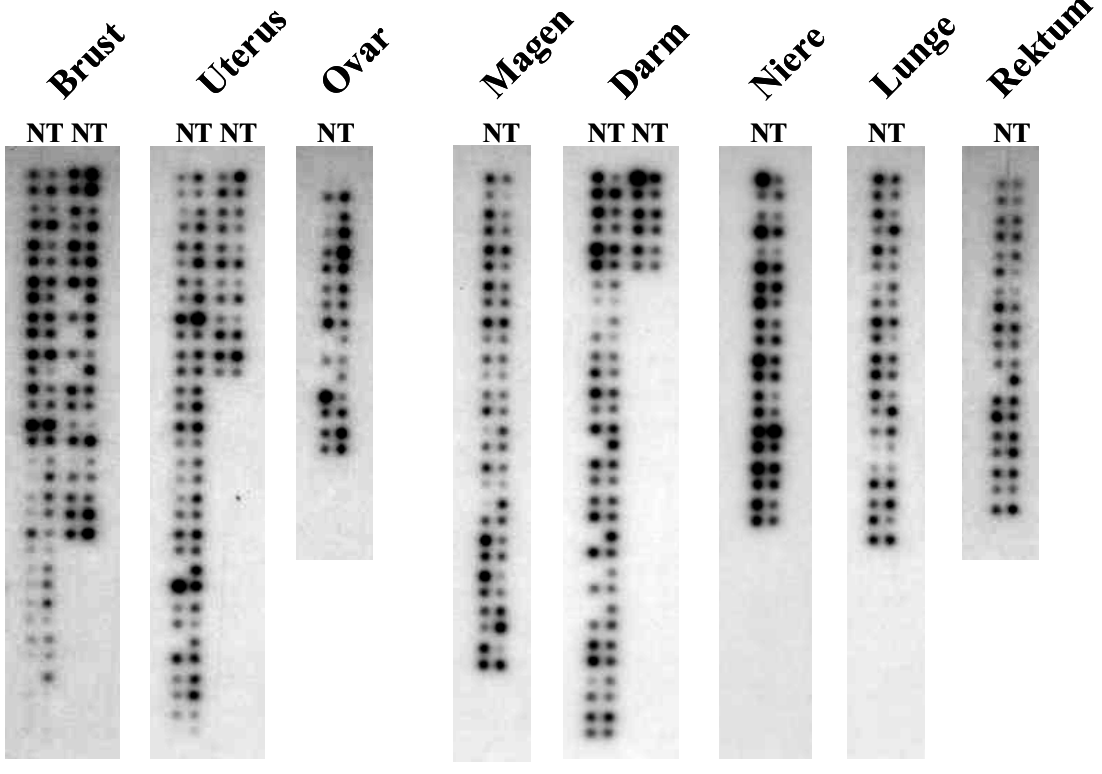

B

\begin{tabular}{lccccccc}
\hline Tumor & \multicolumn{2}{c}{ Hochregulierte BI-1 Expression } & \multicolumn{2}{c}{ Herunterregulierte BI-1 Expression } & $\begin{array}{c}\text { Keine } \\
\text { Unterschiede }\end{array}$ \\
& $\begin{array}{c}\text { Anzahl } \\
\text { der } \\
\text { Patienten }\end{array}$ & $\begin{array}{c}\text { Verhältnis } \\
\pm \text { SD }\end{array}$ & Faktor & $\begin{array}{c}\text { Anzahl der } \\
\text { Patienten }\end{array}$ & $\begin{array}{c}\text { Verhältnis } \pm \\
\text { SD }\end{array}$ & Faktor & $\begin{array}{c}\text { Anzahl der } \\
\text { Patienten }\end{array}$ \\
\hline Brust & $\mathbf{1 5}$ & $3,21 \pm 2,45$ & $2-11,8$ & 5 & $0,47 \pm 0,07$ & $0,40-0,5$ & 30 \\
Uterus & $\mathbf{1 4}$ & $2,55 \pm 0,46$ & $2-3,36$ & 2 & $0,49 \pm 0,02$ & $0,48-0,5$ & 26 \\
Ovar & $\mathbf{7}$ & $3,12 \pm 1,25$ & $2-4,85$ & 2 & $0,34 \pm 0,23$ & $0,17-0,5$ & 5 \\
Magen & 3 & $4,27 \pm 1,57$ & $3-6,05$ & $\mathbf{1 3}$ & $0,43 \pm 0,14$ & $0,16-0,5$ & 12 \\
Darm & 2 & $2,73 \pm 0,93$ & $2-3,39$ & $\mathbf{1 3}$ & $0,47 \pm 0,08$ & $0,29-0,5$ & 19 \\
Niere & 0 & - & - & $\mathbf{1 1}$ & $0,42 \pm 0,11$ & $0,24-0,5$ & 9 \\
Lunge & 4 & $2,35 \pm 0,06$ & $2-2,41$ & $\mathbf{9}$ & $0,44 \pm 0,10$ & $0,31-0,5$ & 8 \\
Rektum & 1 & 2,3 & - & $\mathbf{4}$ & $0,47 \pm 0,05$ & $0,38-0,5$ & 13 \\
\hline
\end{tabular}

Abb. 3.1: Expression der BI-1 mRNA in verschiedenen humanen Tumoren. Der Cancer Profiling Array (Clontech) wurde mit einer BI-1-cDNA-Sonde hybridisiert. Die Signale von verschiedenen Tumoren und den dazugehörigen Normalgeweben von einzelnen Patienten wurden nach 24 Stunden Expositionszeit eingescannt und mit Hilfe eines Phosphorimager verglichen. (A) Cancer Profiling ArrayMembran nach Hybridisierung mit einer BI-1-cDNA-Sonde. Die BI-1-Expressionsstärke in verschiedenen Tumoren ( $\mathrm{T}$ ) wurde mit dem dazugehörigen Normalgewebe (N) verglichen. (B) Ergebnisse der Expressionsanalyse von BI-1 in verschiedenen Tumoren mittels eines Cancer Profiling Arrays. Dargestellt ist die Anzahl der Patienten mit hoch- oder herunterregulierter Expression des BI-1Gens in den verschiedenen Tumoren verglichen mit dem korrespondierenden Normalgewebe, sowie das Verhältnis der BI-1-Signalstärken von Tumor- und Normalgewebe. 


\subsubsection{Nachweis der BI-1-Expression in humanen Mammakarzinomzellen}

Die Untersuchung der Expression des BI-1-Proteins in verschiedenen Mammakarzinomzellinien wurde mittels Western Blot-Analyse mit einem BI-1 spezifischen Antikörper durchgeführt. Gesamt-Proteinextrakte der humanen Mammakarzinomzelllinien MDA-MB-231, MDA-MB-453, MCF-7, HCC70, ZR-75-1 und T-47D wurden isoliert und einer Western Blot-Analyse unterzogen. Das BI-1Protein mit einer Größe von ca. 26 kDa konnte in allen sechs Zelllinien nachgewiesen werden. Die Mammakarzinomzellen MDA-MB-453, HCC70 und T-47D zeigten eine deutlich stärkere Expression von BI-1 im Vergleich zu den MCF-7-, ZR-75-1- und MDA-MB-231-Zellen (Abb. 3.2). Zum Nachweis der aufgetragenen Proteinmengen wurde die Membran mit einem Antikörper gegen $\alpha$-Tubulin rehybridisiert. Zur Quantifizierung der Expressionsstärke von BI-1 wurde die Intensität der Banden beider Proteine mit der Quantity One-Software ermittelt und zueinander ins Verhältnis gesetzt (Abb. 3.2, B). 

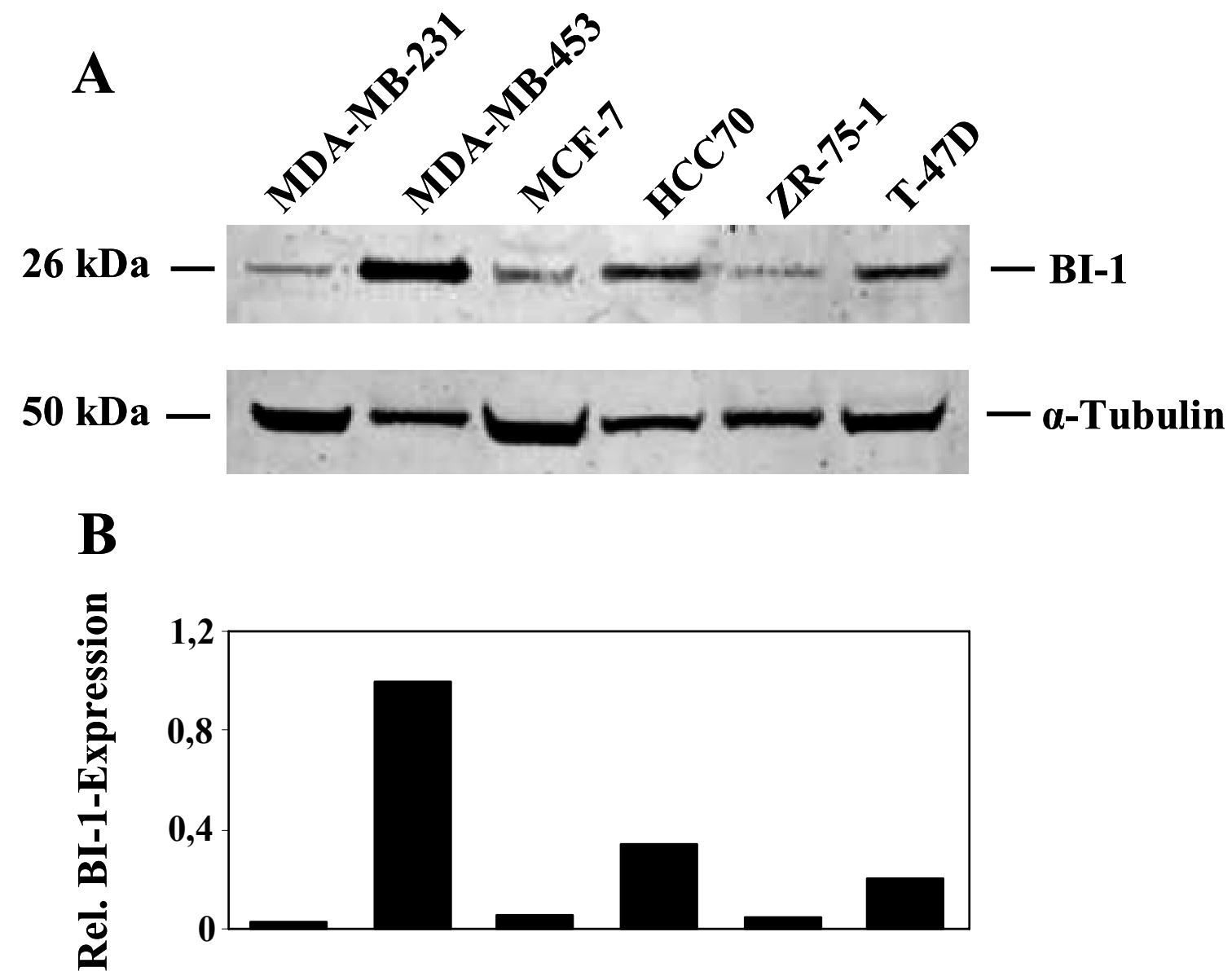

Abb. 3.2: Expressionsanalyse von BI-1 an humanen Mammakarzinomzelllinien mittels Western Blot unter Verwendung eines BI-1 spezifischen Antikörpers. (A) Für die Western Blot-Analyse wurden Gesamt-Proteinextrakte aus MDA-MB-231-, MDA-MB-453-, MCF-7-, HCC70-, ZR-75-1- und T-47D-Zellen verwendet. Eine starke BI-1-Expression ist bei MDA-MB-453-, HCC70- und T-47DZellen zu beobachten, während MCF-7-, ZR-75-1- und MDA-MB-231-Zellen eine schwache Expression zeigen. Zum Nachweis der aufgetragenen Proteinmengen wurde der Western Blot mit einem Antikörper gegen $\alpha$-Tubulin rehybridisiert. (B) Graphische Darstellung des Verhältnisses der Expressionsstärke von BI-1 und $\alpha$-Tubulin in den aufgeführten Mammakarzinomzellen. 


\subsection{Herunterregulierung der BI-1-Expression in den humanen Mammakarzinomzelllinien MCF-7, T-47D und MDA-MB-231 mittels RNA-Interferenz}

Um die mögliche Funktion von BI-1 in den Östrogen-unabhängigen MDA-MB-231Zellen sowie in den Östrogen-abhängigen MCF-7- und T-47D-Zellen zu untersuchen, wurde die BI-1-Genexpression mittels RNA-Interferenz herunterreguliert. Dazu wurden die MDA-MB-231-, MCF-7- und T-47D-Zellen mit BI-1-sequenzspezifischen Duplex(siRNA)-Oligonukleotiden transfiziert. Als Negativkontrolle wurden sequenzspezifische Duplex-siRNA-Oligonukleotide für das Luciferase-Gen von Photinus pyralis für die Transfektion verwendet.

\subsubsection{Herunterregulierung der BI-1-Expression in Mammakarzinomzellen mit Hilfe BI-1-spezifischer siRNA}

Aus den Mammakarzinomzellen MDA-MB-231, MCF-7 und T-47D wurden 45 Stunden nach der Transfektion mit BI-1-spezifischer siRNA Gesamt-Proteine extrahiert, um die Herunterregulierung der BI-1-Expression auf Proteinebene nachzuweisen. Als weitere Kontrollen wurden ebenfalls Gesamt-Proteine von unbehandelten parentalen Zellen und mit Luciferase-spezifischer siRNA transfizierten Zellen extrahiert.

Die Herunterregulierung der BI-1-Expression in mit BI-1-spezifischer siRNA transfizierten MDA-MB-231-, MCF-7- und T-47D-Zellen wurde auf Proteinebene mittels Western Blot-Analyse unter Verwendung eines polyklonalen BI-1-Antikörpers nachgewiesen. Die Expression von BI-1 konnte durch die Transfektion mit BI-1spezifischer siRNA reduziert werden, wohingegen die Transfektion mit Luciferasespezifischer siRNA zu keiner Veränderung der BI-1-Expression führte (Abb. 3.3). Zum Nachweis der aufgetragenen Proteinmengen wurde die Western Blot-Membran mit einem Antikörper gegen $\alpha$-Tubulin rehybridisiert. Durch den Vergleich der Expressionsstärke von BI-1 und $\alpha$-Tubulin konnte eine Reduktion der BI-1Expressionsstärke von 50\% - 80\% ermittelt werden. 


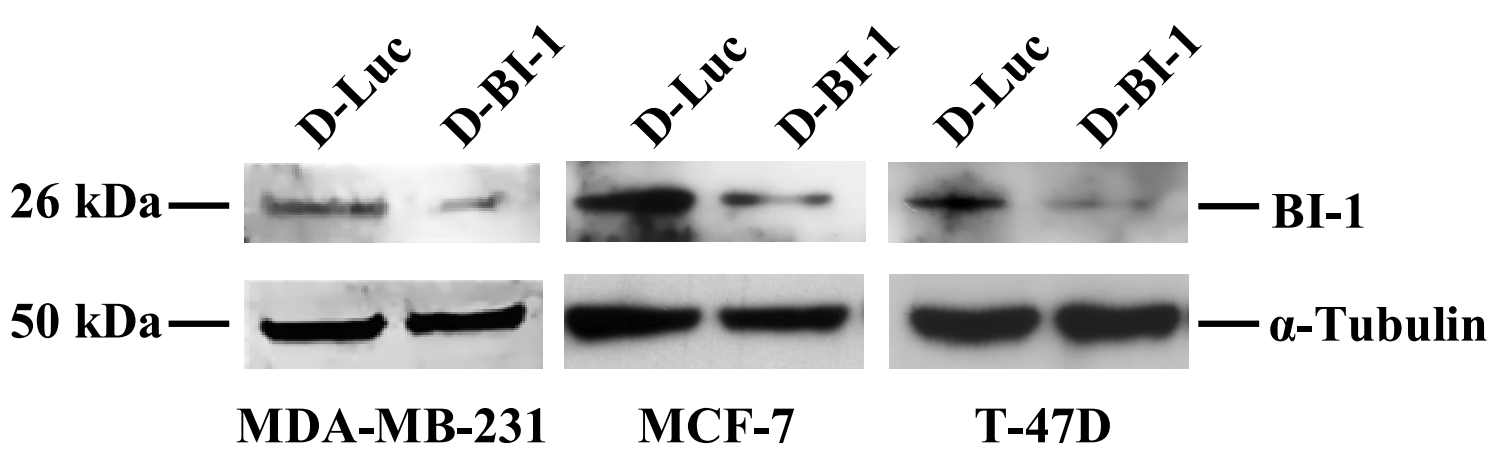

Abb. 3.3: Western Blot-Analyse zur Verifizierung der Herunterregulierung der BI-1-Expression mittels siRNA im MDA-MB-231-, MCF-7- und T-47D-Zellen. 45 Stunden nach der Transfektion mit BI-1-spezifischer siRNA (D-BI-1) konnte eine deutlich reduzierte BI-1-Expression in den Zellen im Vergleich zu mit Luciferase-spezifischer siRNA (D-luc) transfizierten Zellen nachgewiesen werden. Um die eingesetzten Proteinmengen zu vergleichen, wurde die Membran mit einem $\alpha$-Tubulin-spezifischen Antikörper rehybridisiert.

\subsubsection{Apoptoseinduktion in Mammkarzinomzellen nach Transfektion mit BI-1- spezifischer siRNA}

Um den Einfluss einer reduzierten BI-1-Expression auf die Vitalität der MCF-7-, T47D- und MDA-MB-231-Zellen zu untersuchen, wurde die zelluläre Apoptoserate gemessen. Dazu wurden die mit BI-1-spezifischer siRNA transfizierten MCF-7-, T47D- und MDA-MB-231-Zellen nach 45, 72 und 96 Stunden fixiert und mit einem gegen aktive Caspase-3 gerichteten Antikörper und DAPI gefärbt (Abb. 3.4 C und D). Als Negativkontrolle wurden die MCF-7-, T-47D- und MDA-MB-231-Zellen mit siRNA gegen das Luciferase-Gen transfiziert.

Die DAPI-Färbung wurde durchgeführt, um z.B. Apoptose-typische Veränderungen im Zellkern wie Fragmentierung oder Kondensierung unter dem Fluoreszenzmikroskop sichtbar zu machen (Abb. 3.4 A und B).

Zur Bestimmung der Apoptoserate wurden in fünf zufällig gewählten Sichtfeldern die Gesamt-Zellzahl sowie die Caspase-3 (aktiv)-positiven Zellen bestimmt. In Abb. 3.4 E ist zu sehen, dass die Anzahl der apoptotischen MDA-MB-231-Zellen 45 Stunden nach 
der Transfektion auf 10\% ansteigt. 72 bzw. 96 Stunden nach der Transfektion erhöht sich die Anzahl auf 17\% bzw. 32\%. Die Apoptoserate bleibt bei MCF-7-Zellen konstant bei 3 - 5\% und bei T-47D-Zellen bei 5 - 8\%. Bei den kontrolltransfizierten Zellen und bei den unbehandelten parentalen Zellen liegt die Apoptoserate im beobachteten Zeitraum bei $1-5 \%$. 

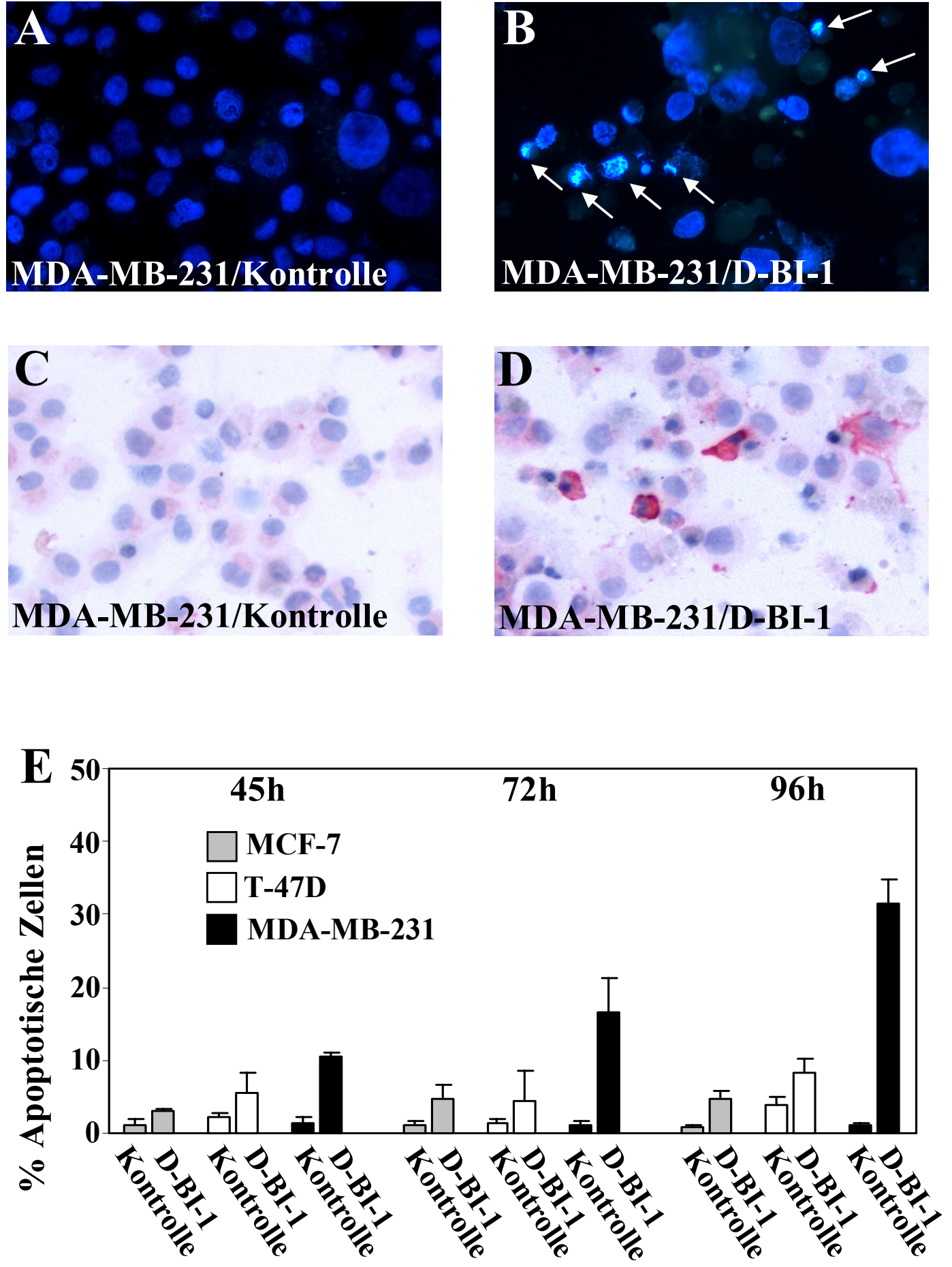

Abb. 3.4: Induktion der Apoptose bei humanen Mammakarzinomzellen durch Transfektion mit BI-1-spezifischer siRNA. MCF-7-, T-47D- und MDA-MB-231-Zellen wurden mit $150 \mathrm{nmol} / 1$ DuplexsiRNA-Oligonukleotiden (D-BI-1) transfiziert und nach 45, 72 und 96 Stunden geerntet. Als Negativkontrolle wurden MCF-7-, T-47D- und MDA-MB-231-Zellen (D-luc) verwendet, die mit DuplexsiRNA-Oligonukleotiden gegen das Luciferase-Gen transfiziert wurden. Die zytozentrifugierten Zellen wurden anschließend mit einen polyklonalem Caspase-3 Antikörper bzw. DAPI gefärbt. (A) zeigt die 
DAPI-Färbung an Kontroll- und (B) an D-BI-1-transfizierten MDA-MB-231-Zellen. Eine große Anzahl an apoptotischen Zellen (weiße Pfeile) wurde in den mit BI-1-spezifischer Duplex-siRNA behandelten Zellen beobachtet. (C) zeigt die immunzytochemische Analyse der Expression von aktive Caspase-3 in Kontroll- und (D) die D-BI-1-transfizierten MDA-MB-231-Zellen. Der Caspase-3-Nachweis ist durch die Rotfärbung des Zytoplasmas zu erkennen. Bei den BI-1-siRNA behandelten Zellen ist eine größere Anzahl an Caspase-3-positiven Zellen im Vergleich zu den kontrolltransfizierten Zellen zu beobachten. Die grafische Zusammenfassung (E) zeigt den prozentualen Anteil apoptotischer Zellen zu verschiedenen Zeitpunkten. Die prozentualen Anteile der Caspase-3-positiven und DAPI-gefärbten apoptotischen Zellen wurden durch Auszählen von fünf zufällig gewählten Sichtfeldern (100-fache Vergrößerung unter Hellfeld-Mikroskopie bei Caspase-3-Färbung und 200-facher Vergrößerung unter dem UV-Mikroskop bei DAPI-Färbung) bestimmt.

\subsection{Identifikation von BI-1-Interaktionspartnern}

\subsubsection{Verwendung des Yeast-Two-Hybrid-Systems zur Identifikation von BI-1 Interaktionspartnern}

Für die Analyse der zellulären Signaltransduktion von BI-1 sollten über das Matchmaker GAL4 Two-Hybrid System 3 (Clontech Heidelberg, Deutschland) potentielle Interaktionspartner von BI-1 identifiziert werden. Zur Generierung des „Bait“-Plasmids wurde der gesamte offene Leserahmen des humanen BI-1 (Nukleotidposition 41 bis 754 der mRNA-Sequenz (NCBI: NM_003217)) unter Beibehaltung des Leserasters an den C-Terminus der GAL-4 DNA-Bindungsdomäne in den pGBKT7-Vektor kloniert (Abb. 3.5). 


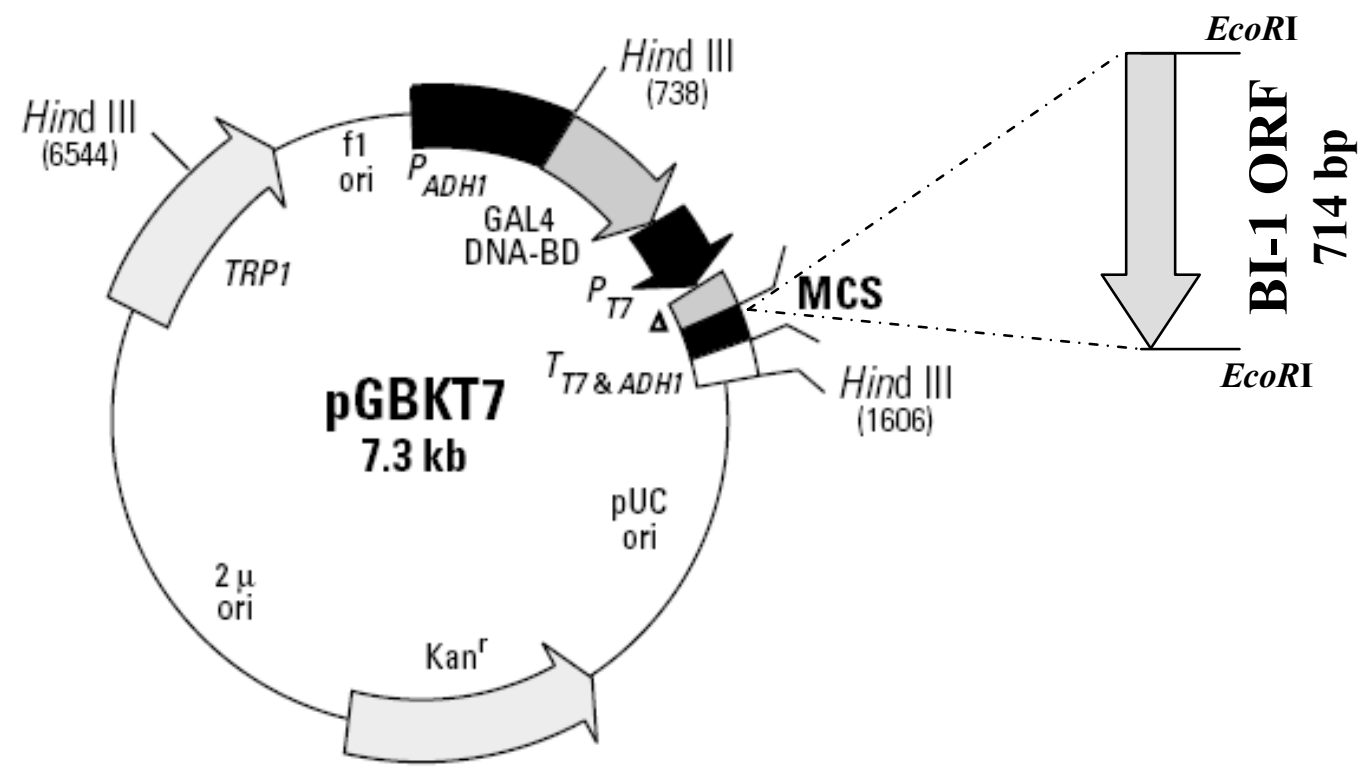

$\Delta$ c-Myc epitope tag

Abkürzungen:

f1 ori

f1 Bakteriophagen Replikationssignal

$\mathrm{P}_{\mathrm{ADH} 1}$

Trunkierter S. cerevisiae ADH1 Promotor

GAL4 DNA-BD

GAL4 DNA Bindungsdomäne

$\mathrm{P}_{\mathrm{T} 7}$

T7 RNA Polymerase Promotor

MCS

Multiple cloning site

$\mathrm{T}_{\mathrm{T} 7 \& \mathrm{ADH} 1}$

Transkriptions-Terminierungssignal für T7 und ADH1

pUC ori

pUC Plasmid Replikationssignal

$\mathrm{Kan}^{\mathrm{r}}$

Kanamycin-Resistenzgen

$2 \mu$ ori

Hefe $2 \mu$ Replikationssignal

TRP1

TRP1 Kodierungssequenz

Abb. 3.5: Schematische Darstellung des für das Yeast-Two-Hybrid-Experiment verwendeten „Bait“-Vektors pGBKT7-BI-1. Der komplette offene Leserahmen von BI-1 (NCBI: NM_003217) wurde in die EcoRI-Schnittstelle des Vektors pGBKT7 einkloniert und für das Yeast-Two-HybridExperiment verwendet (Vektorkarte modifiziert nach Clontech).

Der „Bait"-Vektor pGBKT7-BI-1 wurde in den Saccharomyces cerevisiae AH109Hefe-Stamm transformiert. Anschließend wurde eine humane Prostata-cDNABibliothek im pACT2-Vektor von Matchmaker in die vortransformierte Hefe eingebracht. Die etwa 200 resultierenden positiven Hefe-Kolonien wurden über ein hoch-stringentes Nährmedium (-Leu, -Try, -His, -Ade) selektiert und über das 
identische hochstringente Nährmedium mit X- $\alpha$-Gal-Zusatz zum Nachweis der $\alpha$ Galaktosidase-Aktivität verifiziert. Aus den resultierenden blau angefärbten HefeKolonien wurde Plasmid-DNA isoliert und das Insert unter der Verwendung der Matchmaker AD LD-Insert Screening Amplimer Primer (Clontech) amplifiziert und sequenziert. Insgesamt wurden 45 spezifische cDNA-Sequenzen ermittelt, die mit Hilfe des NCBI Blast Programms (Altschul et al., 1990) mit den Sequenzdaten der Gendatenbank (NCBI) verglichen wurden. Die identifizierten Interaktionspartner von BI-1 wurden hinsichtlich ihrer zellulären Lokalisation und Funktion in der Zelle sowie ihrer möglichen Bedeutung für die Apoptose in den öffentlichen Datenbanken (siehe Abschnitt 2.11) untersucht.

\subsubsection{Beschreibung der identifizierten BI-1-Interaktionspartner aus dem Yeast- Two-Hybrid-Experiment im Hinblick auf ihre Funktion bei der Apoptose}

Um die aus dem Yeast-Two-Hybrid-Experiment identifizierten cDNA-Sequenzen für weiterführende Experimente einzugrenzen, wurden die Literaturdaten der putativen BI1-Interaktionspartner im Hinblick auf den BI-1-involvierten Apoptose-Signalweg näher analysiert. Die folgenden aufgelisteten Gene wurden mit dem intrinsischen ApoptoseSignalweg (Typ II) in Verbindung gebracht, in den auch BI-1 involviert ist (Xu et al., 1998), und somit für eine engere Wahl eingegrenzt (Tab. 3.1). Das Gen Death InducerObliterator 1 (DIO-1) wurde für weiterführende Experimente ausgewählt. DIO-1 stellt ein proapoptotisches Protein dar und ist in den intrinsischen Apoptose- Signalweg involviert (Garcia-Domingo et al., 2003).

\begin{tabular}{|l|l|l|l|}
\hline $\begin{array}{l}\text { Accession } \\
\text { Nummer }\end{array}$ & Gen & $\begin{array}{l}\text { Lokalisation/ } \\
\text { Funktion }\end{array}$ & Literatur \\
\hline NM_022105 & $\begin{array}{l}\text { Death Inducer- } \\
\text { Obliterator 1; DIO-1; } \\
\text { DIDO-1 }\end{array}$ & $\begin{array}{l}\text { Hauptsächlich } \\
\text { Zytoplasma, in der prä- } \\
\text { apoptotischen Phase im } \\
\text { Nukleus / Pro-apoptotisch }\end{array}$ & $\begin{array}{l}\text { Garcia-Domingo et al., } \\
2003\end{array}$ \\
\hline \multirow{2}{*}{ NM_02715 } & $\begin{array}{l}\text { Protein phosphatase 2, } \\
\text { catalytic subunit, alpha } \\
\text { isoform PPP2CA }\end{array}$ & $\begin{array}{l}\text { Zytosol / in metabolischen } \\
\text { Signalwegen, Regulator im } \\
\text { Zellzyklus und Apoptose }\end{array}$ & $\begin{array}{l}\text { Deng et al., 1998; } \\
\text { Turowski et al., 1995; } \\
\text { Tamura et al., 2004 }\end{array}$ \\
\hline
\end{tabular}




\begin{tabular}{|c|c|c|c|}
\hline $\begin{array}{l}\text { Accession } \\
\text { Nummer }\end{array}$ & Gen & $\begin{array}{l}\text { Lokalisation/ } \\
\text { Funktion }\end{array}$ & Literatur \\
\hline NM_00484 & $\begin{array}{l}\text { Homolog of apoptosis- } \\
\text { specific protein; ASP; } \\
\text { APG5-Like, APG5L }\end{array}$ & $\begin{array}{l}\text { Zytoplasma } \\
\text { proapoptotische Funktion }\end{array}$ & $\begin{array}{l}\text { Grand et al., 1995; } \\
\text { Hammond et al., } 1998\end{array}$ \\
\hline NM_024969 & $\begin{array}{lr}\text { TGF-beta } & \text { induced } \\
\text { apoptosis } & \text { protein 2, } \\
\text { TAIP-2 } & \end{array}$ & $\begin{array}{l}\text { N.a. / proapoptotische } \\
\text { Funktion }\end{array}$ & T. Ota et al., 2004 \\
\hline AL592524 & $\begin{array}{l}\text { NADH-ubiquinone } \\
\text { oxidoreductase, } \\
\text { subunit ND2, MTND2 }\end{array}$ & $\begin{array}{l}\text { Mitochondrien; } \\
\text { Respiratorischer Komplex I / } \\
\text { NADH Oxidoreduktase } \\
\text { Aktivität }\end{array}$ & $\begin{array}{l}\text { Shoffner and Wallace, } \\
\text { 1995; Arizmendi et al., } \\
1992\end{array}$ \\
\hline AL672238 & $\begin{array}{l}\text { NADH-ubiquinone } \\
\text { oxidoreductase, } \\
\text { subunit ND3, MTND3 }\end{array}$ & $\begin{array}{l}\text { Mitochondrien; } \\
\text { respiratorischer Komplex I / } \\
\text { NADH Oxidoreduktase } \\
\text { Aktivität }\end{array}$ & $\begin{array}{l}\text { Shoffner and Wallace, } \\
\text { 1995; Arizmendi et al., } \\
1992\end{array}$ \\
\hline NM_005004 & $\begin{array}{l}\text { NADH-ubiquinone } \\
\text { oxidoreductase } 1 \text { beta } \\
\text { subcomplex } \\
\text { NDUFB8 }\end{array}$ & $\begin{array}{l}\text { Mitochondrien; } \\
\text { respiratorischer Komplex I / } \\
\text { NADH Oxidoreduktase } \\
\text { Aktivität }\end{array}$ & $\begin{array}{l}\text { Dunbar et al., 1997; } \\
\text { Loeffen et al., } 1998 ;\end{array}$ \\
\hline AL627169 & $\begin{array}{l}\text { ATP synthase 6; } \\
\text { MTATP6; Subunit } \\
\text { ATPase 6; ATP6 }\end{array}$ & $\begin{array}{l}\text { Mitochondrien } \\
\text { Synthese }\end{array}$ & $\begin{array}{l}\text { Yoneda et al., 1992; De } \\
\text { Coo et al., } 1996\end{array}$ \\
\hline
\end{tabular}

Tab. 3.1: Übersicht der identifizierten putativen BI-1-Interaktionspartner aus dem Yeast-TwoHybrid-Experiment. Insgesamt konnten 45 spezifische PCR-Produkt-Sequenzen mit der Gendatenbank verglichen werden. Davon werden 8 Sequenzen exemplarisch in der Tabelle dargestellt. Die Tabelle enthält die Accession-Nr. sowie den Gennamen, die zelluläre Lokalisation, die bisher bekannte Funktion in der Zelle sowie die jeweiligen Literaturangaben.

\section{4 Überprüfung und Charakterisierung der Interaktion zwischen BI- 1 und Death Inducer-Obliterator 1 (DIO-1)}

DIO-1 wurde im Yeast-Two-Hybrid-Screening als Interaktionspartner von BI-1 identifiziert. Die cDNA von DIO-1 (NM_022105) enthält einen offenen Leserahmen von 1689 bp Länge. Die DIO-1-cDNA kodiert für ein Protein von 562 Aminosäuren 
(NCBI: NP_071388) mit einem Molekulargewicht von 65 kDa. Das DIO-1-Protein besitzt zwei Kernlokalisationssignale (NLS) an den Aminosäurepositionen 165-180 (NLS1) und 190-199 (NLS2), sowie eine PHD-Typ-Zinkfinger-Domäne an der Aminosäureposition 268-322 (Abb. 3.6). Die mit Hilfe des Yeast-Two-Hybrid-Systems identifizierte Nukleotidsequenz ist im 3'-Bereich des offenen Leserahmens der DIO-1 cDNA lokalisiert (Nukleotidposition 1305-1958) und endet 57 bp vor dem Stopcodon TAA (Abb. 3.6A).

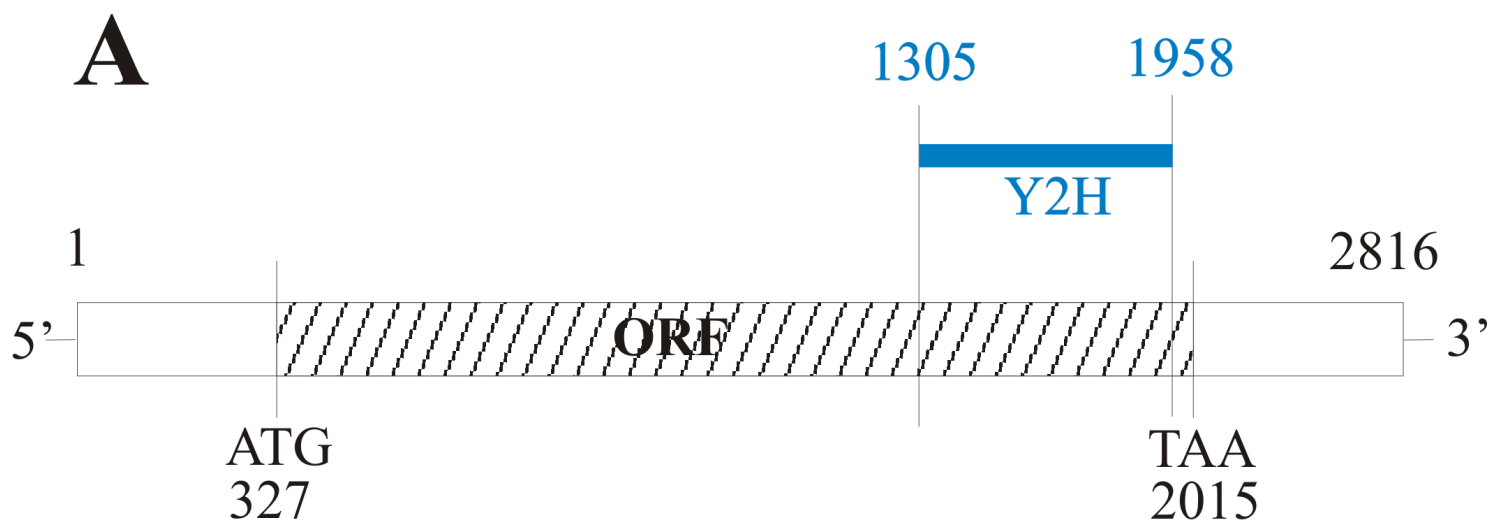

B

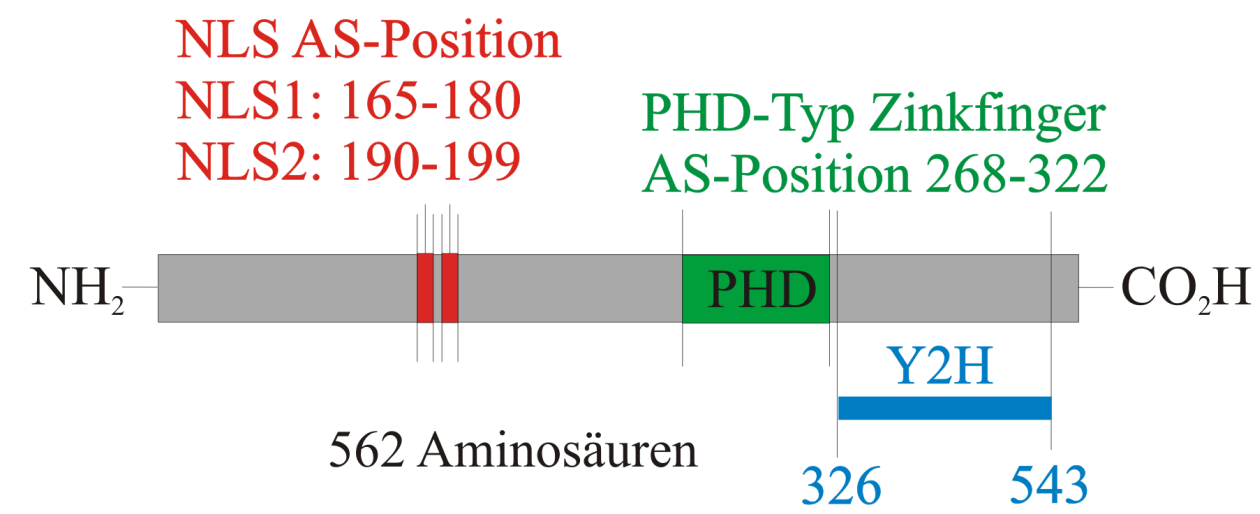

Abb. 3.6: Schematische Darstellung der cDNA- und Proteinsequenz von DIO-1. (A) Die vollständige humane DIO-1 cDNA-Sequenz (Genbank NM_022105) sowie die über das BI-1-Yeast-Two-HybridExperiment identifizierte cDNA-Sequenz (Nukleotidposition 1305-1958, blau dargestellt) sind aufgeführt. (B) Der offene Leserahmen (ORF) von DIO-1 kodiert für ein 562 Aminosäuren großes Protein, welches zwei Kernlokalisationssignale (Aminosäurepositionen 165-180 (NLS1) und 190-199 (NLS2), rot dargestellt) sowie eine PHD-Typ-Zinkfinger-Domäne (Aminosäureposition 268-322, grün dargestellt) enthält. 


\subsubsection{Nachweis der Interaktion von BI-1 und DIO-1 mittels Koimmunopräzipitation}

Um die Interaktion von BI-1 mit DIO-1 auch in vivo zu bestätigen, wurde eine Koimmunopräzipitation (CoIP) durchgeführt. Aus Mangel an gut funktionierenden BI1-Antikörpern wurde das BI-1-GFP-Konstrukt in die humanen PC-3Prostatakarzinomzellen transfiziert. Aus den PC-3-Zellen wurde anschließend GesamtProtein extrahiert und die Immunpräzipitation mit $1 \mathrm{mg}$ Protein durchgeführt. Dazu wurde ein GFP-spezifischer Antikörper und ein Protein A-/Protein G-Agarose-Gemisch verwendet. Das erhaltene Präzipitat wurde mit 2 x Sample- Puffer 10 min bei $95^{\circ} \mathrm{C}$ inkubiert. Anschließend wurden die Proteine über SDS-PAGE aufgetrennt und eine Western Blot-Analyse mit einem DIO-1-spezifischen Antikörper durchgeführt. Als Negativkontrolle wurde die Präzipitation ohne GFP-spezifischen Antikörper durchgeführt. Die Interaktion zwischen BI-1 und DIO-1 konnte jedoch nicht verifiziert werden. Das gleiche negative Ergebnis wurde erhalten, wenn für die Immunopräzipitation der DIO-1-spezifische und für die Western Blot-Analyse der GFPspezifische Antikörper eingesetzt wurde.

\subsubsection{Expressionsanalysen von DIO-1 in humanen Mamma- und Prostatakarzinom-Zelllinien}

Die Expression von DIO-1 wurde in humanen Mammakarzinomzelllinien MDA-MB231, MDA-MB-453, MCF-7, ZR-75-1, HCC-70, T-47D und in den humanen Prostatakarzinomzelllinien PC-3, LNCaP und DU-145 untersucht. Hierfür wurde aus den Mamma- und Prostatakarzinomzellen Gesamtprotein isoliert. Die Proteine (jeweils $50 \mu \mathrm{g})$ wurden über SDS-PAGE aufgetrennt. Anschließend wurde eine Western BlotAnalyse mit einem DIO-1-spezifischen Antikörper durchgeführt. In den Zelllinien MDA-MB-231, HCC-70, ZR-75-1, PC-3 und DU-145 konnte eine distinkte Bande in der Höhe der erwarteten Größe von 68 kDa für DIO-1 nachgewiesen werden. In den Zelllinien T-47D, MCF-7, MDA-MB-453 und LNCaP konnte dagegen nur eine schwache Bande in der Höhe der erwarteten Größe von DIO-1 detektiert werden (Abb. 3.7, A und B). Um zeigen zu können, dass identische Proteinmengen der verschiedenen 
Zelllinien eingesetzt wurden, wurde $\alpha$-Tubulin $(50 \mathrm{kDa})$ mit einem spezifischen Antikörper detektiert. Die Expressionsstärke wurde mit Hilfe der Quantity OneSoftware (siehe Material und Methoden) quantifiziert (Abb. 3.7, C). Die stärkste DIO-1Expression wurde in den Zelllinien MDA-MB-231, HCC-70, ZR-75-1, PC-3 und DU145, die schwächste Expression wurde in den Zelllinien T-47D, MCF-7, MDA-MB-453 und LNCaP festgestellt. 
A

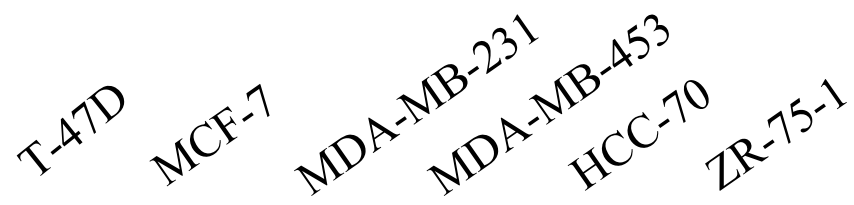

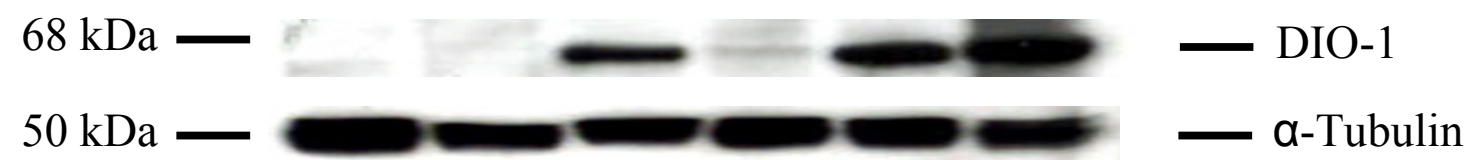

B

C

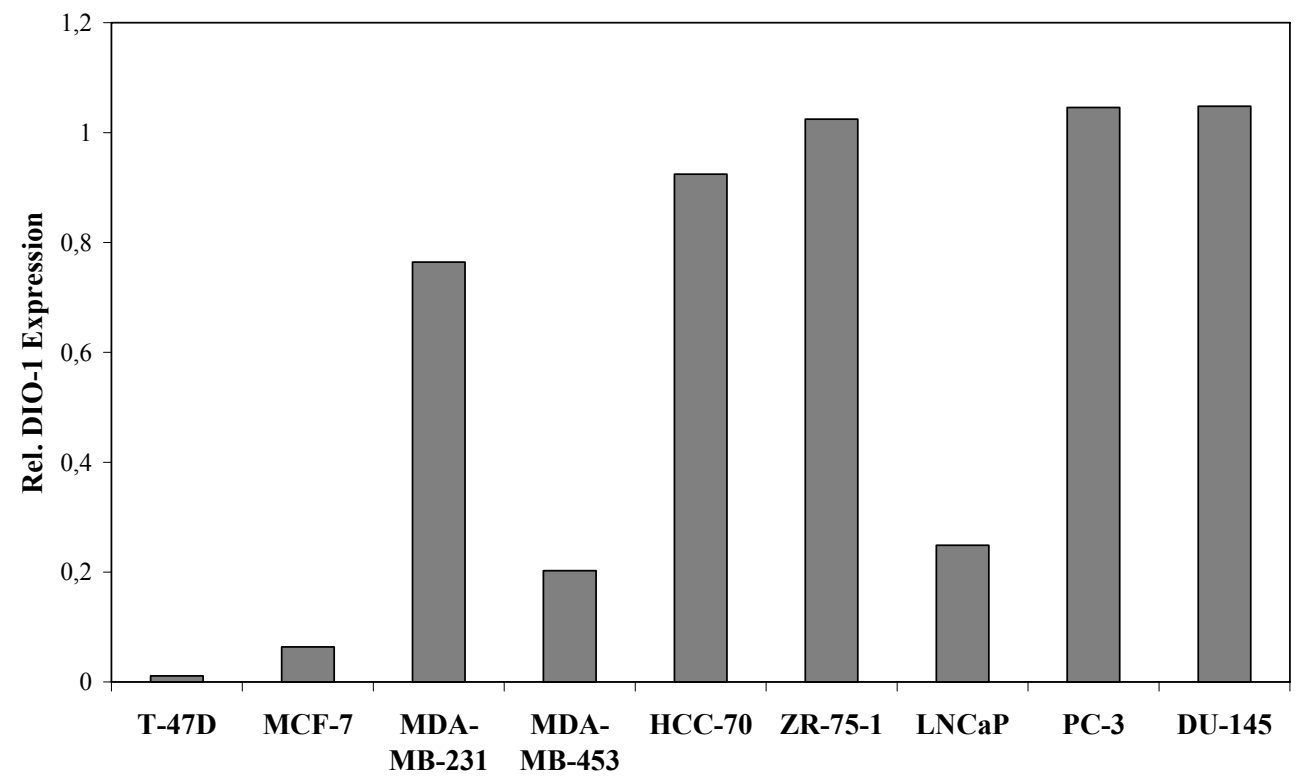

Abb. 3.7: Ergebnis der Expressionsanalyse von DIO-1 in humanen Mamma- und Prostatakarzinomzellen. (A) Die Gesamtproteinextrakte wurden aus verschiedenen humanen Mammakarzinomzelllinien isoliert und einer Western Blot-Analyse mit einem DIO-1-spezifischen Antikörper unterzogen. Eine starke DIO-1-Expression ist bei MDA-MB-231, HCC-70 und ZR-75-1Zellen zu beobachten, während MDA-MB-453-Zellen eine schwache DIO-1-Expression zeigen. Bei T47D- und MCF-7-Zellen ist die schwächste Expression von DIO-1 zu beobachten. (B) Die 
Gesamtproteine wurden aus den humanen Prostatakarzinomzelllinien LNCaP, PC-3 und DU-145 isoliert. Die stärkste Expression ist bei PC-3- und DU-145-Zellen zu beobachten, während LNCaP-Zellen eine schwache DIO-1-Expression zeigen. (C) Ergebnis der Quantifizierung der Expression von DIO-1. Die in (A) und (B) dargestellten Blots wurden eingescannt und mit Hilfe der Quantity One Software ausgewertet. Die relative Expression von DIO-1 ergibt sich aus der Bandenintensität von DIO-1 im Vergleich zu der von $\alpha$-Tubulin.

\subsubsection{Analyse zur subzellulären Kolokalisation von DIO-1-DsRed- und BI-1- GFP-Fusionsproteinen in Säugerzellen}

Für die subzelluläre Kolokalisation von BI-1 und DIO-1 wurde der komplette offene Leserahmen von BI-1 (714 bp) an den C-Terminus und alternativ auch an den NTerminus des GFP-(,green fluorescent protein“) in den pEGFP-C1-Vektor (Clontech) bzw. den pEGFP-N2-Vektor kloniert (Abb. 3.8). Durch die Klonierungen in den pEGFP-C1- und pEGFP-N2-Vektor sollte gezeigt werden, dass die subzelluläre Lokalisation des Fusionsproteins unabhängig von der N- oder C-terminalen Position des GFP-Proteins ist. Der komplette offene Leserahmen von DIO-1 (1689 bp) wurde an den N-Terminus des DsRed („Discosoma sp. red fluorescent protein“) in den pDsRed-N1Vektor (Clontech) kloniert (Abb. 3.9). 


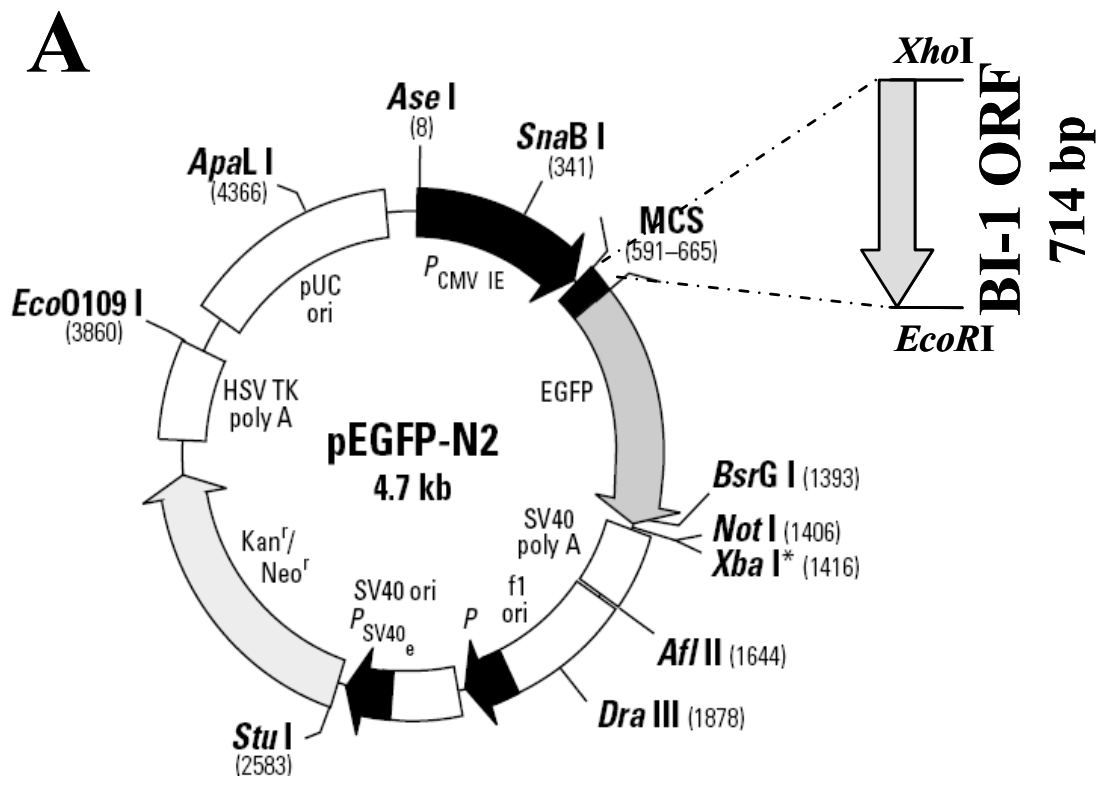

B

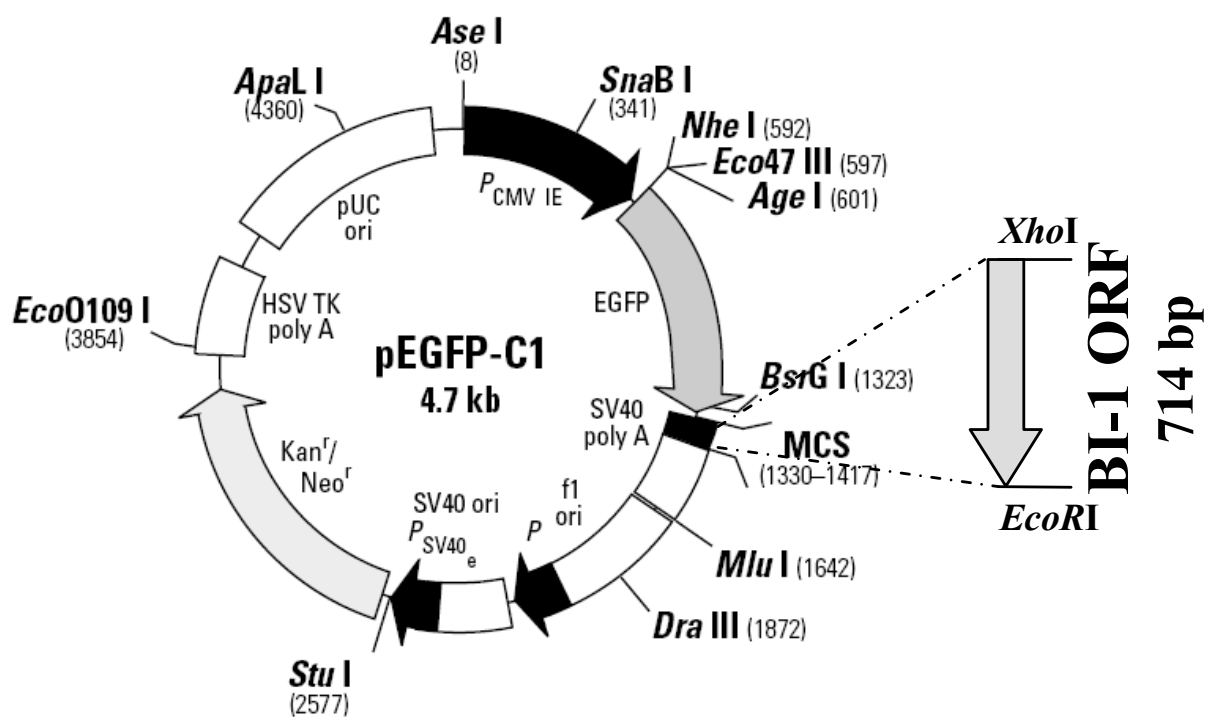

Abkürzungen:

f1 ori

f1 Bakteriophagen Replikationssignal

$\mathrm{P}_{\mathrm{CMV} \text { IE }}$

Human Cytomegalovirus (CMV) immediate early-Promotor

EGFP

Enhanced green fluorescent protein-Gen

$\mathrm{P}_{\mathrm{SV} 40}$

SV40 early-Promotor

MCS

Multiple cloning site

$\mathrm{T}_{\mathrm{T} 7 \& A D H 1}$

Transkriptions-Terminierungssignal für T7 und ADH1

pUC ori

pUC Plasmid-Replikationssignal

$\mathrm{Kan}^{\mathrm{r}} / \mathrm{Neo}^{\mathrm{r}}$

Kanamycin- / Neomycin-Resistenzgen

HSV TK poly A

Herpes simplex virus (HSV) thymidine kinase (TK) polyadenylation-Signal 
Abb. 3.8: Schematische Darstellung der für das subzelluläre Kolokalisationsexperiment verwendeten pEGFP-N2-BI-1- und pEGFP-C1-BI-1-Konstrukte. Der komplette offene Leserahmen von BI-1 (NCBI: NM_003217) wurde in die XhoI/EcoRI-Schnittstelle des Vektors pEGFP-N2 (A) und pEGFP-C1(B) einkloniert und für das Kolokalisationsexperiment verwendet (Vektorkarte modifiziert nach Clontech).

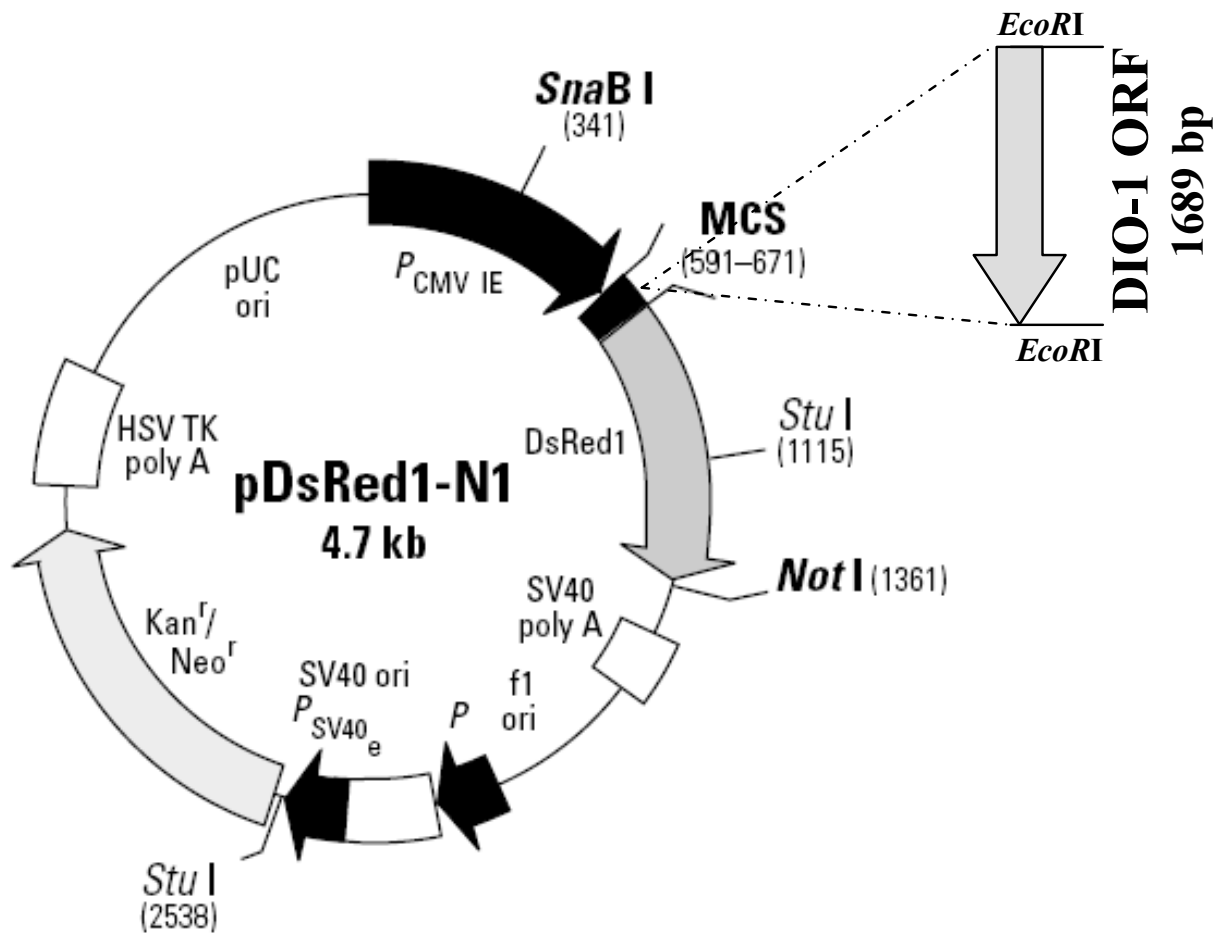

Abkürzungen:

f1 ori

f1 Bakteriophagen Replikationssignal

$\mathrm{P}_{\text {CMV IE }}$

Human Cytomegalovirus (CMV) immediate early-Promotor

DsRed1

Discosoma sp. Red1 protein-Gen

$\mathrm{P}_{\mathrm{SV} 40}$

SV40 early-Promotor

MCS

Multiple cloning site

$\mathrm{T}_{\mathrm{T7 \& ADH1}}$

Transkriptions-Terminierungssignal für T7 und ADH1

pUC ori

pUC Plasmid-Replikationssignal

$\mathrm{Kan}^{\mathrm{r}} / \mathrm{Neo}^{\mathrm{r}}$

Kanamycin- / Neomycin-Resistenzgen

HSV TK poly A

Herpes simplex virus (HSV) thymidine kinase (TK) polyadenylation-Signal

Abb. 3.9: Schematische Darstellung des für das subzelluläre Kolokalisationsexperiment verwendeten pDsRed1-N1-DIO-1-Konstrukts. Der komplette offene Leserahmen von DIO-1 (NCBI: NM_022105) wurde in die EcoRI-Schnittstelle des Vektors pDsRed1-N1 einkloniert und für das Kolokalisationsexperiment verwendet (Vektorkarte modifiziert nach Clontech). 
Circa 24 Stunden nach der Kotransfektion der o.g. BI-1- und DIO-1-Fusionskonstrukte in NIH3T3-Fibroblastenzellen der Maus wurden die Zellen fixiert und mit DAPI gefärbt.

90\% der transfizierten Zellen zeigten eine diffuse Verteilung im Zytoplasma. Dabei zeigten beide Fusionsproteine in der Überlagerung eine teilweise ausgeprägte Kolokalisation im Zytoplasma (Abb. 3.10).
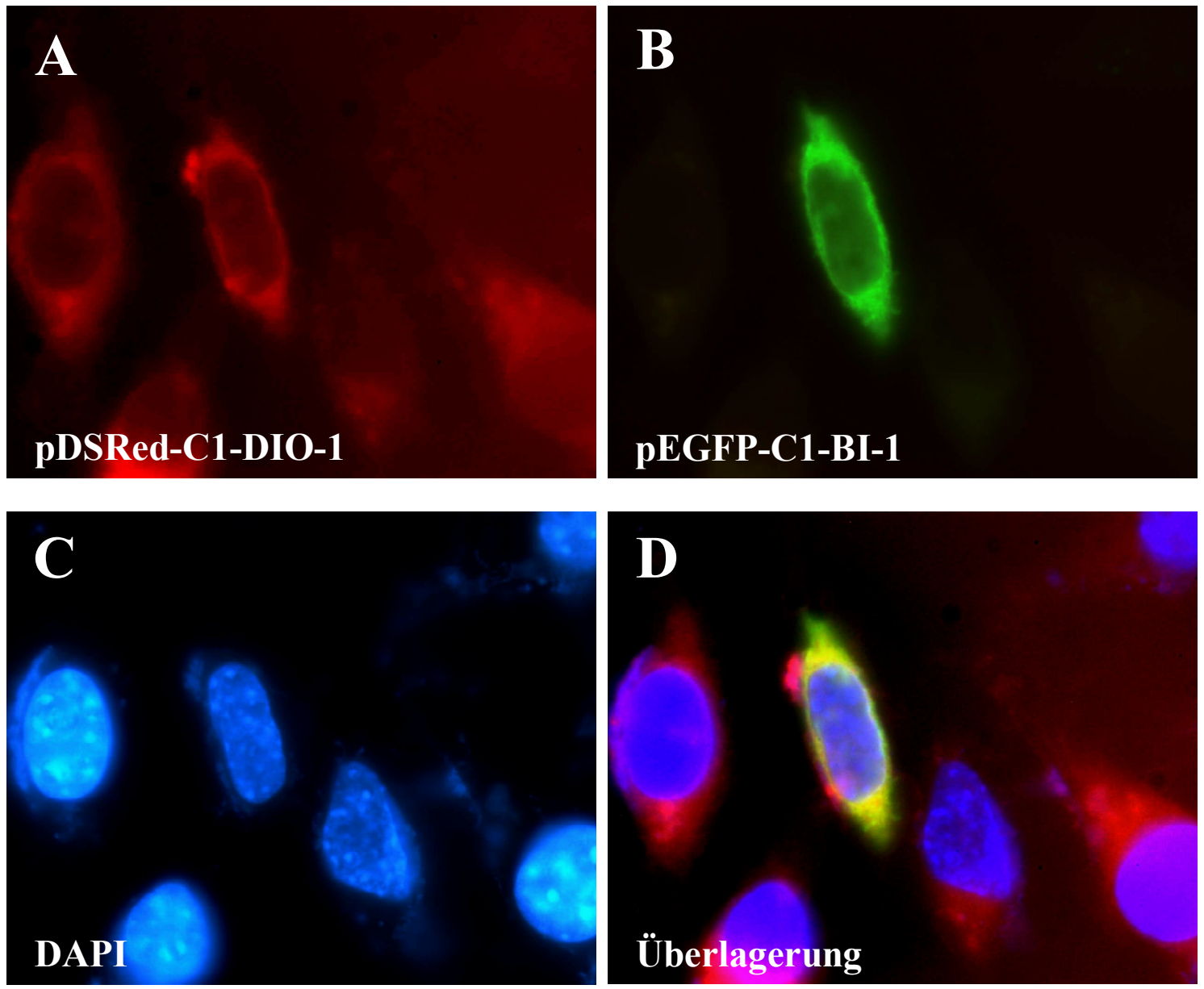

Abb. 3.10: Darstellung der subzellulären Kolokalisation der Fusionsproteine BI-1-GFP und DIO-1DSRed in NIH3T3-Fibroblastenzellen. NIH3T3-Zellen der Maus wurden transient mit den Plasmiden pDSRed-C1-DIO-1- und pEGFP-C1-BI-1- kotransfiziert, für $24 \mathrm{~h}$ inkubiert und anschließend fixiert. Bei etwa 90\% der kotransfizierten Zellen konnte eine diffuse Verteilung der Fusionsproteine im Zytoplasma beobachtet werden. (A) Das DIO-1 Fusionsprotein zeigt bei der Untersuchung unter einem Fluoreszenzmikroskop eine diffuse Verteilung im Zytoplasma. (B) Das BI-1-Fusionsprotein zeigt ebenfalls eine diffuse Verteilung im Zytoplasma. (C) Die Zellkerne wurden mit DAPI gegengefärbt. (D) Überlagerung der Bilder A-C. Die Überlagerung von DIO-1 und BI-1 zeigt eine teilweise ausgeprägte 
Übereinstimmung der zellulären Lokalisation im Zytoplasma. Alle Aufnahmen wurden bei 1000-facher Vergrößerung aufgenommen.

Sowohl das DIO-1-DsRed- als auch das BI-1-GFP-Fusionsprotein konnte in etwa 10\% der kotransfizierten Zellen im Zytoplasma als kugelförmige Struktur lokalisiert werden (Abb. 3.11).
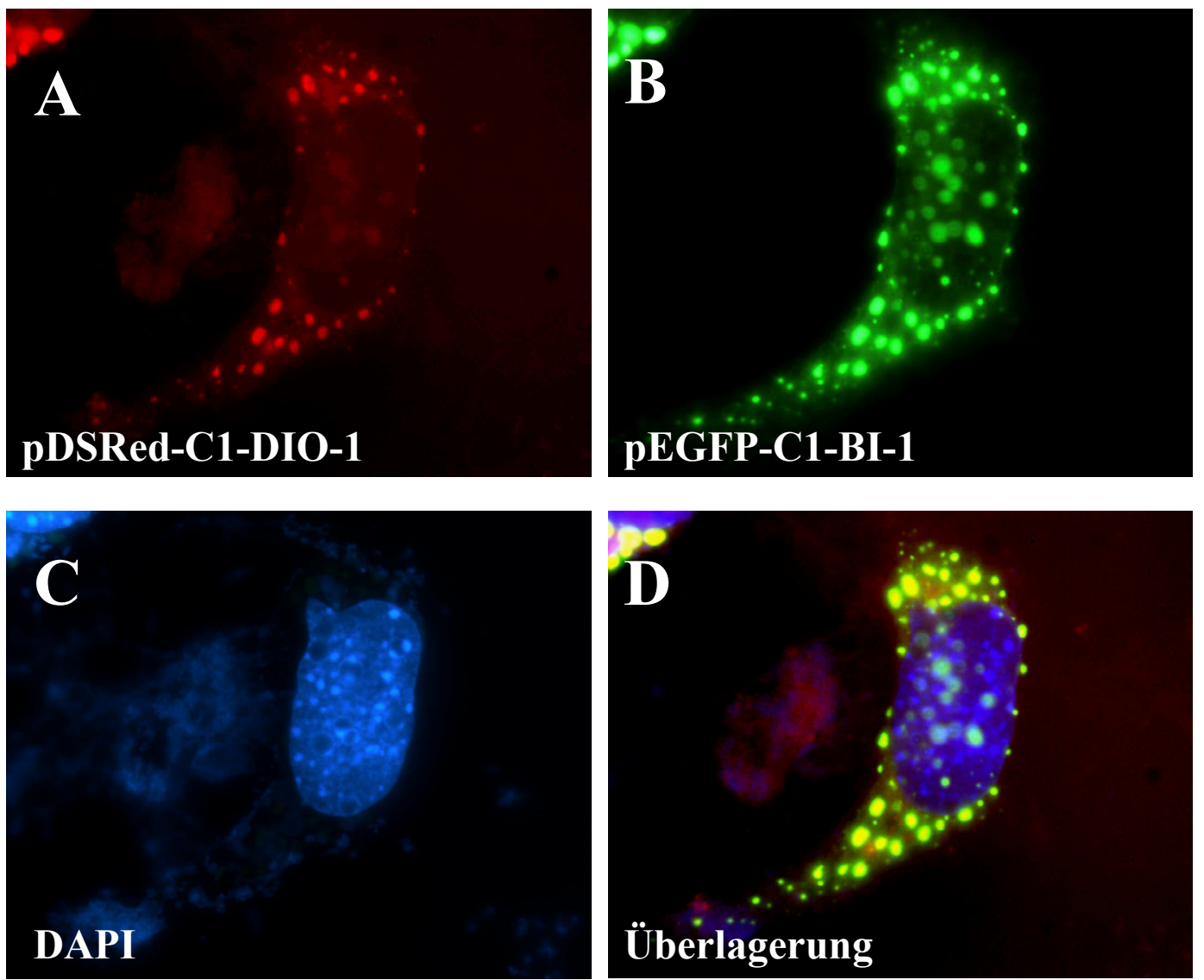

Abb. 3.11: Darstellung der subzellulären Kolokalisation der Fusionsproteine BI-1-GFP und DIO-1dsRed in NIH3T3-Fibroblastenzellen. NIH3T3-Zellen der Maus wurden transient mit den Plasmiden pDSRed-C1-DIO-1- und pEGFP-C1-BI-1- kotransfiziert, für $24 \mathrm{~h}$ inkubiert und anschließend fixiert. Bei etwa 10\% der kotransfizierten Zellen konnten die Fusionsproteine im Zytoplasma als kugelförmige Struktur detektiert werden. (A) Das DIO-1-Fusionsprotein zeigt bei der Untersuchung unter einem Fluoreszenzmikroskop eine Lokalisation im Zytoplasma in kugelförmiger Struktur. (B) Das BI-1Fusionsprotein zeigt ebenfalls eine kugelförmige Lokalisation im Zytoplasma. (C) Die Zellkerne wurden mit DAPI gegengefärbt. (D) Überlagerung der Bilder A-C. Die Überlagerung von DIO-1 und BI-1 zeigt eine hohe Übereinstimmung der zellulären Lokalisation im Zytoplasma. Alle Aufnahmen wurden bei 1000-facher Vergrößerung aufgenommen. 


\subsubsection{Analyse zur subzellulären Kolokalisation von BI-1-GFP-Fusionsproteinen und des endogenen DIO-1-Proteins mittels Immunzytochemie in Säugerzellen}

Um auszuschließen, dass die in Abschnitt 3.4.1 beschriebenen Kolokalisationsmuster im Zytoplasma von NIH3T3-Zellen zellspezifisch sind oder durch die Kotransfektion mit GFP- und DSRed-Fusionsproteine verursacht werden, wurden PC-3-Zellen mit dem BI-1-GFP-Fusionskonstrukt transfiziert und mit einen DIO-1-spezifischen Antikörper immunzytochemisch untersucht.

Dazu wurden PC-3-Prostatakarzinomzellen auf speziellen Objektträgern bis zu einer Konfluenz von 50\%- 80\% kultiviert. Anschließend wurden die Zellen transfiziert und auf dem Objektträger fixiert und das endogene DIO-1-Protein mittels Immunzytochemie mit einem DIO-1-spezifischen Antikörper detektiert.

Die Zellkerne der PC-3-Zellen wurden mit DAPI gegengefärbt. Die subzelluläre Lokalisation von DIO-1 wurde unter einem Fluoreszenz-Mikroskop ausgewertet.

Die kugelförmigen Kolokalisationsstrukturen konnten wiederum in etwa 10\% der BI-1GFP-transfizierten Zellen im Zytoplasma lokalisiert werden (Abb. 3.12, A-C). In den restlichen transfizierten Zellen konnte dagegen ebenfalls eine diffuse Verteilung im Zytoplasma beobachtet werden (Abb. 3.12, D-F). Es wurden keine Unterschiede in der subzellulären Kolokalisation von BI-1 und DIO-1 durch die Transfektion von PC-3Zellen mit dem BI-1-GFP-Fusionskonstrukt und die immunzytochemische Untersuchung mit einen DIO-1-spezifischen Antikörper im Vergleich $\mathrm{zu}$ den Ergebnissen der Kotransfektions-Experiment mit BI-1- und DIO-1-Fusionskonstrukten an NIH3T3-Zellen festgestellt. 

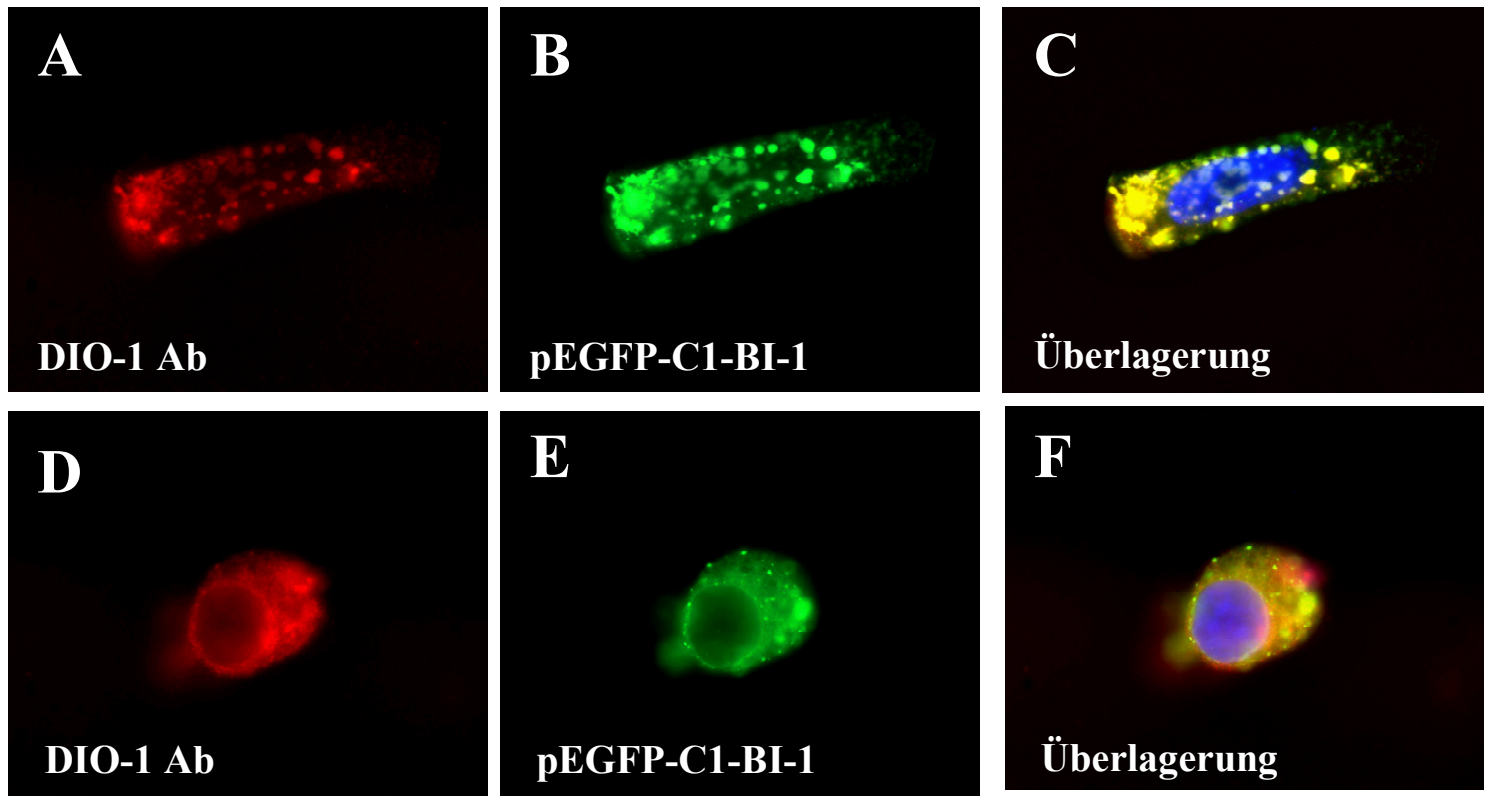

Abb. 3.12: Darstellung der subzellulären Kolokalisation des Fusionsproteins BI-1-GFP und des endogenen DIO-1 in PC-3-Zellen. PC-3-Zellen wurden transient mit dem Plasmid pEGFP-C1-BI-1transfiziert und anschließend wurde eine Immunzytochemie mit dem DIO-1-spezifischen Antikörper durchgeführt. (A-C) Bei etwa 10\% der transfizierten Zellen fand sich sowohl für das endogene DIO-1 als auch für das BI-1-Fusionsprotein eine kugelförmige Kolokalisation im Zytoplasma. (D-F) In den restlichen 90\% der transfizierten Zellen konnte eine diffuse Verteilung des BI-1-Fusionsproteins und des endogenen DIO-1-Proteins im Zytoplasma beobachtet werden. Die Überlagerung von DIO-1 und BI-1GFP zeigt eine partiell hohe Übereinstimmung der zellulären Lokalisation im Zytoplasma. Alle Aufnahmen wurden bei 1000-facher Vergrößerung aufgenommen.

\subsubsection{Untersuchung zur subzellulären Lokalisation des endogenen DIO-1- Proteins mittels Immunzytochemie in Säugerzellen}

Aus der Literatur ist bekannt, dass DIO-1 unter prä-apoptotischen Bedingungen vom Zytoplasma in den Zellkern migriert (Garcia Domingo et al., 2003). Zunächst sollte in der vorliegenden Arbeit jedoch untersucht werden, in welchen Zellkompartimenten das endogene DIO-1 unter normalen Kulturbedingungen lokalisiert ist. Dazu wurden PC-3Prostatakarzinomzellen auf speziellen Objektträgern bis zu einer Konfluenz von 50\%$80 \%$ kultiviert. Anschließend wurden die Zellen auf dem Objektträger fixiert und das endogene DIO-1-Protein mittels Immunzytochemie mit einem DIO-1-spezifischen Antikörper detektiert. Anschließend wurden die Zellkerne der PC-3-Zellen mit DAPI gegengefärbt. Die subzelluläre Lokalisation von DIO-1 wurde unter einem Fluoreszenz- 
Mikroskop ausgewertet. Von fünf zufällig gewählten Ausschnitten (100fache Vergrößerung) wurden die Zellen mit zytoplasmatischer oder nukleärer Verteilung von DIO-1 ausgezählt.

Wie in Abb. $3.13 \mathrm{zu}$ erkennen ist, konnte DIO-1 überwiegend im Zytoplama lokalisiert werden. In etwa $2 \%$ der Zellen wurde jedoch eine Lokalisation von DIO-1 im Zellkern beobachtet (Abb. 3.13, A-C). Bei einer höheren Vergrößerung ist ein gleichmäßig über das gesamte Zytoplasma verteiltes punktuelles Muster der DIO-1 Färbung zu erkennen (Abb. 3.13, D-F).
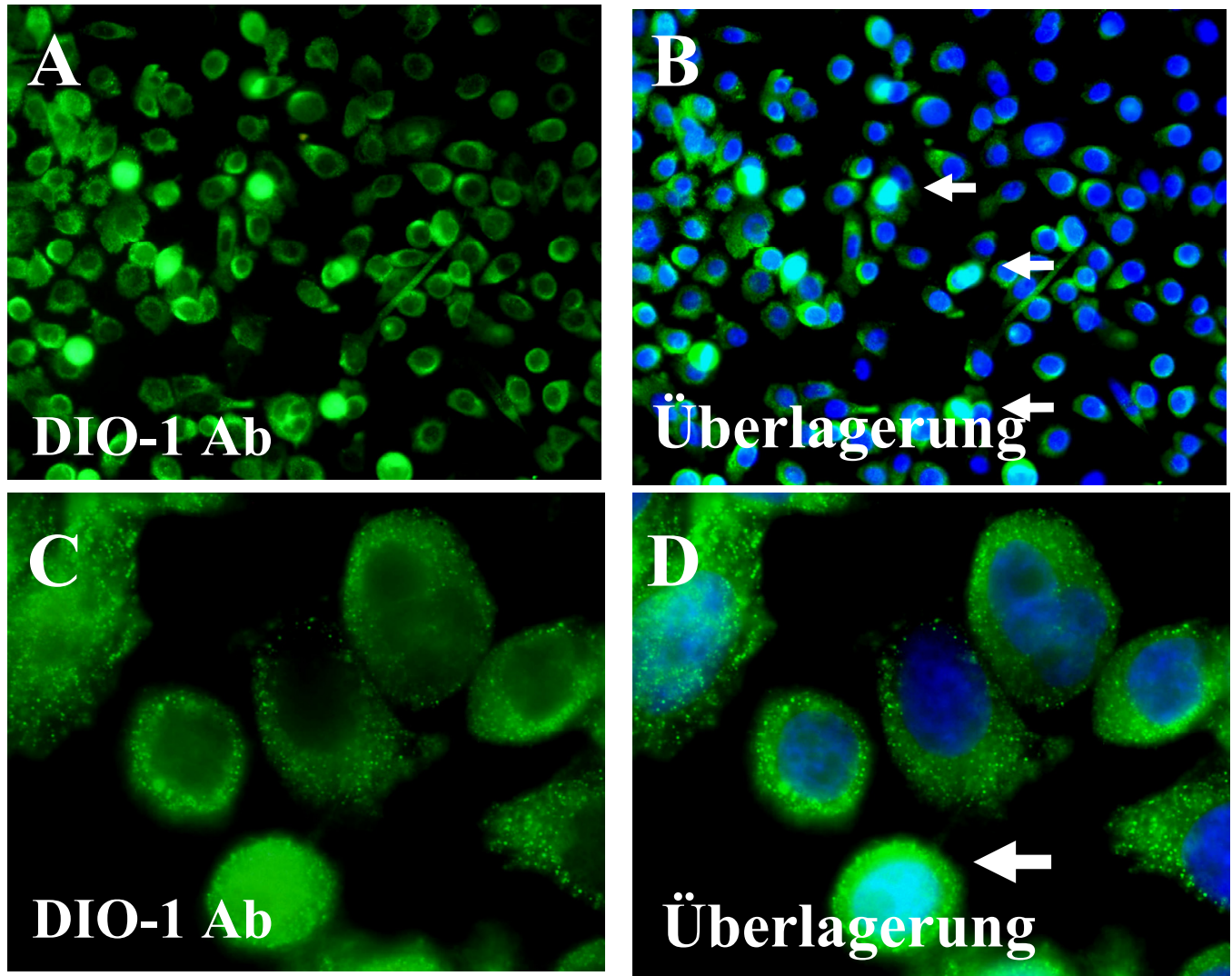

Abb. 3.13: Darstellung der subzellulären Lokalisation von DIO-1 in humanen PC-3Prostatakarzinomzellen mittels Immunzytochemie unter normalen Kulturbedingungen. (A) und (C) PC-3-Zellen wurden mit einem polyklonalen Antikörper gegen DIO-1 angefärbt (grün). Die prozentualen Anteile der Zellen mit jeweilige subzellulären Lokalisation von DIO-1 wurden mittels Auszählen von fünf zufällig gewählten Ausschnitten (100-fache Vergrößerung) durch Fluoreszenz-Mikroskopie bestimmt. In etwa $2 \%$ der Zellen ist zu beobachten, dass DIO-1 im Zellkern (blau) lokalisiert ist (weiße Pfeile in Bild B und D). DIO-1 ist ansonsten gleichmäßig und über das gesamte Zytoplasma punktförmig 
verteilt. Die Aufnahmen A und B wurden in 200-facher, die Aufnahmen C und D wurden in 1000-facher Vergrößerung aufgenommen.

\subsection{Analyse des möglichen Zusammenhangs von BI-1 und DIO-1 in Prostata- und Mammakarzinomzelllinien bei der BI-1- involvierten Apoptose}

\subsubsection{Subzelluläre Lokalisation von DIO-1 nach Herunterregulierung der Expression von BI-1 mittels RNA-Interferenz in Prostatakarzinomzelllinien}

Wie bereits erwähnt migriert DIO-1 unter prä-apoptotischen Bedingungen vom Zytoplasma in den Zellkern (Garcia Domingo et al., 2003). Es ist auch bekannt, dass bei der Herunterregulierung der BI-1-Expression in PC-3-Zellen mittels siRNA Apoptose induziert wird (Grzmil et al., 2003). Im Rahmen dieser Arbeit sollte untersucht werden, ob DIO-1 durch Herunterregulierung der BI-1-Expression in den Zellkern migriert und es einen Zusammenhang zwischen BI-1 und DIO-1 im Apoptose-Signalweg gibt. Dazu wurde die BI-1-Expression in den PC-3-Prostatakarzinomzellen mit Hilfe von BI-1spezifischen Duplex-siRNA-Oligonukleotiden herunterreguliert. Als Kontrolle wurden Duplex-siRNA-Oligonukleotide gegen das Luciferase-Gen verwendet. 48 Stunden nach der Transfektion wurden die PC-3-Zellen fixiert und zur Analyse der subzellulären Lokalisation von DIO-1 mit einem DIO-1-spezifischen Antikörper gefärbt. Anschließend wurden die PC-3-Zellen unter einem Fluoreszenzmikroskop aufgenommen und nachfolgend die subzelluläre Lokalisation von DIO-1 in diesen Zellen quantifiziert (Abb. 3.14 und Abb. 3.15). Dazu wurden die Zellen in fünf zufällig ausgewählten Sichtfeldern entsprechend ihrer subzellulären Lokalisationen von DIO-1 bei einer 200-fachen Vergrößerung ausgezählt. Die mit Luciferase-spezifischer siRNA transfizierten PC-3-Zellen zeigten eine subzelluläre Lokalisation von DIO-1 in 3\% der Zellen im Nukleus, in 9\% der Zellen war eine partielle nukleäre Färbung und in $88 \%$ der Zellen eine zytoplasmatische Verteilung von DIO-1 zu beobachten (Abb. 3.15). Bei den mit BI-1-spezifischer siRNA transfizierten PC-3-Zellen konnte eine Veränderung 
der subzellulären Lokalisation von DIO-1 beobachtet werden (Abb. 3.14, D-F). 38\% der Zellen mit herunterregulierter BI-1-Expression zeigten eine nukleäre Lokalisation von DIO-1, 26\% eine partielle nukleäre und 36\% eine zytoplasmatische Lokalisation von DIO-1 (Abb. 3.15).
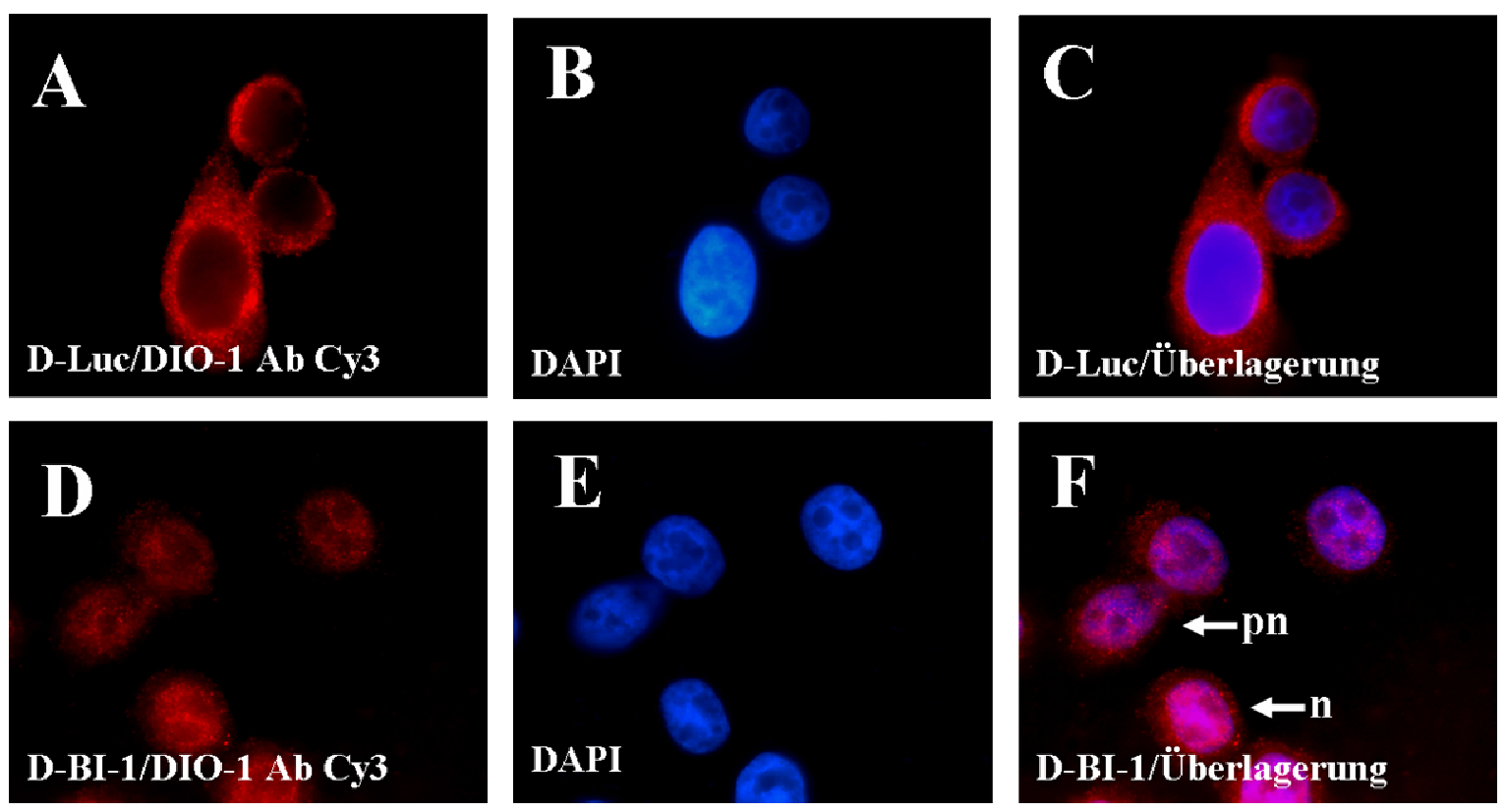

Abb. 3.14: Subzelluläre Lokalisation von DIO-1 nach der Transfektion mit BI-1 Duplex-siRNA (AC) und Luc Duplex-siRNA (D-F, Kontrolle) in PC-3-Zellen. (A) und (D) zeigen die subzelluläre Lokalisation von DIO-1 (rot). In (A) ist DIO-1 diffus im Zytoplasma verteilt, während in (D) DIO-1 partiell-nukleär (Pfeil: pn) und nukleär (Pfeil: n) lokalisiert ist. (B) und (E) zeigen die mit DAPI gegengefärbten Zellkerne. (C) und (F) zeigen die Überlagerung der DIO-1-Antikörper- und DAPIFärbung. Die Immunzytochemie wurde mit einem polyklonalen DIO-1-Antikörper und mit einem Cy3konjugierten Sekundär-Antikörper durchgeführt. Alle Aufnahmen: 1000-fache Vergrößerung. 


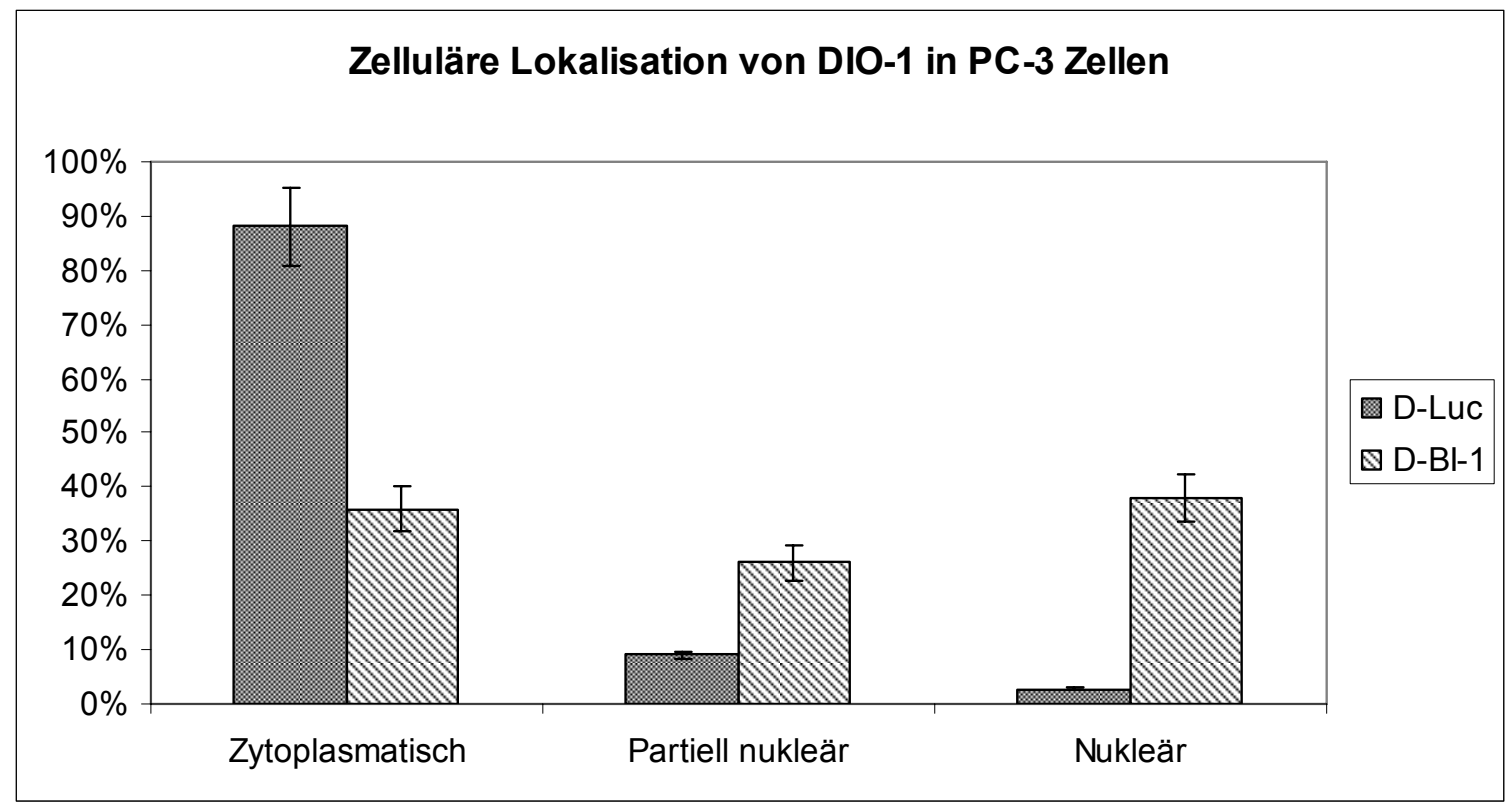

Abb. 3.15: Auswertung der DIO-1-Immunzytochemie an PC-3-Zellen mit herunterregulierter BI-1Expression im Vergleich zu kontrolltransfizierten Zellen. Die mit BI-1- (D-BI-1) bzw. Luciferasespezifischer (D-Luc) siRNA transfizierten PC-3-Zellen wurden für $48 \mathrm{~h}$ inkubiert, fixiert und mit einem DIO-1-spezifischen Antikörper angefärbt. Anschließend wurden die Zellen unter einem Fluoreszenzmikroskop in fünf zufällig ausgewählten Sichtfeldern entsprechend ihrer subzellulären Lokalisationen von DIO-1 bei einer 200-fachen Vergrößerung ausgezählt. Bei den mit BI-1-spezifischer siRNA transfizierten PC-3-Zellen ist eine Translokation von DIO-1 aus dem Zytoplasma in den Nukleus deutlich zu erkennen, während die kontrolltransfizierten Zellen diesen hohen Anteil der nukleären Lokalisation von DIO-1 nicht zeigen.

\subsubsection{Untersuchung der Translokation von DIO-1 in den Zellkern nach gemeinsamer Herunterregulierung der BI-1- und DIO-1-Expression mittels} RNA-Interferenz

Es sollte untersucht werden, ob durch die Kotransfektion von BI-1- und DIO-1spezifischer siRNA eine Veränderung im Migrationsverhalten des DIO-1-Proteins in den Zellkern verursacht wird. Als Kontrolle wurde die Expression von BI-1 und DIO-1 einzeln in PC-3-Zellen herunterreguliert. Weiterhin wurden die PC-3 Zellen zur Kontrolle mit Luciferase-spezifischer siRNA transfiziert. Anschließend wurde eine Immunzytochemie mit einem DIO-1-spezifischen Antikörper durchgeführt. Unter einem Fluoreszenzmikroskop wurden die Zellen mit zytoplasmatischer bzw. nukleärer 
Lokalisation von DIO-1 in fünf zufällig gewählten Sichtfeldern ausgezählt (Abb. 3.17). Nach der Transfektion von DIO-1-siRNA und Luciferase-siRNA konnten keine Veränderungen bezüglich der subzellulären Lokalisation des endogenen DIO-1 in den PC-3-Zellen beobachtet werden (Abb. 3.16, II und III). Etwa 2-3\% der transfizierten Zellen zeigten eine Kernlokalisation (Abb. 3.17). Bei der Herunterregulation der BI-1Expression konnte in $40 \%$ der Zellen eine Translokation von DIO-1 in den Zellkern festgestellt werden (Abb. 3.16, I). Die gleichzeitige Herunterregulierung der Expression von BI-1 und DIO-1 in den PC-3 Zellen resultierte dagegen in keiner Veränderung der subzellulären Lokalisation von DIO-1 im Vergleich zu Luciferase-siRNA-transfizierten Kontrollzellen (3\%; Abb. 3.16, IV). 

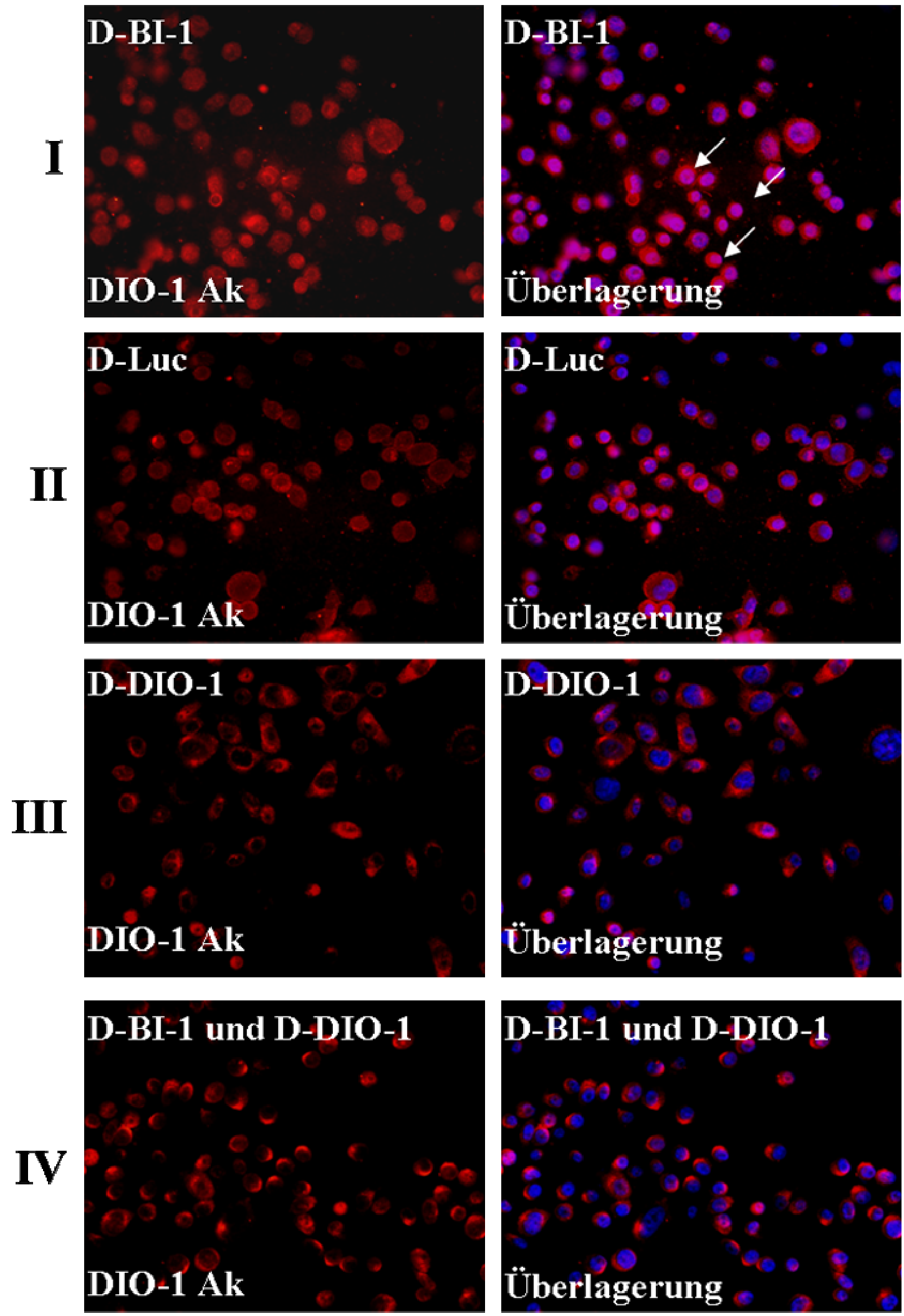

Abb. 3.16: Darstellung der subzellulären Lokalisation von DIO-1 nach der Transfektion mit BI-1siRNA (I), Luciferase-siRNA (II), DIO-1-siRNA (III) und Kotransfektion mit BI-1-und DIO-1- 
siRNA in PC-3-Zellen. DIO-1 (rot) wurde mit einem DIO-1-spezifischen Antikörper detektiert. Die subzelluläre Lokalisation von DIO-1 ändert sich nur in Zellen mit reduzierter BI-1-Expression (I). DIO-1 transloziert in den Zellkern (weiße Pfeile). Die kontrolltransfizierten Zellen (II), die DIO-1-siRNA transfizierten Zellen (III) und die Zellen mit kombiniert-herunterregulierter BI-1- und DIO-1-Expression (IV) zeigen keine Veränderungen in der subzellulären Lokalisation von DIO-1. Die Immunzytochemie wurde mit einem polyklonalen DIO-1-Antikörper und mit einem Cy3-konjugierten Sekundär-Antikörper durchgeführt. Alle Aufnahmen erfolgten bei 200-facher Vergrößerung.

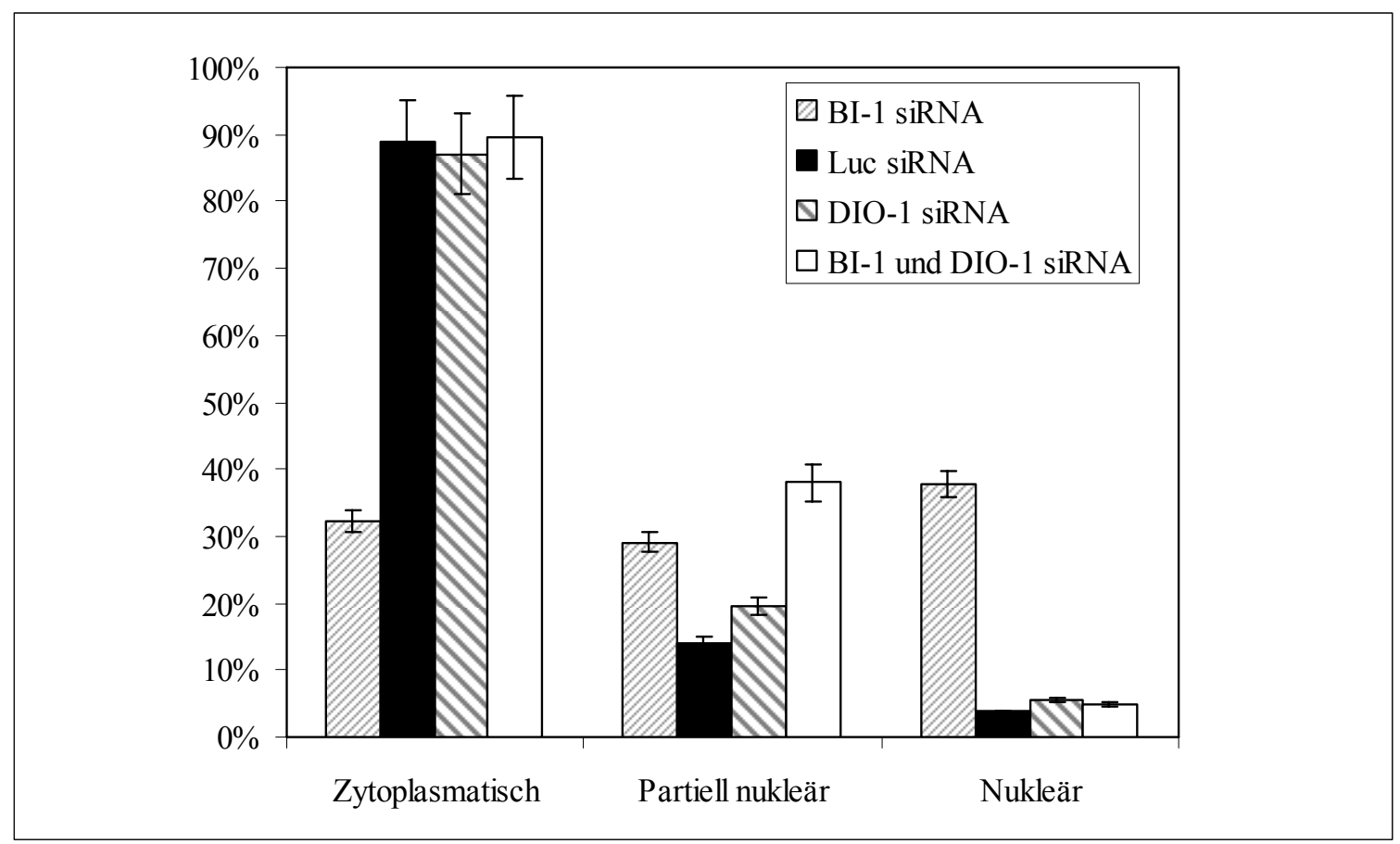

Abb. 3.17: Auswertung der subzellulären Lokalisation von DIO-1 nach der Transfektion mit BI-1siRNA, Luciferase-siRNA, DIO-1-siRNA und Kotransfektion mit BI-1-und DIO-1-siRNA in PC-3Zellen. Die mit BI-1-, Luciferase- (Kontrolle), DIO-1-spezifischer siRNA transfizierten und mit BI-1und DIO-1-spezifischer siRNA kotransfizierten PC-3-Zellen wurden für $48 \mathrm{~h}$ inkubiert, fixiert und mit einem DIO-1-spezifischen Antikörper angefärbt. Anschließend wurden die Zellen unter einem Fluoreszenzmikroskop in fünf zufällig ausgewählten Sichtfeldern entsprechend ihrer subzellulären Lokalisation von DIO-1 bei einer 200-fachen Vergrößerung ausgezählt. Die subzelluläre Lokalisation von DIO-1 änderte sich nur in Zellen mit reduzierter BI-1-Expression. Die DIO-1-siRNA transfizierten Zellen und die Zellen mit kombiniert-herunterregulierter BI-1- und DIO-1-Expression zeigten keine Veränderungen in der subzellulären Lokalisation von DIO-1 im Vergleich zu den kontrolltransfizierten Zellen. 


\subsubsection{Untersuchung des Apoptose-Verhaltens von MDA-MB-231-Zellen bei gleichzeitiger Herunterregulierung der BI-1 und DIO-1 Expression mittels RNA-Interferenz}

Durch eine Herunterregulierung der BI-1-Expression wird sowohl in PC-3-Zellen als auch in MDA-MB-231-Zellen Apoptose induziert (Grzmil et al., 2003 und 2006). In Abschnitt 3.5.1 wurde gezeigt, dass DIO-1 in den Zellkern transloziert, wenn die BI-1Expression mittels RNA-Interferenz herunterreguliert wird. Dagegen konnte keine Translokation von DIO-1 in den Zellkern beobachtet werden, wenn die BI-1- und DIO1-Expression gemeinsam mittels RNA-Interferenz herunterreguliert wurden (3.5.2). Es sollte nun evaluiert werden, ob durch die gemeinsame Herunterregulierung von BI-1 und DIO-1 mittels siRNA überhaupt eine spontane Induktion der Apoptose stattfindet. Damit sollte überprüft werden, ob DIO-1 die proapoptotische Wirkung, die mit einer herunterregulierten BI-1-Expression einhergeht, aufheben kann. Für die Herunterregulierung der BI-1- und DIO-1-Expression wurden PC-3- und MDA-MB231-Zellen mit BI-1- und DIO-1-spezifischer siRNA kotransfiziert. Nach der Transfektion (24, 48 und 72 Stunden) wurden sowohl adhärente als auch nicht adhärente Zellen geerntet und die Caspase-3-Aktivität gemessen. Sowohl bei PC-3- als auch bei MDA-MB-231-Zellen konnte im Vergleich zu den Luciferase-siRNAtransfizierten Kontrollzellen keine gesteigerte Caspase-3-Aktivität (etwa 3\%) durch die gemeinsame Herunterregulierung von BI-1 und DIO-1 gemessen werden (Abb. 3.18, E). 


\section{D-BI-1/D-DIO-1}
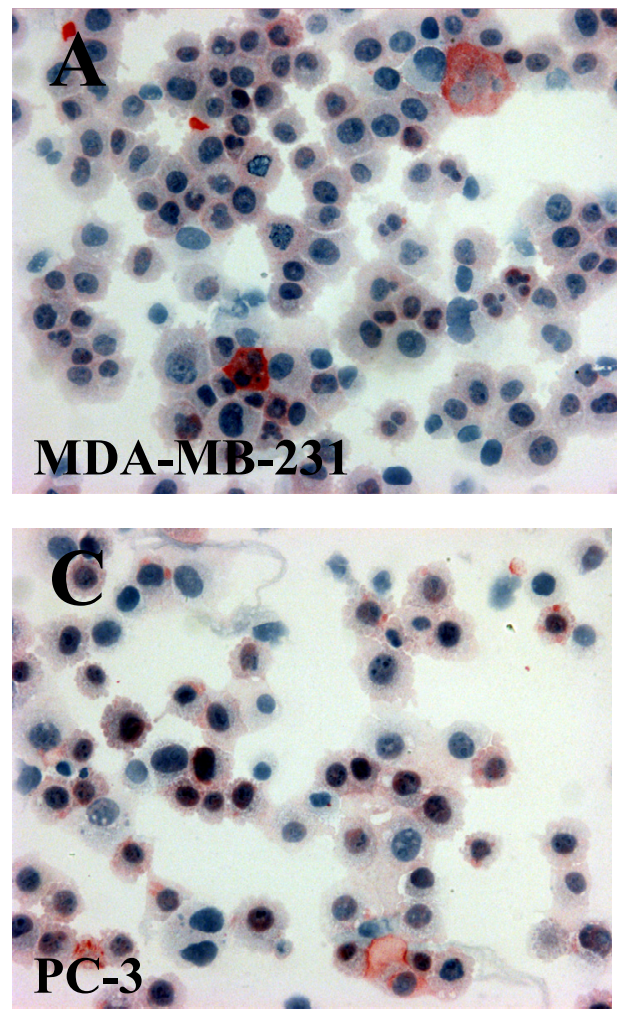

D-Luc
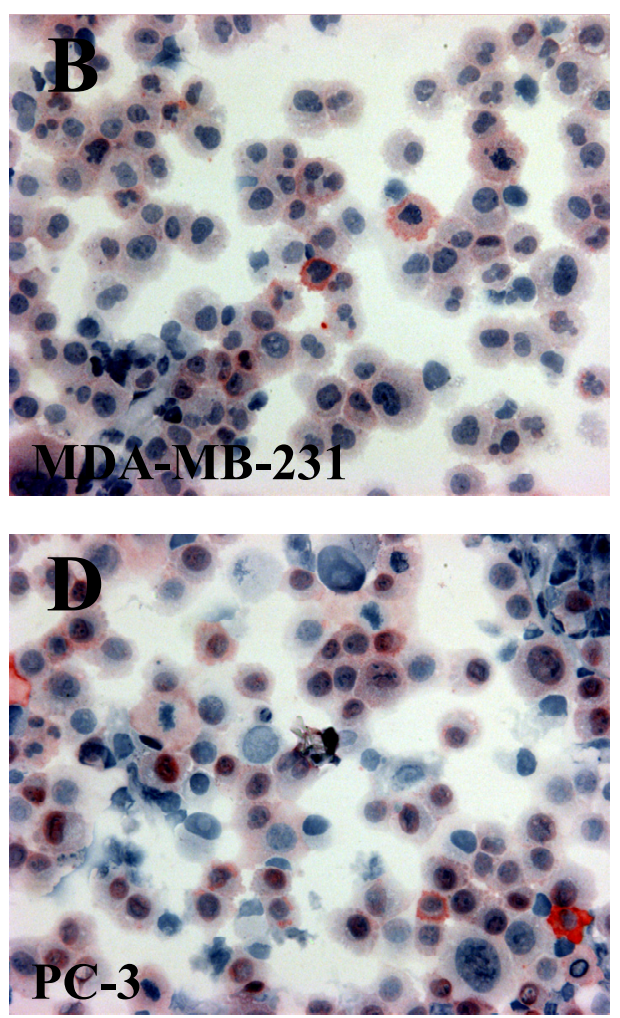

$\mathbf{E}$

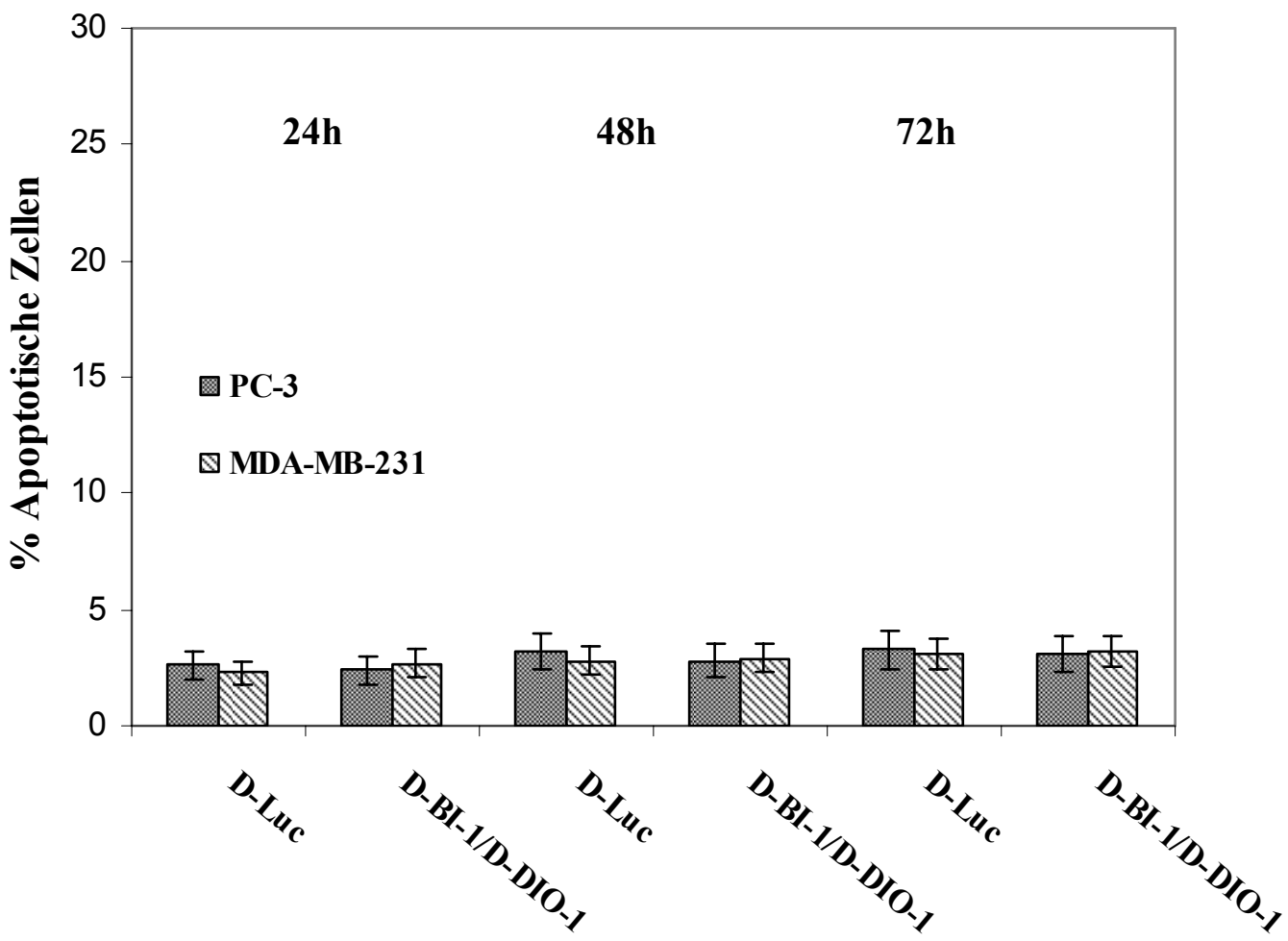


Abb. 3.18: BI-1- und DIO-1-siRNA Kotransfektion von MDA-MB-231 und PC-3-Zellen zur Bestimmung der Apoptoseinduktion. Nach der Transfektion (24, 48 und 72 Stunden) wurden sowohl adhärente als auch nicht adhärente Zellen gesammelt und die Caspase-3-Aktivität bestimmt (rote zytoplamatische Färbung). Die Aufnahmen sind exemplarisch und zeigen BI-1- und DIO-1 siRNAkotransfizierte MDA-MB-231- (A) und PC-3-Zellen (C) 48 h nach der Transfektion. Sowohl bei PC-3als auch bei MDA-MB-231-Zellen wurde keine gesteigerte Apoptoserate (im Vergleich zu den Kontrollzellen - Bilder B und D) beobachtet. (E) Graphische Darstellung der Apoptoserate der transfizierten Zellen in \%. Die Apoptoserate liegt bei etwa 3\% bei allen getesteten Ansätzen. Alle Bilder wurden in 200-facher Vergrößerung aufgenommen.

\subsection{Experimenteller in vivo Ansatz zur Funktionsuntersuchung von BI-1 im Maus-Tumormodell}

In Abschnitt 3.2.2 wurde gezeigt, dass eine Herunterregulierung der BI-1-Expression in kultivierten MDA-MB-231-Zellen mittels Duplex-siRNA-Oligonukleotide Apoptose induziert. Daher sollte nun überprüft werden, ob durch den knock down der BI-1Expression im MDA-MB-231-Tumor-Mausmodell Apoptose ausgelöst und dadurch das Tumorwachstum inhibiert wird. Für die Transfektion in vivo wurde ein siRNA/ Atelocollagen (Ac)-Komplex verwendet. Atelocollagen stellt ein Typ I Collagen aus der Kälberhaut dar, dass durch Pepsin-Behandlung Telopeptid-frei ist und kaum zu einer Immunreaktion in der Maus führt. Aus der Literatur ist bekannt, dass siRNA/ Atelocollagen-Komplexe sehr effizient von eukaryotischen Zellen aufgenommen werden, und dass die siRNA in der Zelle durch das Atelocollagen über einen längeren Zeitraum stabil gehalten wird (Takei et al., 2004). Als Tumormodell sollten MDA-MB231-Zellen direkt in die Mammae von weiblichen Nacktmäusen implantiert werden, wobei sich dort nach etwa zwei Wochen ein Tumor entwickelt (PD Dr. F. Alves, persönliche Mitteilung). Dieses Experiment wurde in Zusammenarbeit mit der Arbeitsgruppe von PD Dr. F. Alves (Abt. Hämatologie/Onkologie, Universitätsklinikum Göttingen) durchgeführt. Sobald der Tumor eine bestimmte Größe erreicht hat, sollte er mit einem BI-1-siRNA/Ac-Komplex behandelt werden. Durch die Kopplung eines Cy5.5-Farbkomplexes an die Duplex-siRNA-Oligonukleotide ist es möglich, über optische Bildgebungsverfahren (Optical Imaging und Infrarot-Mikroskopie) die 
Lokalisation der siRNA/Ac-Komplexe in der Maus zu detektieren. Zusätzlich sollte die Tumorentwicklung über die Flächendetektor-Volumetrische-Computertomographie untersucht werden. Die in vitro-Voruntersuchungen zur Bestimmung der Transfektionseffizienz mit Atelocollagen (Ac) und Stabilität der siRNA erfolgte mit der DIO-1-siRNA, da durch Herunterregulierung der BI-1-Expression in den transfizierten Zellen Apoptose induziert wird und diese dadurch für die Langzeituntersuchung nicht einsetzbar waren.

Im Rahmen eines Pilotexperimentes mit vier Mäusen wurde evaluiert, wie lange die siRNA/Ac-Komplexe in den Tumoren der Mäuse stabil bleiben und wie lange die Wirkung anhält. Das Hauptexperiment wurde mit vierzehn Mäusen durchgeführt, wobei zwei Mäuse keine Tumoren entwickelten.

\subsubsection{Duplex-siRNA-Oligonukleotid-Transfektion von MDA-MB-231-Zellen mittels Atelocollagen}

In dem in vivo-Ansatz sollte die Transfektion der Zellen mit Duplex-siRNAOligonukleotiden über Atelocollagen erfolgen. Zur Überprüfung der Transfektionseffizienz wurden MDA-MB-231-Zellen auf speziellen Objektträgern mit DIO-1-siRNA-Cy5.5/Ac-Komplexen transfiziert, nach 48 Stunden fixiert und mit DAPI angefärbt. Die Transfektionseffizienz betrug etwa 95\%. Mit Hilfe der InfrarotMikroskopie wurde anschließend die zelluläre Lokalisation der DIO-1-siRNA untersucht. Die DIO-1-siRNA-Cy5.5 ist diffus im Zytoplasma der Zellen lokalisiert (Abb. 3.19). 


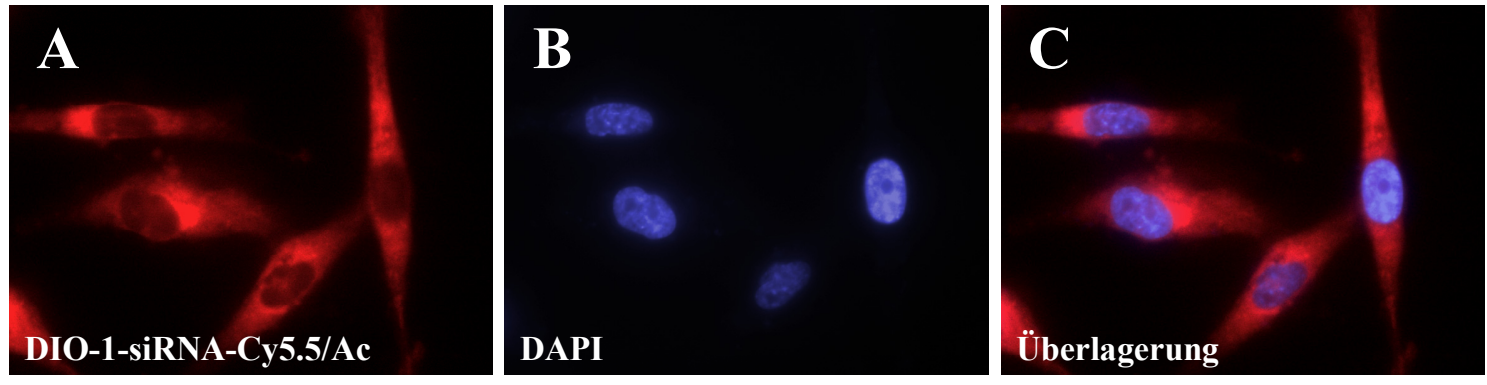

Abb. 3.19: Infrarot-Mikroskopaufnahme von DIO-1-siRNA-Cy5.5/Ac transfizierten MDA-MB-231-

Zellen. Durch die Kopplung eines Cy5.5-Farbkomplexes an die DIO-1-siRNA-Oligonukleotide kann mit Hilfe von Infrarot-Mikroskopie die zelluläre Lokalisation des siRNA/Ac-Komplexes (A) beobachtet werden. Die Zellkerne wurden mit DAPI angefärbt (B). Der siRNA/Ac-Komplex ist im Zytoplasma der Zellen lokalisiert (C).

\subsubsection{Untersuchung der Stabilität und der Wirkungsdauer des siRNA/Ac- Komplexes über einen längeren Zeitraum in vitro}

Der Erfolg des dargestellten in vivo-Ansatzes zur Untersuchung der Funktion von BI-1 im Maus-Tumormodell ist maßgeblich davon abhängig, in welchen Abständen das siRNA/Ac-Gemisch in den Tumor injiziert wird und wie lange es in den Zellen stabil bleibt. Um die Stabilität und die Wirkungsdauer des siRNA/Ac-Komplexes über einen längeren Zeitraum in vitro $\mathrm{zu}$ bestimmen, wurden Duplex-siRNA-Oligonukleotide gegen DIO-1 in MDA-MB-231-Zellen mittels Atelocollagen transfiziert. Nach $1-10$ Tagen wurde aus den Zellen Gesamtprotein extrahiert und über eine Western BlotAnalyse mit einem DIO-1-spezifischen Antikörper untersucht. In Abb. 3.20 ist zu erkennen, dass die Wirkung der DIO-1-siRNA etwa sechs Tage stabil ist. 


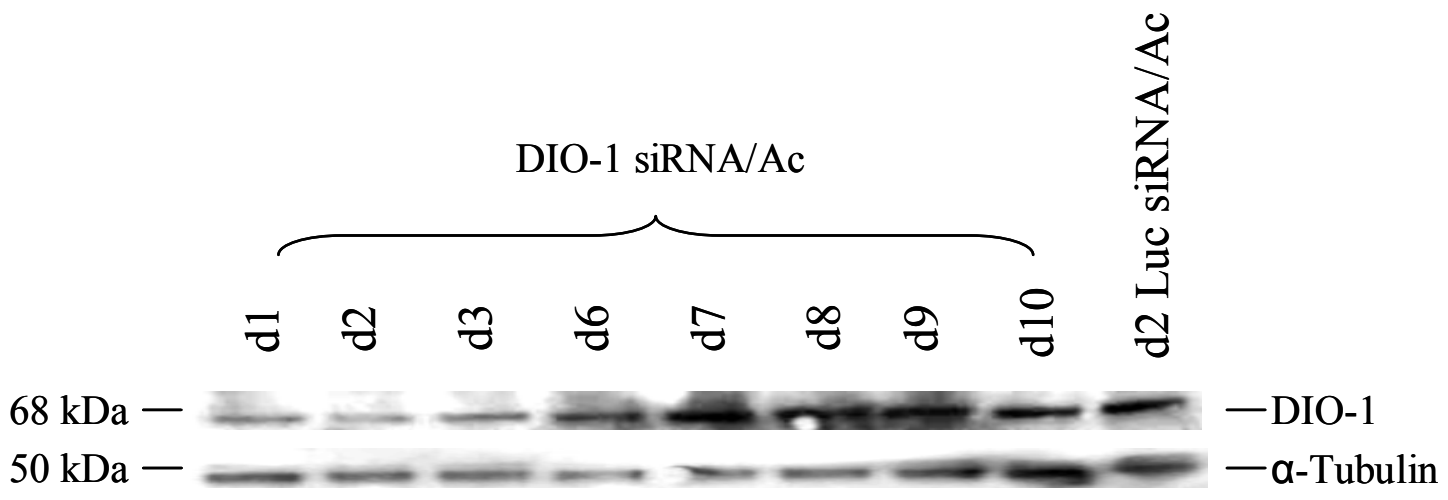

Abb. 3.20: DIO-1-siRNA/Ac-Langzeittest. Duplex-siRNA-Oligonukleotide gegen DIO-1 wurden mittels Atelocollagen in die MDA-MB-231-Zellen transfiziert. In einem Zeitraum von 1-10 Tagen (d1d10) wurden die Gesamtproteine aus den Zellen extrahiert und die Expression von DIO-1 mit einem DIO-1-spezifischen Antikörper mittels Western Blot untersucht. Die Wirkung von DIO-1-siRNA/Ac blieb in diesem Ansatz etwa sechs Tage stabil. Um die eingesetzte Menge des Proteins untereinander vergleichen zu können, wurde die Membran mit einem $\alpha$-Tubulin-Antikörper rehybridisiert.

\subsubsection{Implantation der MDA-MB-231 Zellen in die Mammae der Maus}

Vierzehn Nacktmäusen des Typs NMRI-Foxn 1 wurden jeweils etwa 1 x $10^{6}$ MDAMB-231-Zellen (mit PBS auf 20 $\mu$ l Gesamtvolumen eingestellt) direkt in die Mammae implantiert. Zwei Wochen vor der Implantation wurden diese Mäuse auf ein Spezialfutter ohne Eigenfluoreszenz umgestellt, da das herkömmliche Maus-Futter eine Eigenfluoreszenz im nahen Infrarot-Bereich besitzt und dadurch die Messungen mit dem eXplore Optix-Gerät unspezifische Signale liefert (siehe Material und Methoden).

\subsubsection{Behandlung der Tumore mit Duplex-siRNA/Ac-Komplexen}

Exakt 26 Tage nach der Implantation (d26) wurde sechs Mäusen je 200 $\mu 1$ BI-1-siRNACy5.5(7 $\mu \mathrm{M}) /$ Ac-Komplex $(0,5 \%)$ direkt in die Mammakarzinome $\left(200 \mathrm{~mm}^{3}\right.$ TumorVolumen) injiziert (Abb. 3.21). Die Injektionsvolumina sollten den entsprechenden Tumorvolumina gleichgesetzt werden, was sich in der Praxis als schwierig erwies, da mit der Schieblehre keine zuverlässige Messung in diesem Tumormodell möglich war. 
Als Kontrolle wurden sechs Mäuse mit einem Luc-siRNA-Cy5.5/Ac-Komplex gleicher Konzentration behandelt. Zwei Mäuse entwickelten keinen Tumor nach der Implantation der MDA-MB-231-Zellen.

Die siRNA/Ac-Komplexe wurden 26 und 30 Tage nach der Implantation der MDAMB-231-Zellen direkt in die Tumore injiziert.

In einem Pilotexperiment mit vier Mäusen wurden die siRNA/Ac-Komplexe zunächst sieben Tage nach der ersten Behandlung erneut in den Tumor injiziert, anschließend nach sechs Tagen und zuletzt nach fünf Tagen, um die Wirkung der siRNAs in Abhängigkeit zu den Behandlungs-Zeitabständen zu untersuchen.
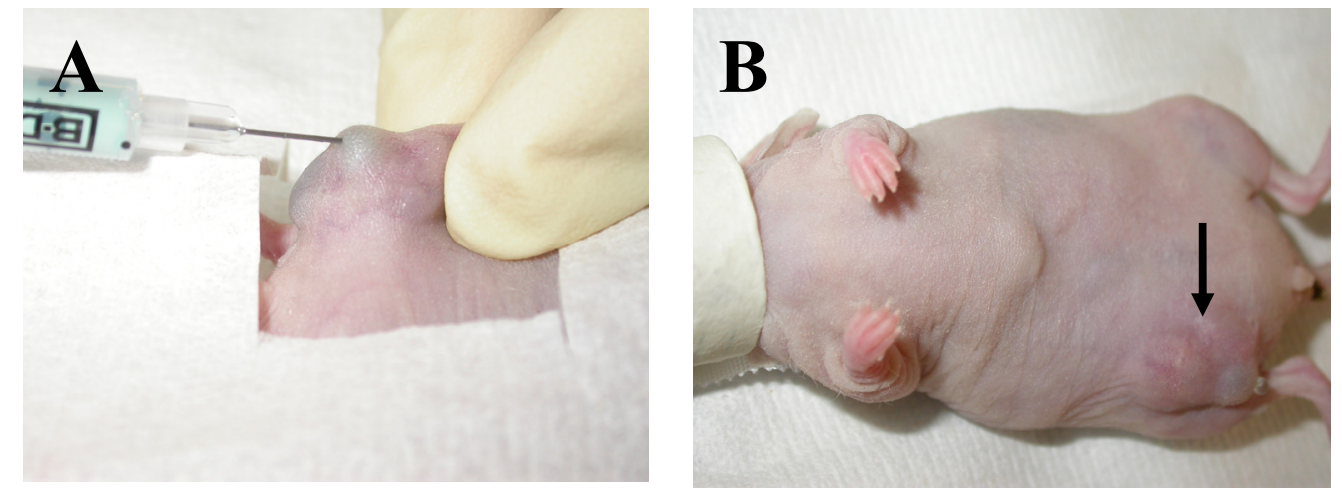

Abb. 3.21: Injektion des siRNA/Ac-Komplexes in den Tumor. (A) Zum Injizieren wurde die Maus mit Isofluran betäubt. Exakt 26 und 30 Tage nach der Implantation der MDA-MB-231-Zellen wurde bei sechs Mäusen der BI-1-siRNA(7 $\mu \mathrm{M}) / A c-K o m p l e x ~(0,5 \%)$ und bei sechs weiteren Mäusen der LucsiRNA(7 $\mu \mathrm{M}) /$ Ac-Komplex $(0,5 \%)$ als Kontrolle direkt in den Tumor injiziert. (B) Eine Maus nach der Injektion des siRNA/Ac-Komplexes. Der siRNA/Ac-Komplex verbleibt im Tumor.

\subsubsection{Messung der Tumorvolumina und die Gewichtsbestimmung der Mäuse während des Zeitraumes des in vivo-Experiments}

Für das in vivo-Experiment mit dem Mammakarzinom-Mausmodell wurden folgende Abbruch-Bedingungen festgelegt:

- Bei einer starken Gewichtsabnahme, sollte das Experiment für das jeweilige Tier abgebrochen werden. 
- Bei einem Tumorvolumen größer $1000 \mathrm{~mm}^{3}$ oder wenn die Bewegungsfreiheit des Tieres beeinflusst wird, sollte das Experiment ebenfalls abgebrochen werden.

- Bei auffälligen Verhaltensstörungen wie Lethargie oder Verhaltensstereotypien sollte das Experiment für das jeweilige Tier abgebrochen werden.

\subsubsection{Pilotexperiment zur Überprüfung der Durchführbarkeit der in vivo- Experimente}

Um die Durchführbarkeit der in vivo-Experimente vorab zu prüfen, wurde ein Pilotexperiment mit einer kleineren Anzahl an Mäusen durchgeführt. Die Behandlungen wurden an je zwei Mäusen für die BI-1-siRNA/Ac- und Luc-siRNA/Ac-Komplexe durchgeführt. Das Pilotexperiment verlief über 49 Tage nach der MDA-MB-231Implantation und am 50. Tag wurden die Mäuse abgetötet und die Tumoren isoliert. Die Behandlungen mit den siRNA/Ac-Komplexen wurden im Abstand von 7, 6 und 5 Tagen durchgeführt (d29, d36, d42 und d47).

Die Gewichtsbestimmung der Mäuse wurde täglich durchgeführt. Während des gesamten Pilotexperiments wurden keine auffälligen Gewichtsabnahmen beobachtet (Abb. 3.22). 


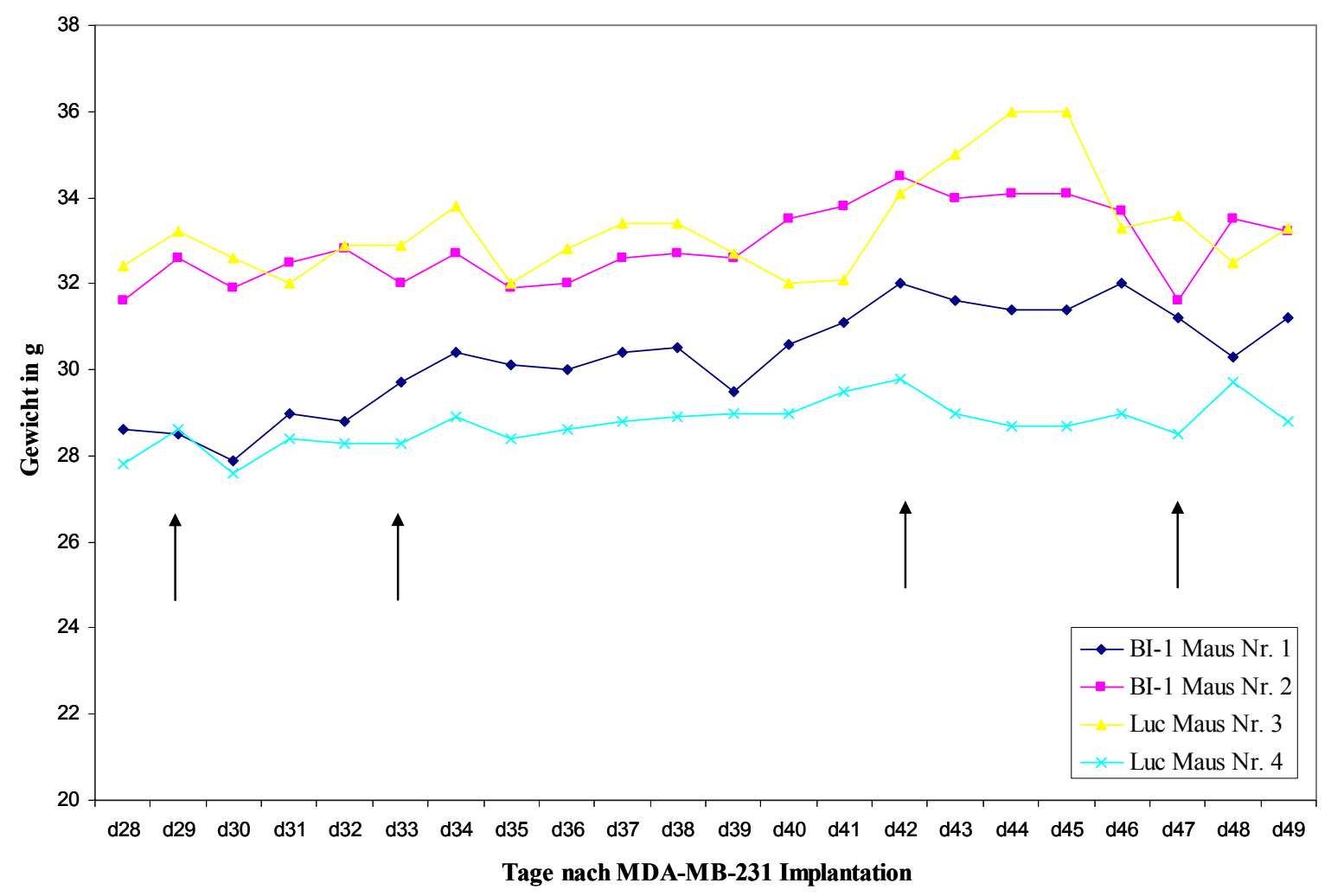

Abb. 3.22: Gewichtsentwicklung der untersuchten Mäuse. Die X-Achse zeigt die Tage nach der Implantation der MDA-MB-231-Zellen. Die Y-Achse stellt das Gewicht der Mäuse in g dar. Eines der Abbruchkriterien für das Experiment ist eine starke Abnahme des Gewichtes. Während der gesamten Dauer des Experiments wurde keine auffällige Gewichtsabnahme beobachtet. Maus 1 und 2 wurden mit BI-1-siRNA/Ac behandelt, Maus 3 und 4 mit Luc-siRNA/Ac.

Für die Tumorprogression wurde die Messung des Tumorvolumens mittels Flächendetektor-Volumetrischer-Computertomographie (FD-VCT) durchgeführt (Abb. 3.23). Die über FD-VCT gemessenen Daten wurden mit einer FD-VCT-MasterSoftware verarbeitet. Die Segmentaufnahmen der Tumoren und die Zusammenstellung der Tumorabbildung erfolgte über eine Advanced Workstation (GE Healthcare). Vier Tage nach der ersten siRNA/Ac-Injektion wurde bei den BI-1 siRNA/Ac behandelten Tumoren bereits ein verlangsamtes Wachstum beobachtet (Abb. 3.23, d33), während bei den Kontrolltumoren keine Verlangsamung des Wachstums erkennbar war. Bei den mit BI-1-siRNA/Ac-behandelten Tumoren wurde im Vergleich zu den LucsiRNA/Ac-behandelten Kontrolltumoren 49 Tage (d49) nach Implantation der MDAMB-231-Zellen ein Volumenunterschied von über $200 \mathrm{~mm}^{3}$ beobachtet. 


\section{Tumorprogression Pilotexperiment}

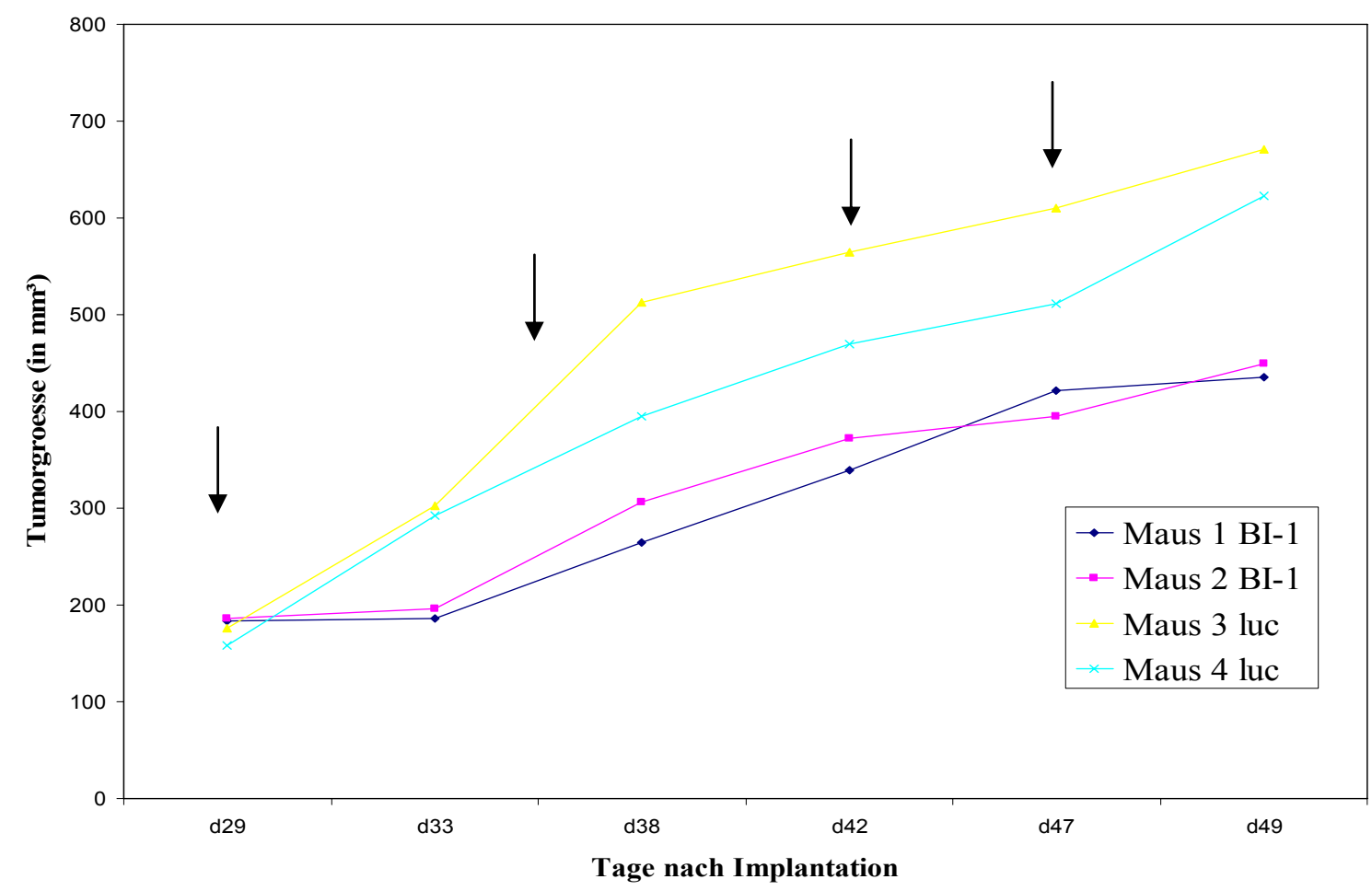

Abb. 3.23: Verlaufsdiagramm der Tumorprogression während des in vivo-Experimentes. Für die Tumorprogression wurde die Messung des Tumorvolumens mittels Flächendetektor-VolumetrischerComputertomographie (FD-VCT) durchgeführt. Nach 49 Tagen ist ein Volumenunterschied von über 200 $\mathrm{mm}^{3}$ bei den mit BI-1-siRNA/Ac behandelten Mäusen im Vergleich zu den mit Luc-siRNA/Ac behandelten Kontrollmäusen zu sehen. Die Pfeile markieren die Injektionszeitpunkte der siRNA/AcKomplexe .

\subsubsection{Vergleich der Tumorprogression von BI-1-Tumoren und Kontroll- Tumoren mittels Röntgendichte-Messung}

Mit Hilfe der Röntgendichte-Messung (gemessen in Hounsfield-Einheiten) ist es möglich, den Gewebezustand im Tumor über FD-VCT zu ermitteln. Den Geweben mit unterschiedlicher Dichte kann eine bestimmte Hounsfield-Einheit zugeordnet werden, wodurch es möglich ist, nekrotische und vitale Tumorgewebe über das Histogramm der FD-VCT-Daten zu unterscheiden. Dabei wird eine negative Hounsfield-Einheit einem nekrotischen Gewebe zugeordnet, während eine positive Hounsfield-Einheit einem vitalen Gewebe zugeordnet wird. Das Maximum einer vitalen Tumorgewebe-Kurve 
liegt dabei um die Hounsfield-Einheit 0. Das Atelocollagen besitzt eine HounsfieldEinheit von -50. Dies hat zur Folge, dass der gesamte Tumor, der mit Atelocollagen behandelt wurde, eine negative Hounsfield-Einheit (Verschiebung um -30 HounsfieldEinheiten) im Histogramm aufweist.

Als Voxel bezeichnet man einen diskreten Wert in kartesischen Koordinaten bei einem räumlichen Datensatz. Dieser stellt den kleinsten definierbaren Punkt innerhalb eines Volumens dar. Mit diesen Daten ist es möglich, ein Histogramm zur Analyse der Nekrose zu erstellen.

Aus den segmentierten Tumordaten wurden die Voxel-Anzahl und die HounsfieldMessungen mittels FD-VCT-Histo-Programm (Programm zur Berechnung von Histogrammen aus FD-VCT-Daten von C. Dullin, Universitätsklinikum Göttingen, Abt. Radiologie) extrahiert.

In Abb. 3.24 ist die Tumorprogression bei der BI-1-siRNA/Ac-behandelten Maus aus dem Pilotexperiment dargestellt. Die Tumorwachstumskurve zeigt eine rechtsschiefe Lage (um den Bezugspunkt -30) am 33. Tag nach der Implantation der MDA-MB-231Zellen. Durch die Veränderung im Tumorgewebe zeigt die Tumorwachstumskurve 38 Tage nach der Implantation eine linksschiefe Lage (um den Bezugspunkt -30) und schließlich eine stark nach linksverschobene Kurve (um den Bezugspunkt -30). 
Tumorprogression bei BI-1 Maus Nr. 2

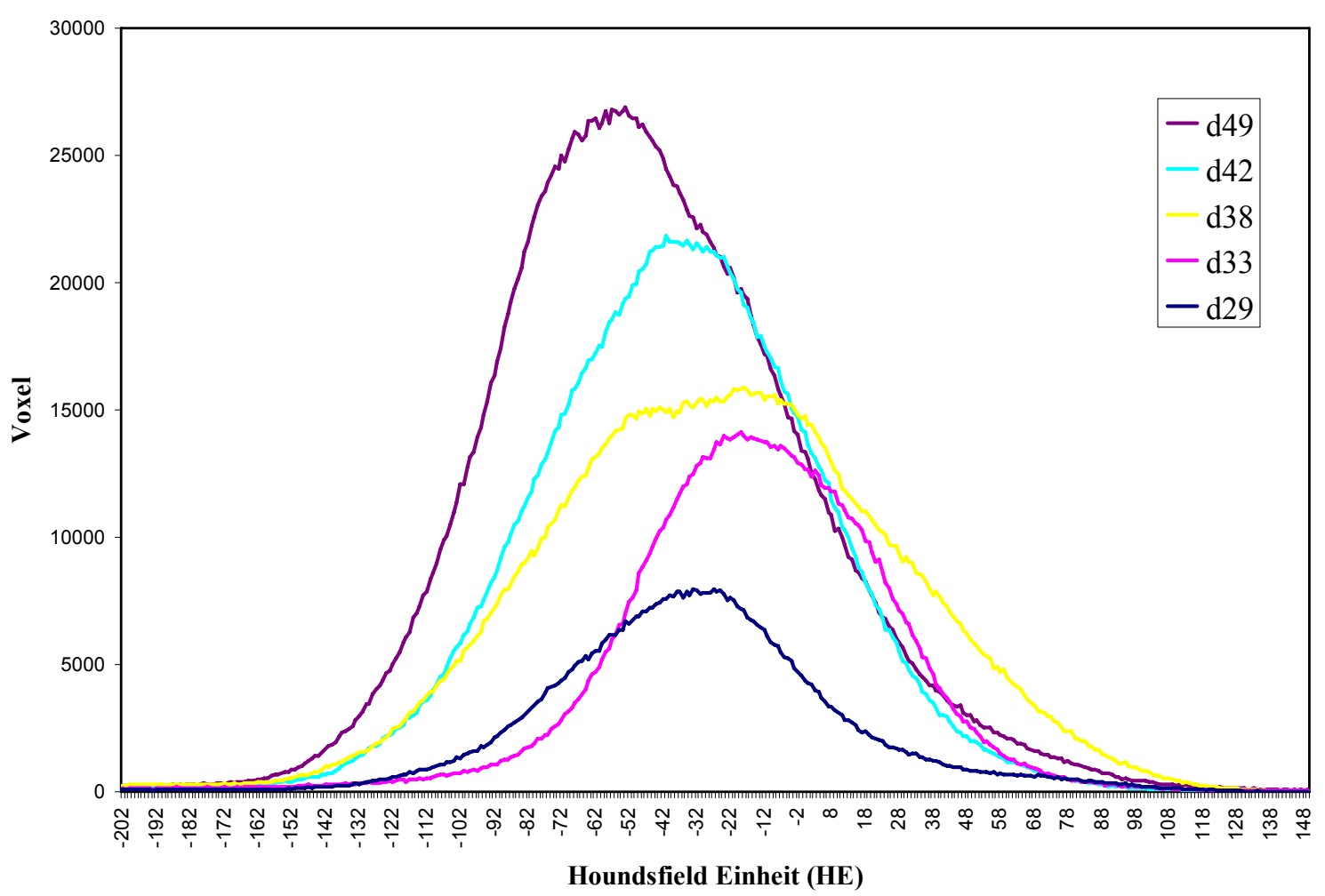

Abb. 3.24: Darstellung der Tumorprogression bei der BI-1-siRNA/Ac-behandelten Maus Nr.2 mittels FD-VCT-Messungen. Über die Hounsfield-Einheit kann die Dichte unterschiedlicher Gewebe bestimmt werden. Ein Tumor hat eine Hounsfield Einheit von Null. Der negative Bereich in der X-Achse wird beim Tumorgewebe dem nekrotischen Anteil zugeordnet. Der Graph zeigt eine Tendenz zum negativen Hounsfield-Bereich und auch die Voxel zeigen nur relativ kleine Volumina im Vergleich zu den Luc-siRNA/Ac-behandelten Tumoren (siehe Abb. 3.30).

Die Tumorwachstumskurve der Luc-siRNA/Ac-behandelten Mäuse aus dem Pilotexperiment zeigt während der gesamten Experimentdauer ein konstantes Wachstum (Abb. 3.25) ohne Veränderung der Kurvenneigung. Hier ist eine beginnende Nekrosephase nicht erkennbar. Am 43. Tag nach der Implantation ist eine nach rechts gerichtete Verbreiterung der Kurvenbasis zu sehen, was auf ein Wachstum von vitalem Tumorgewebe hindeutet. Während ein konstantes Wachstum des Tumors aus der wachsenden Voxel-Anzahl zu sehen ist, bleibt das Maximum der Kurve und auch die Kurvenneigung konstant bei -30 Hounsfield-Einheiten. 


\section{Tumorprogression bei Luc-Maus Nr.4}

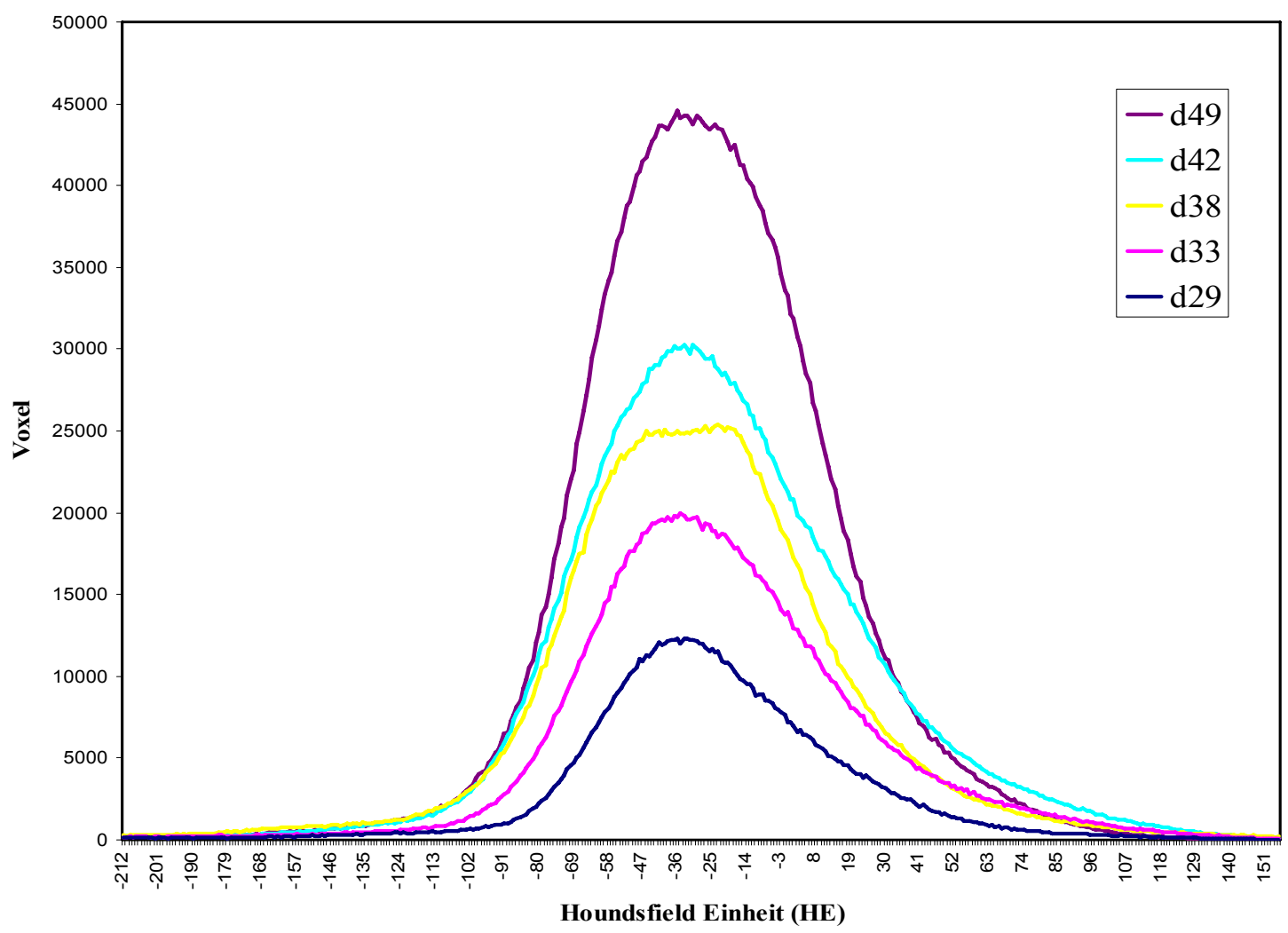

Abb. 3.25: Darstellung der Tumorprogression mit Hilfe der FD-VCT-Messungen in der Luc siRNA/Ac behandelten Maus Nr. 4. Über die Hounsfield-Einheit kann die Dichte unterschiedlicher Gewebe bestimmt werden. Ein Tumor besitzt eine Hounsfield-Einheit um den Nullpunkt herum. Der negative Bereich der X-Achse wird beim Tumorgewebe dem nekrotischen Anteil zugeordnet. Der Graph wächst mit einer geringen Krümmung, und bei $\mathrm{d} 42$ erhält der Graph eine rechtslastige Basis und die Voxel-Anzahl zeigt ein sehr viel größeres Volumen im Vergleich zu den BI-1-siRNA/Ac-behandelten Tumoren (siehe Abb. 3.30).

In Abb. 3.26 sind die überlagerten Histogrammdaten der BI-1- und Luc-siRNA/Ac behandelten Tumore dargestellt. An der Voxel-Anzahl können die Volumenunterschiede der BI-1- und Luc-siRNA/Ac-behandelten Tumore gezeigt werden. Die Unterschiede in der Kurvenneigung sind in dieser Darstellung nahezu vergleichbar. 


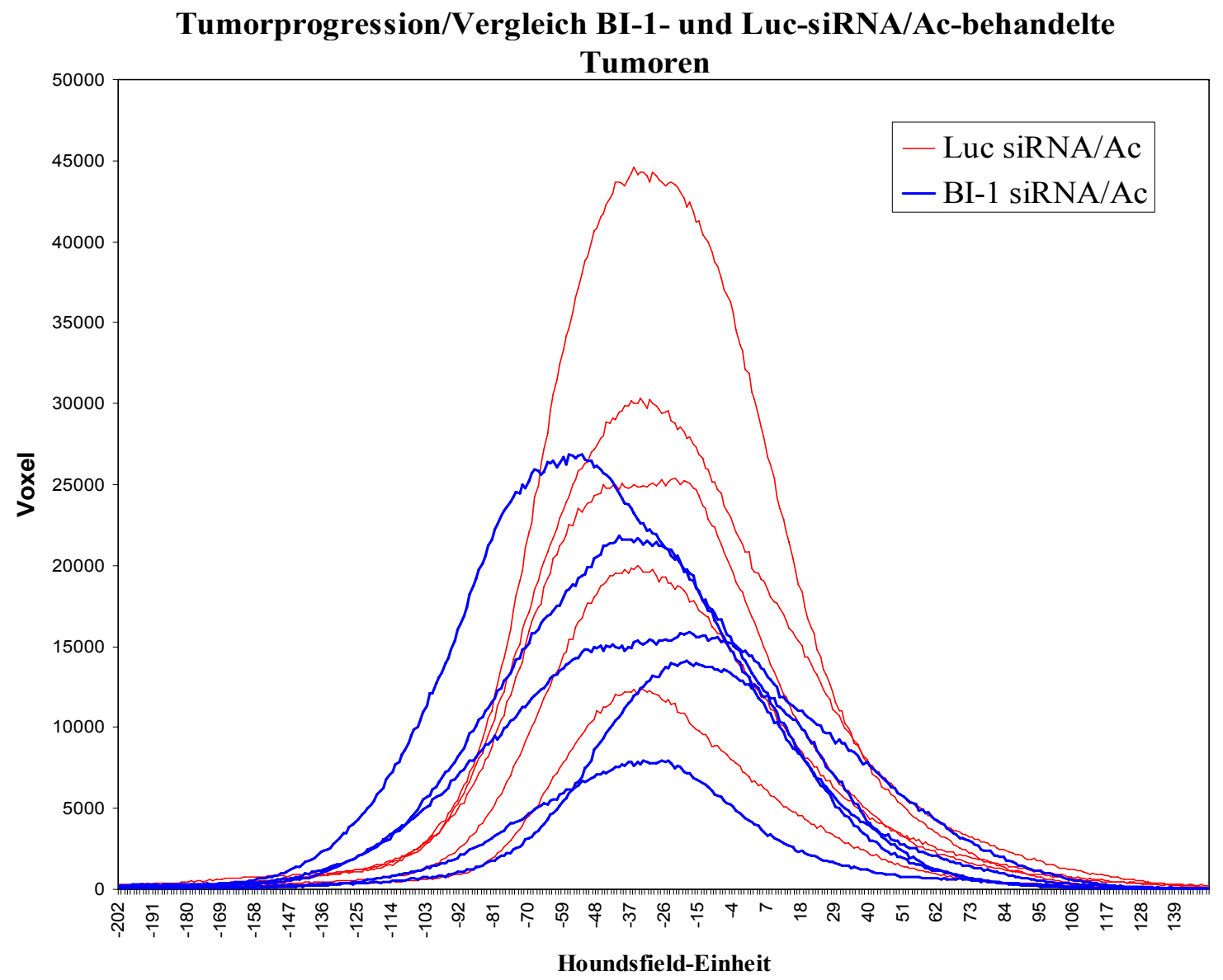

Abb. 3.26: Darstellung der Tumorprogression über FD-VCT-Messungen in Luc-siRNA/Ac und BI1-siRNA/Ac-behandelten Tumoren. Hier wurden die beiden Graphen von Abb. 3.24 und Abb. 3.25 überlagert, um die Effekte der Krümmung optimal darzustellen. Der Graph der BI-1-siRNA/Acbehandelten Tumoren wächst mit linkslastiger Krümmung, während der Graph der Luc-siRNA/Acbehandelten Tumoren ohne Krümmung wächst. Die Voxel-Anzahl zeigt die Volumen-Unterschiede der BI-1- siRNA/Ac-behandelten Tumoren im Vergleich zu den Luc-siRNA/Ac-behandelten Tumoren.

\subsubsection{Molekulare Bildgebung der mit Cy5.5 gekoppelten siRNAs mittels eXplore Optix Imager zur Überprüfung der Stabilität des siRNA/Ac- Komplexes}

Über das Optical Imaging-Verfahren mittels eXplore Optix Imager (GE) ist es möglich, die mit Cy5.5-gekoppelte siRNA in vivo zu lokalisieren. Dadurch ist es möglich zu überprüfen, ob die siRNA/Ac-Komplexe im Tumor gehalten werden oder sich im Körper verteilen und über welchen Zeitraum die siRNA/Ac-Komplexe stabil bleiben. 
Dazu wurde nach jeder siRNA/Ac-Injektion die Maus mittels eXplore Optix Imager gescannt. In Abb. 3.27 ist eine BI-1-Maus (Nr.1) aus dem Pilotexperiment exemplarisch dargestellt, die über einen Zeitraum von sechs Tagen nach der Injektion des BI-1siRNA/Ac-Komplexes mittels eXplore Optix Imager untersucht wurde. Der siRNA/AcKomplex bleibt über den gesamten untersuchten Zeitraum detektierbar und ist somit im Tumor weitestgehend stabil.

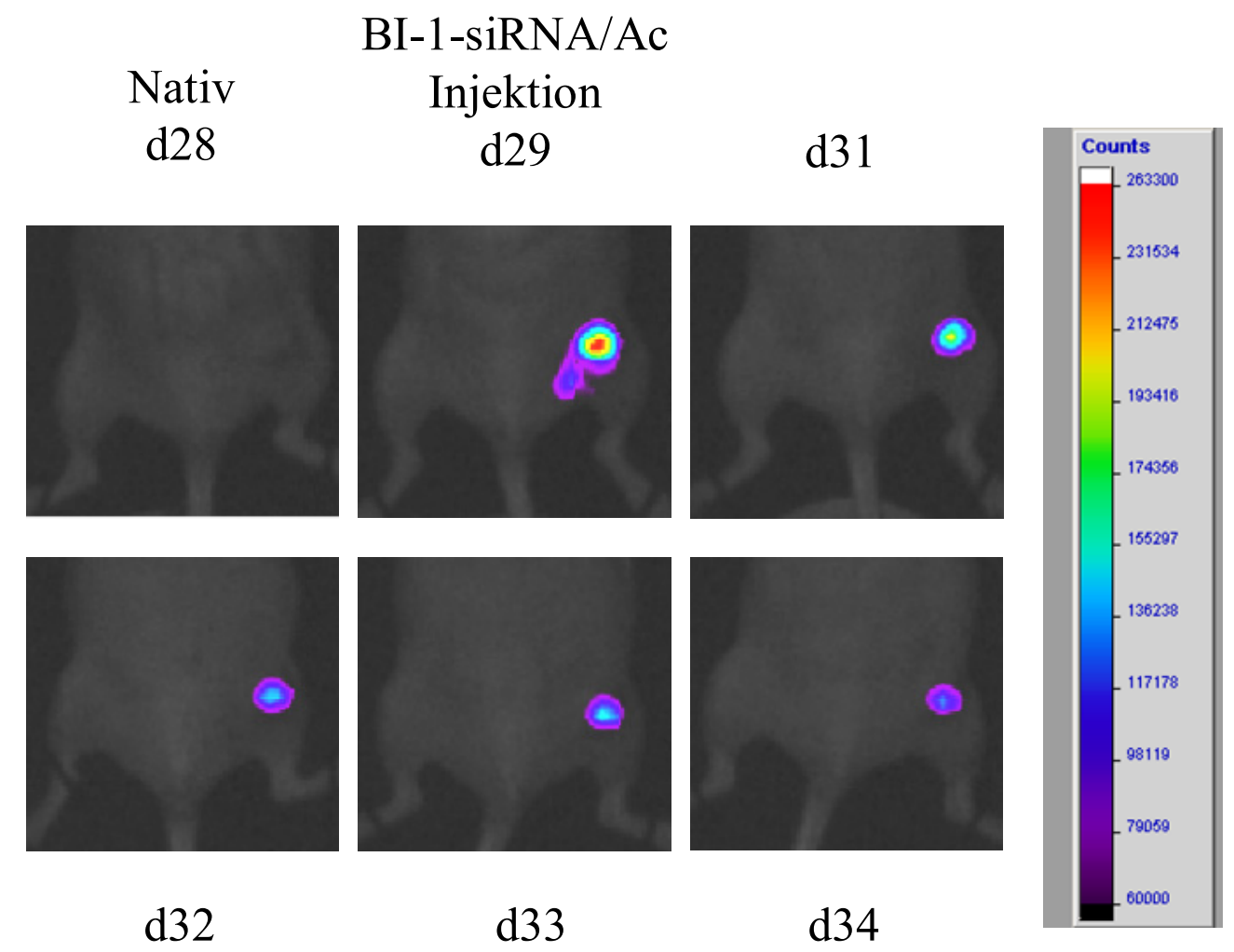

Abb. 3.27: Übersicht der Optical Imaging Daten über einen Zeitraum von sieben Tagen (BI-1-Maus Nr. 1). Am 29. Tag nach der Implantation der MDA-MB-231-Zellen wurde die erste Behandlung mit den BI-1-siRNA/Ac-Komplexen begonnen (Pfeil). Einen Tag zuvor wurde die Maus ohne siRNA/Ac gemessen. Über sechs weitere Tage wurde die Signalstärke gemessen. Im rechten Balkendiagramm sind die Counts abgebildet, die Informationen über die Intensität der Signale liefern. Dabei stellt Rot die intensivste Signalstärke und Lila die schwächste Signalstärke dar. Der siRNA/Ac-Komplex verbleibt im Tumor und wird nicht im Körper verteilt. Am 35. Tag nach der Implantation wurden die Mäuse erneut mit siRNA/Ac-Komplexen behandelt. 


\subsubsection{In vivo-Hauptexperiment}

Das in vivo-Hauptexperiment wurde mit vierzehn Mäusen durchgeführt. Bei zwei Mäusen haben sich keine Tumoren nach der Implantation der MDA-MB-231-Zellen entwickelt.

Die Experiment-Bedingungen gleichen denen des Pilotexperiments. Beim Hauptexperiment wurde der zeitliche Verlauf kürzer gewählt, um die siRNA/AcBehandlungseffekte möglichst ohne die spontane Nekrose beobachten zu können. Die Behandlungsabstände wurden auf vier Tage reduziert, um eine möglichst hohe Effizienz der siRNA/Ac-Komplexe zu gewährleisten.

Das Hauptexperiment lief über einen Zeitraum von 34 Tagen nach der MDA-MB-231Implantation. Am 35. Tag wurden die Mäuse abgetötet und die Tumoren isoliert. Die Behandlungen mit siRNA/Ac wurden im Abstand von vier Tagen durchgeführt (d26 und $\mathrm{d} 30)$.

\subsubsection{Messung der Tumorvolumina und der Gewichtszunahme der Mäuse während des Zeitraumes des in vivo-Experiments}

Die Gewichtsbestimmung der Mäuse wurde täglich durchgeführt. Während des gesamten Hauptexperiments wurden keine auffälligen Gewichtsabnahmen beobachtet ( Abb. 3.28). 


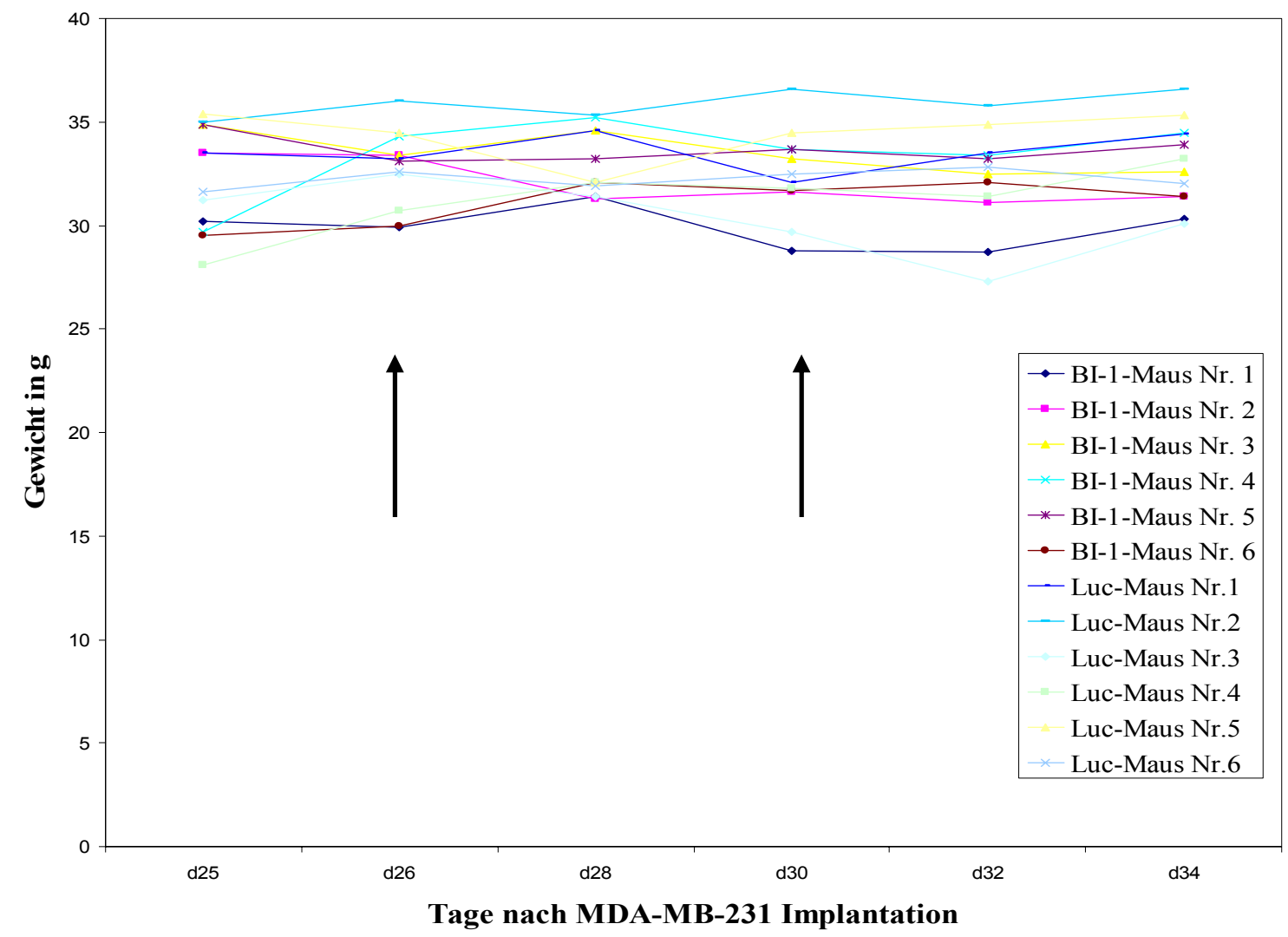

Abb. 3.28: Gewichtsentwicklung der untersuchten Mäuse. Die X-Achse zeigt die Tage nach der Implantation der MDA-MB-231-Zellen. Die Y-Achse stellt das Gewicht der Mäuse in g dar. Eines der Abbruchkriterien für das Experiment war eine starke Abnahme des Gewichts. Während der gesamten Dauer des Experiments wurde keine auffällige Gewichtsabnahme beobachtet. Sechs Mäuse wurden mit den BI-1-siRNA/Ac-Komplexen behandelt und sechs Mäuse mit den Luc-siRNA/Ac-Komplexen. Die Pfeile markieren die Injektionszeitpunkte der siRNA/Ac-Komplexe.

Für die Tumorprogression wurde die Messung des Tumorvolumens mittels Flächendetektor-Volumetrischer-Computertomographie (FD-VCT) durchgeführt (Abb. 3.29).

Vier Tage nach der ersten siRNA/Ac-Injektion wurde bei den BI-1-siRNA/Acbehandelten Tumoren bereits ein verlangsamtes Wachstum beobachtet (Abb. 3.29, d30), während bei den Kontrolltumoren keine Verlangsamung des Wachstums erkennbar war. Bei den mit BI-1-siRNA/Ac-behandelten Tumoren wurde im Vergleich zu den LucsiRNA/Ac-behandelten Kontrolltumoren 34 Tage (d34) nach Implantation der MDAMB-231-Zellen ein Volumenunterschied von durchschnittlich über $75 \mathrm{~mm}^{3}$ beobachtet. 


\section{Tumorprogression in vivo-Studie}

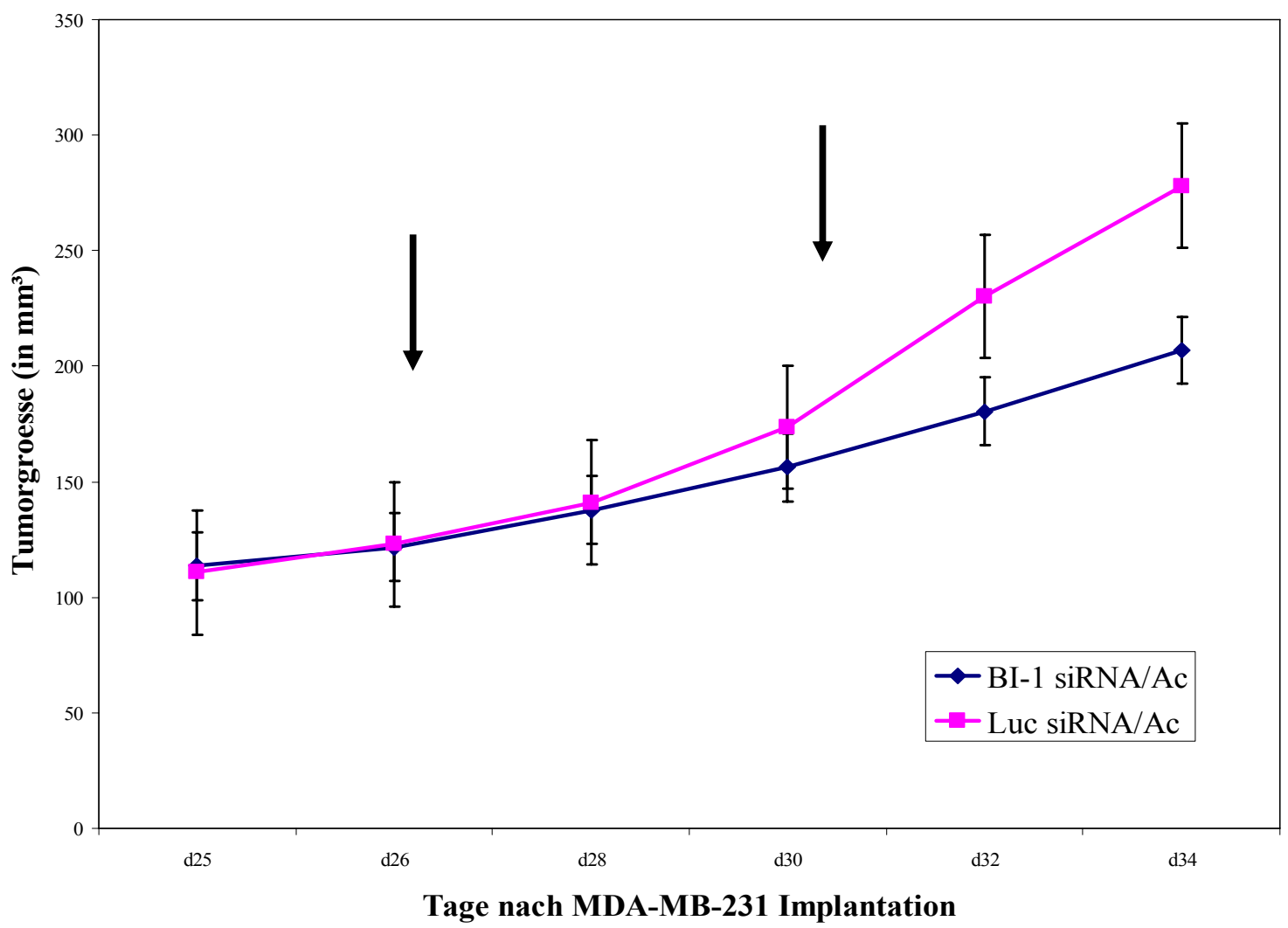

Abb. 3.29: Verlaufsdiagramm der Tumorprogression während des in vivo-Experiments und die Messdaten der Tumorgrößen. Für die Tumorprogression wurde die Messung des Tumorvolumens mittels Flächendetektor-Volumetrische-Computertomographie (FD-VCT) durchgeführt. Ein VolumenUnterschied von durchschnittlich über $75 \mathrm{~mm}^{3}$ ist bei den BI-1-siRNA/Ac injizierten Mäusen im Vergleich zu den Luc-siRNA/Ac injizierten Kontrollmäusen nach 34 Tagen zu sehen. Die Pfeile markieren die Injektionszeitpunkte der siRNA/Ac-Komplexe. Die Balken zeigen Standardfehler zum jeweiligen Zeitpunkt an. 


\begin{tabular}{|c|c|c|c|c|c|c|}
\hline & d25 & d26 $\downarrow$ & d28 & d30 $\downarrow$ & d32 & d34 \\
\hline Bl-1-Maus Nr. 1 & 92 & 99 & 111 & 118 & 135 & 144 \\
\hline BI-1-Maus Nr. 2 & 117 & 121 & 134 & 156 & 167 & 204 \\
\hline Bl-1-Maus Nr. 3 & 68 & 82 & 115 & 125 & 160 & 186 \\
\hline Bl-1-Maus Nr. 4 & 118 & 129 & 135 & 158 & 190 & 230 \\
\hline Bl-1-Maus Nr. 5 & 104 & 107 & 119 & 136 & 155 & 187 \\
\hline Bl-1-Maus Nr. 6 & 182 & 192 & 213 & 245 & 275 & 290 \\
\hline Mittelwert & 113,5 & 121,6 & 137,8 & 156,3 & 180,3 & 206,8 \\
\hline Standardabweichung & 38,3 & 38,2 & 38,1 & 46,3 & 49,7 & 49,5 \\
\hline Standardfehler & 35,8 & 35,8 & 35,8 & 35,8 & 35,8 & 35,8 \\
\hline p-Wert & 0,94 & 0,81 & 0,74 & 0,41 & 0,13 & 0,07 \\
\hline & d25 & d26 $\downarrow$ & d28 & d30 & d32 & d34 \\
\hline Luc-Maus Nr. 1 & 133 & 143 & 171 & 226 & 288 & 339 \\
\hline Luc-Maus Nr. 2 & 114 & 125 & 140 & 180 & 267 & 327 \\
\hline Luc-Maus Nr. 3 & 100 & 128 & 139 & 161 & 218 & 277 \\
\hline Luc-Maus Nr. 4 & 59 & 67 & 81 & 99 & 115 & 128 \\
\hline Luc-Maus Nr. 5 & 148 & 152 & 172 & 202 & 263 & 319 \\
\hline Luc-Maus Nr. 6 & 136 & 144 & 168 & 205 & 257 & 315 \\
\hline Mittelwert & 115 & 126,5 & 145,2 & 178,8 & 234,7 & 284,2 \\
\hline Standardabweichung & 32,3 & 30,9 & 34,9 & 45,0 & 62,9 & 79,3 \\
\hline Standardfehler & 66,5 & 66,5 & 66,5 & 66,5 & 66,5 & 66,5 \\
\hline p-Wert & 0,94 & 0,81 & \begin{tabular}{|l|}
0,74 \\
\end{tabular} & 0,41 & 0,13 & 0,07 \\
\hline
\end{tabular}

Tab. 3.2: FD-VCT-Messdaten der Tumorgrößen (in $\mathbf{m m}^{3}$ ). Die Tabelle zeigt die exakten FD-VCTMessdaten der Tumorgrößen in $\mathrm{mm}^{3}$ sowie den Mittelwert, Standardabweichung, Standardfehler und den p-Wert zu jeweiligen Zeitpunkt an. Die Pfeile markieren die Injektionszeitpunkte der siRNA/AcKomplexe.

Die mittels FD-VCT segmentierten Tumore sind beispielhaft für zwei Mäuse in Abb. 3.30 dargestellt. Die volumetrischen Messungen belegen, dass die BI-1-siRNA/Acbehandelten Tumoren (BI-1-Maus Nr.2) langsamer wuchsen als die mit Luc-siRNA/Acbehandelten Kontrolltumoren (Luc-Maus Nr.2). 
A FD-VCT-Daten der Tumorprogression (BI-1-Maus Nr.2)
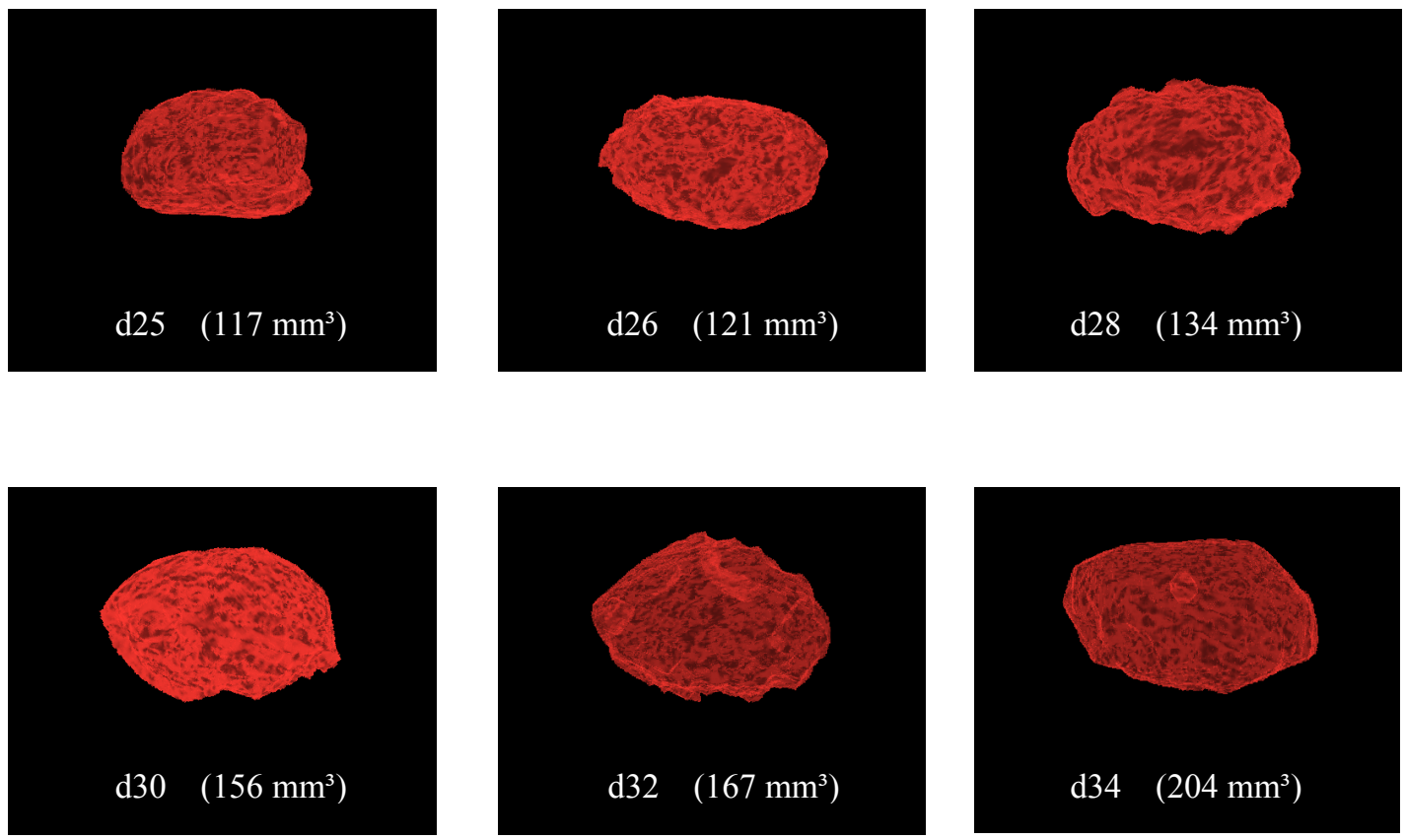

B FD-VCT-Daten der Tumorprogression (Luc-Maus Nr.2)
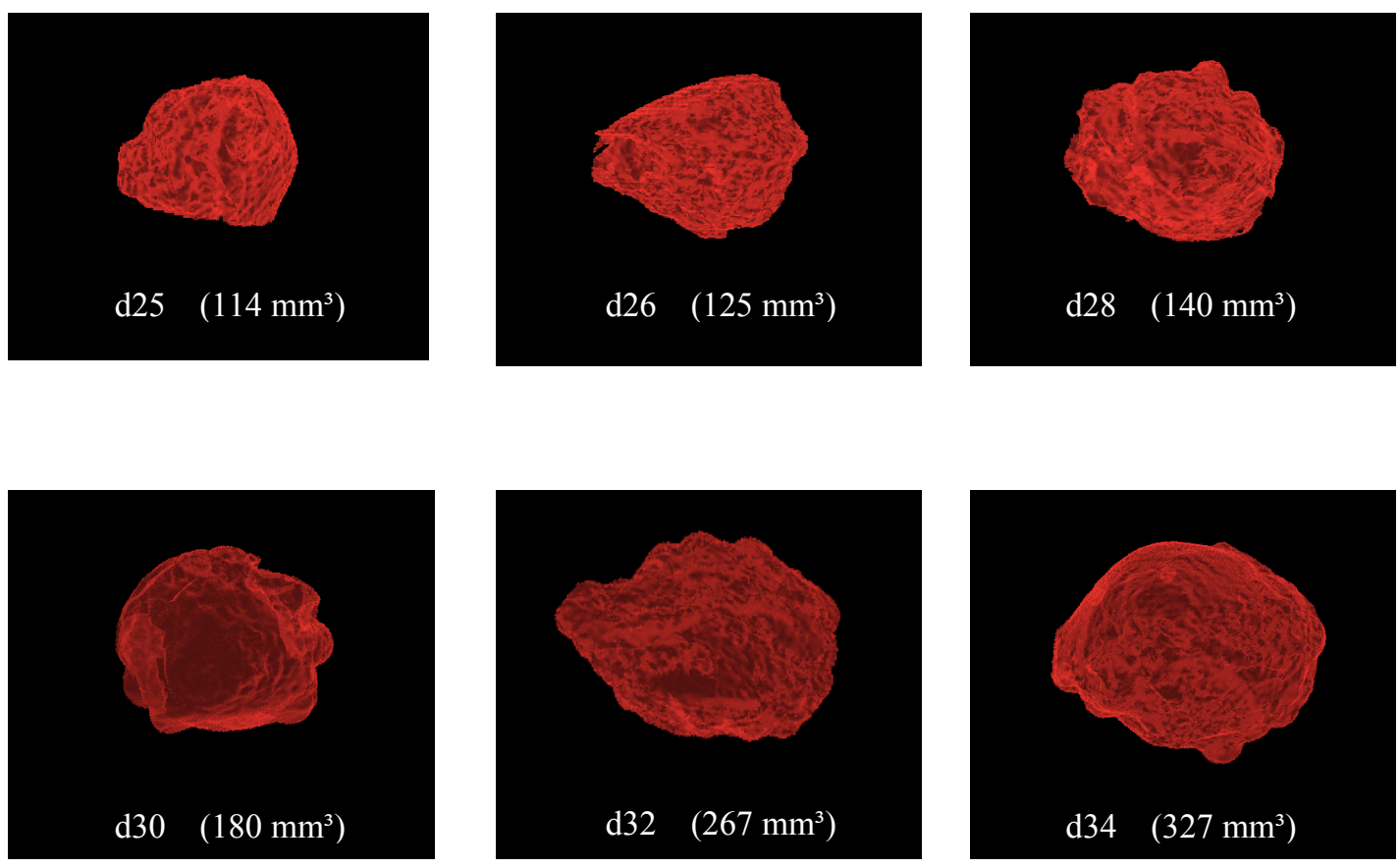

Abb. 3.30: Tumorprogression bei der mit BI-1-siRNA/Ac behandelten Maus Nr. 2 (A) und der mit Luc-siRNA/Ac behandelten Kontroll-Maus Nr. 2 (B). Die Tumorvolumina wurde mit Hilfe der FDVCT erhoben. Im Vergleich zu der Luc-Kontrollmaus Nr. 2 (B) zeigt die BI-1-Maus Nr. 2 (A) ein weniger starkes Tumorwachstum. Die Tumorvolumina bei Ende des Experimentes zeigen einen Unterschied von über $123 \mathrm{~mm}^{3}$. Die Tumoren wurden nach 26 und 30 Tagen nach der MDA-MB-231- 
Implantation mit den entsprechenden siRNA/Ac-Komplexen behandelt. Exakt 34 Tage nach der Implantation wurden die Mäuse abgetötet und die Tumoren isoliert.

Die Abb. 3.31 zeigt den mittels FD-VCT segmentierten Tumor mit der gesamten MausUnterleibs-Rekonstruktion und weitere Abbildungen verschiedener Zeiträume. Die Schwierigkeiten mit der Schieblehre, die genauen Tumorvolumina auszumessen, werden hier deutlich, weil eine genaue Tiefenmessung bei der lebenden Maus nicht möglich ist. Die volumetrische Messung der FD-VCT lieferte daher die zuverlässigeren Daten. 
A FD-VCT-Daten der Tumorprogression (BI-1-Maus Nr.2)

d26
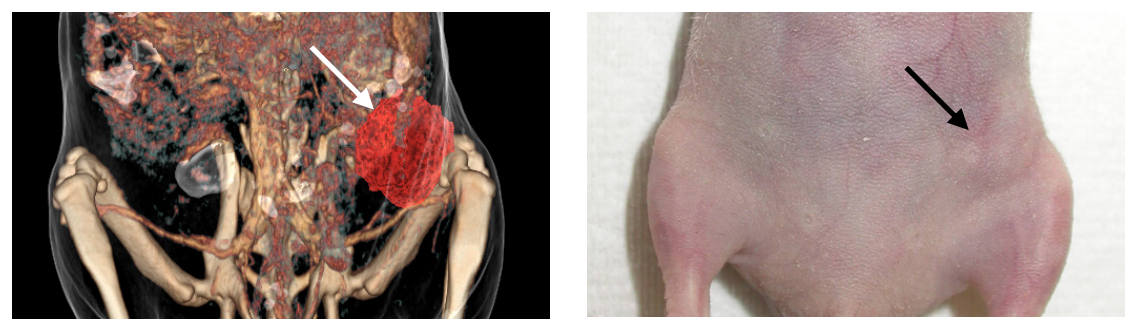

d28
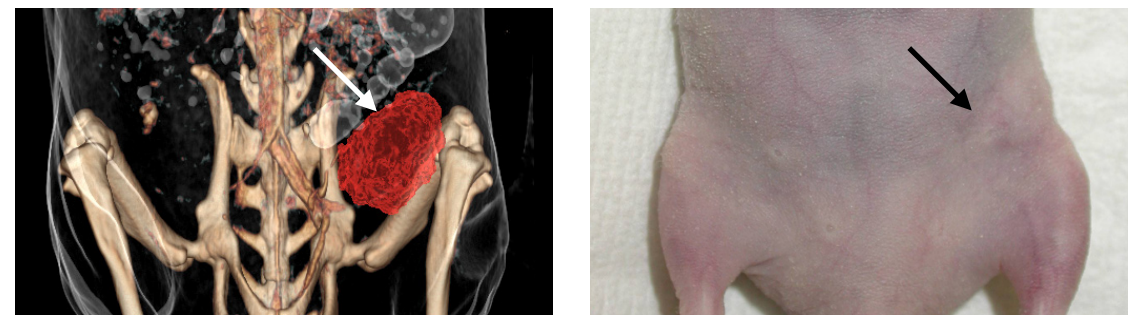

d30
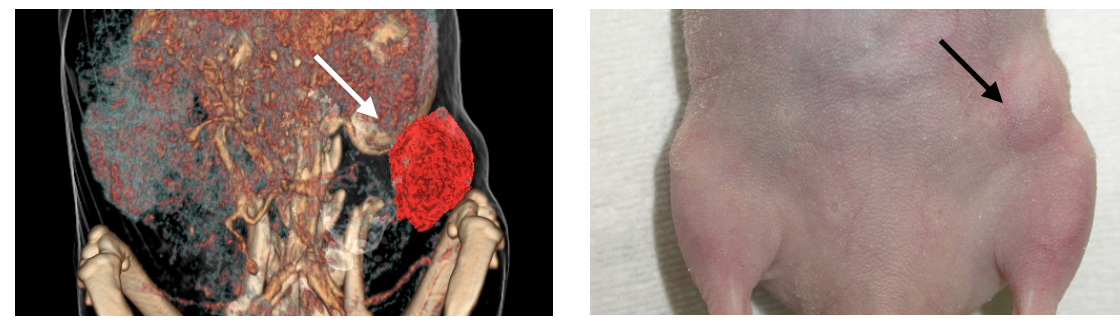

d32
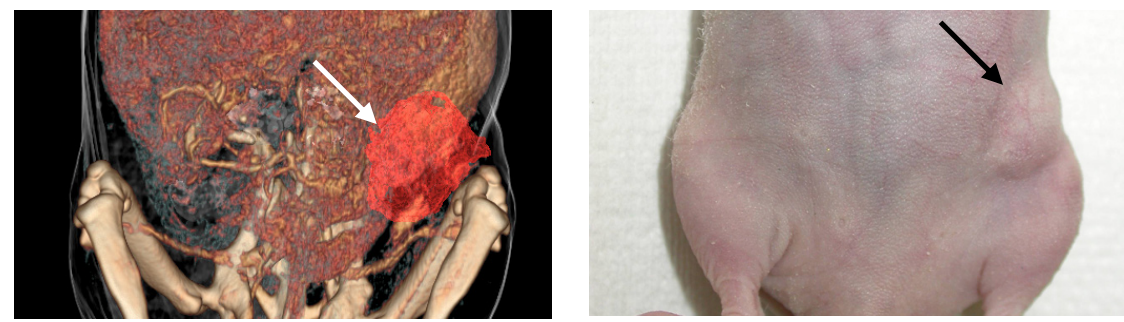

d34
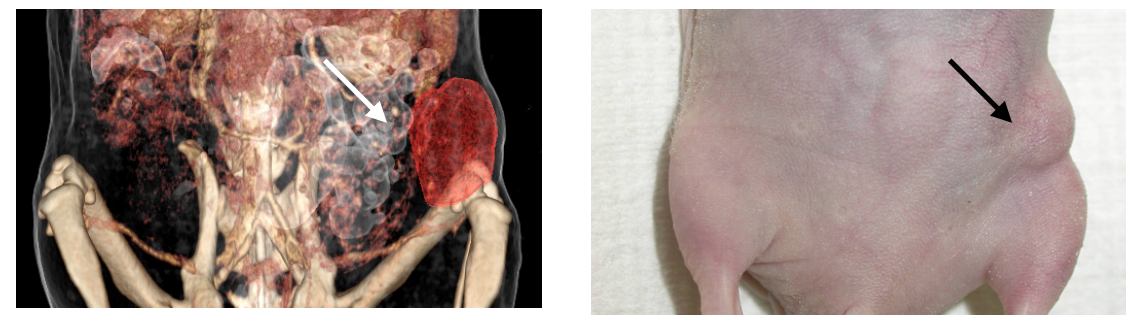
B FD-VCT-Daten der Tumorprogression (Luc-Maus Nr.2)

d26
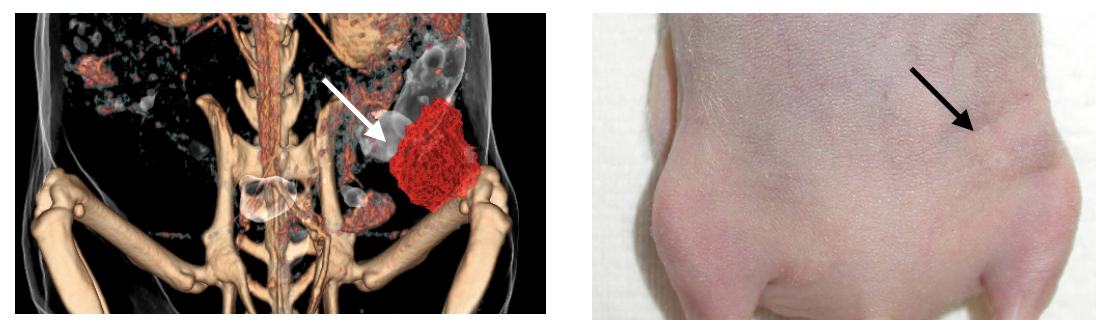

d28
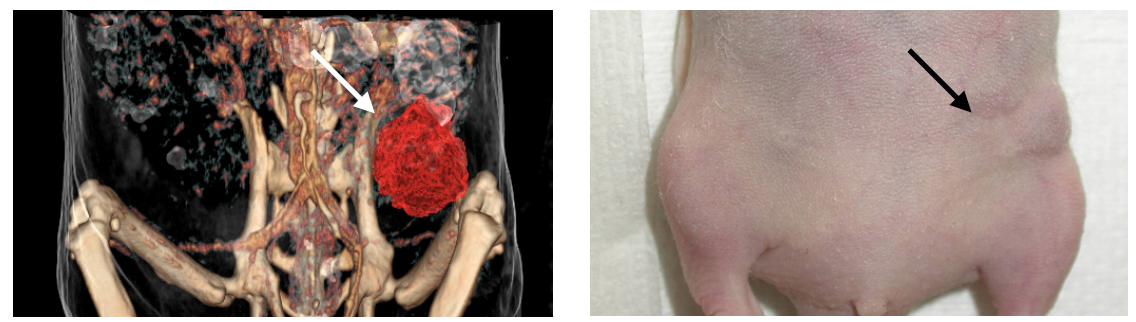

d30
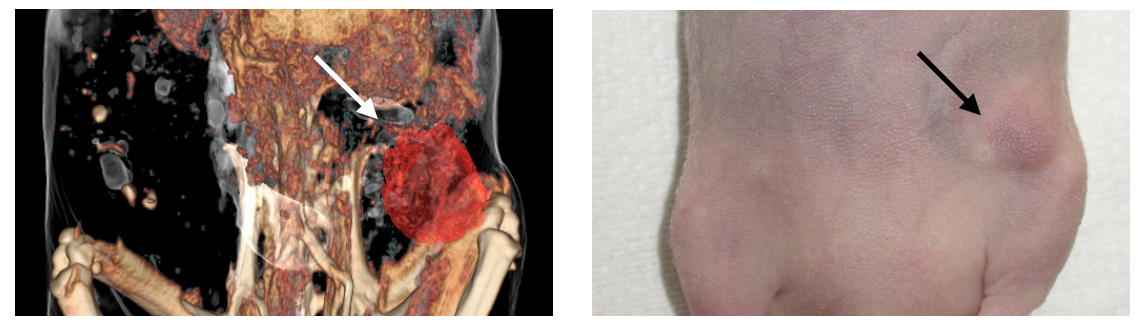

d32
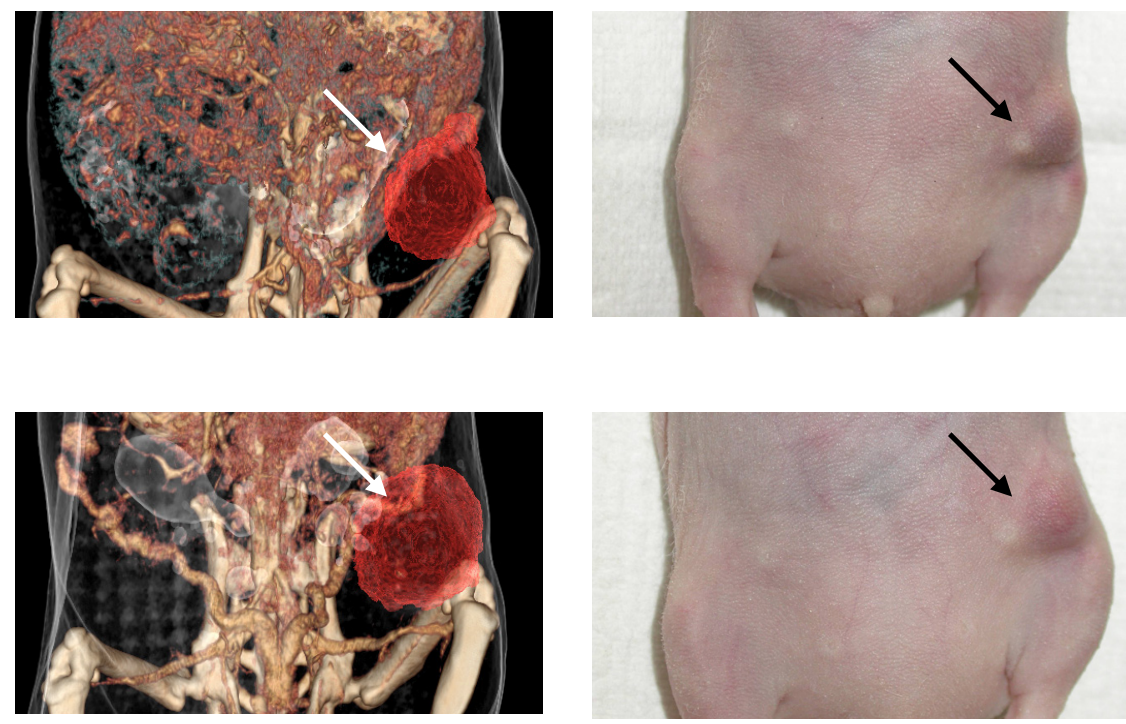

Abb. 3.31: Darstellung der MDA-MB-231-Tumoren mittels FD-VCT und Foto-Material im Vergleich. (A) Exemplarische Tumordarstellung in der BI-1-siRNA/Ac behandelten Maus (BI-1-Maus Nr. 2) über FD-VCT mit einer komplett rekonstruierten Maus und daneben die realen Fotos desselben Tieres zum gleichen Zeitpunkt. (B) Exemplarische Tumordarstellung der Luc-siRNA/Ac behandelten 
Maus (Luc-Maus Nr. 2) über FD-VCT mit einer komplett rekonstruierten Maus und daneben die realen Fotos desselben Tieres zum gleichen Zeitpunkt. Anhand der FD-VCT-Bilder sind die Lage und die tatsächliche Größe des Tumors in der Maus erkennbar.

\subsubsection{Molekulare Bildgebung der mit Cy5.5 gekoppelten siRNAs mittels eXplore Optix Imager}

In Abb. 3.32 sind die Optical Imaging-Daten von BI-1- und Luc-siRNA/Ac behandelten Mäusen abgebildet, welche belegen, dass der siRNA/Ac-Komplex lokal im Tumor verbleibt und zu keinem Zeitpunkt über den Körper verteilt wurde. Die Messungen wurden über den gesamten Zeitraum des Experiments durchgeführt. 
A

BI-1 Maus Nr. 2

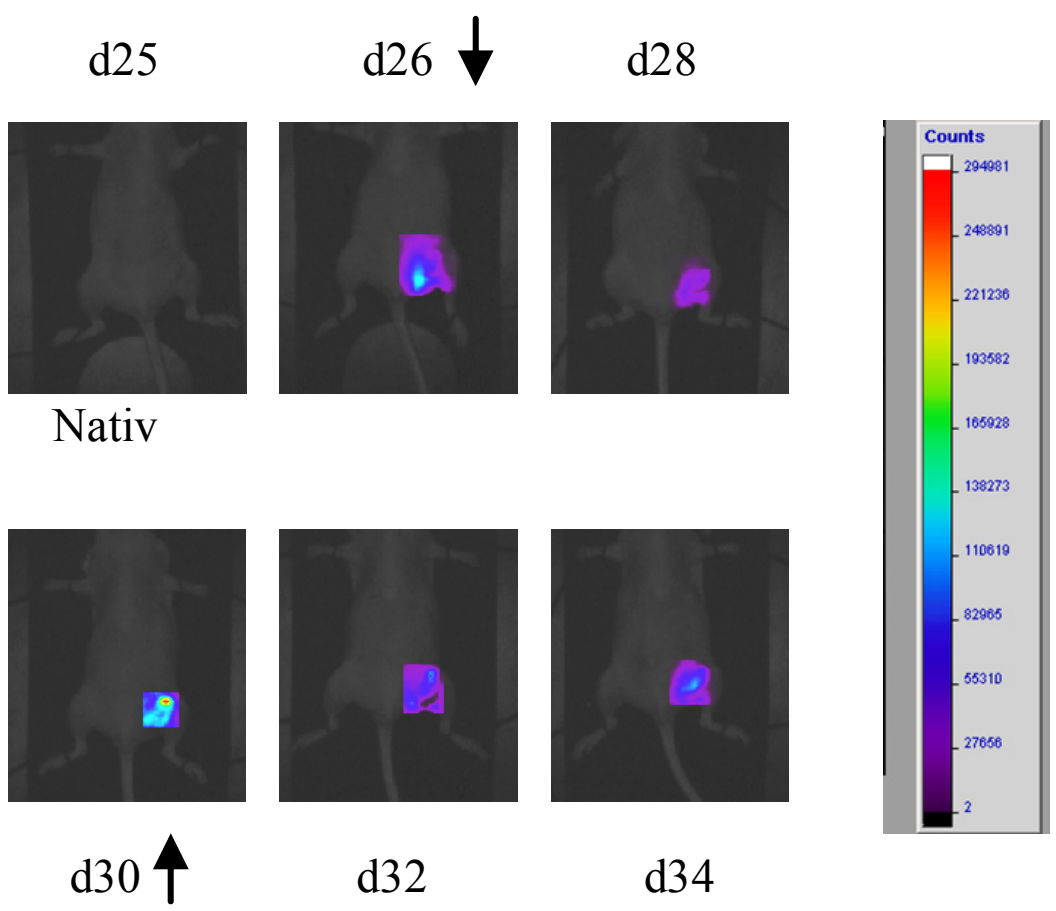

B

Luc Maus Nr. 2
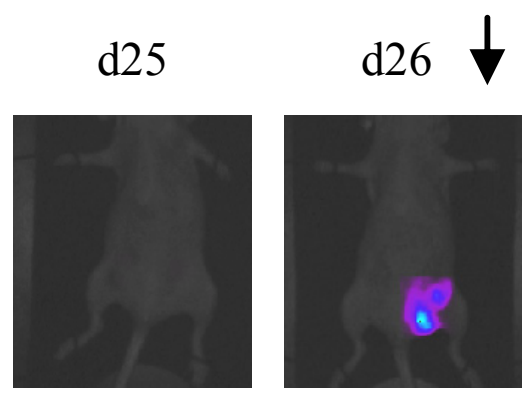

Nativ
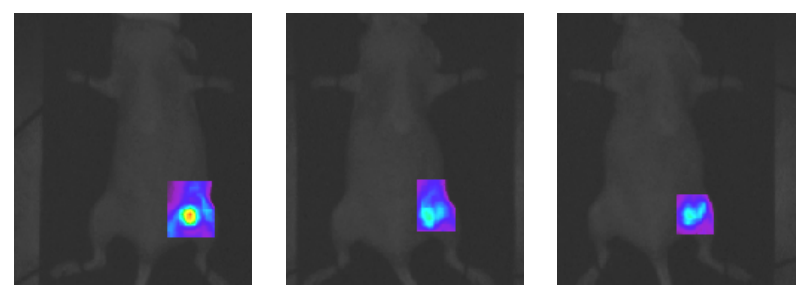

d30 个

d32
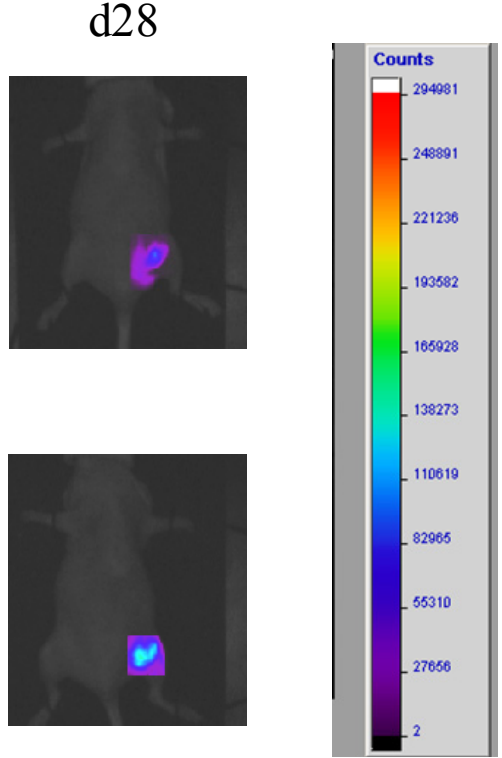

d34 
Abb. 3.32: Übersicht der Optical Imaging-Daten über den gesamten Zeitraum des Experiments. Dargestellt sind die exemplarischen Daten der BI-1-Maus Nr. 2 (A) und der Luc-Maus Nr. 2 (B). Am 26. und 30. Tag nach der Implantation von MDA-MB-231-Zellen wurden die Mäuse mit siRNA/AcKomplexen behandelt (Pfeile). Rechts in dem Balkendiagramm sind die Counts abgebildet, welche Informationen über die Intensität der Signale liefern. Dabei stellt die Farbe rot die intensivste und lila die schwächste Signalstärke dar. Der siRNA/Ac-Komplex verbleibt während des gesamten Experiments im Tumor und wird nicht im Körper verteilt.

\subsubsection{Sektion und Isolierung der Tumoren aus den Mammae der Versuchstiere}

Die Versuchstiere wurden 34 Tage nach der MDA-MB-231-Implantation abgetötet und die Tumoren operativ entfernt und gewogen (Abb. 3.33). Beim Schnitt durch den Tumor waren Unterschiede in der Konsistenz der Gewebe zu beobachten. Die BI-1siRNA/Ac behandelten Tumore besaßen im Inneren der Tumore eine weichere Konsistenz als die mit Luc-siRNA/Ac behandelten Kontrolltumoren (Abb. 3.33). 

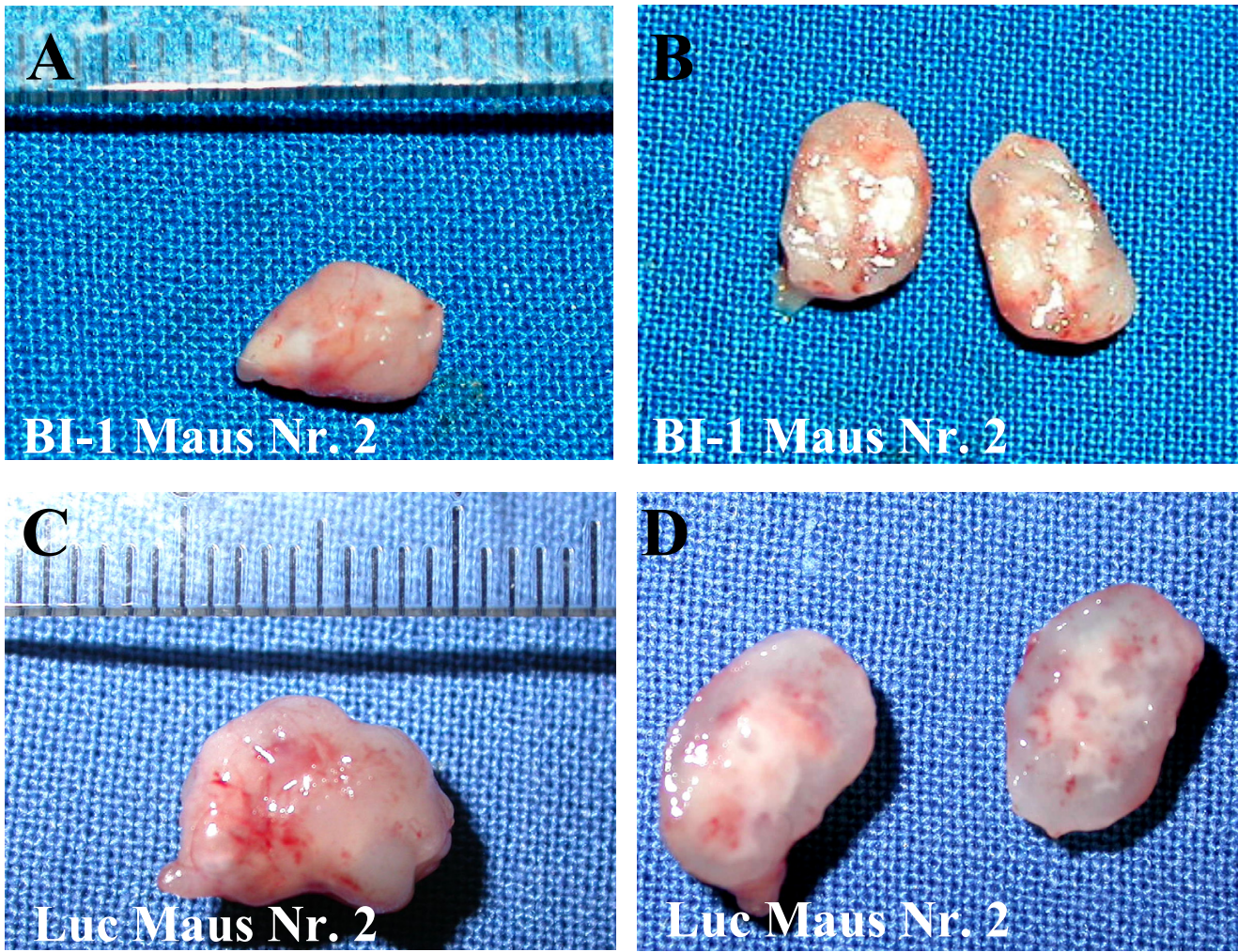

Gewichte der isolierten Tumoren

\begin{tabular}{|l|l|l|l|l|}
\hline BI-1-Maus Nr. & Tumorgewicht (mg) & & Luc-Maus Nr. & Tumorgewicht (mg) \\
\hline 1 & 176 & 1 & 366 \\
\hline 2 & 221 & 2 & 329 \\
\hline 3 & 186 & 3 & 284 \\
\hline 4 & 213 & 4 & 132 \\
\hline 5 & 130 & 5 & 304 \\
\hline 6 & 308 & 6 & 243 \\
\hline Mittelwert & 205,7 & Mittelwert & 276,3 \\
\hline Standardabweichung & 59,6 & Standardabweichung & 82,0 \\
\hline
\end{tabular}

Abb. 3.33: Aufnahmen der isolierten Tumoren aus der BI-1-Maus Nr. 2 (A und B) und der LucMaus Nr. 2 (C und D) und Gewichtmessungen der isolierten Tumore. Die Mäuse wurden 34 Tage nach der MDA-MB-231-Implantation abgetötet und die Tumoren aus den Mammae isoliert. Zum Zeitpunkt der Sektion besaß der Tumor der BI-1-Maus Nr. 2 ein Tumorvolumen von $204 \mathrm{~mm}^{3}$ (A) und wog $221 \mathrm{mg}$. Der Tumor der Luc-Maus Nr. 2 besaß ein Volumen von $327 \mathrm{~mm}^{3}$ (C) und wog $329 \mathrm{mg}$. (B) und (D) zeigen die in der Mitte aufgeschnittenen Tumoren. Die Tabelle darunter zeigt die Tumorgewichte in $\mathrm{g}$. 


\subsubsection{Histologische Untersuchungen an Tumorgewebeschnitten mittels Hämatoxylin-Eosin-Färbung sowie Cy5.5-Infrarotmikroskopie}

Die isolierten Tumoren wurden halbiert und je eine Hälfte für Kryo- und Paraffinschnitte verwendet. Die Paraffingewebeschnitte wurden mit Hämatoxylin-Eosin (HE) gefärbt und die Kryogewebeschnitte wurden mit DAPI gefärbt. Anschließend wurden die Kryoschnitte der Tumoren mit Hilfe der Infrarotmikroskopie auf das Vorhandensein der Cy5.5-gekoppelten siRNA hin untersucht. Dabei sollte nach Injektion die Lokalisation der siRNA/Ac-Komplexe im Inneren des Tumors geklärt werden.

Alle isolierte Tumore konnten in nekrotische, pränekrotische und vitale Bereiche unterteilt werden. Dabei befindet sich der nekrotische Bereich (NB) des Tumors im zentralen Tumorbereich, während sich der vitale Bereich des Tumors im äußeren Bereich des Tumors befindet. Dazwischen liegt der pränekrotische Bereich (PB), der den Übergang vom nekrotischen zum vitalen Tumor darstellt (Abb. 3.34).

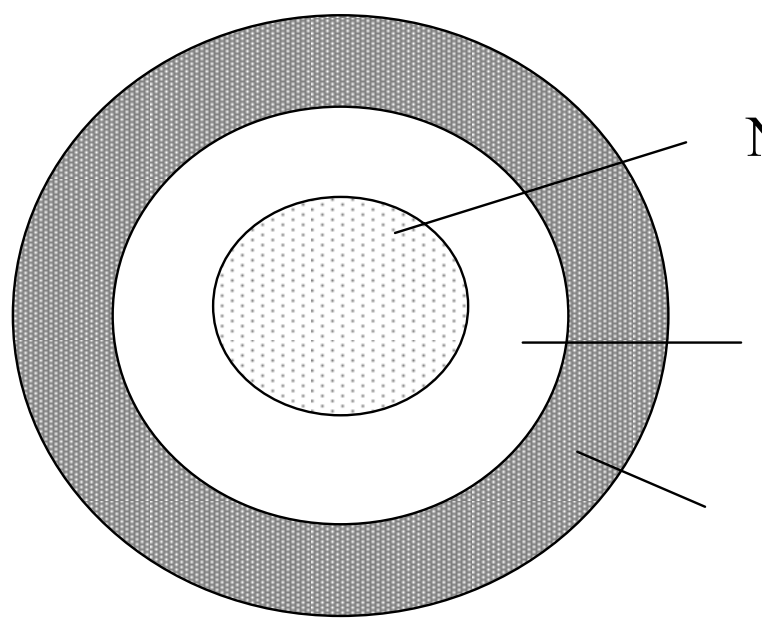

Nekrotischer Bereich (NB)

\section{Pränekrotischer Bereich (PB)}

\section{Vitaler Bereich (VB)}

Abb. 3.34: Schematische Darstellung des Tumors bezüglich der Gliederung in nekrotische- (NB), pränekrotische (PB) und vitale Bereiche (VB). Der nekrotische Bereich (NB) des Tumors befindet sich im zentralen Tumorbereich, während sich der vitale im äußeren Bereich des Tumors befindet. Der Bereich dazwischen stellt den sog. pränekrotischen Bereich dar.

Die in Paraffin eingebetteten Tumorgewebe wurden mit HE gefärbt und unter einem Hellfeld-Mikroskop untersucht. Bei allen Tumoren ist eine massive Nekrose im 
mittleren Bereich des Tumors zu erkennen (Abb. 3.35). Das vitale Gewebe umschließt die nekrotischen Gewebeanteile, wobei kein Unterschied zwischen den BI-1-siRNA/Acbehandelten Mäusen und den Luc-siRNA/Ac-behandelten Mäusen festzustellen ist. In den nekrotischen Tumorarealen sind keine definierten Zellstrukturen sowie eine Abnahme der Zellkernzahl zu erkennen.

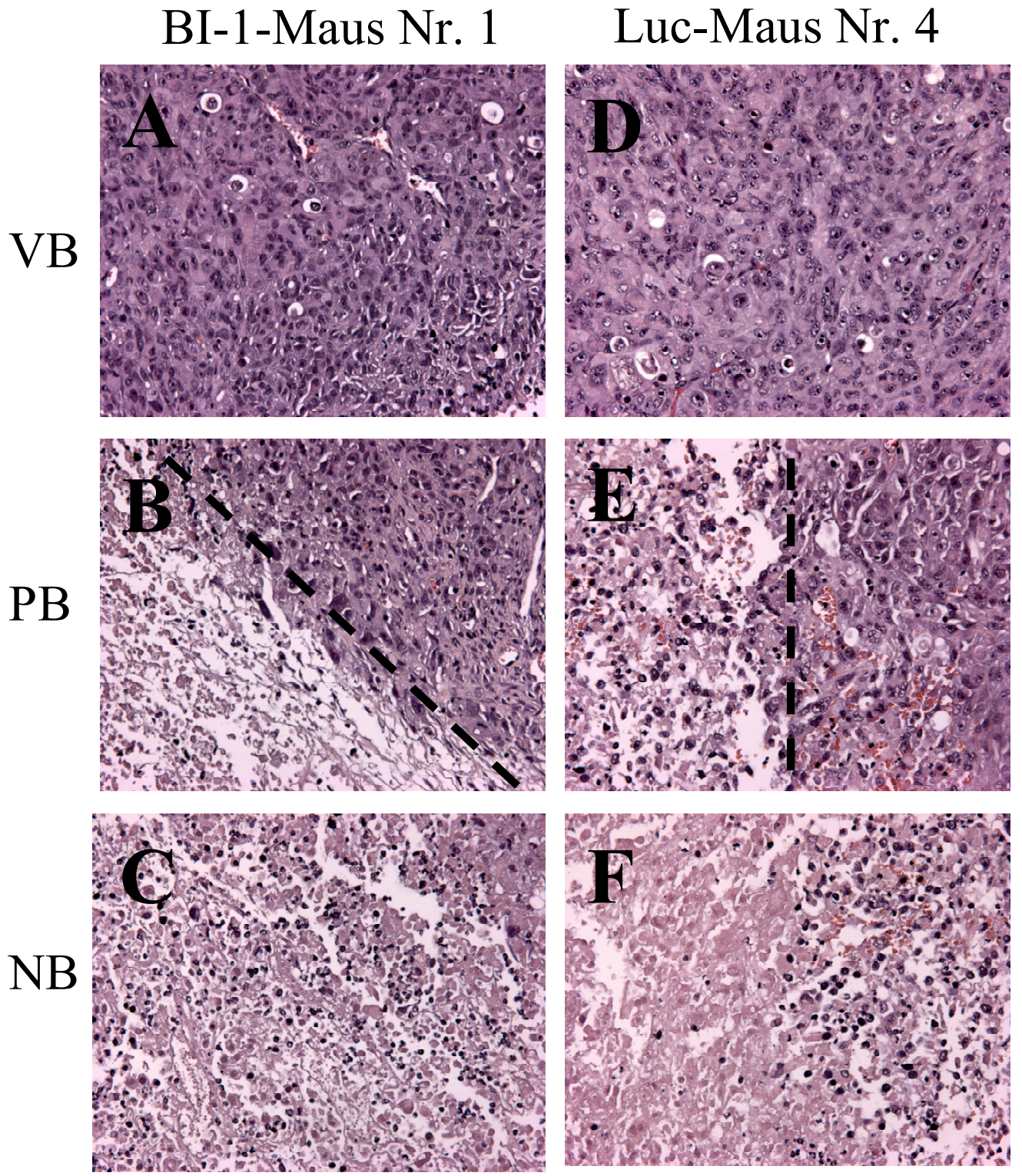

Abb. 3.35: Hellfeld-Mikroskopie-Aufnahmen von Paraffin eingebetteten Gewebeschnitten von

Tumoren aus dem in vivo-Experiment. Die Gewebeschnitte wurden mit Hämatoxylin-Eosin gefärbt. Die Spalten stellen exemplarisch Tumorgewebeschnitte der BI-1-Maus (Daten von BI-1-Maus Nr.1: AC)- und der Luc-Maus-(Daten von Luc-Maus Nr.4:D-F) dar. Die Zeilen VB, PB, NB sind aufgeteilt in 
den vitalen Bereich (VB), pränekrotischen Bereich (PB) und in den nekrotischen Bereich (NB). Es wurden keine Unterschiede in den mikroskopischen Untersuchungen zwischen BI-1-siRNA- und LucsiRNA-transfizierten Tumoren beobachtet. In A und D sind vitale Tumorgewebebereiche zu sehen, die im Randbereich des Tumors das nekrotische Gewebe umschließen. In B und E sind die Übergangsbereiche (gestrichelte Linie) von vitalen Tumorgewebebereichen zu nekrotischen Bereichen zu erkennen. In $\mathrm{C}$ und F sind massive nekrotische Bereiche zu erkennen, die im Zentrum des Tumors lokalisiert sind. Alle Aufnahmen wurden bei 200-facher Vergrößerung aufgenommen.

Bei allen isolierten Tumoren konnten keine Unterschiede in den Infrarotmikrokopischen Untersuchungen festgestellt werden. Abb. 3.36 zeigt einen Ausschnitt aus dem nekrotischen Bereich des Tumors, der vom siRNA/Ac-Komplex infiltriert worden ist. Die siRNA/Ac-Komplexe sind in die Zellformationen infiltriert und gleichmäßig verteilt. Bei allen Tumoren konnten die siRNA/Ac-Komplexe in den Geweben nachgewiesen werden. Die Zellkerne sind mit DAPI gegengefärbt.
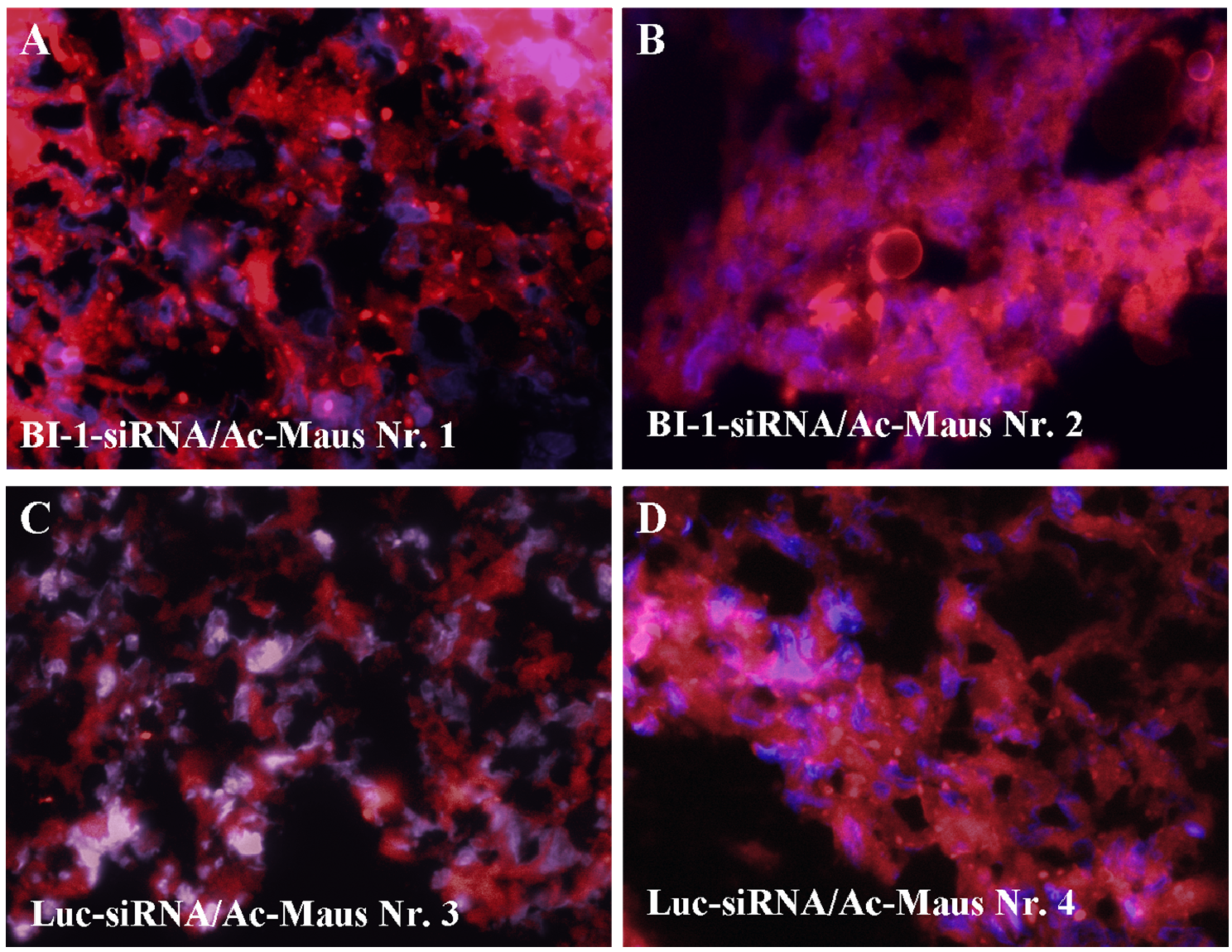

Abb. 3.36: Infrarot-Mikroskopieaufnahmen von siRNA/Ac-transfizierten Tumorgeweben (Kryoschnitt-Objekt). Die Zellkerne wurden mit DAPI gegengefärbt (blau). (A) und (B) BI-1 siRNA/Ac 
transfiziertes Gewebe von den BI-1-Mäusen Nr. 1 und Nr. 3. (C) und (D) Luc-siRNA/Ac transfiziertes Gewebe von den Luc-Mäusen Nr. 2 und Nr. 4 (Kontrolle). Der siRNA/Ac-Komplex ist rot gefärbt und zytoplasmatisch lokalisiert. Die Aufnahmen wurden bei 200-facher Vergrößerung durchgeführt.

Abb. 3.37 zeigt einen Ausschnitt aus dem vitalen Bereich des Tumors, der vom siRNA/Ac-Komplex infiltriert worden ist (rote Färbung). Hier ist zu erkennen, dass der siRNA/Ac-Komplex effektiv in die Zellzwischenräume und in das Zytoplasma der Zellen infiltriert ist. Die Zellkerne sind mit DAPI gegengefärbt.

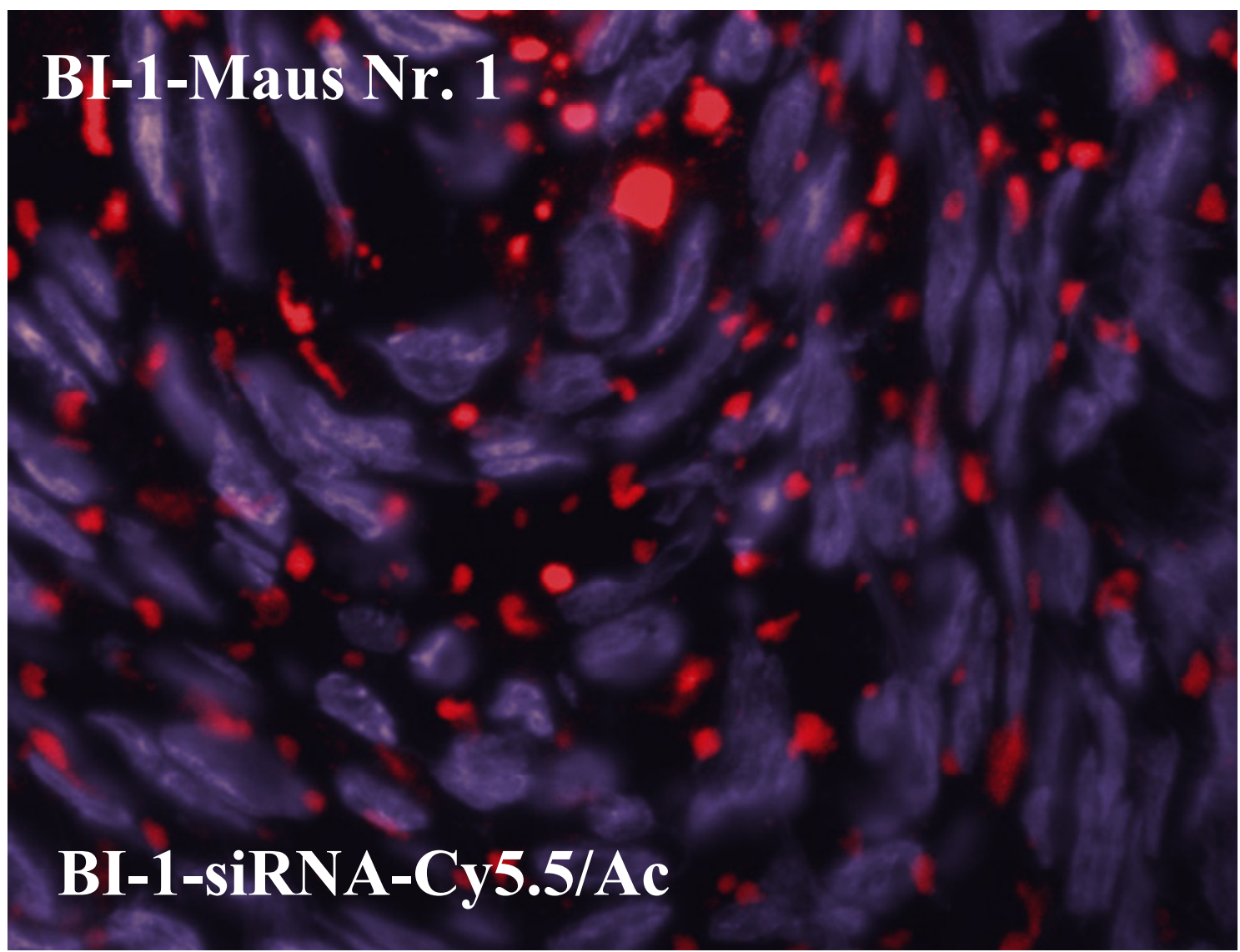

Abb. 3.37: Infrarot-Mikroskopieaufnahme von BI-1-siRNA/Ac-transfiziertem Tumorgewebe (exemplarische Daten der BI-1-Maus Nr.1, Kryoschnitt-Objekt). Der ausgewählte Ausschnitt stammt aus dem vitalen Bereich des Tumors (VB). Die Zellkerne wurden mit DAPI gegengefärbt (blau). Der siRNA/Ac-Komplex ist rot gefärbt und zytoplasmatisch lokalisiert. Die Aufnahme wurde bei 200-facher Vergrößerung aufgenommen. 


\section{Diskussion}

\subsection{Zusammenfassung der Ergebnisse}

Im ersten Teil der hier vorliegenden Arbeit sollte die Expression von BI-1 in verschiedenen humanen Karzinomen untersucht werden. Mit Hilfe des Cancer Profiling Arrays konnte eine Hochregulierung der BI-1-Expression bei Mamma-, Uterus- und Ovarialkarzinomen gefunden werden. Eine Herunterregulierung der BI-1-Expression von 50\% und mehr wurde in Magen-, Darm- und Rektumkrebs detektiert.

Die Expression von BI-1 konnte in den humanen Mammakarzinomzelllinien MDAMB-231, MDA-MB-453, MCF-7, HCC70, ZR-75-1 und -T47D nachgewiesen werden. Die stärkste Expression wurde in den Zelllinien MDA-MB-231, HCC-70 und ZR-75-1, die schwächste Expression in den Zelllinien MCF-7 und MDA-MB-453 festgestellt.

Zur funktionellen Analyse von BI-1 wurde die Expression von BI-1 mittels RNAInterferenz in Mammakarzinomzellen herunterreguliert. Dabei wurde eine Reduktion der BI-1-Expression im Vergleich zu kontrolltransfizierten und unbehandelten Zellen von 50 bis $80 \%$ auf Proteinebene erreicht. Die Herunterregulierung der BI-1-Expression führte zur Apoptose in 32\% der MDA-MB-231-Zellen (96 Stunden nach der siRNATransfektion), wohingegen nur 5\% der MCF-7-Zellen und 8\% der T-47D-Zellen apoptotisch wurden. Bei den kontrolltransfizierten Zellen und bei den unbehandelten parentalen Zellen lag die Apoptoserate im Beobachtungszeitraum bei 1 - 5\%.

Im zweiten Teil der Arbeit sollten putative Interaktionspartner von BI-1 in humanen Prostatazellen näher untersucht werden. Dazu wurde ein Yeast-Two-Hybrid-Screening mit BI-1 als Köderprotein an einer humanen Prostata-cDNA-Bibliothek durchgeführt. DIO-1 wurde dabei als BI-1-Interaktionspartner identifiziert und aufgrund seiner bekannten Rolle in der Apoptose weiter analysiert. Der Nachweis einer direkten Interaktion von BI-1 und DIO-1 mittels Koimmunopräzipitation konnte jedoch nicht erbracht werden.

Um den Zusammenhang der Funktionen von BI-1 und DIO-1 näher zu untersuchen, wurde eine Analyse zur subzellulären Kolokalisation von DIO-1 und BI-1 mit Hilfe von 
DIO-1-DsRed- und BI-1-GFP-Fusionsproteinen sowie mittels Immunzytochemie in Säugerzellen durchgeführt. DIO-1 und BI-1 zeigten bei 90\% der transfizierten NIH3T3Fibroblastenzellen eine diffuse Verteilung im Zytoplasma, die in der Überlagerung teilweise kolokalisieren. Sowohl das DIO-1-DsRed- als auch das BI-1-GFPFusionsprotein konnte in etwa $10 \%$ der kotransfizierten Zellen im Zytoplasma als kugelförmige Struktur lokalisiert werden. Die Herkunft der kugelförmigen Strukturen konnte weder durch die Verwendung eines Endosomen-Markers (EEA1) noch eines Markers für das Endoplasmatische Retikulum (BiP) aufgeklärt werden.

Die Expressionsanalysen von DIO-1 mit Hilfe des Western Blots zeigten eine Expression von DIO-1 in den Mammakarzinomzelllinien MDA-MB-231, MDA-MB453, MCF-7, HCC-70, ZR-75-1, T-47D und in den Prostatakarzinomzelllinien PC-3, LNCaP und DU-145.

Da bekannt ist, dass DIO-1 unter Apoptose-induzierenden Bedingungen in den Kern wandert, wurde die subzelluläre Lokalisation von DIO-1 nach Herunterregulierung der BI-1-Expression in Prostatakarzinomzelllinien untersucht. Dabei konnte in 38\% der PC3-Zellen mit reduzierter BI-1-Expression eine nukleäre Lokalisation, in 26\% eine partiell nukleäre und in 36\% eine zytoplasmatische Lokalisation von DIO-1 beobachtet werden. Die kontrolltransfizierten PC-3-Zellen zeigten hingegen in nur 3\% der Zellen eine DIO-1-Lokalisation im Kern, in 9\% eine partiell nukleäre und in $88 \%$ eine zytoplasmatische Verteilung von DIO-1. Bei der gemeinsamen Herunterregulierung der Expressionen von BI-1 und DIO-1 mittels RNAi in den Prostata- sowie in den Mammakarzinomzelllinien konnte keine gesteigerte Caspase-3-Aktivität im Vergleich zu den kontrolltransfizierten Zellen gemessen werden.

Im dritten Teil der Arbeit sollte der Effekt der Apoptose-Induktion nach Transfektion von BI-1-spezifischen Duplex-siRNA-Oligonukleotiden in induzierte Mammakarzinome bei Nacktmäusen untersucht werden. Etwa zwei Wochen nach der Implantation von MDA-MB-231-Zellen in die Brustdrüse der Nacktmäuse entwickelten sich Tumoren, die mit BI-1-siRNA/Atelocollagen (Ac)-Komplexen im Abstand von vier Tagen behandelt wurden. Über das eXplore Optix-System war es möglich, die mit dem Fluorophor Cy5.5 gekoppelte siRNA in vivo zu lokalisieren. Der siRNA/AcKomplex blieb über den gesamten Zeitraum hinweg im Tumor detektierbar und weitestgehend stabil. Über Flächendetektor-Volumetrische-Computertomographie (FD- 
VCT) wurden die Tumorentwicklung alle zwei Tage beobachtet und die Daten analysiert. Die mittels FD-VCT segmentierten Tumordaten belegen, dass die BI-1siRNA/Ac-behandelten Tumoren langsamer wachsen als die mit Luc-siRNA/Acbehandelten Kontrolltumoren.

\subsection{Analyse der BI-1-Expression in humanen Karzinomen}

Das BI-1-Gen stellt ein ubiquitär exprimiertes Gen dar und wird u.a. in Geweben wie Prostata, Testis, Herz, Gehirn, Lunge, Placenta, Leber, Niere und Pankreas exprimiert (Xu und Reed, 1998). Mittels eines cDNA-Arrays konnte BI-1 als überexprimiertes Gen im humanen Prostatakarzinomgewebe im Vergleich zum Normalgewebe identifiziert werden. Durch die Analyse einer Reihe weiterer Prostatakarzinome mittels quantitativer real time RT-PCR konnten diese Ergebnisse aus dem cDNA-Array verifiziert werden (Grzmil et al., 2003). Zusätzlich wurde die Expression von BI-1 im tumorfreien Epithel und Stroma der Prostata und Tumorepithel der Prostata verglichen. Mit Hilfe der quantitativen real time RT-PCR nach lasergestützer Mikrodissektion konnte gezeigt werden, dass in den Stromageweben von 5 radikalen Prostatektomien die BI-1Genexpression im Vergleich zu den zugehörigen tumorfreien Epithelgeweben geringer ist. Im Tumorepithel der Prostata konnte eine höhere BI-1-Expression im Vergleich zum tumorfreien Epithel der Prostata nachgewiesen werden. Weiterhin konnte eine BI1-Expression hauptsächlich in den Epithelzellen der Prostata nachgewiesen werden, wohingegen BI-1 nur schwach in benignen Prostatahyperplasien exprimiert wird.

Die mittels quantitativer real time RT-PCR gezeigte Überexpression von BI-1 in Prostatakarzinomzellen im Vergleich zum Normalgewebe konnte mit Hilfe der mRNAin situ-Hybridisierung mit einer BI-1-spezifischen antisense-cRNA-Sonde bestätigt werden (Grzmil et al., 2003). Auch Welsh et al. (2001) konnten mit Hilfe von cDNAMikroarray-Analysen in Prostatakarzinomen eine Überexpression des BI-1-Gens ermitteln. Weiterhin konnte eine Hochregulierung der Expression des BI-1-Gens in humanen Mammakarzinomen (van't Veer et al., 2002) und in Glioblastomen (Schmits et al., 2002) im Vergleich zum Normalgewebe nachgewiesen werden. 
Ob grundsätzlich eine Überexpression des BI-1-Gens in weiteren humanen Karzinomen vorliegt, wurde in der vorliegenden Arbeit über einen Cancer Profiling Array analysiert. Dabei wurde eine Hochregulierung der BI-1-Expression bei Mammakarzinomen (15 von 50 Patienten), Uteruskarzinomen (14 von 42 Patienten) und Ovarialkarzinomen (7 von 14 Patienten) gefunden. Eine Herunterregulierung der BI-1-Expression von 50\% oder mehr wurde im Magenkrebs (13 von 28 Patienten), Darmkrebs (13 von 34 Patienten), Nierenkrebs (11 von 20 Patienten), Lungenkrebs (9 von 21 Patienten) und Rektumkrebs (4 von 18 Patienten) detektiert. Die stärkste Hochregulierung des BI-1Gens wurde bei Mammakarzinomen nachgewiesen. Die stärkste Herunterregulierung der BI-1-Expression wurde in Nieren-, Magen- und Lungenkrebs gefunden. Die Hochregulierung der BI-1-Expression in Mammakarzinomen und die Herunterregulierung im Magenkrebs wurde ebenfalls von Van't Veer et al. (2002) und Kim et al. (2003) über cDNA-Mikroarray-Studien von Primären Brusttumoren und Magenkrebs gefunden.

Diese Ergebnisse deuten daruf hin, dass eine BI-1-Überexpression bei Brust-, Ovarund Uteruskrebs und eine Herunterregulation bei Nieren-, Lungen- und Magenkrebs vorliegt. In Brust, Ovar und Uterus wird unter anderem der Östrogenrezeptor $\alpha$ (ER- $\alpha$ ) exprimiert (Diez-Perez, 2006). Der ER- $\alpha$ ist häufig in Brustkrebs vorhanden und wird als prognostischer Indikator für den Erfolg einer Behandlung verwendet. Etwa 50\%$60 \%$ der Frauen mit ER- $\alpha$-positiven Brustkrebs profitieren durch eine endokrine Therapie. Im Gegensatz dazu hat eine endokrine Therapie nur äußerst selten Erfolg bei ER- $\alpha$-negativen Patientinnen (Pietras, 2006).

Bei den östrogen-abhängigen Tumoren wird Östrogen als Wachstumsfaktor verwendet. Wenn Östradiol an den Östrogenrezeptor (ER) gebunden wird, bildet sich ein ÖstradiolER-Komplex und dimerisiert. Dieser bindet anschließend an spezifische DNASequenzen wie z.B. estrogen response elements (EREs) und leitet die Transkription ein (Pietras, 2006). Der genaue Rolle der ER-Expression in der Pathogenese des Bruskrebs ist noch unbekannt.

Eine Untersuchung über einen möglichen Zusammenhang zwischen der BI-1 Expression und dem Östrogenrezeptor $\alpha$, die von Van't Veer et al. postuliert wurde, wurde von Grzmil et al. (2006) durchgeführt. Eine immunhistochemische Expressionsanalyse an Brustkrebs-Biopsieproben konnte einen möglichen 
Zusammenhang zwischen der BI-1 Expression und dem Östrogenrezeptor $\alpha$ jedoch nicht bestätigen (Grzmil et al., 2006).

In der vorliegenden Arbeit konnte gezeigt werden, dass die Regulierung der BI-1Expression in humanen Karzinomen durch aus variiert. Um eine mögliche klinische Relevanz dieser Untersuchungen zu evaluieren, sind weitere Studien notwendig.

\subsection{Die Rolle von BI-1 bei der Apoptose in humanen Karzinomzellen}

Aus der Literatur ist bekannt, dass BI-1 in der Lage ist, Bax-induzierte Apoptose in Hefe und Säugerzellen $\mathrm{zu}$ inhibieren und ausserdem mit Bcl-2 und Bcl- $\mathrm{X}_{\mathrm{L}} \mathrm{zu}$ interagieren ( $\mathrm{Xu}$ und Reed, 1998). Andere Studien haben gezeigt, dass eine herunterregulierte BI-1-Expression eine erhöhte Anfälligkeit für Zelltod an Pflanzenzellen zur Folge hat (Bolduc und Brisson, 2002). In humanen 293-Zellen konnte eine herunterregulierte Pflanzen-BI-1-Expression die Bax-induzierte Apoptose (Bolduc et al., 2001) inhibieren. BI-1 wurde als Inhibitor des TNF-related apoptosisinducing ligand (TRAIL) identifiziert (Burns und El-Deiry, 2001). BI-1 ist ein Protein mit einer krypoprotektiven Funktion, welche evolutionär konserviert ist und eine wichtige Rolle in der Stress-Resistenz sowohl in Pflanzen als auch bei Tieren spielt (Chae et al., 2003).

\subsubsection{Apoptose-Induktion bei Prostatakarzinomzellen durch Herunterregulierung der BI-1-Expression}

Die spezifische BI-1-Herunterregulierung führt zu beschleunigtem Zelltod in androgenunabhängigen Prostatakarzinomzellen PC-3, während die androgen-abhängigen LNCaP-Zellen nur eine moderate Erhöhung der Apoptoserate zeigt (Grzmil et al., 2003). Aus der Literatur ist bekannt, dass PC-3-Zellen gegenüber androgen-abhängigen LNCaP-Zellen eine erhöhte Resistenz gegenüber Apoptose-induzierenden Reagenzien besitzen (Wang et al., 1999; Marcelli et al., 2000). Weiterhin wurde gezeigt, dass eine Überexpression von Bcl- $\mathrm{X}_{\mathrm{L}}$ (ein Interaktionspartner von BI-1) die Resistenz von PC-3- 
Zellen gegenüber Staurosporin-induzierter Apoptose unterstützt (Li et al., 2001a). Das Bcl- $\mathrm{X}_{\mathrm{L}}$-Gen wird in PC-3-Zellen im Vergleich $\mathrm{zu}$ LNCaP- und DU145-Zellen überexprimiert (Li et al., 2001b). Daher führt die Herunterregulierung der BI-1Expression in PC-3-Zellen möglicherweise zu einer höheren Apoptoserate im Vergleich zu LNCaP- und DU 145-Zellen.

\subsubsection{Apoptose-Induktion bei Mammakarzinomzellen durch Herunterregulierung der BI-1-Expression}

In der vorliegenden Arbeit konnte gezeigt werden, dass BI-1 in verschiedenen humanen Mammakarzinomzelllinien exprimiert wird, und dass dessen spezifische Herunterregulierung $\mathrm{zu}$ einem ausgeprägten programmierten Zelltod in östrogenunabhängigen MDA-MB-231-Zellen führt. Bei der Apoptose-Induktion durch Herunterregulierung der BI-1-Expression sind viele regulierende Faktoren aus anti- und pro-apoptotischen Proteinen denkbar. Im folgenden Abschnitt werden diese Faktoren mit der Apoptose-Induktion durch Herunterregulierung der BI-1-Expressionen in Zusammenhang gebracht. Eine schematische Darstellung am Ende des Abschnitts (Abb. 4.38) gibt einen Überblick über das Zusammenwirken der verschiedenen anti- und proapoptotischen Faktoren auf die Apoptose-Signalkaskade.

\section{Auswirkung der BI-1-Expression auf den Apoptose-Signalweg}

Die Herunterregulierung der BI-1-Expression mittels spezifischer siRNA in der Mammakarzinomzellinie MDA-MB-231 resultierte in einer signifikant höheren Apoptoserate im Vergleich zu der in MCF-7- und T-47D-Zellen. Die unterschiedliche Induzierbarkeit der Apoptose durch die Herunterregulierung von BI-1 in den verschiedenen Mammkarzinomzellen könnte auf die Unterschiede in der BI-1Expression der Zellen zurückgehen. Die BI-1-Expressionsstärke ist in den MCF-7Zellen um zweifach und in T-47D um siebenfach höher als in MDA-MB-231-Zellen. Eine Herunterregulierung der Expression des ohnehin schon geringer exprimierten, antiapoptotischen Proteins BI-1 könnte in den MDA-MB-231-Zellen schneller zu einer Verschiebung der Balance Richtung Apoptose führen. Die endogene Expression von 
BI-1 war zudem nach der Transfektion mit spezifischen BI-1-siRNA-Oligonukleotiden bei MDA-MB-231-Zellen geringfügig niedriger als bei MCF-7- und T-47D-Zellen.

\section{Auswirkung der Bcl-2-Expression auf den Apoptose-Signalweg}

Ein weiterer wichtiger Aspekt ist, dass das anti-apoptotische Protein Bcl-2 (ein Interaktionspartner von BI-1) in $40-80 \%$ der humanen Mammakarzinome überexprimiert ist, und dass die Bcl-2-spezifische Herunterregulation Apoptose induziert und die Chemosensitivität von Brustkrebs verstärkt (Nahta und Esteva, 2003). Teixeira et al. (1995), Wang und Phang (1995) und Kandouz et al. (1999) konnten zeigen, dass Östrogen eine Auswirkung auf die Apoptose-Induktion durch die erhöhte Expression von Bcl-2 in östrogen-abhängigen, humanen Mammakarzinomzellen wie MCF-7 und T-47D besitzt. Die Überexpression von Bcl-2 in MCF-7-Zellen führt zudem zu einer Resistenz gegenüber TNF-induzierter Apoptose (Jaattela et al., 1995). Das Bcl2-Expressionslevel in MCF-7-Zellen ist um 4,5fach höher im Vergleich zu MDA-MB231-Zellen (Kandouz et al., 1996). T-47D-Zellen haben ein niedrigeres Expressionslevel von Bcl-2 als MCF-7-Zellen, zeigen aber eine starke Expression von Bcl-X $\mathrm{L}_{\mathrm{L}}$ dem zweiten Interaktionspartner von BI-1 (Butt et al., 1996).

\section{Auswirkung der Caspasen- und XIAP-Expression auf den Apoptose-Signalweg}

Die Apoptoseresistenz von MCF-7-Zellen nach der Herunterregulierung der BI-1Expression könnte auch durch die niedrige Expression von Caspase-9 und das Fehlen der Caspase-3-Expression hervorgerufen werden. Caspase-9 und Caspase-3 sind für die durch Bax vermittelte Apoptose-Induktion notwendig (Yang et al., 2003). Die XIAPExpression (ein Caspase-Inhibitor der IAP-Familie), der die proteolytische Prozessierung der Pro-Caspasen und die Aktivität der Caspase-9 blockiert, ist signifikant höher in MCF-7-Zellen im Vergleich zu MDA-MB-231-Zellen (Srinivasula et al., 2001; Huang et al., 2001). Im Gegensatz zu MCF-7-Zellen exprimieren die T47D-Zellen Caspase-3 und niedrige Level an XIAP. Die moderate Induktion der Apoptose in T-47D-Zellen durch die Herunterregulierung von BI-1 könnte zum einen durch die niedrige Expression von Caspase-3 und XIAP erklärt werden, aber auch 
dadurch, dass die Apoptose in MCF-7-Zellen über die Caspase-6 und bei T-47D über die Caspasen-3/7 induziert wird (Mooney et al., 2002).

Die Unterschiede in den Expressionslevel von Caspasen und dem Caspase-Inhibitor XIAP könnten die höhere Apoptoseresistenz der MCF-7-Zellen im Vergleich zu MDAMB-231-Zellen nach Herunterregulierung der BI-1-Expression erklären.

\section{Veränderung im Gleichgewicht zwischen den anti- und pro-apoptotischen Proteinen und deren Auswirkung auf die Apoptose-Induktion in T-47D und MDA- MB-231-Zellen}

Ein weiterer Apoptose-Induktions-Mechanismus in T-47D- und MDA-MB-231-Zellen ist ebenfalls denkbar, z.B. eine Veränderung im Gleichgewicht zwischen den antiapoptotischen Proteinen (z.B. BI-1/Bcl-2/Bcl-X $\mathrm{X}_{\mathrm{L}}$ ) und den pro-apoptotischen Proteinen (z.B. Bax/DIO-1). Wie in Abschnitt 4.5.3 beschrieben zeigt DIO-1 eine niedrigere Expressionrate in MCF-7- und T-47D-Zellen im Vergleich zu MDA-MB-231-Zellen. Dies könnte ebenfalls eine Erklärung für die Unterschiede in der Apoptose-Induktion durch die Herunterregulierung der BI-1-Expression sein, da die hier erhobenen Daten darauf hindeuten, dass DIO-1 ein Gleichgewicht zu BI-1 bildet (siehe Abschnitt 4.5.6).

Die Reaktion auf die Apoptose-Induktion mittels BI-1-siRNA zeigt, dass hoch invasive und östrogen-unabhängige MDA-MB-231-Zellen sensitiver auf die Induktion reagieren als nicht invasive, östrogen-abhängige T-47D-Zellen. Dies deutet auch auf eine wichtige Rolle von BI-1 in der Progression von Mammakarzinomen hin.

Der Zusammenhang zwischen der Östrogenrezeptor- und der BI-1-Expression wurde von Grzmil et al. (2006) untersucht. Einen signifikanten Unterschied in der BI-1Expression nach Behandlung mit Östradiol und den Anti-Östrogenen ICI und Tamoxifen konnte weder in verschiedenen östrogen-abhängigen Mammakarzinomzellen noch in den östrogenrezeptor-positiven Prostatakarzinomzellen PC-3 festgestellt werden (Grzmil et al., 2006). Die Expression von BI-1 scheint daher zellspezifisch $\mathrm{zu}$ sein und ist hormon-unabhängig in Prostata- und Mammakarzinomzellen. 


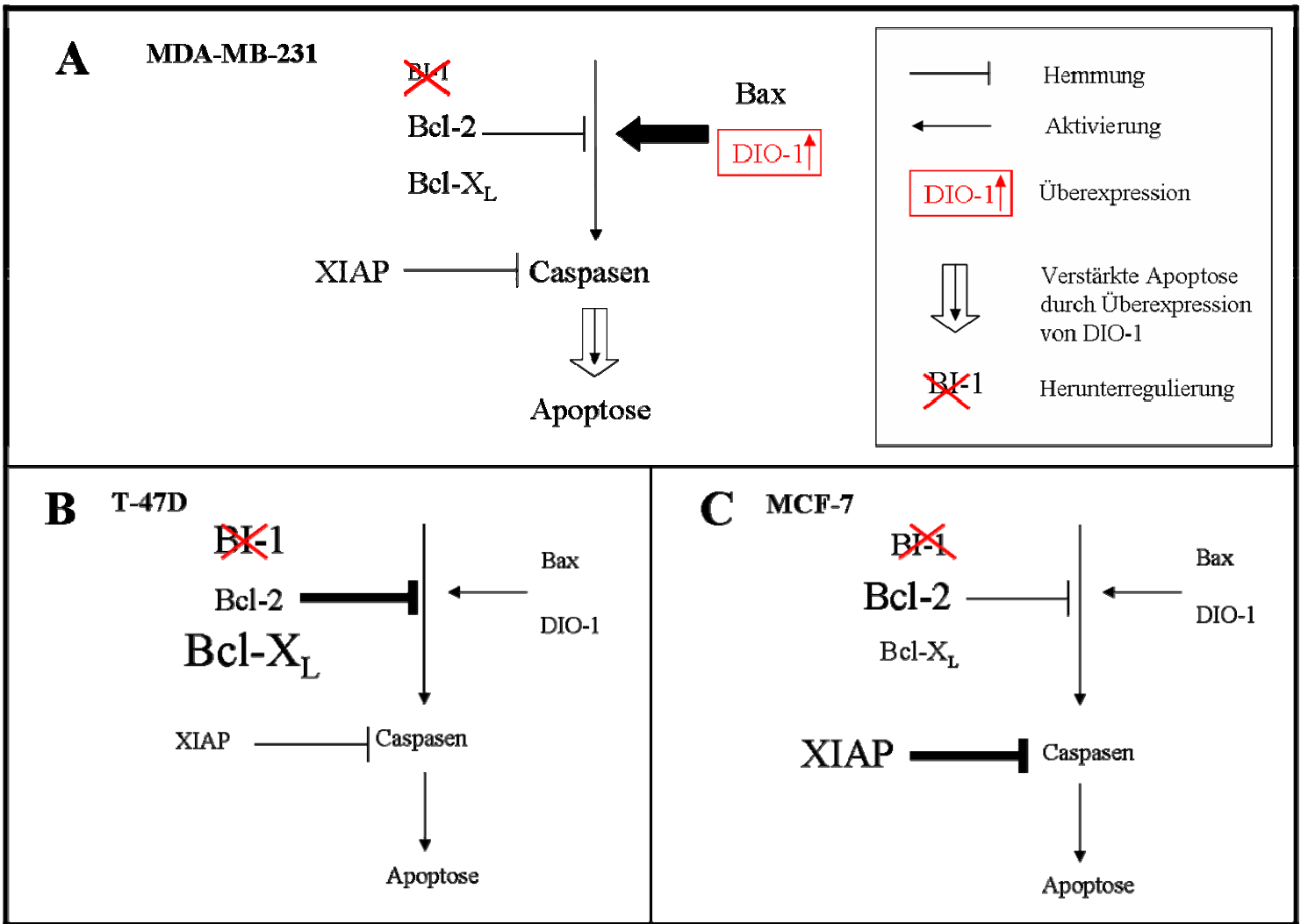

Abb. 4.38: Schematische Darstellung der möglichen Apoptose-Induktion bei MDA-MB-231, T-47D und MCF-7. Je nach Expressionsstärke wurden die Proteinnamen größer (bei hoher Expression) oder kleiner (bei niedriger Expression) dargestellt. Die Stärke der Aktivierung und Hemmung wurde durch die Liniendicke dargestellt (dicke Linie für einen stärkeren Einfluss). Die schematischen Darstellungen zeigen die Apoptose-Induktion bei MDA-MB-231-(A), T-47D- (B) und MCF-7-Zellen (C). Die BI-1Expressionsstärke ist in den MCF-7-Zellen um zweifach und in T-47D um siebenfach höher als in MDAMB-231-Zellen. Das Bcl-2-Expressionslevel ist in MCF-7-Zellen um 4,5-fach höher als im Vergleich zu MDA-MB-231-Zellen. T-47D-Zellen haben ein niedrigeres Expressionslevel von Bcl-2 als MCF-7Zellen, zeigen aber eine starke Expression von Bcl-X $\mathrm{L}_{\mathrm{L}}$. Die XIAP-Expression ist bei MCF-7-Zellen sehr viel höher als bei MDA-MB-231-Zellen oder T-47D-Zellen. Der DIO-1-Expression ist bei MCF-7- und T-47D-Zellen niedriger als in MDA-MB-231-Zellen. Die Apoptose-Induktion durch die Herunterregulierung von BI-1 zeigt, dass MDA-MB-231-Zellen sensitiver auf die Induktion reagieren als T-47D- oder MCF-7-Zellen.

\subsection{Isolierung von weiteren putativen Interaktionspartnern von BI-1}

Über ein Yeast-Two-Hybrid-Screening mit einer humanen Prostata-cDNA-Bibliothek konnten insgesamt 45 spezifische PCR-Produkt-Sequenzen mit der Gendatenbank 
verglichen werden. Dabei wurden die Interaktionspartner im Hinblick auf den BI-1involvierten Apoptose-Signalweg näher analysiert. Die acht ausgewählten Gene (siehe Ergebnis-Teil Abschnitt 3.3.2) wurden mit dem intrinsischen Apoptose-Signalweg (Typ II) in Verbindung gebracht, in den auch BI-1 involviert ist (Xu et al., 1998). Von diesen acht Genen wurde DIO-1 für weitere Experimente ausgewählt, da DIO-1 ein proapoptotisches Protein darstellt (Garcia-Domingo et al., 2003) und zu dessen Einfluß auf der Tumorigenese keine Literaturdaten vorhanden waren.

Der Anteil falsch-positiver-Klone im Yeast-Two-Hybrid-Screening wurde zwar aufgrund effektiver Selektionsmethoden beträchtlich reduziert (Bartel et al., 1993), dennoch ist es weiterhin notwendig, spezifische Interaktionen von solchen zu unterscheiden, die durch die ektopische Überexpression der jeweiligen Proteine zustande kommen.

Für eine Verifikation der in der Hefe gefundenen Interaktion von DIO-1 und BI-1 wurde ein Koimmunopräzipitationsexperiment durchgeführt. Da kein funktioneller Antikörper gegen BI-1 vorhanden war, wurden die Zellen mit einem BI-1-GFPFusionskonstrukt transient transfiziert. Anschließend wurden Immunpräzipitationen mit einem GFP-spezifischen bzw. DIO-1-spezifischen Antikörper durchgeführt und der Interaktionspartner mit dem jeweils anderen Antikörper über eine Western Blot-Analyse nachgewiesen. Die Interaktion zwischen DIO-1 und BI-1 war durch diese Methode nicht verifizierbar. Ein Grund hierfür könnte sein, dass es aufgrund einer sterischen Behinderung durch GFP zwischen dem Fusionsprotein BI-1-GFP und DIO-1 zu keiner Wechselwirkung kommen kann. Weiterhin ist es möglich, dass BI-1 nicht direkt mit DIO-1 interagiert, sondern über ein Brückenprotein indirekt bindet. Dieses wird durch die Tatsache gestützt, dass eine Interaktion zwischen BI-1 und DIO-1 auch in einem direkten Yeast-Two-Hybrid-Experiment nicht bestätigt werden konnte.

Dennoch ist eine physische Interaktion nicht unbedingt im Antagonismus zwischen pround anti-apoptotischen Bcl-2-Familienmitgliedern erforderlich (Zha und Reed, 1997). BI-1 könnte ohne direkte Interaktion oder über eine indirekte Interaktion über ein Brückenprotein die Funktion von DIO-1 beeinflussen.

Ein Beispiel für ein solches Brückenprotein ist das MDM2-Protein. MDM2 ist ein onkogenes Protein, das einen zellulären Inhibitor des p53-Tumorsupressors darstellt (de Oca Lina et al., 1995). Das MDM2-Protein kann als Brückenprotein mit p53- und dem 
Retinoblastom-Protein (einem weiteren Tumorsupressorprotein) einen trimeren Komplex bilden und dadurch p53 und somit auch seine apoptotischen Effekte (Yap et al., 1999) stabilisieren.

Ein solches Modell wäre auch bei BI-1 und DIO-1 denkbar. Um den genauen Interaktionsmechanismus zu klären, sind weitere Interaktionsstudien zwischen BI-1 und DIO-1 notwendig. Dass es einen funktionellen Zusammenhang der beiden Proteinen gibt, wird im Abschnitt 4.5.6 verdeutlicht.

\subsection{Der BI-1-Interaktionspartner DIO-1}

DIO-1 wurde ursprünglich mittels differential display-PCR in Prä-B WOL-1-Zellen (aus dem Knochenmark von BALB-Mäusen stammende untransformierte IL-7 abhängige Prä-B-Zellen) bei der Suche nach Genen identifiziert, die in die Apoptose involviert sind (Garcia-Domingo et al., 1999).

\subsubsection{Charakterisierung von DIO-1}

Das humane DIO-1-Gen ist auf dem Chromosom 20q13.33 lokalisiert und das murine DIO-1 konnte auf Chromosom 2H4 lokalisiert werden (Garcia-Domingo et al., 1999).

Das humane und das murine DIO-1-Gen besitzen einen ähnlichen genomischen Aufbau (Fütterer et al., 2005). Sie bestehen aus jeweils 16 Exons, welche alternativ gespleißt werden (Abb. 4.39). Weiterhin zeigt DIO-1 einen hohen Grad (74\%) an struktureller Konservierung im offenen Leserahmen zwischen Mensch und Maus (Garcia-Domingo et al., 1999).

DIO-1 liegt als single copy-Gen in Genom der Maus und des Menschen vor. DIO-1 wird in Prä-B WOL-1-Zellen sehr schwach exprimiert. Northern Blot-Analysen ergaben drei Isoformen, sowohl beim humanen als auch beim murinen DIO-1 (Garcia-Domingo et al., 1999). 


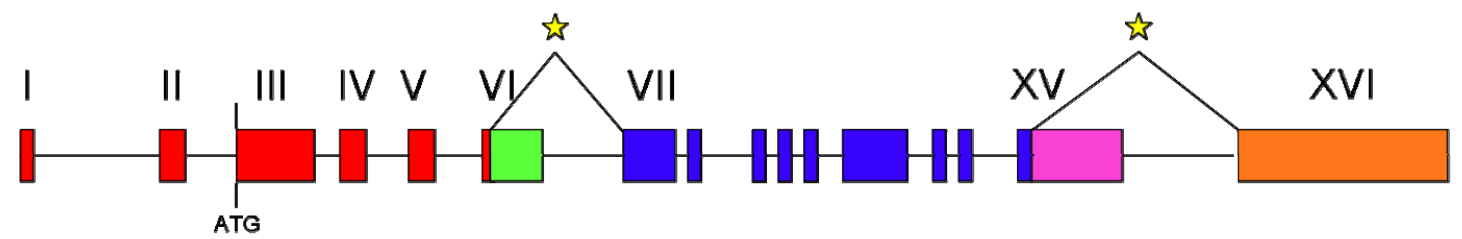

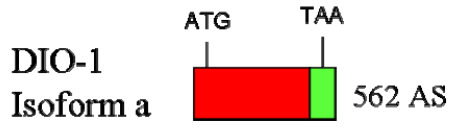

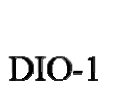

Isoform b

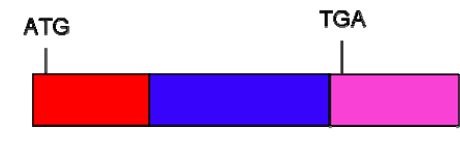

1189 AS

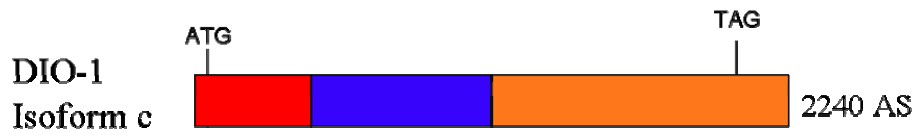

Gemeinsame Exons

Exons der DIO-1 Isoform b und Isoform $\mathrm{c}$

Spezifische Exons

Nicht-kanonische Spleißstellen

Abb. 4.39: Darstellung der genomischen Organisation des humanen DIO-1-Gens und der DIO-1 Protein-Isoformen (Accession-Nr. NM_022105). Die gemeinsamen Exons der DIO-1 Isoformen a, b und c sind als rote Rechtecke und die Introns sind als schwarze Linien eingezeichnet. Die gemeinsamen Exons von Isoform $\mathrm{b}$ und $\mathrm{c}$ sind als blaue Rechtecke und die für die Isoformen $\mathrm{a}, \mathrm{b}$ und $\mathrm{c}$ spezifischen Exons sind jeweils in grün, pink und orange markiert. Die nicht-kanonischen Spleißstellen wurden mit einem Stern markiert (modifiziert nach Fütterer et al., 2005).

\subsubsection{Zur Proteinstruktur von DIO-1}

Die Homologien zwischen der humanen und der murinen DIO-1 Isoform b und Isoform c liegen bei $77,8 \%$ bzw. 73,1\% auf Proteinebene. Die murine DIO-1 Isoform a kodiert für ein 614 Aminosäuren langes Protein, Isoform b für ein 1183 Aminosäuren langes Protein und die Isoform c für ein 2256 Aminosäuren langes Protein.

DIO-1 besitzt zwei Kernlokalisationssignalsequenzen (NLS = nuclear localization signal), eine transkriptionelle Aktivierungsdomäne in der N-terminalen Region, zwei zentrale Zinkfinger-Motive und einen Lysin-reichen Carboxyl-Terminus (Abb. 4.40). 

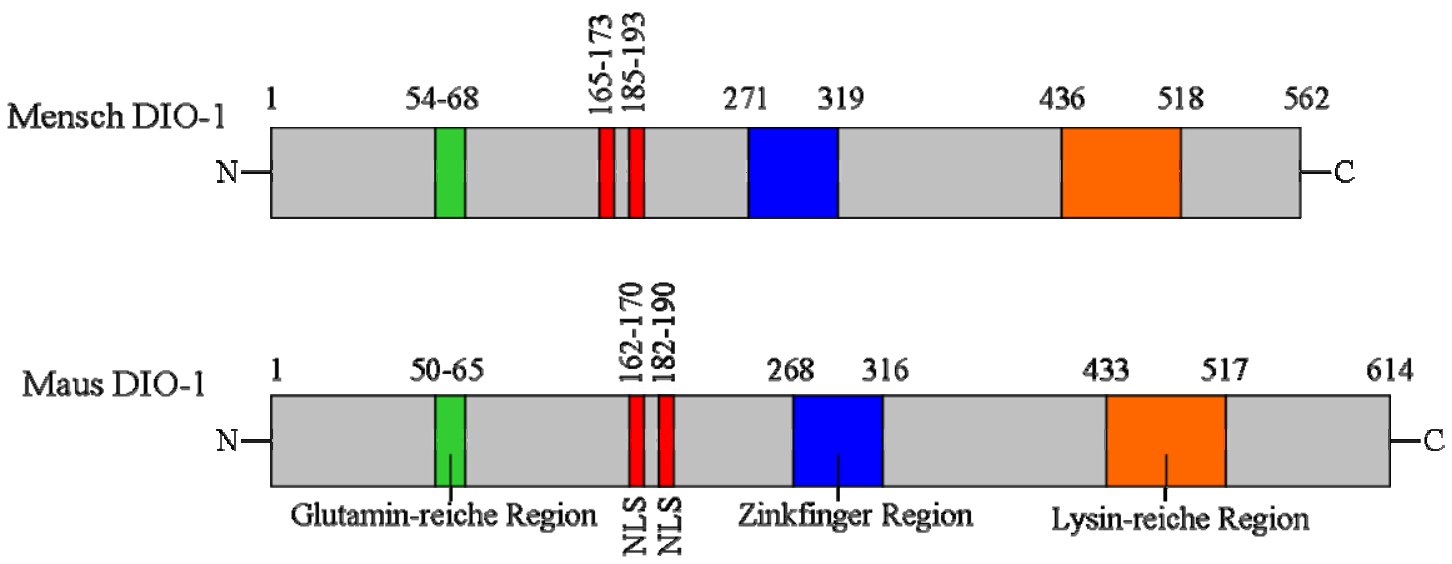

Abb. 4.40: Darstellung der Proteinstruktur des humanen und murinen DIO-1 (Isoform a). Die Glutamin-reiche Region ist in grün, die beiden Kernlokalisationssignale (nuclear localization signal = NLS) sind in rot, die Zinkfinger-Domänen in blau und die Lysin-reiche Region in orange dargestellt. Die Zahlen stellen die Aminosäure-Positionen der jeweiligen Domänen dar. Die Accession-Nr. der verwendeten Sequenzen sind beim Menschen NP_542986 und bei der Maus NP_035935 (modifiziert nach Garcia-Domingo et al., 1999).

Mit Hilfe eines computergestützten Proteinstrukturmodells von DIO-1 (HMMerProgramm; http://hmmer.wustl.edu) konnten Sanchez-Pulido et al. (2004) im Cterminalen konservierten Bereich von DIO-1 Isoform c eine Spen paralog and ortholog C-terminal (SPOC)-Domäne (Abb. 4.41) identifizieren, die Protein-ProteinInteraktionen vermittelt. Diese Domäne wurde in Proteinen wie z.B. MKL1 (megakaryoblastic leukemia 1), RBM15 (RNA-binding motif protein 15) und PHF3 (PHD finger protein 3) nachgewiesen, die mit Krebs, Apoptose und Transkription assoziiert sind (Sanchez-Pulido et al., 2004). 


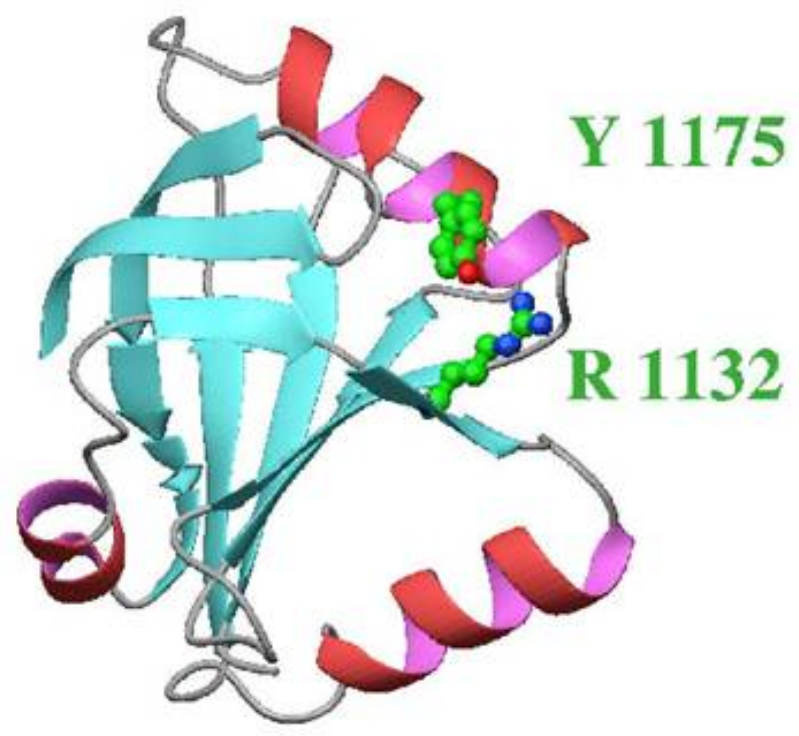

Abb. 4.41: Computergestütztes Proteinstrukturmodell der humanen DIO-1 Isoform c. Die Aminosäuren Tyrosin (Y) 1175 und Arginin (R) 1132 sind in der SPOC-Domäne (Aminosäureposition 1093-1199) stark konserviert und spezifisch für die posttranslationale Modifikation (Methylierung) dieser Domäne (Quelle: Sanchez-Pulido et al., 2004).

Die Koimmunopräzipitation und SDS-Page-Analyse mit DIO-1/myc- und DIO-1/FlagFusionsproteinen zeigten, dass DIO-1 Oligomere formen kann. Die DIO-1-Oligomere konnten auch bei NLS-Deletionsmutanten nachgewiesen werden. Die genaue HomoOligomerisierungsregion konnte jedoch nicht determiniert werden (Garcia-Domingo et al., 2003).

Die SPOC-Domäne liegt bei der humanen DIO-1 Isoform c an der AminosäurePosition 1093-1199 und könnte für eine solche Oligomerisierung zuständig sein. Aber auch die Zinkfinger-Domäne, die direkt C-terminal von der SPOC-Domäne liegt, könnte für die Oligomerisierung verantwortlich sein. Eine Untersuchung mit entsprechenden mutierten SPOC- oder Zink-Finger-Domänen könnte diese Frage klären. Mit diesen Deletionsmutanten wäre es ebenfalls möglich zu untersuchen, ob die Funktion von DIO-1 durch die Mutation einer dieser Domäne beeinflusst wird.

Bei der Western Blot-Analyse von Proteinen, die unter nicht denaturierenden Konditionen extrahiert wurden, konnten drei Protein-Banden für DIO-1 detektiert werden (Garcia-Domingo et al., 2003). Um zu überprüfen, ob die drei Banden durch 
verschiedene Phosphorylierungszustände hervorgerufen werden, wurden DIO-1/Flagund DIO-1 $\Delta$ NLS/Flag-Fusionskonstrukte in 293T-Zellen transient transfiziert und mit Anti-Phosphothreonin-, Anti-Phosphoserin- und Anti-Phosphotyrosin-Antikörpern immunpräzipitiert. Die zwei oberen Banden wurden mit Anti-Phosphoserin und AntiPhosphorthreonin immunpräzipitiert, die unterste Bande konnte nicht detektiert werden (Garcia-Domingo et al., 2003).

Die multiplen Banden scheinen jedoch nicht nur durch die Phosphorylierung verursacht zu werden, da eine Phosphatase-Behandlung der Zellen keine Veränderung der multiplen Banden hervorrief. Obwohl dieses Ergebnis gegen eine Phosphorylierung von DIO-1 spricht, konnten Untersuchungen der verschiedenen DIO-1-Formen nach induzierter Apoptose zeigen, dass das zytoplasmatische DIO-1 phosphoryliert in vitalen Zellen vorliegt, während die dephosphorylierte nukleäre Form von DIO-1 nach der Induktion von Apoptose $\mathrm{zu}$ finden war (Garcia-Domingo et al., 2003). Die Phosphorylierung könnte somit eine regulierende Funktion für die Aktivierung von DIO-1 haben.

In der vorliegenden Arbeit wurde die Suche nach putativen Phosphorylierungsstellen über ein computergestütztes Modell (Netphos 2.0; http:/www.cbs.dtu.dk/services/ NetPhos) durchgeführt. Dieses Modell zeigt eine hohe Wahrscheinlichkeit zahlreicher Phosphorylierungsstellen für die Aminosäuren Serin, Threonin und Tyrosin in der DIO1-Sequenz (Abb. 4.42). 
NetPhos 2.0: Mögliche Phosphorylierungsstellen von DIO-1

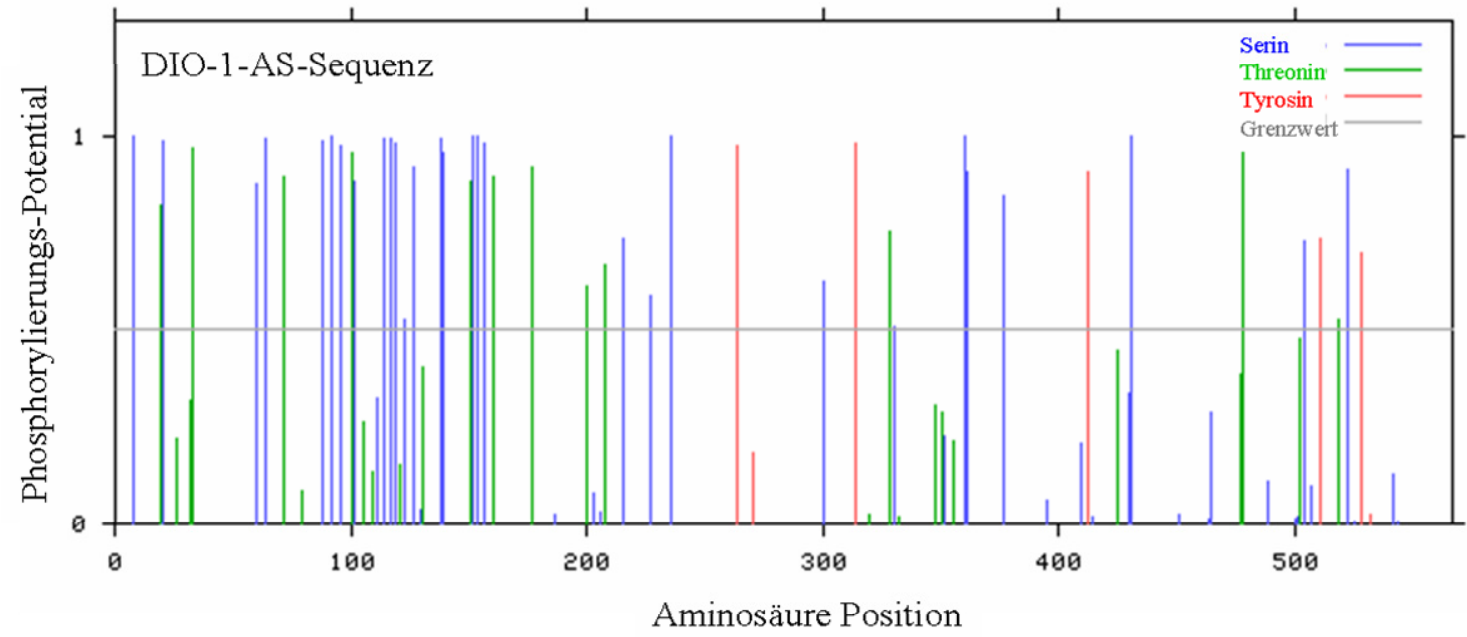

Abb. 4.42: Putative Phosphorylierungsstellen in der DIO-1-Sequenz. Für die Suche nach putativen Phosphorylierungsstellen wurde das Computerprogramm Netphos 2.0 verwendet. DIO-1 besitzt zahlreiche putative Phosphorylierungsstellen (oberhalb des Grenzwertes) für Serin, Threonin und Tyrosin (Quelle: http://www.cbs.dtu.dk/services/NetPhos /).

Es ist bisher nicht bekannt, welche Rolle DIO-1 bei der Apoptose-Induktion spielt. Sowohl die Oligomerisierung als auch die Phosphorylierung scheinen eine wichtige Rolle bei der Funktion von DIO-1 zu spielen. Hierbei sollten die Domänen für die Interaktionen mit anderen Proteinen und die Phosphorylierungsstellen von DIO-1 näher untersucht werden, um diese Fragen zu klären.

\subsubsection{Expressionsanalysen von DIO-1}

DIO-1 wird ubiquitär exprimiert und eine DIO-1-Expression konnte u.a. in MausGeweben wie Testis, Herz, Gehirn, Lunge, Milz, Leber, Niere und Skelettmuskel nachgewiesen werden. Das DIO-1-Gen wird während der Embryonalentwicklung des Huhns in den Extremitäten exprimiert. Die DIO-1-Expression ist dabei in distalen proliferierenden Mesodermalzellen der sich entwickelnden Hühnerextremitäten vorhanden, wo es den Überwuchs (von Zellen) durch Apoptose-Induktion inhibiert (Garcia-Domingo et al., 1999).

Weiterhin wird DIO-1 in Apoptose-induzierten WOL-1 Zellen im Gegensatz zu den in der Wachstumsphase befindlichen Zellen stark exprimiert. DIO-1 ist in den Zellen 
hochreguliert, bei denen Interleukin-7 (IL-7) dem Kulturmedium entzogen wurde, oder in solchen, die mit IFN- $\gamma$ (Zytokine) oder Dexamethason (Glucocorticoid) behandelt worden sind. Bei Zellen, die Etoposide-, UV-Strahlung- oder p53-induzierte-Apoptose ausgesetzt wurden, konnte keine Hochregulierung von DIO-1 beobachtet werden (Garcia-Domingo et al. 1999).

Die ektopische Überexpression von DIO-1 führt in Säuger-Zellen in vitro zu Apoptose, die durch die Blockade der Caspase-Aktivität über den Caspase-Inhibitor Benzyloxycarbonyl-Val-Ala-Asp-Fluoromethyl Ketone (z-vad-fmk) verhindert werden kann. Dabei wurde die Hochregulierung der DIO-1-Expression durch eine p53unabhängige Apoptose-Induktion erzeugt. Die Induktion der Apoptose durch Inaktivierung von p53 (Zellkultur bei $39^{\circ} \mathrm{C}$, Zugabe von $17 \beta$-Estradiol und SerumEntzug) resultiert in der Translokation von DIO-1 vom Zytoplasma in den Nukleus. Gleichzeitig wird die Expression von DIO-1 sowohl auf RNA- als auch auf Proteinebene erhöht (Garcia-Domingo et al., 1999).

Die Apoptose-Induktion durch die DIO-1-Überexpression konnte durch CaspaseInhibitoren wie z-vad-fmk (Garcia-Domingo et al., 1999) und auch über Bcl2Überexpression inhibiert werden (Bras et al., 1999).

Die im Rahmen dieser Arbeit durchgeführten Expressionsanalysen an humanen Mamma- und Prostatakarzinomzelllinien zeigten, dass DIO-1 in allen Zelllinien exprimiert wird. Dabei konnte die stärkste Expression in den Mammkarzinomzellen MDA-MB-231, HCC-70, ZR-75-1 und in den Prostatakarzinomzellen PC-3 und DU145 festgestellt werden. Die schwächste DIO-1-Expression wurden in den Mammkarzinomzellen T-47D, MCF-7, MDA-MB-453 und in den Prostatakarzinomzellen LNCaP beobachtet werden. Von den untersuchten Mammakarzinomzellen MCF-7, MDA-MB-231 und T-47D besitzt MDA-MB-231Zellen eine verstärkte DIO-1-Expression im Vergleich zu MCF-7- oder T-47D-Zellen. Die Induzierbarkeit der Apoptose durch BI-1-Herunterregulierung war bei MDA-MB231-Zellen deutlich höher als bei MCF-7- oder T-47D-Zellen. Diese Beobachtungen würden die Hypothese unterstützen, dass eine hohe Expression von DIO-1 zu einer erhöhten Induzierbarkeit der Apoptose durch Herunterregulierung von BI-1 führt. Allerdings lässt sich diese Beobachtung nur teilweise auf Prostatakarzinomzellen übertragen, da DU145-Zellen trotz gleicher DIO-1-Expression im Vergleich zu PC-3- 
Zellen eine deutlich schlechtere Induzierbarkeit durch die BI-1-Herunterregulierung zeigten (Grzmil et al., 2003). Wie in Abschnitt 4.3.2 beschrieben, spielen bei der Induzierbarkeit der Apoptose auch die Expression von weiteren anti- und proapoptotischen Proteinen eine Rolle.

\subsubsection{Zur subzellulären Lokalisation von DIO-1 und seiner Funktion in der Apoptose}

In der vorliegenden Arbeit konnte gezeigt werden, dass DIO-1 zusammen mit BI-1 im Zytoplasma der Säugerzellen lokalisiert ist. Die dabei über die Fusionsproteine BI-1GFP und DIO-1-DsRed beobachtete kugelförmige Kolokalisation konnte keiner Struktur zugeordnet werden. Um einen Akkumulationseffekt durch die Überexpression der Fusionsproteine auszuschliessen, wurde die transiente Transfektion nur mit einem BI-1-GFP-Fusionskonstrukt (siehe Abschnitt 3.4.3) durchgeführt und das endogene DIO-1 über Immunzytochemie detektiert. Auch in diesem Ansatz zeigte sich bei etwa 10\% der transfizierten Zellen eine kugelförmige Kolokalisation von BI-1-GFP und dem endogenen DIO-1-Protein. Ein Akkumulationseffekt durch die Überexpression der Fusionsproteine liegt somit nicht vor.

Dass DIO-1-Oligomere die in der vorliegenden Arbeit beobachteten kugelförmigen Strukturen bilden, kann ausgeschlossen werden, da bei zellulären LokalisationsUntersuchungen mit einem DIO-1-Antikörper eine solche Struktur nicht beobachtet werden konnte. In der vorliegenden Arbeit konnte daher die Ursache für die kugelförmigen Strukturen nicht geklärt werden.

Die Untersuchungen von Fütterer et al. (2005) haben gezeigt, dass die murine DIO-1 Isoform a im Zytosol lokalisiert ist, während Isoform b und c im Nukleus zu beobachten sind. Die DIO-1 Isoform c ist am meiotischen synaptonemalen Zentralen Element lokalisiert und hat Kontakt mit Chromatinstrukturen durch die Bindung von Histonen (Fütterer et al., 2005). Die N-terminale Domäne von DIO-1, welche in allen Isoformen vorhanden ist, ist an der Bindung von Histonen beteiligt. Dies führt zu der Annahme, dass die DIO-1 Isoformen a und b ebenfalls in der Lage sind, an Histone zu binden (Fütterer et al., 2005). 
Wenn bei Säugerzellen Apoptose durch Serum-Entzug induziert wird, transloziert DIO1 in den Zellkern. Dass die Kernlokalisation essentiell für die Apoptose-Induktion ist, konnte durch DIO-1-NLS-Deletionsmutanten gezeigt werden. Dazu wurde ein DIO-1$\Delta$ NLS-Konstrukt in FL5.12-Zellen stabil transfiziert, die Zellen unter IL-3-Entzug gesetzt und anschließend die Procaspase-3- und -9-Level untersucht. Dabei konnten keine Unterschiede im Procaspase-3- und -9-Level im Vergleich zu kontrolltransfizierten Zellen festgestellt werden. Daher ist für die Hochregulierung der Caspase-Level die nukleäre Lokalisation von DIO-1 notwendig. Eine weitere Beobachtung war, dass DIO-1-ANLS in der Lage ist, die Zellen vor Apoptose zu schützen. Die mit DIO-1- $\triangle$ NLS stabil transfizierten Zellen hatten eine um 50\% reduzierte Apoptoserate nach $24 \mathrm{~h}$ und eine um 66\% reduzierte Apoptoserate nach $48 \mathrm{~h}$ IL-3-Entzug im Vergleich zu kontrolltransfizierten Zellen. Dieses Verhalten ähnelt einer dominant negativen Mutationsform. Es wurde angenommen, dass DIO-1-ANLS in der Lage ist, mit dem Wildtyp-DIO-1-Protein zu oligomerisieren und dadurch die Kernmigration zu verhindern, was zur Apoptose führt (Garcia-Domingo et al., 2003).

\subsubsection{Die Herunterregulierung der BI-1-Expression führt zur Akkumulation von DIO-1 im Nukleus}

In der vorliegenden Arbeit sollte auch untersucht werden, ob die Apoptose-Induktion durch die Herunterregulierung der BI-1-Expression über die Translokation von DIO-1 vom Zytoplasma in den Zellkern ausgelöst wird. Dazu wurde die BI-1-Expression in PC-3-Prostatakarzinomzellen mit Hilfe von BI-1-spezifischen Duplex-siRNAOligonukleotiden herunterreguliert. Die mit Luciferase-spezifischer siRNA transfizierten PC-3-Zellen (Kontrolle) zeigten vorwiegend eine zytoplamatische Verteilung von DIO-1 (88\%), wohingegen in nur 3\% der Zellen DIO-1 im Nukleus lokalisiert war. Bei den mit BI-1-spezifischer siRNA transfizierten PC-3-Zellen konnte eine Veränderung der subzellulären Lokalisation von DIO-1 beobachtet werden. Ungefähr 38\% der Zellen mit herunterregulierter BI-1-Expression zeigten eine nukleäre Lokalisation von DIO-1, 26\% eine partiell nukleäre und 36\% eine zytoplasmatische Lokalisation von DIO-1. Die Apoptose-Induktion durch die Herunterregulierung der BI1-Expression mittels siRNA in den PC-3-Prostatakarzinomzellen resultierte in $38 \%$ 
aktive Caspase-3-positiven Zellen (Grzmil et al., 2003), was mit den Ergebnissen der DIO-1-Translokation in den Nukleus übereinstimmt.

Eine Hypothese ist, dass die BI-1- und DIO-1-Proteinmengen eine Balance in der Apoptose-Signalkaskade bilden. BI-1 könnte DIO-1 daran hindern, in den Zellkern zu translozieren und übt dadurch seine antiapoptotische Wirkung aus. Die gemeinsame Herunterregulierung der BI-1- und DIO-1-Expression mittels spezifischer siRNA in den Mammakarzinomzellen MDA-MB-231 und in den Prostatakarzinomzellen PC-3 zeigt dagegen keine Apoptose-Induktion.

Dieses Ergebnis deutet einerseits darauf hin, dass BI-1 in der Lage ist, die Translokation von DIO-1 in den Zellkern $\mathrm{zu}$ inhibieren. Es ist möglich, dass BI-1 die Oligomerisierung von DIO-1 verhindert und dadurch die Migration von DIO-1 in den Zellkern unterbindet. Es ist ebenso möglich, dass durch die Herunterregulierung von BI1 die Translokation von DIO-1 über einen bisher unbekannten Signalweg eingeleitet wird.

Weiterhin wurde in der vorliegenden Arbeit gezeigt, dass bei gemeinsamer Herunterregulierung der Expressionen von BI-1 und DIO-1 in Säugerzellen keine Veränderungen in der subzellulären Lokalisation von DIO-1 auftreten und somit keine spontane Apoptose induziert wird. Dieser Nachweis deutet auf die Notwendigkeit eines Gleichgewichts der Expressionslevel zwischen BI-1 und DIO-1 hin.

\subsubsection{Die Funktion von BI-1 und dessen Interaktionspartnern in der Apoptose}

Um die Zusammenhänge zwischen BI-1 und dessen Interaktionspartnern in der Apoptose zu verstehen, ist es notwendig, einen Überblick über die Interaktionspartnern von BI-1 zu geben.

In der Literatur sind $\mathrm{Bcl}-2$ und $\mathrm{Bcl}-\mathrm{X}_{\mathrm{L}}$ als Interaktionspartner von $\mathrm{BI}-1$ beschrieben. Bcl-2 wurde ursprünglich als onkogenes Protein identifiziert (Tschujumoto et al., 1985), dessen zentrale Rolle in der Inhibierung der Apoptose zu liegen scheint (Reed, 1997). Vom Bcl-2-Protein wurde berichtet, dass es mit vielen Proteinen Interaktionen eingehen kann, wie z. B. mit dem pro-apoptotischen CED-4-Protein, der RAF-1-Kinase und der Calcineurin-Phosphatase (Reed 1997). Diese Interaktionen könnten auch für andere Proteine zutreffen, wie z. B. auf das BI-1-Protein (Xu und Reed, 1998). Die anti- 
apoptotische Wirkung von BI-1 könnte durch die Interaktion zwischen BI-1 und Bcl-2 zustande kommen.

$\mathrm{Xu}$ und Reed (1998) haben zur Funktion des BI-1-Proteins die Hypothese aufgestellt, dass BI-1 als Rezeptor oder Ionenkanal wirken könnte. Es ist auch möglich, dass BI-1 einen heterodimeren Komplex mit dem anti-apoptotischen Protein Bcl-2 bildet, und dass aufgrund der angenommenen Interaktion zwischen diesen Proteinen ein regulierender Mechanismus besteht. BI-1 könnte einen durch Bcl-2 geformten Ionenkanal kontrollieren oder Bcl-2 könnte einen hypothetischen BI-1-Ionenkanal modulieren (Xu und Reed 1998).

Eine weitere Hypothese wie BI-1 eine Resistenz gegen ER-Stress-induzierte Apoptose aufbaut, ist, dass BI-1 in der Lage ist, den Kalziumgehalt im ER zu reduzieren (Westphalen et al., 2005). Die Mehrzahl der eukaryotischen BI-1-Proteinsequenzen beinhalten RXR- und/oder KKXX-ähnliche Aminosäure-Sequenzen in der Nähe des Carboxyl-Terminus. Das Auftreten dieser konservierten Aminosäure-Motive in der BI1-Sequenz führte zu der Annahme, dass BI-1 im ER lokalisiert ist (Hückelhoven, 2004). Durch die Reduktion des Kalziumgehalts im ER durch BI-1 würde auch weniger Kalzium freigesetzt. Das führt dazu, dass die Kalzium-abhängige Cysteinprotease Calpain in einer inaktiven Form verbleibt (Wang, 2000). Die Aktive Calpain-Protease ist in der Lage, die Procaspase-3 in die aktive Caspase-3 (Blomgren et al., 2001) und Bcl- $\mathrm{X}_{\mathrm{L}}$ von der anti-apoptotischen Form in eine pro-apoptotische Form zu prozessieren (Nakagawa et al., 2003).

In Abb. 4.43 ist die mögliche Funktion von BI-1 und dessen Interaktionspartnern in der Apoptose schematisch dargestellt. Um den Mechanismus von BI-1 und DIO-1 im Hinblick auf die Apoptose zu klären, ist es notwendig, die Zusammenhänge der im BI-1 involvierten Apoptose-Signalweg aktiven anti- und pro-apoptotischen Proteine näher zu charakterisieren. 


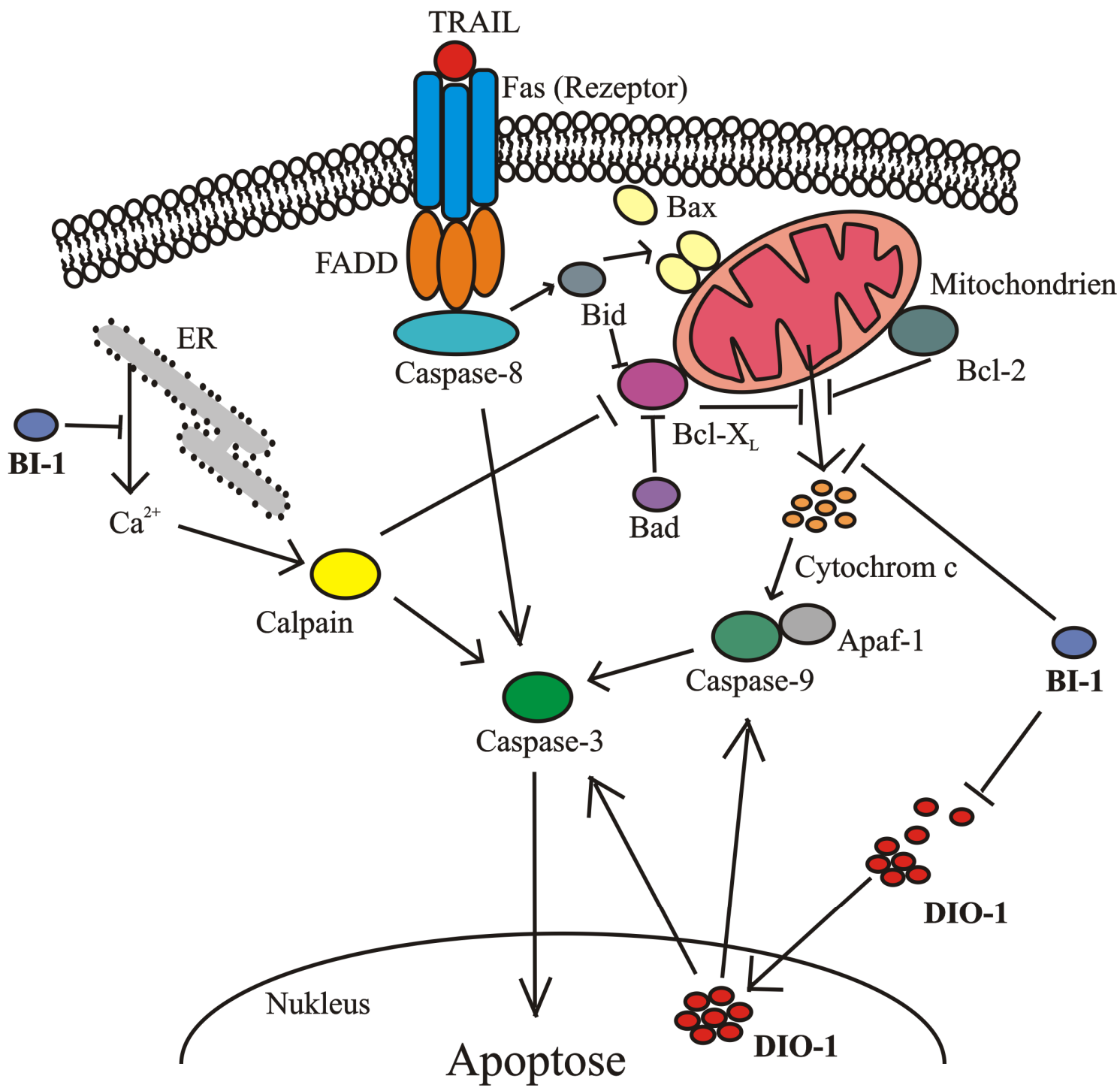

Abb. 4.43: Aktivierung und Inhibierung von Apoptose durch Death Ligand transmittierte Signale zum Death Receptor. Death Receptor Fas ist ein Mitglied der Tumor Necrosis Factor Receptor Familie, eine Familie der Transmembran-Rezeptoren, die eine Reihe von Zelloberflächen-Rezeptoren beinhalten. Die Aktiverung von Fas hat die Mobilisierung von Fas-assoziierten Proteinen mit der Fas associated death Domain (FADD) zur Folge. Weiterhin bindet die Procaspase-8 an FADD und wird aktiviert. Die Aktivierung der Caspase-8 führt zur Aktivierung von Effektor-Caspasen (unter anderem Caspase-3) und Bid (ein Mitglied der pro-apoptotischen Bcl-2-Familie). Durch die Prozessierung von Bid durch die Caspase-8 kann das verkürzte Bid in die Mitochondrien translozieren, wo es über die Bax-aktivierten spannungsabhängigen Anionen-Kanäle (nicht eingezeichnet) Cytochrom c freisetzt. Dies aktiviert die Caspase-Kaskade durch die Interaktion von Cytochrom c mit dem Apaf-1/Pro-Caspase-9-Komplex. Die Freisetzung von Cytochrom c kann durch die anti-apoptotischen Proteine Bcl-2 und Bcl- $\mathrm{X}_{\mathrm{L}}$ inhibiert werden, wobei Bcl- $\mathrm{X}_{\mathrm{L}}$ wiederum durch Bid und Bad (ein Mitglied der pro-apoptotische Bcl-2-Familie) inhibiert werden kann. BI-1 könnte in diesem Zusammenhang mit Bcl-2 und Bcl- $\mathrm{X}_{\mathrm{L}}$ interagieren und die Freisetzung von Cytochrom c verhindern. Die Induktion der Apoptose durch ER-Stress kann den 
Kalziumgehalt im ER hochregulieren und die Freisetzung von Kalzium aus dem ER bewirken. Das Kalzium aus dem ER bringt Calpain, eine Kalzium-abhängige Cystein-Protease in eine aktive Form, welche die Pro-Caspase-3 in eine aktive Caspase-3 prozessiert. Calpain kann ebenfalls Bcl- $\mathrm{X}_{\mathrm{L}}$ von einer anti-apoptotischen Form in eine pro-apoptotische Form prozessieren. BI-1 reduziert den Kalziumgehalt im ER, was dazuführen kann, dass weniger Kalzium aus dem ER freigesetzt wird und so Calpain in der inaktiven Form bleibt. BI-1 könnte ebenfalls DIO-1 daran hindern, in den Zellkern zu translozieren und so die Aktivierung von Procaspase-3 und 9 verhindern.

\subsection{Untersuchungen zur Funktion von BI-1 mittels Herunterregulierung der BI-1-Expression in induzierten Mammakarzinomen bei Nacktmäusen}

\subsubsection{Untersuchungen mittels molekularer Bildgebungsverfahren}

Als molekulare Bildgebungsverfahren werden die in vivo-Charakterisierung und Messungen biologischer Prozesse auf zellulärer und molekularer Ebene bezeichnet (Weissleder und Mahmood, 2001). In den letzten sieben Jahren wurden durch die Entwicklung leistungsfähiger Computertechnologien nicht-invasive und auf molekularer Ebene quantitativ erfassbare in vivo-Bildgebungstechniken entwickelt. Ziel der molekularen Bildgebung ist es, anatomische und physiologische Veränderungen bei Krankheiten oder die Behandlung der Krankheiten auf molekularer Ebene zu untersuchen. In der Forschung könnten die Techniken angewandt werden, um z.B. phänotypische Veränderungen an transgenen oder knock out-Mäusen zu untersuchen.

Ein großer Vorteil hierbei ist die Möglichkeit, den Krankheitsverlauf bei ein und derselben Maus über einen längeren Zeitraum hinweg zu beobachten. Bei Anwendung herkömmlicher Methoden zur Untersuchung des Behandlungsverlaufs einer Krankheit an Mäusen ist eine um das vielfache größere Anzahl an Mäusen notwendig im Vergleich zu den nicht-invasiven molekularen Bildgebungsverfahren, da nach jedem Behandlungstag die Mäuse getötet und z.B. histologisch untersucht werden müssen (Abb. 4.44). 


\section{A \\ Herkömmliche Methode: 18 Tiere nach drei Behandlungstagen}

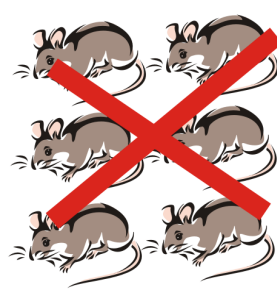

1. Behandlungstag

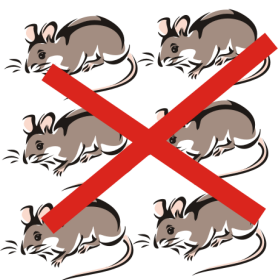

2. Behandlungstag

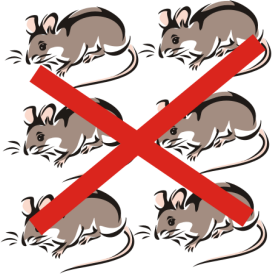

3. Behandlungstag

Nicht-invasive molekulare Bildgebung: Dieselben 6 Tiere nach drei Behandlungstagen

B
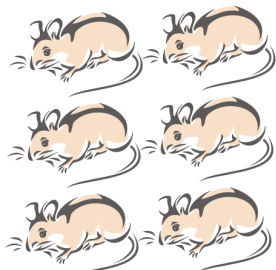

1. Behandlungstag
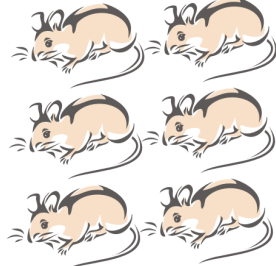

2. Behandlungstag

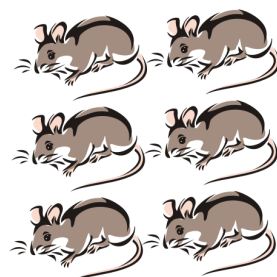

3. Behandlungstag

Abb. 4.44: Vorteil eines nicht-invasiven molekularen Bildgebungsverfahren im Vergleich zur herkömmlichen Untersuchungsmethode. Bei einem Experiment zur Untersuchung des Behandlungserfolgs bei einer Krankheit würden bei der herkömmlichen Methode (A) nach jedem Behandlungstag die Mäuse für die Untersuchung abgetötet werden. Dazu wären 18 Tiere nach drei Behandlungstagen notwendig, während bei dem nicht-invasiven molekularen Bildgebungsverfahren (B) nur 6 Tiere benötigt werden.

Die statistische Signifikanz wäre bei der herkömmlichen Methode im Vergleich zu den nicht-invasiven molekularen Bildgebungsverfahren trotz größerer Anzahl an Mäusen unerheblich, da die unterschiedlichen physiologischen Gegebenheiten der jeweiligen Mäuse und somit ein unterschiedlicher Verlauf der Krankheit statistisch nicht erfassbar wird. Die Aussagekraft bei den nicht-invasiven molekularen Bildgebungsverfahren ist bei solchen Experimenten höher einzuschätzen als bei der herkömmlichen Methode, da die Behandlungsergebnisse von denselben Ausgangsbedingungen analysiert werden. 


\subsubsection{Experimenteller in vivo -Ansatz zur Untersuchung der Funktion von BI-1}

Die Behandlung von Krebs über die RNAi-Technologie hat sich zu einer effektiven Methode entwickelt. Die virale Übertragung der siRNA-Oligonukleotide ist zwar effizient, kann aber schwerwiegende Nebeneffekte zur Folge haben (Scanlon, 2004). Die kationischen Lipid-Komplexe sind ebenfalls ein effektives Mittel zur Übertragung von siRNA (Sorensen et al., 2003), können aber in in vivo-Modellen Immunreaktionen verursachen (Sioud und Sorensen, 2003). Für die Herunterregulierung der GenExpression über siRNA in vivo ist es ebenfalls wichtig, dass die siRNA vor der Degradation durch Nukleasen geschützt sind, und dass die Wirkung der siRNA über einen längeren Zeitraum hinweg stabil bleibt. Minakuchi et al. (2004) konnten zeigen, dass die siRNA-Moleküle im Komplex mit Atelocollagen (Ac) effektiv in die Zellen transduziert werden können, und dass sie vor der Degradation durch Nukleasen geschützt sind. Atelocollagen ist ein Typ I Collagen aus der Kälberhaut, das Telopeptidfrei ist und dadurch kaum zu einer Immunreaktion in der Maus führt (Ochya et al., 2002). Takeshita et al. (2005) konnten weiterhin zeigen, dass die siRNA/Ac-Komplexe über sog. enhanced permeability and retention (ERP)-Effekte selektiv in Tumoren akkumulieren. Der ERP-Effekt beschreibt ein Phänomen, bei dem Makromoleküle aufgrund der vaskulären Anomalien in soliden Tumoren längere Zeit im Gewebe verbleiben können. Die erhöhte vaskuläre Dichte durch die Neoangiogenese und das Fehlen der glatten Muskelschicht in Gefäßen solider Tumoren sind die Ursache für den ERP-Effekt (Greish et al., 2003; Satchi-Fainaro et al., 2004).

Aufgrund dieser Eigenschaften wurde für den experimentellen in vivo-Ansatz die siRNA-Behandlung mittels Atelocollagen-Komplex angewendet. Für die ApoptoseInduktion durch die Herunterregulierung der BI-1-Expression in vivo wurde ein MDAMB-231-Tumor-Mausmodell verwendet. Da die Herunterregulierung der BI-1Expression in vitro in Mamma- und Prostatakarzinomzellen zur Apoptose-Induktion führt, sollte nun getestet werden, ob eine Injektion von BI-1-spezifischen siRNAOligonukleotiden in einen Tumor in einer Reduktion der Tumorgröße oder sogar in einem Wachstumsstop resultiert. Dazu wurden mit Cy5.5 markierte BI-1-siRNA Atelocollagen-Komplexe in einen MDA-MB-231-Tumor injiziert. Durch die Cy5.5- 
Markierung war es möglich, die siRNA/Ac-Komplexe mit Hilfe des eXplore OptixSystems in vivo über den gesamten Zeitraum des Experiments zu detektieren.

Ein ähnliches Experiment wurde bereits von Minakuchi et al. (2004) und Takeshita et al. (2005) beschrieben, die einen siRNA/Atelocollagen-Komplex in vivo eingesetzt haben. Takeshita et al. (2005) behandelten Knochenmetastasen mit EZH2- und p110- $\alpha$ siRNA/Ac-Komplexen in vivo und beobachteten die Behandlungserfolge über ein Biolumineszenz-Bildgebungsverfahren. Dabei wurde die biolumineszente humane Prostatakarzinomzelllinie PC-3M-luc-C6 in den linken Herz-Ventrikel von Nacktmäusen injiziert, wobei sich nach etwa 8 Tagen ein Tumor mit einem Volumen zwischen 50-100 $\mathrm{mm}^{3}$ entwickelte. Die Mäuse wurden dann mit EZH2- und p110- $\alpha$ siRNA/Ac-Komplexen behandelt (die siRNA/Ac-Komplexe wurden über die Schwanzvene injiziert). Es konnte gezeigt werden, dass die über die Ac-Komplexe vermittelten EZH2- und p110- $\alpha$-siRNAs in der Lage waren, das Wachstum von Knochenmetastasen zu inhibieren. Über die Biolumineszenz war es möglich, die Tumorausbreitung und das Wachstum während des gesamten Zeitraums des Experiments zu analysieren (Takeshita et al., 2005).

In der vorliegenden Arbeit wurde eine ähnliche Strategie verfolgt. Hierbei sollten die Mammakarzinome direkt (durch Injektion) mit dem BI-1-siRNA/Ac-Komplex behandelt werden. Als Tumormodell wurden MDA-MB-231-Zellen in die Mammae von weiblichen Nacktmäusen implantiert, die nach etwa drei Wochen Tumoren entwickelten. Im Rahmen eines Pilotexperiments mit vier Mäusen wurde zunächst evaluiert, wie lange die siRNA/Ac-Komplexe in den Tumoren der Mäuse stabil bleiben. Das Hauptexperiment wurde mit vierzehn Mäusen durchgeführt, wobei zwei Mäuse keine Tumoren entwickelten. Mit den zwölf verbliebenen Mäusen wurde die Tumorprogression über Flächendetektor-Volumetrische-Computertomographie (FDVCT) beobachtet und die Behandlung mit den siRNA/Ac-Komplexen über molekulare optische Bildgebungsverfahren (eXplore Optix) überprüft. 


\subsubsection{Kontrolle der Stabilität des siRNA/Ac-Komplexes mittels molekularen optischen Bildgebungsverfahren (eXplore Optix) und Detektion über die Infrarot-Mikroskopie}

Über die Kopplung des Fluorophors Cy5.5 mit der siRNA war es möglich, unter Verwendung des eXplore Optix-Systems die siRNA/Ac-Komplexe in vivo zu detektieren. Die siRNA/Ac-Komplexe waren zu jedem Zeitpunkt des Experiments in den Mammatumoren der Mäuse detektierbar. Die Stabilität des siRNA/Ac-Komplexes wurde zuvor in einem Pilotexperiment getestet. Der siRNA/Ac-Komplex blieb bis zu sieben Tage in vivo stabil.

Mittels Infrarot-Mikroskopie konnte anschließend der siRNA/Ac-Komplex in den Kryogewebeschnitten der behandelten Tumore detektiert werden. So konnte demonstriert werden, dass die siRNA/Ac-Komplexe in die Zellformationen infiltrieren und gleichmässig im Gewebe verteilt sind.

\subsubsection{Auswertung der Tumorprogression mit Hilfe von FD-VCT}

Es wurden bereits Ergebnisse der in vivo-Experimente mit iRNA-behandelten PC-3Zellen in der Maus publiziert. Takei et al. (2006) verwendeten bei der siRNA/AcBehandlung bei implantierten PC-3-Zellen in der Maus siRNA gegen Midkine (Wachstums- und Differenzierungsfaktor) und Paclitaxel (in Chemotherapie eingesetzter chemischer Wirkstoff der Gruppe Taxane). Die Erfolge der siRNA/AcBehandlung wurden dabei über die Volumenmessungen an der Schieblehre und mit Hilfe immunzytochemischer Daten dargestellt. Dabei waren für die Experimente sechs Mäuse pro Gruppe (sechs Gruppen insgesamt) mit dreimaliger Wiederholung notwendig, um eine statistische Signifikanz zu erreichen. Durch die große Anzahl an Mäusen konnten Messfehler, die durch die Schieblehren-Messung oder auch aufgrund der Unterschiede im Tumorwachstum bei verschiedenen Mäusen entstehen, reduziert werden.

Die FD-VCT kann die Messfehler, die über die Schieblehre verursacht werden, minimieren. Über die Schieblehre können z.B. keine Tiefenmessungen vorgenommen werden, etwa wenn der Tumor nicht direkt subkutan implantiert wurde. Messfehler bei 
subkutan implantierten Tumoren entstehen z.B. auch durch die Haut. Wie stark die Unterschiede in den Messungen sein können, verdeutlicht die Messungen, die im Rahmen des Hauptexperiments durchgeführt wurde (Abb. 4.45). Dargestellt ist eine exemplarische Messung der Tumorvolumina über FD-VCT und Schieblehre. Messunterschiede im Tumorvolumen von bis $\mathrm{zu} 100 \mathrm{~mm}^{3}$ wurden im Extremfall beobachtet. Eine solche Fehlmessung wird durch die allgemeine Rechenformel (Tumorvolumen $=(B r e i t e)^{2} \times$ Länge $/ 2$; Takei et al., 2001), die für die Tumorvolumenmessungen üblich ist, begünstigt. Da Tumoren, wie die Rechenformel suggeriert, keine gleichmässige elliptische Oberfläche besitzen, kommt dadurch ein erheblicher mathematischer Fehler hinzu. 
A Vergleich zwischen Volumenmessung über Schieblehre und FD-VCT (BI-1)

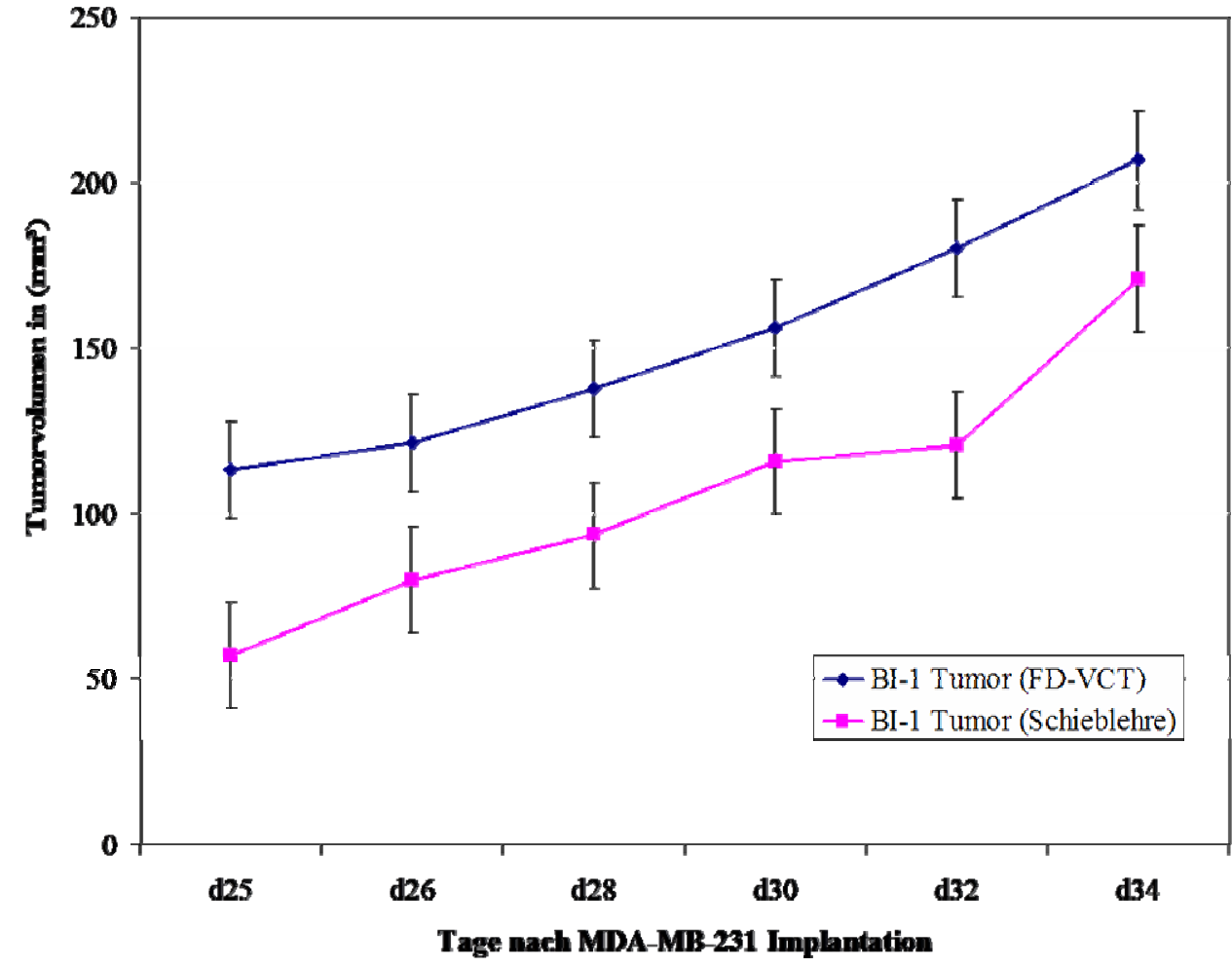

B Vergleich zwischen Volumenmessung über Schieblehre und FD-VCT (Luc)

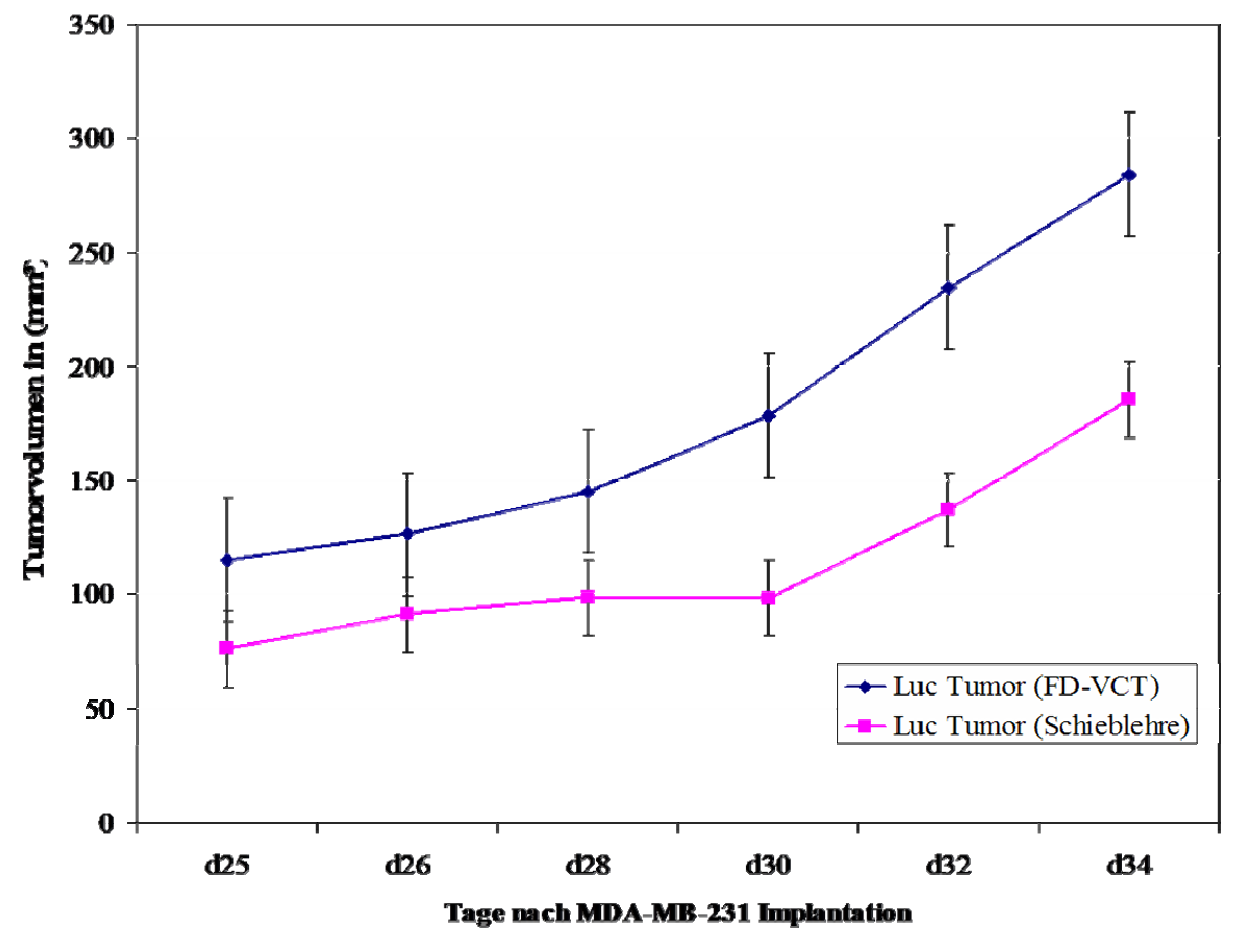

Abb. 4.45: Darstellung der Unterschiede in der Volumenmessung mit Hilfe der Schieblehre und der FD-VCT. Dargestellt sind die Messungen der Tumorvolumina über FD-VCT und Schieblehre von BI-1(A) und Luc-siRNA (B) behandelten Tumoren aus dem Hauptexperiment. Ein Unterschied im 
Tumorvolumen von bis zu $100 \mathrm{~mm}^{3}$ war im Extremfall (d34, Luc Tumor) zu beobachten. Berechnet wurde das Tumorvolumen unter Verwendung der allgemein üblichen Formel zur Berechnung von Tumorvolumina: Tumorvolumen $=(\text { Breite })^{2} \mathrm{x}$ Länge $/ 2$.

Weiterhin ist durch die Verwendung der FD-VCT möglich die Minimierung von Versuchstieren. Da die Messungen an ein und derselben Maus durchgeführt werden können, ist die statistische Fehlerberechung aufgrund des unterschiedlichen Tumorwachstums bei verschiedenen Mäusen nicht mehr notwendig. Die von Takei et al. (2006) verwendete Anzahl an Mäusen (108) könnte so auf 36 reduziert werden (sechs Mäuse pro Gruppe bei sechs Mäusen ohne Wiederholung).

Der FD-VCT arbeitet mit Flächendetektoren mit hoher Detektorelementdichte (1024 x 1024 Elemente), was eine sehr hohe Ortsauflösung von ca. 0,2 mm ermöglicht. Über die Hounsfield-Messung ist es weiterhin möglich, die unterschiedlichen Gewebetypen zu unterscheiden (Abb. 4.46). Die Auflösung der Rekonstruktion kann zudem über eine Kontrastmittelzugabe verbessert werden. 


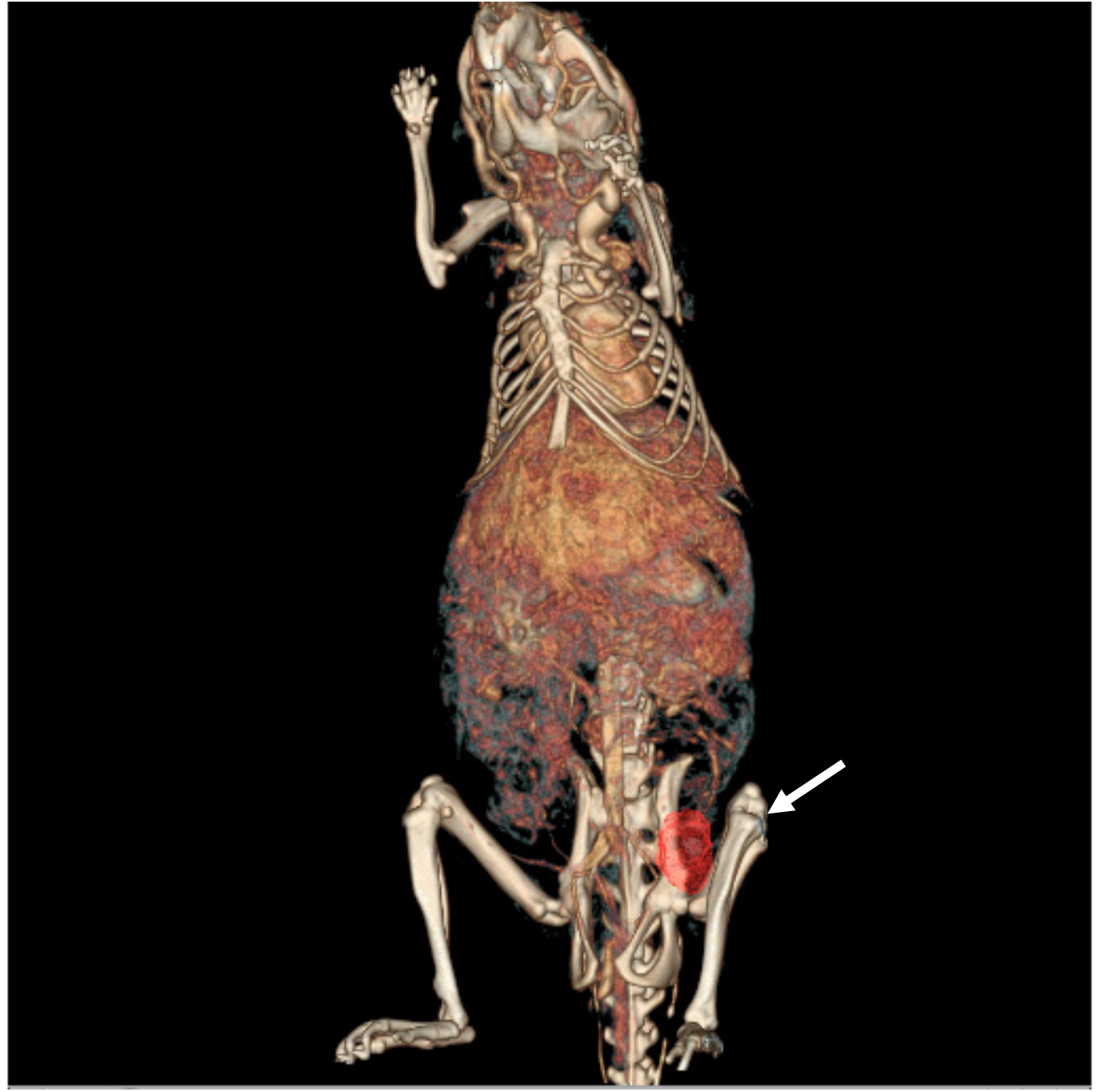

Abb. 4.46: Darstellung einer über FD-VCT rekonstruierten Nacktmaus. Die Messung über die FDVCT ermöglicht eine Rekonstruktion der Maus mit hoher Auflösung. Die verschiedenen Gewebetypen wurden mit verschiedenen Farben dargestellt. Der Tumor ist mit einem weissen Pfeil markiert.

In der vorliegenden Arbeit wurden die Mäuse über einen Zeitraum von 34 Tagen nach der Implantation der MDA-MB-231-Zellen mit den siRNA/Ac-Komplexen behandelt und die Tumorprogression mittels FD-VCT beobachtet. Ein großer Vorteil dieses System ist, dass die Volumina der Tumoren sehr genau vermessen werden können. Weiterhin ist es theoretisch möglich, die Nekrosebildung der Tumore durch die Unterschiede in den Houndsfield-Daten $\mathrm{zu}$ beobachten. In dem hier verwendeten Tumormodell konnte jedoch keine Nekrosebildung mittels FD-VCT dargestellt werden. Der Grund dafür liegt in dem schnellen Tumorwachstumsverhalten der MDA-MB-231Zellen. Die Blutgefäßbildung kann bei dem schnellen Wachstum des Tumors nicht Schritthalten und es kommt zu einem Blutversorgungsmangel im Inneren des Tumors. 
Aufgrund dieses Versorgungsmangels werden die Zellen dort nekrotisch. Dabei entsteht im Inneren des Tumors ein hoher Druck, was dazu führen kann, dass Blutgefäße im Inneren beschädigt werden (Vaupel, 2004). Wenn bei der Messung mit dem FD-VCT Kontrastmittel in die Schwanzvene der Maus injiziert werden, gelangen die Kontrastmittel über die Blutgefäße ins Innere des Tumors, wobei sie sich durch das Leck in den Blutgefäßen im Tumor sammeln. Dies verfälscht die HounsfieldMessungen und führt dazu, dass der vitale Anteil des Tumors nicht vom nekrotischen unterschieden werden kann. Daher war es in der vorliegenden Arbeit nicht möglich über die Hounsfield-Messungen den vitalen Anteil des Tumors von nekrotischen genau zu differenzieren. Ein weiterer Effekt der spontanen Nekrosebildung ist, dass nach der Sektion der Maus in den histologischen Untersuchungen keine Unterschiede zwischen den kontrollbehandelten und den mit BI-1-siRNA behandelten Tumoren zu erkennen ist. In Abb. 4.47 ist schematisch dargestellt, wie sich im Inneren der Tumore möglicherweise Nekrose entwickelt. Die Unterschiede nach der Behandlung der Tumoren ist in diesem Modell nur durch die Unterschiede im Tumorvolumen zu erkennen. Durch die Verwendung von neueren Kontrastmittel wie Fenestra LC wäre es möglich, das vitale und nekrotische Tumorgewebe auch in diesem Tumormodell zu unterscheiden. Fenestra LC stellt ein Kontrastmittel dar, welches 24 Stunden nach der Gabe die Wirksamkeit verliert und daher nicht mehr detektierbar ist. Zum Zeitpunkt des Experimentes war das Kontrastmittel Fenestra LC noch nicht erhältlich; die Wirksamkeit von Fenestra LC konnte aber durch ein Testexperiment an einer Maus bestätigt werden. Weiterhin könnte auch ein anderes Tumormodell verwendet werden, welches keine oder nur eine geringe spontane Nekrose der Tumoren zeigt. Ein solches Tumormodell könnten subkutan implantierte PC-3-Zellen darstellen. Die humane Prostatakazinomzelllinie PC-3 zeigt deutlich geringere spontane Nekroseraten als MDA-MB-231-Zellen im in vivo-Tumor-Mausmodell (Blakey et al., 2002). Durch die Verwendung solcher Tumormodelle wäre eine Darstellung der Unterschiede zwischen vitalen und nekrotischen Geweben durch die Behandlung mit siRNA mittels FD-VCT oder histologischer Analysen möglich. 


\section{Luc-siRNA}

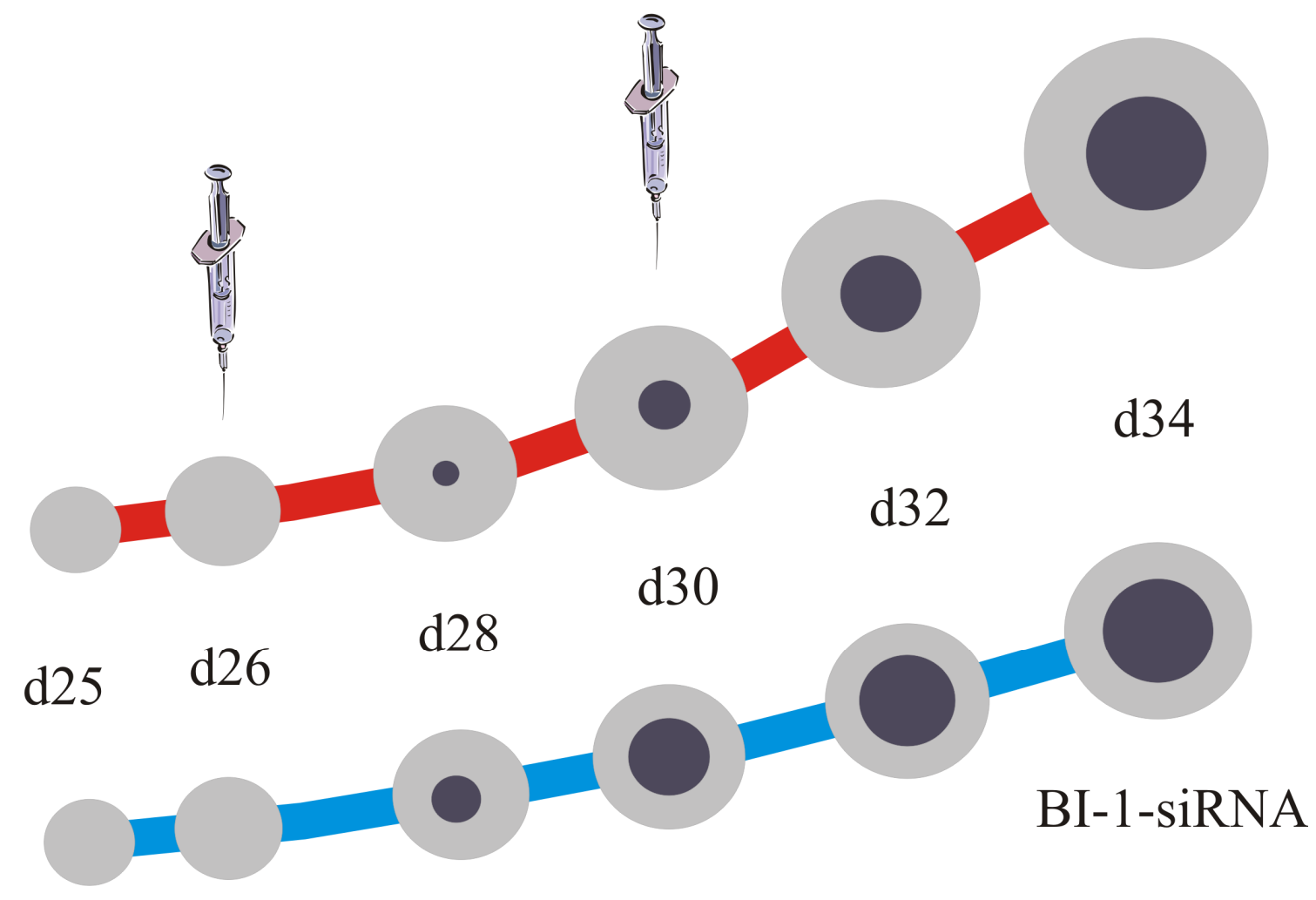

Abb. 4.47: Schematische Darstellung der Tumorprogression von BI-1- und Luc-siRNA behandelten Mäusen und die möglichen Nekrose-Entwicklungen. Die dargestellten Graphen (blau und rot) sind aus den Messungen des Tumorvolumens der hier vorliegenden Arbeit entnommen. Die Abbildungen der Spritzen markieren den Zeitpunkt der siRNA/Ac-Behandlungen. In dieser Darstellung soll verdeutlicht werden, wie sich eine spontane Nekrose im Inneren des Tumors entwickeln kann. Die BI-1-siRNA/Ac behandelten Tumoren entwickeln Nekrose durch die Zugabe des siRNA/Ac-Komplexes, während die Luc-siRNA behandelten Mäusen spontane Nekrose entwickeln. Zum Zeitpunkt d34 ist es nicht mehr möglich, durch die histologischen Untersuchungen Unterschiede in den BI-1- und Luc-siRNA/Ac behandelten Tumoren zu erkennen.

\subsubsection{BI-1-Herunterregulierung im MDA-MB-231-Tumormodell führt zur Reduktion des Tumorwachstums in vivo}

Die durch die in vivo-Experimente ermittelten Daten bestätigen die Ergebnisse aus den in vitro-Experimenten. In den in vitro-Experimenten konnte gezeigt werden, dass die Herunterregulierung der BI-1-Expression über spezifische siRNA in MDA-MB-231Zellen Apoptose induzieren kann. 
Durch diesen experimentellen in vivo-Ansatz war es möglich, ein verzögertes Tumorwachstum durch die Herunterregulierung der BI-1-Expression in vivo zu demonstrieren. Es konnte gezeigt werden, dass die Herunterregulierung der BI-1Expression $\mathrm{zu}$ einer Reduktion des Tumorwachstum im Vergleich $\mathrm{zu}$ den kontrollbehandelten Tumoren führt. Diese Reduktion des Tumorwachstums kann dadurch erklärt werden, dass die BI-1-siRNA/Ac-Komplexe im Tumorinneren Apoptose induzieren und so das Tumorwachstum gehemmt wird. Die direkte Injektion der siRNA/Ac-Komplex in den Tumor zur Übertragung der spezifischen siRNA kann nicht alle Zellen im Tumor erreichen, weshalb eine vollständige Induktion der Apoptose in allen Zellen des Tumors nicht möglich war.

Die über das in vitro-Experiment ermittelte Zeitraum, in dem der siRNA/Ac-Komplex in den Zellen stabil bleibt, konnte im in vivo-Experiment mit Hilfe des eXplore Optix bestätigt werden.

Im Pilotexperiment wurden die Mäuse über 50 Tage und im Hauptexperiment über 35 Tage behandelt. Der Zeitraum wurde dabei für das Hauptexperiment kürzer gewählt, um die spontanen Nekrose, die im Inneren der MDA-MB-231-Tumoren nach gewisser Zeit auftreten, so gering wie möglich zu halten.

Die Unterschiede im Wachstum zwischen BI-1- und Luc-siRNA/Ac behandelten Tumoren konnten über die Volumenmessung mittels FD-VCT verglichen werden. Ein Volumen-Unterschied von über $75 \mathrm{~mm}^{3}$ konnte dabei bei dem Hauptexperiment ermittelt werden. Beim Pilotexperiment, welches über einen um 15 Tage längeren Zeitraum lief, konnte sogar ein Volumenunterschied von über $200 \mathrm{~mm}^{3}$ ermittelt werden. Die Wachstumskurve der Tumoren aus dem Pilot- und Hauptexperiment zeigen die gleichen Tendenzen und die Daten sind miteinander vergleichbar.

Aufgrund der längeren Laufzeit des Pilotexperimentes konnte die Unterschiede im Tumorwachstum zwischen den Luc-siRNA/Ac-Komplex behandelten Tumoren und den mit BI-1-siRNA/Ac-Komplex behandelten Tumoren in den Histogrammen der FD-VCT deutlicher dargestellt werden.

Die hier verwendeten molekularen Bildgebungsverfahren ermöglichen die Durchführung von Langzeitstudien in ein und demselben Tier, wodurch präzise Daten zu Tumor-Wachstumsverhalten, Stabilität der siRNA/Ac-Komplexe und 
Behandlungsergebnissen erhoben werden konnten. Bisher gibt es in der Literatur keine Beschreibungen von Experimenten, bei denen beide Verfahren kombiniert worden sind. Mit den beiden kombinierten molekularen Bildgebungsverfahren ist es daher möglich, eine sehr genaue Datenerhebung der Tumortherapien in vivo bei einer erheblichen Reduktion der Versuchstiere durchzuführen. So können physiologische und molekulare Vorgänge über einen längeren Zeitraum verfolgt und in Zusammenhang gebracht werden.

In dieser Arbeit konnte gezeigt werden, dass BI-1 eine wichtige Rolle im Wachstumsverhalten von Mammakarzinomen in vivo spielt. Daher kann eine BI-1siRNA/Ac-Behandlung einen möglichen Ansatz für eine Tumortherapie beim Menschen darstellen.

\subsection{Ausblick auf weiterführende Arbeiten}

Um die Wirkung von BI-1 und DIO-1 zueinander zu untersuchen, sollte die Interaktion von DIO-1 und BI-1 näher charakterisiert werden. Da eine direkte Interaktion nicht nachgewiesen werden konnte, sollte zunächst die Interaktion von BI-1 und DIO-1 unter dem Aspekt, dass eine indirekte Interaktion vorliegen kann, verifiziert werden. Es sollte mit Hilfe von Brückenproteinen-Identifizierungs-Kits nach Brückenproteinen gesucht werden, die BI-1 und DIO-1 miteinander verbinden. Anschließend sollten durch direkte Interaktionsexperimente die Regionen untersucht werden, die für diese Interaktionen verantwortlich sind.

Um einen funktionellen Zusammenhang zwischen DIO-1 und BI-1 zu untersuchen, könnten Proteom-Analysen an humanen Karzinomzellen unter Herunterregulierung / Hochregulierung von DIO-1 / BI-1 durchgeführt werden. Die Unterschiede / Gemeinsamkeiten der Proteinexpression könnten weitere Informationen bei der Vervollständigung der BI-1 und DIO-1 involvierten Apoptose-Signalwege liefern.

Auch sollten weitere Interaktionspartner von BI-1 näher charakterisiert werden. PPP2CA, welches beim Yeast-Two-Hybrid-Screening gefunden wurde, ist im Hinblick darauf interessant, dass die Dephosphorylierung von Bcl-2 durch PP2A zur 
Apoptoseresistenz führt (Simizu et al., 2004; Tamura et al., 2004). PP2A besteht aus drei Untereinheiten: aus der katalytischen Untereinheit C (PPP2CA), aus der regulatorischen Untereinheit B und aus der strukturellen Untereinheit A (Janssens und Goris, 2001; Schonthal, 2001). Über das Yeast-Two-Hybrid-Screening wurde die Untereinheit $\mathrm{C}$ als Interaktionspartner von BI-1 identifiziert. Die Interaktion sollte nun über eine unabhängige Methode wie z.B. Koimmunopräzipitation verifiziert werden. Anschließend kann die Interaktionsregion der beiden Proteine über direkte Yeast-TwoHybrid-Experimente eingegrenzt werden.

Weiterhin sollte geklärt werden, ob BI-1 phosphoryliert wird. Die Computeranalyse der Aminosäuresequenz zeigt eine hohe Wahrscheinlichkeit für die Phosphorylierungsstellen Serin und Tyrosin (Abb. 4.48) in der BI-1-Sequenz an.

NetPhos 2.0: Mögliche Phosphorylierungsstellen von BI-1

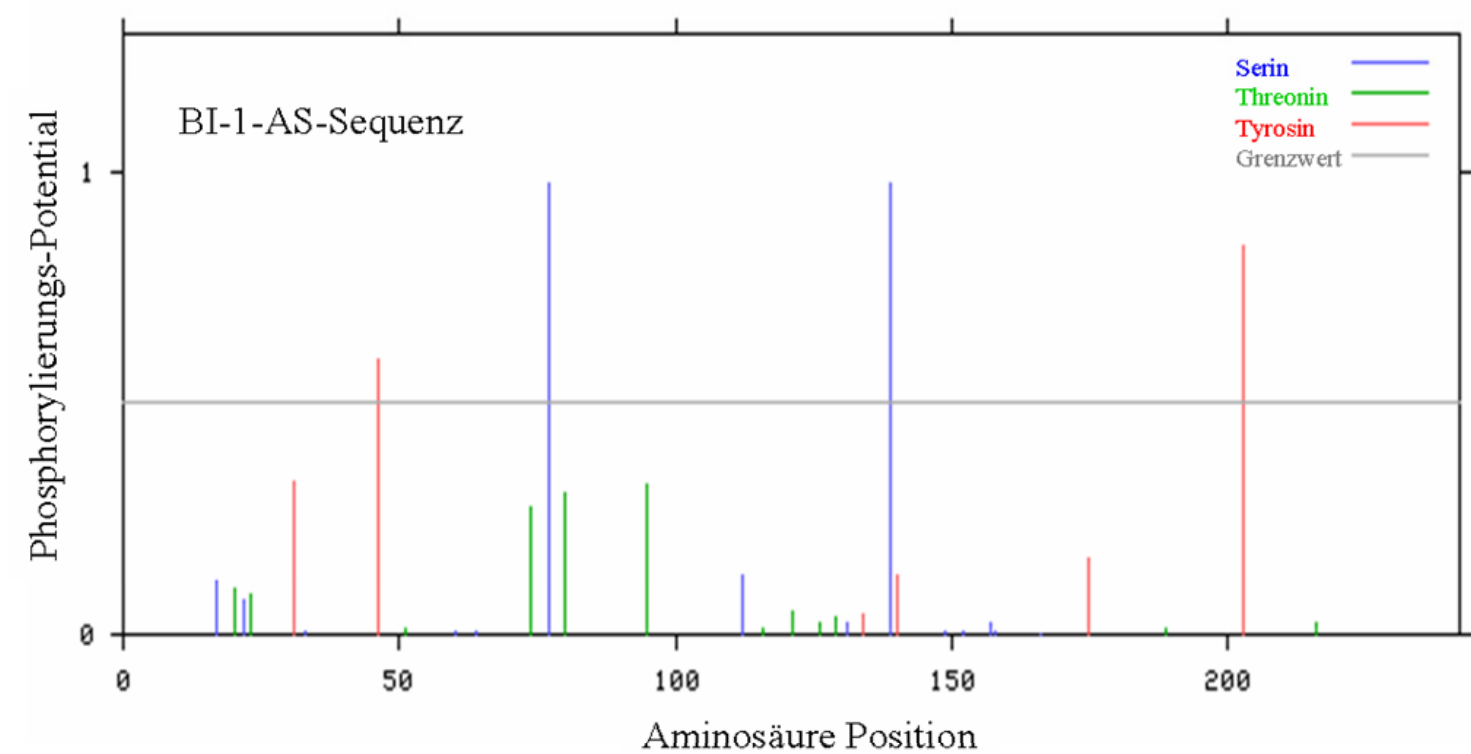

Abb. 4.48: Putative Phosphorylierungsstellen von BI-1. Für die Suche nach putativen Phosphorylierungsstellen wurde das Computerprogramm Netphos 2.0 verwendet. BI-1 hat je zwei putative Phosphorylierungsstellen für Serin und Tyrosin (Quelle: http://www.cbs.dtu.dk/services/ NetPhos/).

Über Immunpräzipitation von BI-1 und anschließender 2D-SDS-PAGE sowie Western Blot-Analyse mit einem Phospho-Serin-spezifischen Antikörper kann die Phosphorylierung untersucht werden. Der Vergleich von Proteinen aus Zellen, die mit dem PP2A-Inhibitor Okadasäure behandelt wurden, und aus unbehandelten Zellen zeigt 
zudem, ob PP2A BI-1 dephosphoryliert ist. Durch Einführung von Mutationen an den putativen Phosphorylierungsstellen könnte untersucht werden, ob eine Regulation der BI-1-Aktivität über die Dephosphorylierung durch z.B. PP2A stattfindet. Weiterhin sollte die subzelluläre Kolokalisation von BI-1 und PP2A untersucht werden.

Es wurde gezeigt, dass DIO-1 über zahlreiche Phosphorylierungsstellen verfügt und dass DIO-1 in phosphorylierter und dephosphorylierter Form in den Zellen vorliegt (Garcia-Domingo et al., 2003). Um herauszufinden, ob PP2A für die Dephosphorylierung von DIO-1 verantwortlich ist, sollte die Interaktion von DIO-1 mit PP2A untersucht werden. Über ein Inhibierung von PP2A und Herunterregulierung der BI-1-Expression könnte geprüft werden, ob DIO-1 in der Lage ist, in den Zellkern zu migrieren. Mittels Überexpression von DIO-1 könnte auch die Schutzwirkung von BI-1 in Zellen bei inhibierter PP2A überprüft werden.

BI-1 beinhaltet ein KKXX-ähnliches Motiv im C-terminalen Bereich (Dohm et al., 2006). Die KKXX-Motive sind für die Endozytose zuständig und charakteristisch für ER-Membranproteine (Itin et al., 1995). Durch Deletions- und Insertions-Mutanten sollte untersucht werden, ob das KKXX-ähnliche Motiv von BI-1 funktionell ist. Damit könnte geprüft werden, ob die Domäne für die ER-Lokalisation von BI-1 verantwortlich ist.

Mit Hilfe des experimentellen in vivo-Ansatzes konnte demonstriert werden, dass durch die Herunterregulierung von BI-1 das Wachstum von Mammakarzinomen in Nacktmäusen inhibiert wird. Um diesen Effekt besser untersuchen zu können, sollte ein Tumormodell verwendet werden (wie z.B. die Prostatakarzinomzelllinie PC-3), bei dem die Nekrose durch das Tumorwachstum geringer ausfällt. Damit wären die Unterschiede der BI-1-siRNA/Ac behandelten und der Kontrollzellen sowohl im FD-VCT als auch in den histologischen Untersuchungen sichtbar. Auch unterschiedliche Konzentrationen der siRNA/Ac-Komplexe sollten ausgetestet werden, um die effektivste Konzentration für die Behandlung zu evaluieren. Durch verbesserte Technologien in der Herstellung der siRNA könnte die Effektivität der Behandlung ebenfalls gesteigert werden. Daher sollten neue siRNA-Techniken, wie z.B. die Stealth-Technologie der Fa. Qiagen für weitere in vivo-Experimente verwendet werden, wobei die Effektivität der siRNABehandlung noch einmal gesteigert werden kann. Auch der Einsatz neuartiger 
Kontrastmittel, wie z.B. Fenestra LC könnten zudem bessere Histogrammdaten liefern, d.h. vitale und nekrotische Zellen im Tumor könnten optimaler unterschieden werden. Damit wäre es möglich, die Nekrosebildung im Tumor während der siRNA-Behandlung mit Hilfe des FD-VCT zu detektieren. Durch die neuere Version der eXplore OptixSoftware (seit Oktober 2006 verfügbar) ist es ausserdem möglich, einen 3Dtopographischen Scan der mit Cy5.5 gekoppelten siRNA durchzuführen, wobei eine Tiefenmessung vorgenommen werden kann. Auf diese Weise könnten die Daten des FD-VCT und des eXplore-Optix-Systems fusioniert werden. Eine Software für die Fusionierung der Daten ist seit November 2006 verfügbar. Eine präzisere Lokalisation und Darstellung der siRNA/Ac-Komplexe im Tumor wäre damit ebenfalls möglich. 


\section{Zusammenfassung}

Im ersten Teil der Arbeit wurde die Expression von BI-1 in verschiedenen humanen Karzinomen untersucht. Mit Hilfe des Cancer Profiling Arrays konnte eine Hochregulierung der BI-1-Expression bei Mamma-, Uterus- und Ovarialkarzinomen festgestellt werden. Eine Herunterregulierung der BI-1-Expression von 50\% und mehr wurde im Magen-, Darm- und Rektumkrebs detektiert.

Weiterhin konnte die Expression von BI-1 in den humanen Mammakarzinomzelllinien MDA-MB-231, MDA-MB-453, MCF-7, HCC70, ZR-75-1 und T-47D nachgewiesen werden. Die stärkste Expression wurde in den Zelllinien MDA-MB-231, HCC-70 und ZR-75-1, die schwächste Expression in den Zelllinien MCF-7 und MDA-MB-453 festgestellt.

Die Funktion von BI-1 wurde mit Hilfe von gene silencing-Experimenten in den etablierten Mammakarzinomzellinien untersucht. Es wurde eine Reduktion der BI-1Expression im Vergleich zu kontrolltransfizierten und unbehandelten Zellen von 50 bis $80 \%$ auf Proteinebene erreicht. Die Herunterregulierung der BI-1-Expression führte zur Apoptose in 32\% der MDA-MB-231-Zellen 96 Stunden nach der siRNA-Transfektion, wohingegen nur 5\% der MCF-7-Zellen und 8\% der T-47D-Zellen apoptotisch wurden. Bei den kontrolltransfizierten Zellen und bei den unbehandelten parentalen Zellen hingegen lag die Apoptoserate im beobachteten Zeitraum bei 1 - 5\%. Diese Daten deuten auf eine wichtige Rolle von BI-1 in der Apoptose beim Mammakarzinom hin.

Im zweiten Teil der Arbeit wurden putative Interaktionspartner von BI-1 in humanen Prostatazellen näher untersucht. Dazu wurde ein Yeast-Two-Hybrid-Screening mit einer humanen Prostata-cDNA-Bibliothek und BI-1 als Köderprotein durchgeführt. DIO-1 wurde dabei als BI-1-Interaktionspartner identifiziert und aufgrund seiner proapoptotischen Rolle in der Apoptose weiter analysiert. Der Nachweis einer direkten Interaktion von BI-1 und DIO-1 mittels Koimmunopräzipitation konnte jedoch nicht erbracht werden. Um den Zusammenhang der Funktionen von BI-1 und DIO-1 näher zu untersuchen, wurde eine Analyse zur subzellulären Kolokalisation von DIO-1 und BI-1 mit Hilfe von DIO-1-DsRed- und BI-1-GFP-Fusionsproteinen sowie mittels 
Immunzytochemie in Säugerzellen durchgeführt. DIO-1 und BI-1 zeigten bei $90 \%$ der transfizierten NIH3T3-Fibroblastenzellen eine diffuse Verteilung im Zytoplasma. Es konnte gezeigt werden, dass DIO-1 zusammen mit BI-1 im Zytoplasma lokalisiert ist. Sowohl das DIO-1-DsRed- als auch das BI-1-GFP-Fusionsprotein konnte in etwa 10\% der kotransfizierten Zellen im Zytoplasma als kugelförmige Struktur lokalisiert werden, die jedoch keiner bekannten Zellstruktur zugeordnet werden konnte.

Die durchgeführte Expressionsanalyse an humanen Mamma- und Prostatakarzinomzelllinien zeigte, dass in allen Zelllinien DIO-1 exprimiert wird.

Dabei konnte die stärkste Expression in den Mammkarzinomzellen MDA-MB-231, HCC-70, ZR-75-1 und in den Prostatakarzinomzellen PC-3 und DU-145 festgestellt werden. Die schwächste DIO-1-Expression wurden in den Mammkarzinomzellen T47D, MCF-7, MDA-MB-453 und in den Prostatakarzinomzellen LNCaP beobachtet werden.

Da bekannt ist, dass DIO-1 unter Apoptose-induzierenden Bedingungen in den Kern migriert, wurde die subzelluläre Lokalisation von DIO-1 nach Herunterregulierung der BI-1-Expression in Prostatakarzinomzelllinien untersucht. Dabei konnte in 38\% der PC3-Zellen mit reduzierter BI-1-Expression eine nukleäre Lokalisation, in $26 \%$ eine partiell nukleäre und in 36\% eine zytoplasmatische Lokalisation von DIO-1 beobachtet werden. Die kontrolltransfizierten PC-3-Zellen zeigten hingegen in nur 3\% der Zellen eine DIO-1-Lokalisation im Kern, in 9\% eine partiell nukleäre und in $88 \%$ eine zytoplasmatische Verteilung von DIO-1. Bei der gemeinsamen Herunterregulierung der Expressionen von BI-1 und DIO-1 mittels RNAi in den Prostata- sowie Mammakarzinomzelllinien konnte keine gesteigerte Caspase-3-Aktivität im Vergleich zu den kontrolltransfizierten Zellen gemessen werden.

Die hier gezeigten Daten deuten darauf hin, dass BI-1 und DIO-1 eine Balance in der Apoptose-Signalkaskade bilden, und dass deren Funktionen in der Apoptose assoziiert sind.

Im dritten Teil der Arbeit wurde der Effekt der Apoptose-Induktion durch die Einführung von BI-1-spezifischen Duplex-siRNA-Oligonukleotiden in induzierte Mammakarzinome bei Nacktmäusen untersucht. Etwa zwei Wochen nach der Implantation von MDA-MB-231-Zellen in die Nacktmäuse entwickelten sich Tumoren, 
die mit BI-1-siRNA/Atelocollagen (Ac)-Komplexen im Abstand von vier Tagen behandelt wurden. Über das eXplore Optix-System war es möglich, die mit Cy5.5 gekoppelte siRNA in vivo zu lokalisieren. Der siRNA/Ac-Komplex blieb über den gesamten Zeitraum hinweg im Tumor detektierbar und weitestgehend stabil. Über Flächendetektor-Volumetrische-Computertomographie (FD-VCT) wurde die Tumorentwicklung alle zwei Tage beobachtet und die Daten analysiert. Die mittels FDVCT segmentierten Tumordaten belegen, dass die BI-1-siRNA/Ac-behandelten Tumoren langsamer wachsen als die mit Luc-siRNA/Ac-behandelten Kontrolltumoren (75 $\mathrm{mm}^{3}$ Tumorendvolumenunterschied).

Mit Hilfe von Infrarot-mikrosokopischen Untersuchungen an Kryo-Gewebeschnitten konnten die siRNA/Ac-Komplexe in den Tumorgeweben nachgewiesen werden.

Es konnte gezeigt werden, dass BI-1 eine wichtige Rolle in der Tumorprogression von Mammakarzinomen in vivo spielt. Daher kann eine BI-1-siRNA/Ac-Behandlung einen möglichen Ansatz für eine Tumortherapie darstellen. Die hier verwendeten molekularen optischen Bildgebungsverfahren stellen weiterhin eine effektive Methode zur Untersuchung von anatomischen und physiologischen Veränderungen der Tumor-MausModelle auf molekularer Ebene dar. 


\section{Literaturverzeichnis}

Altschul, S. F., Gish, W., Miller, W., Myers, E. W., Lipman, D. J. (1990). Basic local alignment search tool. J Mol Biol. 215:403-410.

Arizmendi, J. M., Runswick, M. J., Skehel, J. M. and Walker, J. E. (1992). NADH: ubiquinone oxidoreductase from bovine heart mitochondria. A fourth nuclear encoded subunit with a homologue encoded in chloroplast genomes. FEBS Lett. 301(3): 237-42.

Baek, D., Nam, J., Koo, Y. D., Kim, D. H., Lee, J., Jeong, J. C., Kwak, S. S., Chung, W. S., Lim, C. O., Bahk, J. D., Hong, J. C., Lee, S. Y., Kawai-Yamada, M., Uchimiya, H. and Yun, D. J. (2004). Bax-induced cell death of Arabidopsis is meditated through reactive oxygen-dependent and -independent processes. Plant Mol Biol. 56(1): 15-27.

Bailly-Maitre, B., Fondevila, C., Kaldas, F., Droin, N., Luciano, F., Ricci, J. E., Croxton, R., Krajewska, M., Zapata, J. M., Kupiec-Weglinski, J. W., Farmer, D. and Reed, J. C. (2006). Cytoprotective gene bi-1 is required for intrinsic protection from endoplasmic reticulum stress and ischemia-reperfusion injury. Proc Natl Acad Sci U S A. 103(8): 2809-14.

Bartel, P., Chien, C. T., Sternglanz, R. and Fields, S. (1993). Elimination of false positives that arise in using the two-hybrid system. Biotechniques. 14(6): 920-4.

Berges, R. R., Vukanovic, J., Epstein, J. I., CarMichel, M., Cisek, L., Johnson, D. E., Veltri, R. W., Walsh, P. C. and Isaacs, J. T. (1995). Implication of cell kinetic changes during the progression of human prostatic cancer. Clin Cancer Res. 1(5): 47380 .

Bernstein, E., Caudy, A. A., Hammond, S. M., Hannon, G. J. (2001). Role for a bidentate ribonuclease in the initiation step of RNA interference. Nature. 409:363-366. 
Birnboim, H. C., Doly, J. (1979). A rapid alkaline extraction procedure for screening recombinant plasmid DNA. Nucl Acids Res. 7: 1513-1523.

Blakey, D. C., Westwood, F. R., Walker, M., Hughes, G. D., Davis, P. D., Ashton, S. E. and Ryan, A. J. (2002). Antitumor activity of the novel vascular targeting agent ZD6126 in a panel of tumor models. Clin Cancer Res. 8(6): 1974-83.

Blomgren, K., Zhu, C., Wang, X., Karlsson, J. O., Leverin, A. L., Bahr, B. A., Mallard, C. and Hagberg, H. (2001). Synergistic activation of caspase-3 by m-calpain after neonatal hypoxia-ischemia: a mechanism of "pathological apoptosis"? J Biol Chem. 276(13): 10191-8.

Bolduc, N. and Brisson, L. F. (2002). Antisense down regulation of NtBI-1 in tobacco BY-2 cells induces accelerated cell death upon carbon starvation. FEBS Lett. 532(1-2): $111-4$.

Bolduc, N., Ouellet, M., Pitre, F. and Brisson, L. F. (2003). Molecular characterization of two plant BI-1 homologues which suppress Bax-induced apoptosis in human 293 cells. Planta. 216(3): 377-86.

Burns, T. F. and El-Deiry, W. S. (2001). Identification of inhibitors of TRAILinduced death (ITIDs) in the TRAIL-sensitive colon carcinoma cell line SW480 using a genetic approach. J Biol Chem. 276(41): 37879-86.

Butt, A. J., Firth, S. M., King, M. A. and Baxter, R. C. (2000). Insulin-like growth factor-binding protein-3 modulates expression of Bax and Bcl-2 and potentiates p53independent radiation-induced apoptosis in human breast cancer cells. J Biol Chem. 275(50): 39174-81.

Byrom, M., Pallotta, V., Brown, D. and Ford, L. (2002). Visualizing siRNA in mammalian cells: Fluorescence analysis of the RNAi effect. In TechNotes. 9(3); Ambion, Austin. 
Cailleau, R., Olive, M. and Cruciger, Q. V. (1978). Long-term human breast carcinoma cell lines of metastatic origin: preliminary characterization. In Vitro. 14(11): 911-5.

Chae, H. J., Ke, N., Kim, H. R., Chen, S., Godzik, A., Dickman, M. and Reed, J. C. (2003). Evolutionarily conserved cytoprotection provided by Bax Inhibitor-1 homologs from animals, plants, and yeast. Gene. 323: 101-13.

Chae, H. J., Kim, H. R., Xu, C., Bailly-Maitre, B., Krajewska, M., Krajewski, S., Banares, S., Cui, J., Digicaylioglu, M., Ke, N., Kitada, S., Monosov, E., Thomas, M., Kress, C. L., Babendure, J. R., Tsien, R. Y., Lipton, S. A. and Reed, J. C. (2004). BI-1 regulates an apoptosis pathway linked to endoplasmic reticulum stress. Mol Cell. 15(3): 355-66.

Cogoni, C. and Macino, G. (2000). Post-transcriptional gene silencing across kingdoms. Review. Curr Opin Genet Dev. 10:638-43.

Collins, J. A., Schandi, C. A., Young, K. K., Vesely, J. and Willingham, M. C. (1997). Major DNA fragmentation is a late event in apoptosis. J Histochem Cytochem. 45:923-934.

Cowling, R. T. and Birnboim, H. C. (1998). Preliminary characterization of the protein encoded by human testis-enhanced gene transcript (TEGT). Mol Membr Biol. 15(4): 177-87.

Deng, X., Ito, T., Carr, B., Mumby, M. and May, W.S. Jr. (1998). Reversible phosphorylation of $\mathrm{Bcl} 2$ following interleukin 3 or bryostatin 1 is mediated by direct interaction with protein phosphatase 2A. J Biol Chem. 273(51): 34157-63.

Dohm, C. P., Siedenberg, S., Liman, J., Esposito, A., Wouters, F. S., Reed, J. C., Bahr, M. and Kermer, P. (2006). Bax inhibitor-1 protects neurons from oxygenglucose deprivation. J Mol Neurosci. 29(1): 1-8. 
Dunbar, D. R., Shibasaki, Y., Dobbie, L., Andersson, B. and Brookes, A. J. (1997). In situ hybridisation mapping of genomic clones for five human respiratory chain complex I genes. Cytogenet Cell Genet. 78(1): 21-4.

Elbashir, S. M., Lendeckel, W. and Tuschl, T. (2001)a. RNA interference is mediated by 21- and 22-nucleotide RNAs. Genes Dev. 15:188-200.

Elbashir, S. M., Harborth, J., Lendeckel, W., Yalcin, A., Weber, K., Tuschl, T. (2001)b. Duplexes of 21-nucleotide RNAs mediate RNA interference in cultured mammalian cells. Nature. 411:494-498.

Feinberg, A. P. and Vogelstein, B. (1983). A technique for radiolabeling DNA restriction endonuclease fragments to high specific activity. Anal Biochem. 132:6-13.

Feldkamp, J., Pascher, E., Perniok, A., Scherbaum, W. A. (1999). Fas-mediated apoptosis is inhibited by TSH and iodine in moderate concentrations in primary human thyrocytes in vitro. Horm Metab Res. 31:355-358.

Fischer, R., Schmitt, M., Bode, J. G. and Haussinger, D. (2001). Expression of the peripheral-type benzodiazepine receptor and apoptosis induction in hepatic stellate cells. Gastroenterology. 120(5): 1212-26.

Futterer, A., Campanero, M. R., Leonardo, E., Criado, L. M., Flores, J. M., Hernandez, J. M., San Miguel, J. F. and Martinez, A. C. (2005). Dido gene expression alterations are implicated in the induction of hematological myeloid neoplasms. J Clin Invest. 115(9): 2351-62.

Garcia-Domingo, D., Leonardo, E., Grandien, A., Martinez, P., Albar, J. P., Izpisua-Belmonte, J. C. and Martinez, A. C. (1999). DIO-1 is a gene involved in onset of apoptosis in vitro, whose misexpression disrupts limb development. Proc Natl Acad Sci U S A. 96(14): 7992-7. 
Garcia-Domingo, D., Ramirez, D., Gonzalez de Buitrago, G. and Martinez, A. C. (2003). Death inducer-obliterator 1 triggers apoptosis after nuclear translocation and caspase upregulation. Mol Cell Biol. 23(9): 3216-25.

Garty, H., Lindzen, M., Scanzano, R., Aizman, R., Füzesi, M., Goldshleger, R., Farman, N., Blostein, R. and Karlish, S. J. D. (2002). A functional interaction between CHIF and Na-K-ATPase: Implication for regulation by FXYD proteins. Am $J$ Physiol Renal Physiol. 283:F607-F615.

Gazdar, A. F., Kurvari, V., Virmani, A., Gollahon, L., Sakaguchi, M., Westerfield, M., Kodagoda, D., Stasny, V., Cunningham, H. T., Wistuba, II, Tomlinson G., Tonk, V., Ashfaq, R., Leitch, A. M., Minna, J. D. and Shay, J. W. (1998). Characterization of paired tumor and non-tumor cell lines established from patients with breast cancer. Int J Cancer. 78(6): 766-74.

Gershoni, J. M. and Palade, G. E. (1982). Electrophoretic transfer of proteins from sodium dodecyl sulfate-polyacrylamide gels to a positively charged membrane filter. Anal Biochem. 124:396-405.

Gershoni, J. M. and Palade, G. E. (1983). Protein blotting: principles and applications. Review. Anal Biochem. 131:1-15.

Grand, R. J., Milner, A. E., Mustoe, T., Johnson, G. D., Owen, D., Grant, M. L. and Gregory, C. D. (1995). A novel protein expressed in mammalian cells undergoing apoptosis. Exp Cell Res. 218(2): 439-51.

Greish, K., Fang, J., Inutsuka, T., Nagamitsu, A. and Maeda, H. (2003). Macromolecular therapeutics: advantages and prospects with special emphasis on solid tumour targeting. Clin Pharmacokinet. 42(13): 1089-105. 
Grzmil, M., Kaulfuss, S., Thelen, P., Hemmerlein, B., Schweyer, S., Obenauer, S., Kang, T. W. and Burfeind, P. (2006). Expression and functional analysis of Bax inhibitor-1 in human breast cancer cells. J Pathol. 208(3): 340-9.

Grzmil, M., Thelen, P., Hemmerlein, B., Schweyer, S., Voigt, S., Mury, D. and Burfeind, P. (2003). Bax inhibitor-1 is overexpressed in prostate cancer and its specific down-regulation by RNA interference leads to cell death in human prostate carcinoma cells. Am J Pathol. 163(2): 543-52.

Hammond, E. M., Brunet, C. L., Johnson, G. D., Parkhill, J., Milner, A. E., Brady, G., Gregory, C. D. and Grand, R. J. (1998). Homology between a human apoptosis specific protein and the product of APG5, a gene involved in autophagy in yeast. FEBS Lett. 425(3): 391-5.

Hammond, S. M., Boettcher, S., Caudy, A. A., Kobayashi, R. and Hannon, G. J. (2001a). Argonaute2, a link between genetic and biochemical analyses of RNAi. Science. 293:1146-1150

Hammond, S. M., Caudy, A. A. and Hannon, G. J. (2001b). Post-transcriptional gene silencing by double-stranded RNA. Nature Rev Genet. 2:110-119.

Hanahan, D. (1983). Studies on transformation of Escherichia coli with plasmids. $J$ Mol Biol. 166(4): 557-80.

Hannon, G. J. (2002). RNA interference. Review. Nature. 418:244-251.

Horoszewicz, J. S., Leong, S. S., Kawinski, E., Karr, J. P., Rosenthal, H., Chu, T. M., Mirand, E. A., Murphy, G. P. (1983). LNCaP model of human prostatic carcinoma. Cancer Res. 43:1809-1818.

Huang, Y. H. and Zhen, Y. S. (2001). [Rhein induces apoptosis in cancer cells and shows synergy with mitomycin]. Yao Хие Хие Вao. 36(5): 334-8. 
Huckelhoven, R. (2004). BAX Inhibitor-1, an ancient cell death suppressor in animals and plants with prokaryotic relatives. Apoptosis. 9(3): 299-307.

Huckelhoven, R., Dechert, C. and Kogel, K. H. (2003). Overexpression of barley BAX inhibitor 1 induces breakdown of mlo-mediated penetration resistance to Blumeria graminis. Proc Natl Acad Sci US A. 100(9): 5555-60.

Hutvagner, G. and Zamore, P. D. (2002). RNAi: nature habors a double-strand. Curr Opin Genet Dev. 12:225-232.

Itin, C., Kappeler, F., Linstedt, A. D. and Hauri, H. P. (1995). A novel endocytosis signal related to the KKXX ER-retrieval signal. Embo J. 14(10): 2250-6.

Jaattela, M., Benedict, M., Tewari, M., Shayman, J. A. and Dixit, V. M. (1995). Bcl-x and Bcl-2 inhibit TNF and Fas-induced apoptosis and activation of phospholipase A2 in breast carcinoma cells. Oncogene. 10(12): 2297-305.

Jackson, M. R., Nilsson, T. and Peterson, P. A. (1990). Identification of a consensus motif for retention of transmembrane proteins in the endoplasmic reticulum. Embo J. 9(10): 3153-62.

Janssens, V. and Goris, J. (2001). Protein phosphatase 2A: a highly regulated family of serine/threonine phosphatases implicated in cell growth and signalling. Biochem $J$. 353(Pt 3): 417-39.

Jean, J. C., Oakes, S. M. and Joyce-Brady, M. (1999). The Bax inhibitor-1 gene is differentially regulated in adult testis and developing lung by two alternative TATA-less promoters. Genomics. 57(2): 201-8.

Kaighn, M. E., Narayan, K. S., Ohnuki, Y., Lechner, J. F., Jones, L. W. (1979). Establishment and characterization of a human prostatic carcinoma cell line (PC-3). Invest Urol. 17:16-23. 
Kandouz, M., Lombet, A., Perrot, J. Y., Jacob, D., Carvajal, S., Kazem, A., Rostene, W., Therwath, A. and Gompel, A. (1999). Proapoptotic effects of antiestrogens, progestins and androgen in breast cancer cells. J Steroid Biochem Mol Biol. 69(1-6): 463-71.

Kandouz, M., Siromachkova, M., Jacob, D., Chretien, Marquet, B., Therwath, A. and Gompel, A. (1996). Antagonism between estradiol and progestin on Bcl-2 expression in breast-cancer cells. Int J Cancer. 68(1): 120-5.

Kawai, M., Pan, L., Reed, J.C. and Uchimiya, H. (1999). Evolutionally conserved plant homologue of the Bax inhibito J. C.r-1 (BI-1) gene capable of suppressing Baxinduced cell death in yeast(1). FEBS Lett. 464(3): 143-7.

Kawai-Yamada, M., Jin, L., Yoshinaga, K., Hirata, A. and Uchimiya, H. (2001). Mammalian Bax-induced plant cell death can be down-regulated by overexpression of Arabidopsis Bax Inhibitor-1 (AtBI-1). Proc Natl Acad Sci U S A. 98(21): 12295-300.

Kawai-Yamada, M., Ohori, Y. and Uchimiya, H. (2004). Dissection of Arabidopsis Bax inhibitor-1 suppressing Bax-, hydrogen peroxide-, and salicylic acid-induced cell death. Plant Cell. 16(1): 21-32.

Kim, J. Y., Kim, Y. H., Chang, I., Kim, S., Pak, Y. K., Oh, B. H., Yagita, H., Jung, Y. K., Oh, Y. J. and Lee, M. S. (2002). Resistance of mitochondrial DNA-deficient cells to TRAIL: role of Bax in TRAIL-induced apoptosis. Oncogene. 21(20): 3139-48.

Kim, B., Bang, S., Lee, S., Jung, Y., Lee, C., Choi, K., Lee, S. G., Lee, K., Lee, Y., Kim, S. S., Yeom, Y. I., Kim, Y. S., Yoo, H. S., Song, K. and Lee, I. (2003) Expression profiling and subtype specific expression of stomach cancer. Cancer Res. 63(23): 8248-55. 
Kirby, K. S. (1956). A new method for the isolation of deoxyribonucleic acids: evidence on the nature of bonds between deoxyribonucleic acid and protein. Biochem $J$. 66:495-504.

Kothakota, S., Azuma, T., Reinhard, C., Klippel, A., Tang, J., Chu, K., McGarry, T. J., Kirschner, M. W., Koths, K., Kwiatkowski, D. J., Williams, L. T. (1997). Caspase-3-generated fragment of gelsolin: effector of morphological change in apoptosis. Science. 278:294-298.

Krajewska, M., Moss, S. F., Krajewski, S., Song, K., Holt, P. R. and Reed, J. C. (1996). Elevated expression of Bcl-X and reduced Bak in primary colorectal adenocarcinomas. Cancer Res. 56(10): 2422-7.

Laemmli, U. K. (1970). Cleavage of structural proteins during the assembly of the head of bacteriophage T4. Nature. 227:680-685.

Li, X., Marani, M., Mannucci, R., Kinsey, B., Andriani, F., Nicoletti, I., Denner, L. and Marcelli, M. (2001). Overexpression of BCL-X(L) underlies the molecular basis for resistance to staurosporine-induced apoptosis in PC-3 cells. Cancer Res. 61(4): 1699-706.

Li, X., Marani, M., Yu, J., Nan, B., Roth, J. A., Kagawa, S., Fang, B., Denner, L. and Marcelli, M. (2001). Adenovirus-mediated Bax overexpression for the induction of therapeutic apoptosis in prostate cancer. Cancer Res. 61(1): 186-91.

Loeffen, J. L., Triepels, R. H., van den Heuvel, L. P., Schuelke, M., Buskens, C. A., Smeets, R. J., Trijbels, J. M. and Smeitink, J. A. (1998). cDNA of eight nuclear encoded subunits of NADH:ubiquinone oxidoreductase: human complex I cDNA characterization completed. Biochem Biophys Res Commun. 253(2): 415-22. 
Marcelli, M., Marani, M., Li, X., Sturgis, L., Haidacher, S. J., Trial, J. A., Mannucci, R., Nicoletti, I. and Denner, L. (2000). Heterogeneous apoptotic responses of prostate cancer cell lines identify an association between sensitivity to staurosporineinduced apoptosis, expression of Bcl-2 family members, and caspase activation. Prostate. 42(4): 260-73.

Maniatis, T. and Efstratiadis, A. (1980). Fractionation of low molecular weight DNA or RNA in polyacrylamide gels containing $98 \%$ formamide or $7 \mathrm{M}$ urea. Methods Enzymol. 65:299-305.

Marmur, J. (1960). A procedure for the isolation of deoxyribonucleic acid from microorganisms. J Mol Biol. 3: 208-218.

Minakuchi, Y., Takeshita, F., Kosaka, N., Sasaki, H., Yamamoto, Y., Kouno, M., Honma, K., Nagahara, S., Hanai, K., Sano, A., Kato, T., Terada, M. and Ochiya, T. (2004). Atelocollagen-mediated synthetic small interfering RNA delivery for effective gene silencing in vitro and in vivo. Nucleic Acids Res. 32(13): e109.

Montes de Oca Luna, R., Wagner, D. S. and Lozano, G. (1995). Rescue of early embryonic lethality in mdm2-deficient mice by deletion of p53. Nature. 378(6553): 203-6.

Mooney, L. M., Al-Sakkaf, K. A., Brown, B. L. and Dobson, P. R. (2002). Apoptotic mechanisms in T47D and MCF-7 human breast cancer cells. Br J Cancer. 87(8): 90917.

Nahta, R. and Esteva, F. J. (2003). Bcl-2 antisense oligonucleotides: a potential novel strategy for the treatment of breast cancer. Semin Oncol. 30(5 Suppl 16): 143-9. 
Naka, T., Matsumoto, T., Narazaki, M., Fujimoto, M., Morita, Y., Ohsawa, Y., Saito, H., Nagasawa, T., Uchiyama, Y. and Kishimoto, T. (1998). Accelerated apoptosis of lymphocytes by augmented induction of Bax in SSI-1 (STAT-induced STAT inhibitor-1) deficient mice. Proc Natl Acad Sci U S A. 95(26): 15577-82.

Nakagawa, T., Kim, T. S., Murai, N., Endo, T., Iguchi, F., Tateya, I., Yamamoto, N., Naito, Y. and Ito, J. (2003). A novel technique for inducing local inner ear damage. Hear Res. 176(1-2): 122-7.

Nakamura, K., Bossy-Wetzel, E., Burns, K., Fadel, M. P., Lozyk, M., Goping, I. S., Opas, M., Bleackley, R. C., Green, D. R. and Michalak, M. (2000). Changes in endoplasmic reticulum luminal environment affect cell sensitivity to apoptosis. $J$ Cell Biol. 150(4): 731-40.

Ochiya, T., Nagahara, S., Sano, A., Itoh, H. and Terada, M. (2001). Biomaterials for gene delivery: atelocollagen-mediated controlled release of molecular medicines. Curr Gene Ther. 1(1): 31-52.

Olert, J., Wiedorn, K. H., Goldmann, T., Kuhl, H., Mehraein, Y., Scherthan, H., Niketeghad, F., Vollmer, E., Muller, A. M. and Muller-Navia, J. (2001). HOPE fixation: a novel fixing method and paraffin-embedding technique for human soft tissues. Pathol Res Pract. 197(12): 823-6.

Reed, J. C. (1997). Double identity for proteins of the Bcl-2 family. Nature. 387(6635): 773-6.

Rojas, A. M., Sanchez-Pulido, L., Futterer, A., van Wely, K. H., Martinez, A. C. and Valencia, A. (2005). Death inducer obliterator protein 1 in the context of DNA regulation. Sequence analyses of distant homologues point to a novel functional role. Febs J. 272(14): 3505-11. 
Saiki, R. K., Scharf, S., Faloona, F., Mullis, K. B., Horn, G. T., Erlich, H. A., Arnheim, N. (1985). Enzymatic amplification of beta-globin genomic sequences and restriction site analysis for diagnosis of sickle cell anemia. Science. 230:1350-1354.

Sambrook, J., Fritsch, E. F. and Maniatis, T. (1989) Molecular cloning: a laboratory manual ( $2^{\text {nd }}$ edition). Cold Spring Habour, New York, USA.

Sanger, F., Nicklen, S. and Coulson, A. R. (1977). DNA sequencing with chainterminating inhibitors.Biotechnology. 24:104-108.

Sanchez, P., de Torres Zabala, M. and Grant, M. (2000). AtBI-1, a plant homologue of Bax inhibitor-1, suppresses Bax-induced cell death in yeast and is rapidly upregulated during wounding and pathogen challenge. Plant J. 21(4): 393-9.

Sanchez-Pulido, L., Rojas, A. M., van Wely, K. H., Martinez, A. C. and Valencia, A. (2004). SPOC: a widely distributed domain associated with cancer, apoptosis and transcription. BMC Bioinformatics. 5: 91.

Satchi-Fainaro, R., Puder, M., Davies, J. W., Tran, H. T., Sampson, D. A., Greene, A. K., Corfas, G. and Folkman, J. (2004). Targeting angiogenesis with a conjugate of HPMA copolymer and TNP-470. Nat Med. 10(3): 255-61.

Scanlon, K. J. (2004). Anti-genes: siRNA, ribozymes and antisense. Curr Pharm Biotechnol. 5(5): 415-20.

Schmits, R., Cochlovius, B., Treitz, G., Regitz, E., Ketter, R., Preuss, K. D., Romeike, B. F. and Pfreundschuh, M. (2002). Analysis of the antibody repertoire of astrocytoma patients against antigens expressed by gliomas. Int J Cancer. 98(1): 73-7.

Schonthal, A. H. (2001). Role of serine/threonine protein phosphatase 2A in cancer. Cancer Lett. 170(1): 1-13. 
Schweyer, S., Hemmerlein, B., Radzun, H. J. and Fayyazi, A. (2000). Continuous recruitment, co-expression of tumour necrosis factor-alpha and matrix metalloproteinases, and apoptosis of macrophages in gout tophi. Virchows Arch. 437:534-539.

Scorrano, L. (2003). Divide et impera: $\mathrm{Ca} 2+$ signals, mitochondrial fission and sensitization to apoptosis. Cell Death Differ. 10(12): 1287-9.

Sharp, P. A. (2001). RNA interference-2001. Genes Dev. 15:485-490.

Simizu, S., Tamura, Y. and Osada, H. (2004). Dephosphorylation of Bcl-2 by protein phosphatase 2A results in apoptosis resis tance. Cancer Sci. 95(3): 266-70.

Sioud, M. and Sorensen, D. R. (2003). Cationic liposome-mediated delivery of siRNAs in adult mice. Biochem Biophys Res Commun. 312(4): 1220-5.

Sorensen, D. R., Leirdal, M. and Sioud, M. (2003). Gene silencing by systemic delivery of synthetic siRNAs in adult mice. J Mol Biol. 327(4): 761-6.

Srinivasula, S. M., Hegde, R., Saleh, A., Datta, P., Shiozaki, E., Chai, J., Lee, R. A., Robbins, P. D., Fernandes-Alnemri, T., Shi, Y. and Alnemri, E. S. (2001). A conserved XIAP-interaction motif in caspase-9 and Smac/DIABLO regulates caspase activity and apoptosis. Nature. 410(6824): 112-6.

Stenzel, K. H., Miyata, T. and Rubin, A. L. (1974). Collagen as a biomaterial. Annu Rev Biophys Bioeng. 3(0): 231-53.

Takei, Y., Kadomatsu, K., Goto, T. and Muramatsu, T. (2006). Combinational antitumor effect of siRNA against midkine and paclitaxel on growth of human prostate cancer xenografts. Cancer. 107(4): 864-73. 
Takei, Y., Kadomatsu, K., Yuzawa, Y., Matsuo, S. and Muramatsu, T. (2004). A small interfering RNA targeting vascular endothelial growth factor as cancer therapeutics. Cancer Res. 64(10): 3365-70.

Takeshita, F., Minakuchi, Y., Nagahara, S., Honma, K., Sasaki, H., Hirai, K., Teratani, T., Namatame, N., Yamamoto, Y., Hanai, K., Kato, T., Sano, A. and Ochiya, T. (2005). Efficient delivery of small interfering RNA to bone-metastatic tumors by using atelocollagen in vivo. Proc Natl Acad Sci U S A. 102(34): 12177-82.

Tamura, Y., Simizu, S. and Osada, H. (2004). The phosphorylation status and antiapoptotic activity of Bcl-2 are regulated by ERK and protein phosphatase $2 \mathrm{~A}$ on the mitochondria. FEBS Lett. 569(1-3): 249-55.

Teixeira, C., Reed, J. C. and Pratt, M. A. (1995). Estrogen promotes chemotherapeutic drug resistance by a mechanism involving Bcl-2 proto-oncogene expression in human breast cancer cells. Cancer Res. 55(17): 3902-7.

Tu, H., Jacobs, S. C., Borkowski, A. and Kyprianou, N. (1996). Incidence of apoptosis and cell proliferation in prostate cancer: relationship with TGF-beta1 and bcl2 expression. Int J Cancer. 69(5): 357-63.

Turowski P., Fernandez A., Favre B., Lamb N. J. and Hemmings B. A. (1995). Differential methylation and altered conformation of cytoplasmic and nuclear forms of protein phosphatase 2A during cell cycle progression. J Cell Biol. 129(2): 397-410.

Tuschl, T., Zamore, P. D., Lehmann, R., Bartel, D. P., Sharp, P. A. (1999). Targeted mRNA degradation by double-stranded RNA in vitro. Genes Dev. 13:3191-3197.

Tuschl, T. (2001). RNA Interference and Small Interfering RNAs. Chembiochem Europ J Chem Biol. 2:239-245. 
Umland, O., Ulmer, A. J., Vollmer, E. and Goldmann, T. (2003). HOPE fixation of cytospin preparations of human cells for in situ hybridization and immunocytochemistry. J Histochem Cytochem. 51(7): 977-80.

Vaupel, P. (2004). The role of hypoxia induced factors in tumor progression. Oncologist. 9(Suppl 5): 10-7.

Villalva, C., Trempat, P., Greenland, C., Thomas, C., Girard, J. P., Moebius, F., Delsol, G. and Brousset, P. (2002). Isolation of differentially expressed genes in NPMALK-positive anaplastic large cell lymphoma. Br J Haematol. 118(3): 791-8.

Villalva, C., Trempat, P. R., Zenou, C., Delsol, G. and Brousset, P. (2001). [Gene expression profiling by suppression subtractive hybridization (SSH): a example for its application to the study of lymphomas]. Bull Cancer. 88(3): 315-9.

Waddel (1956). J Lab Clin Med. 48:11-314.

Wallace, D. C., Shoffner, J. M., Trounce, I., Brown, M. D., Ballinger, S. W., Corral-Debrinski, M., Horton, T., Jun, A. S. and Lott, M. T. (1995). Mitochondrial DNA mutations in human degenerative diseases and aging. Biochim Biophys Acta. 1271(1): 141-51.

Walter, L., Dirks, B., Rothermel, E., Heyens, M., Szpirer, C., Levan, G. and Gunther, E. (1994). A novel, conserved gene of the rat that is developmentally regulated in the testis. Mamm Genome. 5(4): 216-21.

Walter, L., Marynen, P., Szpirer, J., Levan, G. and Gunther, E. (1995). Identification of a novel conserved human gene, TEGT. Genomics 28(2): 301-4.

Wang, K. K. (2000). Calpain and caspase: can you tell the difference? Trends Neurosci. 23(1): 20-6. 
Wang, T. T. and Phang, J. M. (1995). Effects of estrogen on apoptotic pathways in human breast cancer cell line MCF-7. Cancer Res. 55(12): 2487-9.

Wang, X. Z., Beebe, J. R., Pwiti, L., Bielawska, A. and Smyth, M. J. (1999). Aberrant sphingolipid signaling is involved in the resistance of prostate cancer cell lines to chemotherapy. Cancer Res. 59(22): 5842-8.

Weissleder, R. and Mahmood, U. (2001). Molecular imaging. Radiology. 219(2): 31633.

Welsh, J. B., Sapinoso, L. M., Su, A. I., Kern, S. G., Wang-Rodriguez, J., Moskaluk, C. A., Frierson, H. F. Jr., and Hampton, G. M. (2001). Analysis of gene expression identifies candidate markers and pharmacological targets in prostate cancer. Cancer Res. 61(16): 5974-8.

Westphalen, B. C., Wessig, J., Leypoldt, F., Arnold, S. and Methner, A. (2005). BI1 protects cells from oxygen glucose deprivation by reducing the calcium content of the endoplasmic reticulum. Cell Death Differ. 12(3): 304-6.

Wiedorn, K. H., Olert, J., Stacy, R. A., Goldmann, T., Kuhl, H., Matthus, J., Vollmer, E. and Bosse, A. (2002). HOPE--a new fixing technique enables preservation and extraction of high molecular weight DNA and RNA of $>20 \mathrm{~kb}$ from paraffinembedded tissues. Hepes-Glutamic acid buffer mediated Organic solvent Protection Effect. Pathol Res Pract. 198(11): 735-40.

Xu, Q. and Reed, J. C. (1998). Bax inhibitor-1, a mammalian apoptosis suppressor identified by functional screening in yeast. Mol Cell. 1(3): 337-46.

Yang, X. K., Xing, H., Zheng, F., Gao, Q. L., Wang, W., Lu, Y. P. and Ma, D. (2003). Role of apoptosis-associated genes and caspase-3 in cisplatin-resistant human ovarian cancer cell lines. Zhonghua Fu Chan Ke Za Zhi. 38(3): 158-61. 
Yap, D. B., Hsieh, J. K., Chan, F. S. and Lu, X. (1999). mdm2: a bridge over the two tumour suppressors, p53 and Rb. Oncogene. 18(53): 7681-9.

Yoneda, M., Chomyn, A., Martinuzzi, A., Hurko, O. and Attardi, G. (1992). Marked replicative advantage of human mtDNA carrying a point mutation that causes the MELAS encephalomyopathy. Proc Natl Acad Sci U S A. 89(23): 11164-8.

Yu, L. H., Kawai-Yamada, M., Naito, M., Watanabe, K., Reed, J. C. and Uchimiya, H. (2002). Induction of mammalian cell death by a plant Bax inhibitor. FEBS Lett. 512(1-3): 308-12.

Zha, H. and Reed, J. C. (1997). Heterodimerization-independent functions of cell death regulatory proteins Bax and Bcl-2 in yeast and mammalian cells. J Biol Chem. 272(50): 31482-8. 


\section{Lebenslauf}

\section{Persönliche Daten:}

Name

Geburtsdaturm

Geburtsort

Nationalität

Bildungsweg:

1981-1982

1982-1984

1984-1985

1985-1987

1987-1988

1988-1989

1989-1994

1994-1995

1995-2001

2001

2002
Tae-Won Kang

03.07.1974

Jin-Hae, Süd-Korea

deutsch
Besuch der Grundschule Hag-Dong in Seoul / Süd-Korea

Besuch der Brüder-Grimm-Schule in Göttingen

Besuch der Orientierungsstufe Weende-Nord in Göttingen

Besuch der Grundschule Gu-Jong in Seoul / Süd-Korea

Besuch der Shin-Sa Gymnasium in Seoul / Süd-Korea

Besuch der Dong-Jung Gymnasium in Tae-Gu / SüdKorea

Besuch der Theodor-Heuss Gymnasium in Göttingen

Physikstudium an der Georg-August-Universität in Göttingen

Biologiestudium an der Georg-August-Universität in Göttingen

Diplomarbeit am Institut für Humangenetik der GeorgAugust-Universität in Göttingen

Experimentelle Arbeiten zur Dissertation am Institut für Humangenetik der Georg-August-Universität in Göttingen 


\section{Danksagung}

Ich möchte Herrn Prof. Dr. W. Engel für seine Betreuung, seine Unterstützung in jeglicher Hinsicht und für die schnelle und gründliche Durchsicht der Manuskripte danken.

Bei Frau PD Dr. Hoyer-Fender bedanke ich mich für die Übernahme des Korreferats.

Mein besonderer Dank gilt meinem Betreuer PD Dr. Peter Burfeind für die Überlassung des Themas, seine freundschaftliche Unterstützung und für die gründliche Durchsicht der Manuskripte.

Ferner möchte ich mich ganz herzlich bei Dr. Silke Kaulfuß für ihre freundlichen Unterstützungen und für die Durchsicht der Manuskripte danken.

Meinen Kollegen aus den Laboren 311/312 möchte ich für die gute Zusammenarbeit und die freundschaftliche Atmosphäre bedanken. Ganz besonders danken möchte ich Michael Kickstein und Antje Ulrich für ihre Unterstützung und für die gute Zusammenarbeit. Mein Dank gilt ebenfalls allen anderen Mitarbeitern des Instituts für Humangenetik.

Bei PD Dr. Frauke Alves, ihrer Arbeitsgruppe und Christian Dullin möchte ich mich für eine exzellente Zusammenarbeit bei den in vivo-Experimenten bedanken. Herrn PD Dr. Stefan Schweyer danke ich für die Unterstützung bei der histologischen Analysen der in vivo-Studie.

Bei Henk, Milena, Semi und Patrick möchte ich mich für ihre Unterstützung und Freundschaft danken. Meinen „Botanikern“ danke ich für die schönen Mittagszeiten.

Marta danke ich dafür, dass sie mich in jeglicher Hinsicht unterstützt hat.

Mein größter Dank gilt meinen Eltern für all ihre Unterstützungen und Liebe. 